Design of an Anti Head Check profile based on stress relief

Ir. R.P.B.J. Dollevoet 
This research project was sponsored by the Dutch Rail-Infra manager ProRail B.V.

Design of an Anti Head Check profile based on stress relief

PhD Thesis, University of Twente, Enschede, The Netherlands

Ir. R.P.B.J. Dollevoet

Keywords: RCF, Head Checks, Profile, Wheel, Rail Contact, Cracks, Track, Friction.

Cover design: Rolf Dollevoet \& Rick Noordink (copyright cover photo by DeltaRail)

Printed by Wöhrmann Print Service, Zutphen, The Netherlands.

ISBN 978-90-365-3073-6

Copyright (C) 2010 by ir. R.P.B.J. Dollevoet, Enschede, The Netherlands

All rights reserved. No part of this publication may be reproduced, stored in a retrieval system or transmitted in any form or by any means, electronic, mechanical, photocopying, recording or otherwise, without the prior permission in writing from the proprietor. 


\title{
DESIGN OF AN ANTI HEAD CHECK PROFILE BASED ON STRESS RELIEF
}

\section{PROEFSCHRIFT}

\author{
ter verkrijging van, \\ de graad van doctor aan de Universiteit Twente, \\ op gezag van de Rector Magnificus, \\ prof. dr. H. Brinksma, \\ volgens besluit van het College voor Promoties, \\ in het openbaar te verdedigen op \\ donderdag 7 oktober 2010 om 13.15 uur
} door

Rolf Petrus Bernardus Johannes Dollevoet geboren op 8 december 1970 te 's-Hertogenbosch, Nederland. 
Dit proefschrift is goedgekeurd door de promotor:

Prof.dr.ir. D.J. Schipper

en assistent-promotor:

Dr.ir. Z. Li

Samenstelling van de promotiecommissie:

Prof.dr. F. Eising

Prof.dr.ir. D.J. Schipper

Dr.ir. Z. Li

Prof.dr.ir. R. Akkerman

Prof.dr.ir. L.A.M. van Dongen

Prof.dr.ir. C. Esveld

Prof.dr.ir. J. Huètink

Prof.dr. G. Shen

Ir. F. Verheij
Technische Universiteit Twente, voorzitter

Technische Universiteit Twente, promotor

Technische Universiteit Delft, assistent-promotor

Technische Universiteit Twente

Technische Universiteit Twente

Technische Universiteit Delft

Technische Universiteit Twente

Tongji University, China

ProRail, Manager Infrasystemen, referent 
Aan Linda, Floris en Lucas

Aan mijn ouders 



\section{Summary}

Head Checking $(\mathrm{HC})$ is a major type of Rolling Contact Fatigue (RCF) in railway rails across the globe. It mainly occurs on curved tracks in the rail shoulder of the gauge side and at the gauge corner because of the large lateral force. The related track radii are between $500-3000 \mathrm{~m}$. It initiates from the surface due to high surface shear stresses arising at wheel-rail contact.

$\mathrm{HC}$ has severe economic consequences as well as on the safety of railway operations. The serious accident caused by $\mathrm{HC}$ at Hatfield in the United Kingdom in October 2000 raised awareness to treat it seriously. The yearly total $\mathrm{HC}$ treatment-related cost was about 50 million euros in the Netherlands when the occurrence of $\mathrm{HC}$ was at its highest.

Although a number of treatment methods for $\mathrm{HC}$ are possible, it is concluded that preventing or retarding $\mathrm{HC}$ initiation by optimal rail profile design is the most effective in terms of implementability, cost and time span. This thesis therefore aims at the design of an anti-HC profile of rails, based on a fundamental understanding of the mechanical mechanism of $\mathrm{HC}$ initiation.

To such end, an investigation has been carried out on the quantitative relationship between $\mathrm{HC}$ occurrences, contact geometry, stresses and microslip. $\mathrm{HC}$ initiation has been reproduced under controlled laboratory conditions on a full-scale wheel-rail test rig. At the same time, $\mathrm{HC}$ initiation has been monitored in the field under service conditions. Using a non-Hertzian rolling contact solution method, it is found that $\mathrm{HC}$ initiation location tends to be at a distance $7-12 \mathrm{~mm}$ from the gauge face, where the surface shear stress is the highest as a result of the large geometrical spin in the wheel-rail contact. 
The optimization is therefore focused on the gauge part of the profile, with the objective of relieving the maximum shear stress. As the $54 \mathrm{E} 1$ rail is predominantly used on the Dutch railway network, the optimization is performed on it. After a statistical analysis of the AHC performance of the $54 \mathrm{E} 1$ and $46 \mathrm{E} 3$ profiles, it is concluded that an undercut of the $54 \mathrm{E} 1$ profile at the gauge corner, with the maximum undercut at about $9 \mathrm{~mm}$ from the gauge face, should achieve the objective. Together with a number of constraints arising from the existing 54E1 profile, from vehicle running performance, track structure and contact mechanics, an optimal Anti Head Checking 54E1 (AHC $54 \mathrm{E} 1)$ profile is designed.

This designed profile has shown its merits:

By avoiding contact in the HC-prone part of the rail, the maximum surface shear stress is greatly reduced, mainly owing to the decrease of spin in the contact.

A monitored field test shows that the AHC 54E1 profile can largely delay the $\mathrm{HC}$ formation and once $\mathrm{HC}$ arises, it also decreases the crack growth by a factor of half. The AHC profile changes due to wear, so that it has to be restored with cyclic grinding to maintain its effectiveness.

Large-scale application on the Dutch railway network shows that

$\mathrm{HC}$ in 2008 was reduced by about $70 \%$ with respect to 2004 when $\mathrm{HC}$ was the most widespread.

At the same time, no negative influence of the AHC 54E1 on the running performance of the trains has been reported, either from the monitored site or from the large-scale application.

As a result, the AHC 54E1 profile has been normalized as a standard European rail profile named 54E5 at 1:40, see prEN 13674-1, June, 2009.

Recommendations for further research and development are made at the end of the thesis. 


\section{Samenvatting}

Head Checks $(\mathrm{HC})$ zijn het leeuwendeel van Rolling Contact Fatigue (RCF) verschijnselen in spoorstaven binnen de spoorwereld. Deze verschijnen vrijwel altijd in bogen in de railschouder aan de rijkant en specifiek in de gauge corner vanwege de hoge laterale krachten.

De bedoelde bogen hebben een boogstraal tussen de 500 - $3000 \mathrm{~m}$. De HC initierren vanuit het oppervlak welke zijn toe te schrijven aan de hoge oppervlakte schuifspanning ontstaan in het wiel-rail contact.

$\mathrm{HC}$ hebben enorme economische gevolgen maar ook gevolgen voor de veiligheid tijdens spoorbedrijf. Het zware ongeluk veroorzaakt door $\mathrm{HC}$ in Hatfield Engeland, oktober 2001, heeft iedereen wakker geschud om dit probleem serieus op te pakken. De totale kosten veroorzaakt door $\mathrm{HC}$ waren ongeveer 50 miljoen euro in Nederland, toen de hoeveelheid $\mathrm{HC}$ op een piek zaten.

Ofschoon een aantal behandelmethoden voor HC mogelijk zijn, kan er geconcludeerd worden dat voorkomen of vertragen van $\mathrm{HC}$ initiatie middels optimaal rail profiel ontwerp de meest effectieve manier is in termen van implementeerbaarheid, kosten en tijdspanne. Deze dissertatie heeft daarom het doel om tot een ontwerp van een anti-HC railprofiel te komen, gebaseerd op het fundamenteel doorgronden van het mechanische mechanisme van $\mathrm{HC}$ initiatie.

Vervolgens heeft onderzoek plaatsgevonden naar de kwantitatieve relatie tussen $\mathrm{HC}$ verschijningsvormen, contact geometrie, spanningen en micro-slip. $\mathrm{HC}$ initiatie is onder laboratoriumomstandigheden nagebootst en op ware schaal geproduceerd op een wiel-rail testbank.

Tegelijkertijd zijn HC gemonitord in de baan tijdens spoorbedrijf. Gebruikmakend van een non-Hertz rolling contact oplosmethode blijkt dat HC 
initiatie locaties de neiging hebben om te ontstaan op een afstand van $7-12$ $\mathrm{mm}$ van de rijkant, waar de oppervlakte schuifspanning het hoogst is vanwege de hoge geometrische spin in het wiel-rail contact.

De optimalisatie is daarom geconcentreerd op de rijkant/gauge corner gebied in het railprofiel, met als doel om de maximale schuifspanning te ontlasten. De 54E1 spoorstaaf is meest voorkomend in het Nederlandse spoornetwerk waarop de optimalisatie is uitgewerkt. $\mathrm{Na}$ een statistische analyse van de AHC prestaties van 54E1 en 46E3 kan geconcludeerd worden dat een ondersnijding van het 54E1 profiel in de gauge corner, met een maximale ondersnijding op $9 \mathrm{~mm}$ vanaf de rijkant, het onderzoeksdoel bereikt is.

Samen met een aantal voorwaarden vanuit het huidige 54E1 profiel, vanuit rijeigenschappen van rollend materieel, baan bovenbouw structuur en contact mechanica, is een optimaal anti Head Check 54E1 (AHC 54E1) ontworpen.

Het ontworpen profiel heeft zijn verdiensten al laten zien:

Door direct contact te vermijden in het $\mathrm{HC}$-gevoelig deel van de rail, wordt de maximale oppervlakte schuifspanning sterk verminderd, voornamelijk als gevolg van vermindering van de spin in het contactvlak. Een gemonitord testbaanvak toont aan dat het AHC 54E1 profiel het vermogen heeft tot vertraging van $\mathrm{HC}$ vorming en als er eenmaal $\mathrm{HC}$ zijn ontstaan ook de scheurgroeisnelheid met de helft wordt verminderd. Het AHC profiel verandert van vorm door slijtage, wat betekent dat er een herstelactie moet worden uitgevoerd via cyclisch slijpen om effectiviteit te behouden.

Door op grote schaal dit toe te passen in het Nederlandse railnetwerk resulteert dat het aantal $\mathrm{HC}$ in 2008 zijn gereduceerd tot $70 \%$ van de $\mathrm{HC}$ omvang in 2004; toen de HC op zijn hoogtepunt waren.

Tegelijkertijd heeft het AHC 54E1 profiel geen negatieve invloed of negatieve vermeldingen opgeleverd op de rijeigenschappen van treinen, ook niet in de testbaanvakken als ook niet vanuit de landelijke implementatie.

Als gevolg van het AHC 54E1 ontwikkelde profiel is dit profiel uiteindelijk genormaliseerd als een standaard Europese railprofiel genaamd 54E5 voor 1:40, zie prEN 13674-1, juni, 2009.

Aanbevelingen voor vervolgonderzoek en verdere ontwikkelingen zijn aan het eind van deze dissertatie beschreven. 


\section{Contents}

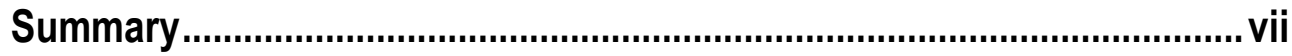

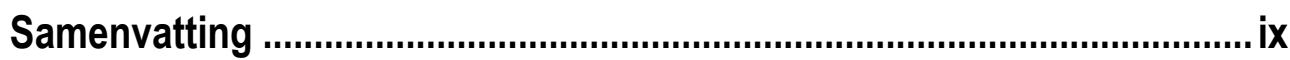

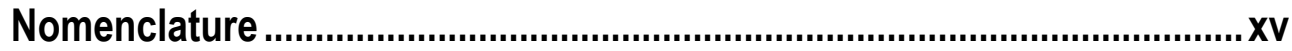

Chapter 1 Head Checks: phenomenon and consequences ............17

1.1 Introduction and background.......................................................

1.2 Rolling Contact Fatigue of railway rails .........................................17

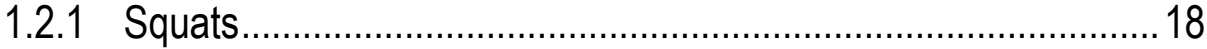

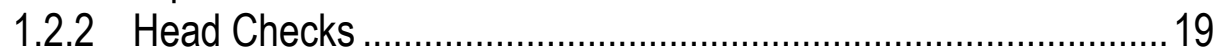

1.2.3 A brief comparison between $\mathrm{HC}$ and Squats ...........................20

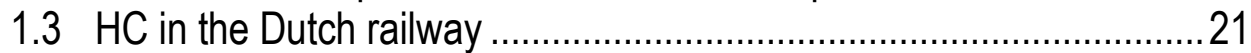

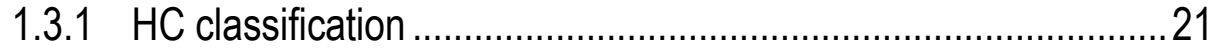

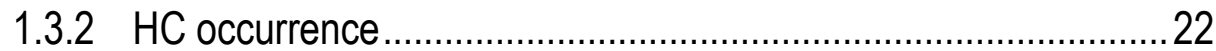

1.4 Consequences of HC on RAMS and LCC ………......................22

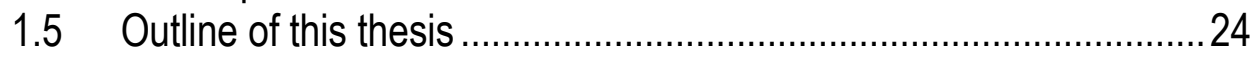

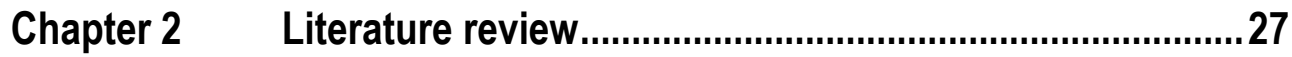

2.1 Introduction to the wheel-rail system.............................................27

2.2 Comparison of rail and wheel RCF with other types of fatigue .........34

2.2.1 General mechanism of fatigue..................................................34

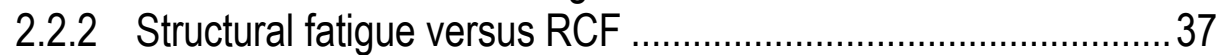

2.2.3 RCF of rails and of machine elements .......................................42

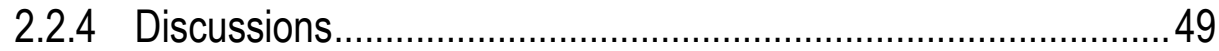

2.3 Head Checks: State-of-the-art of understanding and solutions .......50

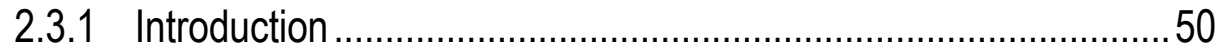

2.3.2 An overview of possible general causes of $\mathrm{HC}$........................52

2.3.3 Loading conditions and $\mathrm{HC}$.....................................................53 
2.3.4 Rail grades and $\mathrm{HC}$ .58

2.3.5 HC and contact geometry, stress and strain .............................59

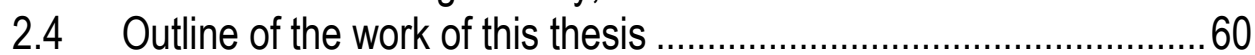

\section{Chapter 3 Loading conditions of Head Checking initiation ............65}

3.1 Introduction .65

3.2 $\mathrm{HC}$ initiation under controlled laboratory conditions and stress analysis

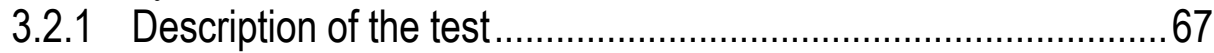

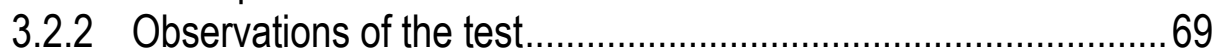

3.2.3 Analysis of the test for $\mathrm{HC}$ initiation.............................................

3.2.3.1 The solution method .......................................................

3.2.3.2 Analysis of the Lab Test ...................................................72

3.2.3.3 Analysis of the measurement at $20,000^{\text {th }}$ wheel pass ...........76

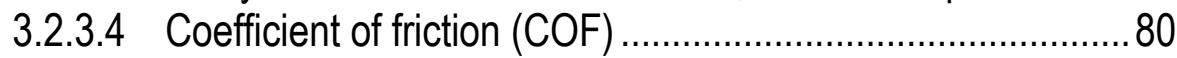

3.2.3.5 Analysis of the measurement at $50,000^{\text {th }}$ wheel pass ...........81

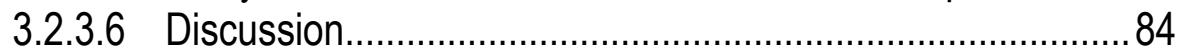

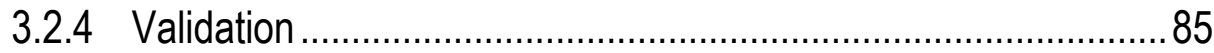

3.3 HC initiation and stress analysis under operational conditions........87

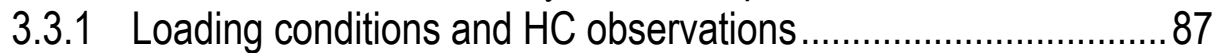

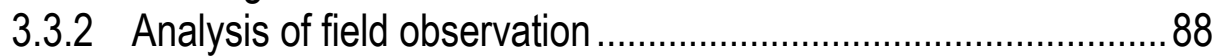

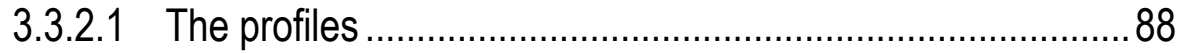

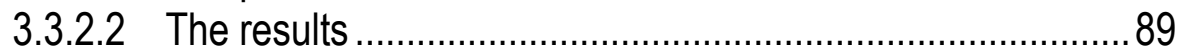

3.3.2.3 Relation between surface shear stress and $\mathrm{HC}$ initiation......90

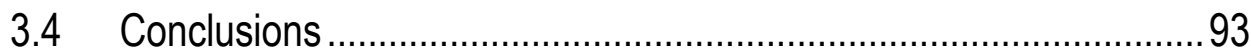

Chapter 4 Designing and testing an Anti Head Check rail profile .95

4.1 Designing an AHC rail profile .......................................................95

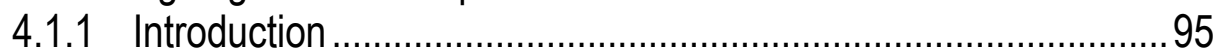

4.1.2 Observations and statistics....................................................96

4.1.3 Design principle and constraints.............................................. 100

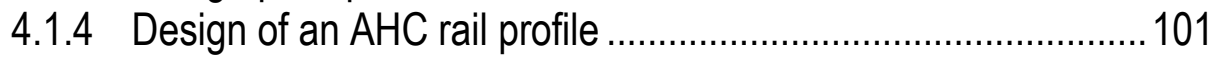

4.2 Theoretical analyses of the AHC profile ........................................ 107

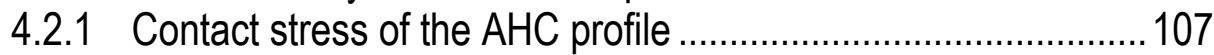

4.2.1.1 Measurement and observations ........................................ 107

4.2.1.2 Calculated maximal shear stress......................................112

4.2.1.3 Contact between new rails and worn S1002 ....................112 
4.2.1.4 Relation between $\mathrm{HC}$ initiation, wear rate and shear stress with worn AHC 54E1

4.2.1.5 More general observation of $\mathrm{HC}$ initiation, wear rate and shear stress

4.2.1.6 Some conclusions.............................................................. 118

4.2.2 Analysis of running performance ............................................ 118

4.3 In-service performance monitoring of the AHC profile ................... 120

4.3.1 RCF and wear.................................................................. 120

4.4 Performance of the AHC profile in large-scale application ............ 122

4.4.1 $\mathrm{HC}$ and the associated cost reduction...................................... 122

4.4.2 Stability and comfort .......................................................... 123

4.4.3 Normalization..................................................................... 123

4.5 Conclusions ..................................................................... 123

Chapter $5 \quad$ Conclusions and further research................................ 125

5.1 Conclusions .......................................................................... 125

$5.2 \quad$ Further research ..................................................................... 127

5.2.1 Optimal grinding interval .................................................. 127

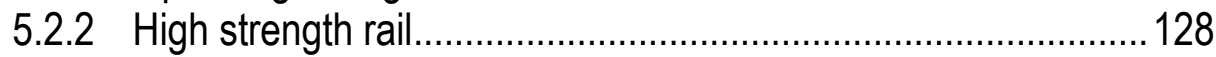

5.2 .3 Friction management........................................................ 128

5.2.4 Managing the wheel-rail system ......................................... 129

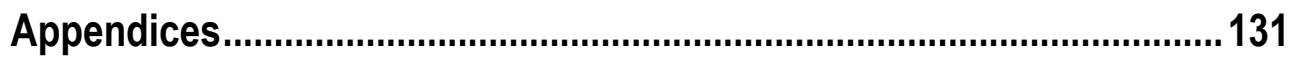

Appendix A: Contact variation wheel/rail interface ................................. 133

Appendix B: Dutch Rail profiles .......................................................... 135

Profile 60E1 ................................................................................ 135

Profile 46E3 …........................................................................ 136

Profile 54E1 ................................................................................... 137

Profile 54E5 ........................................................................ 138

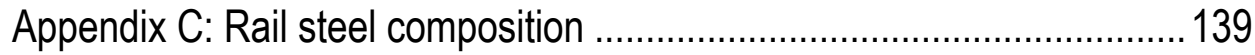

Appendix D: HC tests in the Netherlands ........................................... 141

Appendix E: Quasi-quarter Space ...................................................... 143

Publications related to HC by Rolf Dollevoet ........................................ 145

Acknowledgements 



\section{Nomenclature}

\section{Abbreviations:}

$\mathrm{AHC}$

$\mathrm{AOA}$

COF

EC

FE

GCC

$\mathrm{HC}$

IM

LCF

MGT

NDT

NS

PSB

PYS

RCF

RSSB

UIC

US

VAS

WLRM

= Anti-Head Check (profile)

= Angle of attack

= Coefficient of friction

= Eddy-Current measurement device

$=$ Finite Elements

= Gauge-corner cracking

$=$ Head Checks or Head Checking

= Infra-Manager (i.e. ProRail)

= Low cycle fatigue

= Million gross tonnage

$=$ Non destructive test

= Nederlandse Spoorwegen (i.e. Dutch rolling stock owner)

= Persistent slip bands

$=$ Primary yaw stiffness of bogie

$=$ Rolling Contact Fatigue

= Rail safety and standard board

$=$ International Union of Railways (Paris)

$=$ Ultrasonic measurement device

= Voestalpine Schienen $\mathrm{GmbH}$

$=$ Whole life rail model

\section{Profiles:}

46E3

$=$ rail profile

$54 \mathrm{E} 1$

$=$ rail profile

54E5

60E2

$=$ AHC 54E1 rail profile adopted in the norm prEN 13674-1

$=$ rail profile

S1002

$=$ standard wheel profile 


\section{Symbols:}

$\alpha$

$c, c_{x}$

$\delta$

$\delta_{0}$

$\delta_{\text {avr }}$

G

$M_{z}$

$\mu$

$p_{0}$

$\sigma_{x}, \sigma_{y}, \sigma_{z}$

\section{$\tau_{\max }$}

$\tau_{x}, \tau_{y}$

$\phi$

$\mathrm{T}, T_{x}, T_{y}$

$\psi$

$\Omega$

$V, V_{x}, V_{y}$

$\mathrm{V}_{\mathrm{x}}, \mathrm{V}_{\mathrm{y}}$

$W$

$x, y, z$

$\Delta Y$

$\gamma, \gamma_{x}, \gamma_{y}$

$Y_{\text {cnt }}$

$Y_{\text {cntrig }}$

$Y_{\text {cur }}$

$Y_{g}$
$=$ Rail inclination. Radian

$=$ Circumferential velocity of wheel and its projection on the $x$ axis. $\mathrm{m} / \mathrm{s}$

$=$ Contact angle. Radian

= Contact angle at rigid body contact point. Radian

$=$ Average contact angle in the contact area. Radian

= Shear modulus; is $82 \mathrm{GPa}$ for wheel and rail. $\mathrm{Pa}$

$=$ Spin moment in the contact area. $\mathrm{N} \cdot \mathrm{m}$

$=$ Coefficient of friction. Dimensionless

$=$ Maximum pressure. $\mathrm{Pa}$

$=$ Normal stress components in $x, y$ and $z$ directions. $P a$

= Maximum surface shear stress. $\mathrm{Pa}$

$=$ Surface shear stress in the $x$ and $y$ directions. $P a$

$=$ Spin in the contact area. $1 / \mathrm{m}$

$=$ Tangential contact force and its components in $x$ and $y$ directions. $N$

$=$ Yaw angle. Radian

= Angular velocity of wheel. Radian $/ \mathrm{s}$

$=$ Wheel velocity and its components in $x$ and $y$ directions. $\mathrm{m} / \mathrm{s}$

$=$ Micro-slip in the $x$ and $y$ directions. Dimensionless

$=$ Frictional work. $\mathrm{J} / \mathrm{m}$

$=$ Axes of Cartesian coordinate system, with $x$ in the rolling direction, $z$ pointing into the rail in the local normal direction of the rail profile. $m$

$=$ Wheel lateral displacement. $m$

$=$ Creepage and its components in $x$ and $y$ directions. Dimensionless

$=$ Distance from the centre line of the rail profile. $m$

$=Y_{\text {cnt }}$ of rigid body contact point. $m$

$=$ Lateral coordinate in the curvi-linear discretization coordinate system. $m$

$=$ Horizontal distance measured from gauge face. $m$ 


\section{Chapter 1 Head Checks: phenomenon and consequences}

\subsection{Introduction and background}

The real steel-to-steel contact area between a wheel of a train and a rail is very small in relation to the wheel and rail dimensions. The size of the contact area is important with respect to the running behaviour of the train in general and in curves in particular.

Because of the heavy loads and the small wheel/rail contact area, high stresses will occur in wheel and rail. Every cycle of a wheel/axle results in a stress cycle in the material of wheel and rail. This cyclic stressing of the material means fatigue during lifetime. This problem is exacerbated in the wheel/rail contact due to friction, Li (2002) and Popovici (2010). It results in cracks in wheel and rail and occurs in a very early stage of the lifetime cycle nowadays in railways, Zoeteman et al. (2009, and IHHA (2001). This is better known as Rolling Contact Fatigue (RCF) and RCF is a worldwide problem for Rail-Infra managers (IM).

\subsection{Rolling Contact Fatigue of railway rails}

The steel-on-steel contact of railway wheels and rails takes place in an open system. The pursuit of travelling fast and carrying more has led to everincreasing contact force between the wheels and rails. The static contact pressure can often be higher than $1 \mathrm{GPa}$, Esveld (2001). Because a certain level of friction is needed for traction and braking, wheel-rail contact is usually not lubricated. Wear and tear is therefore inevitable. The coefficient of friction (COF) may vary between 0.02 for a leaf-contaminated rail to 0.6 for a dry and clean situation, Popovici (2010). Under low friction the wheel may slip during acceleration and may skid during braking, causing wheel burns on the rails. 
With a high friction level the stress may exceed the yield strength of the material, causing surface plastic deformation. In the presence of defects in the track, and particularly on the surface, such as indentation, corrugation and wheel burns, dynamic wheel-rail interaction takes place, and the dynamic stress can be much higher. With each wheel passage a rail may experience a cycle of plastic deformation. Under the cyclic wheel load the plastic deformation may accumulate, until the ductility of the rail material is exhausted, and fatigue cracks may initiate and grow. This is known as surface-initiated RCF. Nowadays, with the high contact stress, surfaceinitiated RCF occurs in a very early stage of the lifetime of rails. Another type of RCF may initiate subsurface in the rails at metallurgical defects, such as "Tache ovals", Bergkvist (2005).

A detailed classification of rail defects can be found in the UIC fiche $712 \mathrm{R}$ (2002). Owing to improvement in the rail manufacturing process, subsurfaceinitiated RCF has been greatly reduced in the past decades. On the other hand, due to an increase in speed and axle load etc, surface-initiated RCF has in the past decade become the major problem for many railways.

The current surface-initiated RCF manifests itself in two types: Squats and Head Checks $(\mathrm{HC})$. Figure 1.1 shows what $\mathrm{HC}$ and their cross section may look like. Figure 1.2 shows a severe Squat and a cross section of a Squat after four-point bending.

\subsubsection{Squats}

A mature Squat has typically a "two-lung" shape with widened running band, and with $U, V$ or $Y$ shaped cracks. The cracks may branch down when they have a depth of $3-5 \mathrm{~mm}$. Squats are usually found on tangent tracks and in curves of large radius. Squats usually initiate from rail surface geometry defects such as indentations, wheel burns and short pitch corrugation. There are also theories about Squat initiation from white etching martensitic layer on the running surface of the rail, Carroll and Beynon (2007). The material inhomogeneity at the heat-affected zone of welds of continuously welded rail also causes Squats. Squats may occur in all types of tracks, slab or ballasted, with passenger, freight or mixed traffic, on conventional, metro or high speed tracks, no matter whether they have timber or concrete sleepers, Li et al. (2008, 2009). Since indentations and welds are inevitable, the best treatment of Squats would be early detection and early removal by, e.g. rail grinding, $\mathrm{Li}$ et al. (2010). 


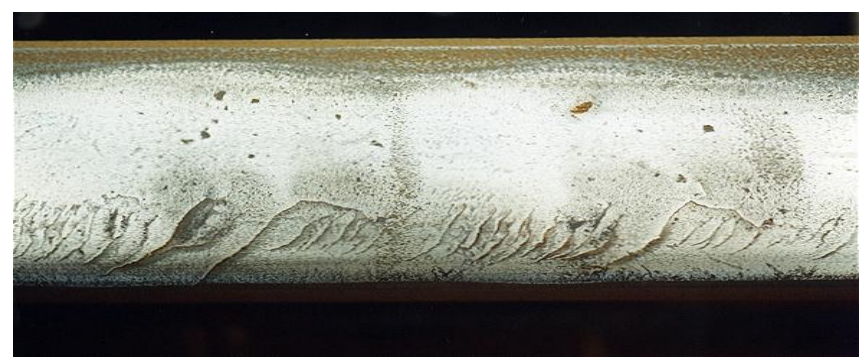

(a)

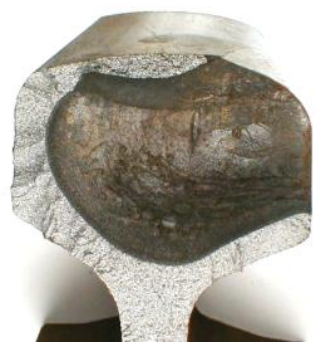

(b)

Figure 1.1 Severe Head Checks (a) and cross section of a severe single Head Check (b).

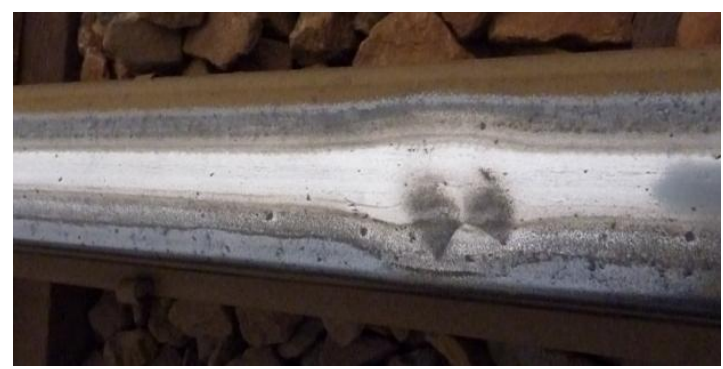

(a)

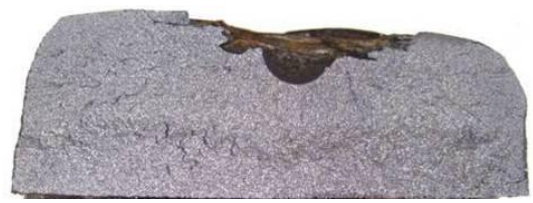

(b)

Figure 1.2 A typical severe Squat (a) and cross section of a Squat after four point bending (b).

\subsubsection{Head Checks}

$\mathrm{HC}$ occur mostly on curved tracks of radii less than $3000 \mathrm{~m}$ and in switches and crossings. They are found around the gauge corner of the outer (high) rail, usually with many of them clustered at uniform intervals. The surface cracks take an orientation angle $\alpha$ with respect to the lateral direction y (see Figure 1.3). In the initial stage, the short cracks grow at a shallow angle with the rail surface. At a later stage these cracks can sometimes grow at a more steep angle. This crack growing tends to occur when cracks reach $30 \mathrm{~mm}$ in 
visual (surface) length, and at this stage the probability of rail fracture becomes very high.

Severe $\mathrm{HC}$ particularly threaten the safety of traffic due to the multiple cracks which, when a fracture occurs, will result in disintegration of the rail and, in turn, to derailment.

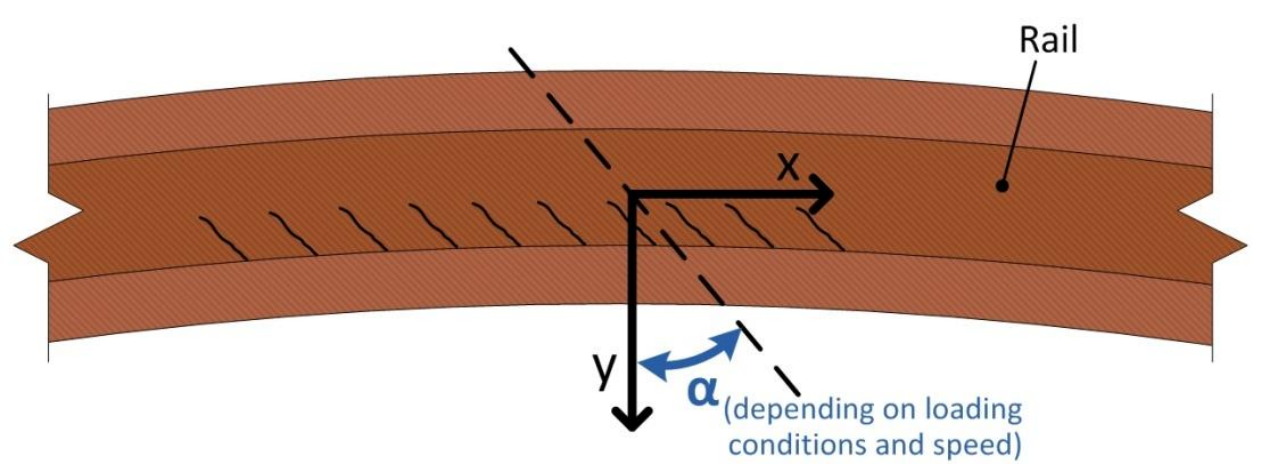

Figure 1.3 Head Checks in gauge corner of high rail. The traffic is in the $x$ direction.

\subsubsection{A brief comparison between $\mathrm{HC}$ and Squats}

These two types of RCF are distinctly different from each other in a number of main aspects (see Table 1.1). The approach to treat them will therefore be different. In this thesis the focus is on HC, and wherever RCF is used, it means $\mathrm{HC}$, except otherwise indicated.

A distinction is made between cyclic loading and dynamic loading: in cyclic loading the inertia of the bodies does not have to be, and is usually not, taken into account in the stress and strain calculation, while for dynamic loading, it should be. Since the macro-mechanics of $\mathrm{HC}$ is quasi-static, no inertia effect due to wave propagation in continuum is considered for the evaluation of stress and strain. 
Table 1.1 Comparison of major characteristics of HC and Squats

\begin{tabular}{|l|l|l|}
\hline & Head Checks & Squats \\
\hline $\begin{array}{l}\text { Locations to } \\
\text { occur }\end{array}$ & $\begin{array}{l}\text { Mainly on outer rail of curved } \\
\text { tracks of radii smaller than } \\
3000 \mathrm{~m}\end{array}$ & $\begin{array}{l}\text { Mainly on straight tracks or curved } \\
\text { tracks of radii larger than } 3000 \mathrm{~m}\end{array}$ \\
\hline $\begin{array}{l}\text { Locations to } \\
\text { occur }\end{array}$ & $\begin{array}{l}\text { On gauge shoulder and } \\
\text { gauge corner }\end{array}$ & On rail crown / head \\
\hline Initiation due to & $\begin{array}{l}\text { Lateral contact force and } \\
\text { geometrical spin }\end{array}$ & $\begin{array}{l}\text { Mainly due to pre-existing } \\
\text { geometrical defects (size }>6 \mathrm{~mm} \text { ) } \\
\text { and the resulting high frequency } \\
\text { dynamic force }\end{array}$ \\
\hline $\begin{array}{l}\text { Macro- } \\
\text { mechanics }\end{array}$ & Quasi-static & $\begin{array}{l}\text { Dynamic; continuum dynamics and } \\
\text { wave propagation }\end{array}$ \\
\hline
\end{tabular}

\subsection{HC in the Dutch railway}

On the Dutch railways more than 6000 trains operate daily on almost $7000 \mathrm{~km}$ of track (railway lines), transporting 1.2 million passengers and 100.000 tons of freight. The Dutch network is the most densely used in Europe and therefore needs special management to control safety and perform maintenance while trains keep running. Due to the intensive exploitation of the track, it is a challenge to control and manage this amount of train traffic versus track maintenance, like RCF, of the infra provider. Further contributing to the challenge is the fact that there are two different owners of the railway system: one owner of the "wheels" - the rolling stock of NS, and one of the "rails" - the infra part of ProRail, while the vehicle-track interaction system, and the wheel/rail contact in particular, has to be treated in an integral manner. Since 2001, the Dutch Rail-Infra manager has been actively investigating the causes and elaborating strategies to reduce the RCF problem, Smulders and Hiensch (2003), and Ringsberg et al. (2000). It has become clear that the causes for the sudden rise in RCF are multiple.

\subsubsection{HC classification}

To understand the size and severity of the development of $\mathrm{HC}$ damage in the Dutch rail network, a standardised visual inspection and classification method has been developed as a Dutch guideline. Table 1.2 gives an overview of the $\mathrm{HC}$ classification used in the RCF visual inspection. 
Table 1.2 Severity classification of HC in the Netherlands

\begin{tabular}{|l|l|l|}
\hline Defect severity & Abbreviation & Description \\
\hline Light & L & Surface crack $<10 \mathrm{~mm}$ \\
\hline Medium & M & Surface crack $10 \mathrm{~mm}-20 \mathrm{~mm}$ \\
\hline Heavy & Z & Surface crack $20 \mathrm{~mm}-30 \mathrm{~mm}$ \\
\hline Severe & ZE & Surface crack of $30 \mathrm{~mm}$ or more \\
\hline
\end{tabular}

\subsubsection{HC occurrence}

Inspections by visual inspection, Ultrasonic (US) testing and Eddy Current (EC) testing have been carried out every 6 months on the complete network. The total Dutch network was divided in $50 \mathrm{~m}$ sections in which the maximum crack length found determines the damage classification of the section.

Figure 1.4 shows the amount of $\mathrm{HC}$ in plain tracks and turnouts between 2002, when the occurrence of $\mathrm{HC}$ started to be systematically and consistently counted, and 2004 when the occurrence of $\mathrm{HC}$ was at a climax. About $40 \%$ of track was infected with RCF and there seems to be an increasing trend. The need for research was obvious.

\subsection{Consequences of HC on RAMS and LCC}

$\mathrm{HC}$ has a severe consequence on safety. The well-known disaster with casualties was Hatfield (October 2000) where the rail was fractured over $35 \mathrm{~m}$ with around 300 critical HC cracks, Cannon et al. (2003), and Smith (2003), see Figure 1.5.

After this disaster the European Union started up a safety inspection to avoid another problem of RCF. The inspections related to RCF (focused on $\mathrm{HC}$ and less on Squats) and maintenance costs involved are tremendous. Total amount of rail defects worldwide costs around €2 billion per year, Cannon et al. (2003), and Magel et al. (2004). In the Netherlands around 50 million (in 2004 and costs still growing fast) was spent on $\mathrm{HC}$ a year on inspection, renewal and preventive actions such as grinding. The normal life of a rail is about $25-35$ years. If it is infected by $\mathrm{HC}$ and not treated on time, the lifetime can be reduced to $2-3$ years. $\mathrm{HC}$ results in a dramatic rise in life cycle costs. 


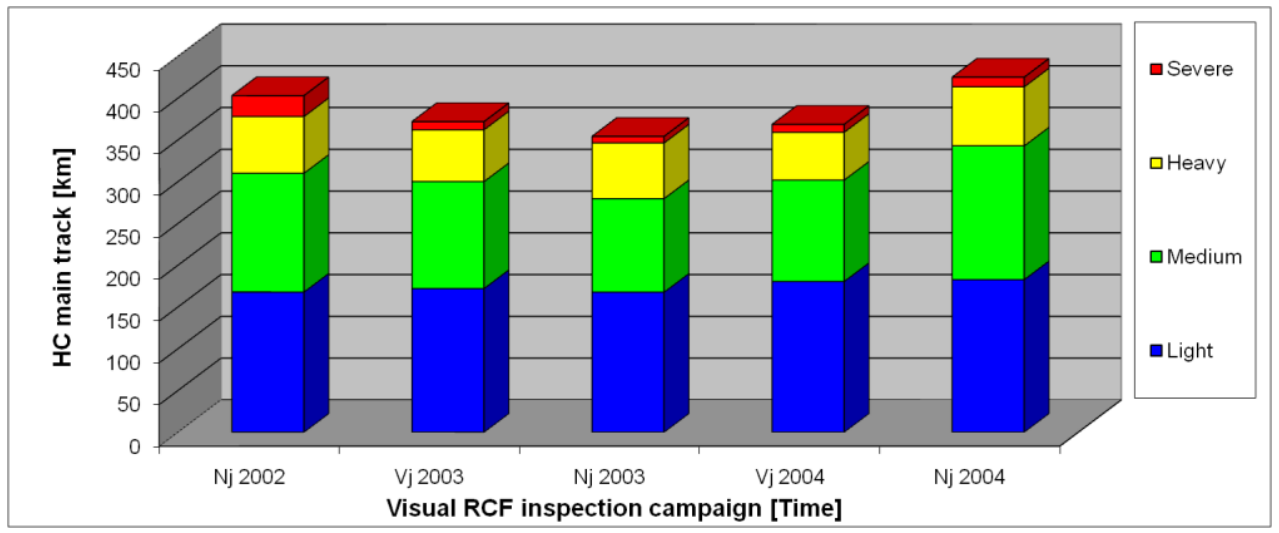

(a)

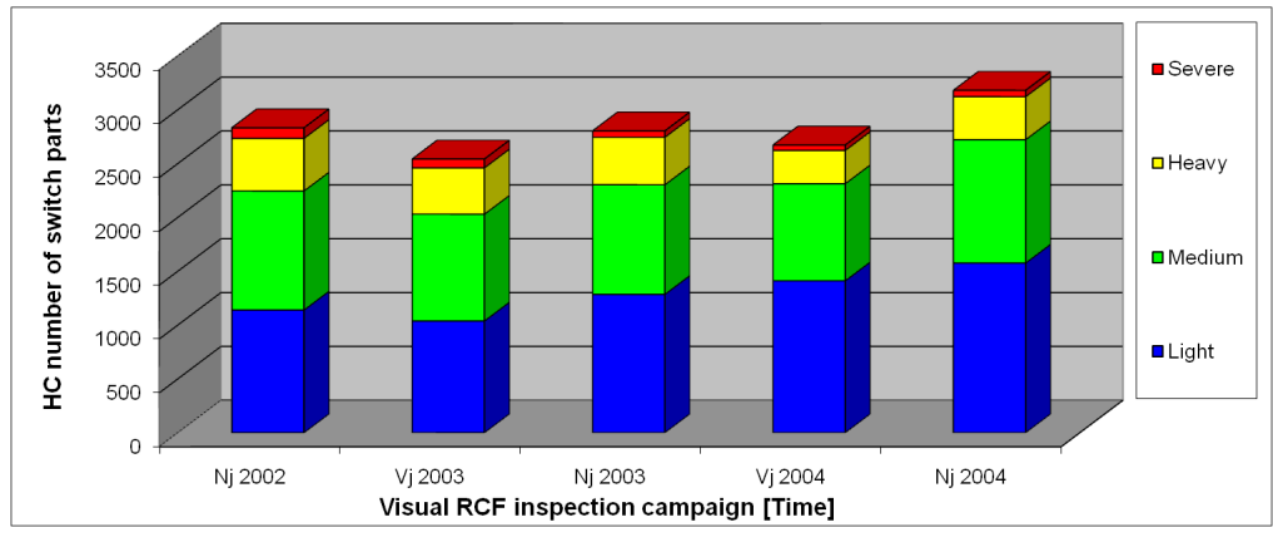

(b)

Figure 1.4 HC defects in (a) straight track in kilometres and (b) switch parts in numbers for 2002-2004 in the Netherlands. Visual inspection is carried out twice a year ( $n j$ and vj) parallel to Ultrasonic measurements by train.

Obviously $\mathrm{HC}$ and the associated inspection, maintenance and renewal also affect negatively reliability, availability, maintainability and safety (RAMS) of the railway network. 


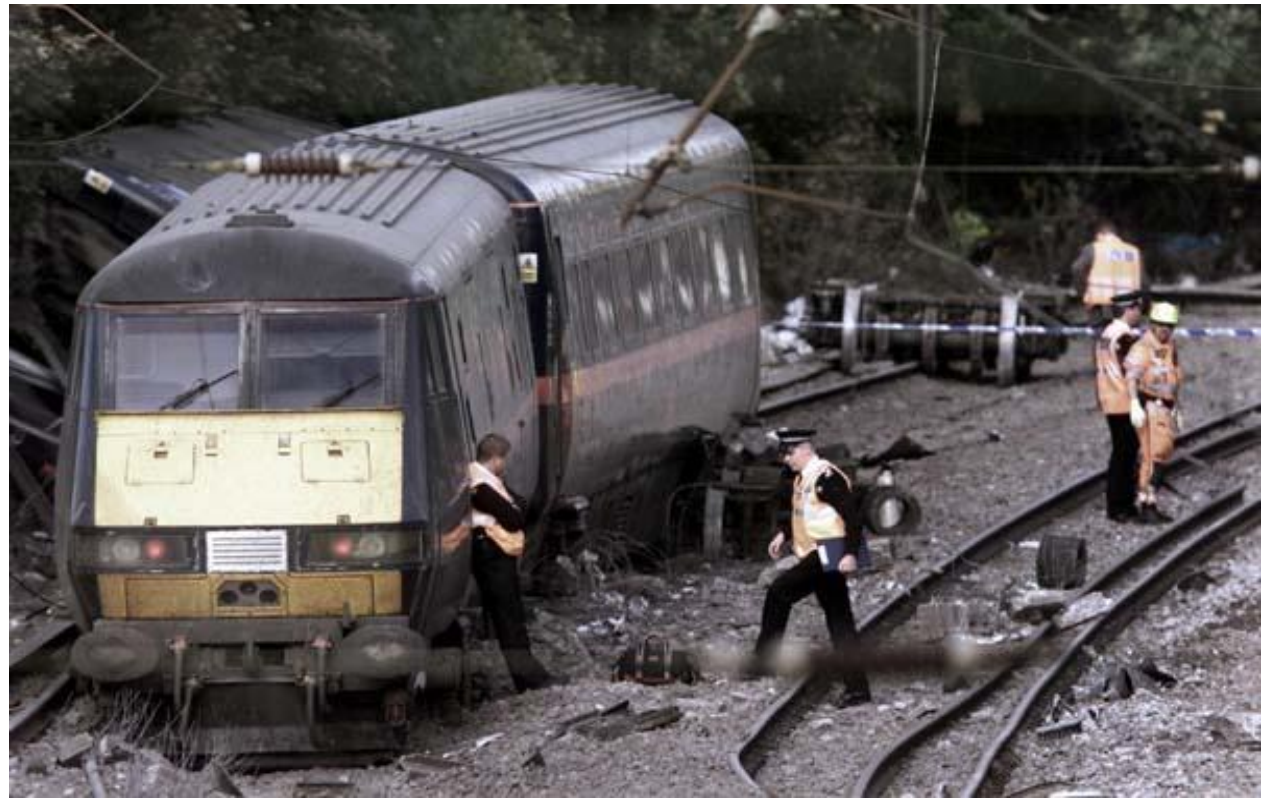

Figure 1.5 Hatfield derailment on $17^{\text {th }}$ of October 2000 because of broken rail due to Head Checks (photo Network Rail).

The Whole Life Rail Model (WLRM) reported by the Rail Safety \& Standards Board in the United Kingdom Burstow (2003) is good research on the parameters that have the most influence on understanding the phenomenon of HC. It is a simple way of understanding why RCF occurs and how to predict it.

However, a great deal of knowledge is still lacking on how to calculate the precise location of the $\mathrm{HC}$ initiation point, which could serve as input for maintenance rules or as guidelines, so Rail-Infra managers can control $\mathrm{HC}$ on time. WLRM only predicts the possibility of growth arising from a certain raildefect status, and under conditions that are known or assumed. More knowledge is needed to focus on the effects of RAMS and LCC.

\subsection{Outline of this thesis}

In view of the undesired impact $\mathrm{HC}$ has on the railways as well as on society, this thesis aims at effective solution, which can either significantly reduce $\mathrm{HC}$ or help prevent it. 
To this end, Chapter 2 reviews state-of-the-art of research, discusses loading conditions and influential factors, and identifies reasons for the increase in occurrences of HC. Next, in Chapter 3, the fundamental mechanism of $\mathrm{HC}$ is analysed with the aid of laboratory tests, field monitoring and numerical analyses. A potential principle for preventing/reducing $\mathrm{HC}$ is subsequently derived. In Chapter 4, this principle is applied to the design of an Anti Head Check $(\mathrm{AHC})$ rail profile. The effectiveness of the profile designed is checked by stress analysis. The profile's performances are presented firstly when tested on a monitored section of track and later when proven by large-scale application on the entire Dutch network. Finally, Chapter 5 discusses conclusions that have been reached as well as recommendations for further research.

\section{References:}

[1] Bergkvist, A., 2005, On the Crack driving Force in Elastic-plastic Fracture Mechanics with application to Rolling Contact Fatigue in Rails, PhD. thesis, Chalmers University of Technology, Sweden.

[2] Burstow, M., 2003, Whole Life Rail Model application and development: Development of a Rolling Contact Fatigue damage parameter, Rail Safety \& Standards Board and AEATechnology (AEATR-ES-2003-832, issue 1).

[3] Cannon, D.F., Edel, K.O., Grassie, S.L. and Sawley, K., 2003, Rail defects: an overview, Fatigue and Fracture of engineering Materials and Structures, 26 (10), pp. 865-887.

[4] Carroll, R.I. and Beynon, J.H., 2007, Rolling contact fatigue of white etching layer: Part 1: Crack morphology, Wear, Vol. 262, no. 9-10, pp. 1253-1266.

[5] Esveld C., 2001, Modern Railway Track, second edition, ISBN 90800324-3-3, MTR-productions, Zaltbommel, The Netherlands.

[6] IHHA (International Heavy Haul Association), 2001, Best practice in Heavy Haul, Virginia Beach, USA.

[7] Li, Z., 2002, Wheel-Rail rolling contact and its application to wear simulations, PhD thesis, ISBN 90-407-2281-1, Delft University of Technology, The Netherlands.

[8] Li, Z., Zhao, X.,Esveld, C., Dollevoet, R.P.B.J. and Molodova M., 2008, An investigation into the causes of Squats: correlation analysis and numerical modeling, Wear 265, pp. 1349-1355. 
[9] Li, Z., Zhao, X., Molodova, M. and Dollevoet, R.P.B.J., 2009, The validation of some numerical predictions on Squats growth, Proceedings 8th International Conference on Contact Mechanics and Wear of Rail/Wheel Systems, ISBN 978-88-904370-0-7, Florence, Italy, 15 - 18 September, pp. 369 - 378.

[10] Li, Z., Molodova, M., Zhao, X. and Dollevoet, R.P.B.J., 2010, Squat treatment by way of minimum action based on early detection to reduce life cycle costs, Proceedings of the 2010 joint rail conference, 27 - 29 April, Urbana-Champaign, Illinois, USA.

[11] Magel, E., Scroba, P., Sawley, K. and Kalousek, J., 2004, Control of Rolling Contact Fatigue in Rails, Arema Conference Proceedings, National Research Council, Canada.

[12] Popovici, R.I., 2010, Friction in Wheel-Rail contacts, PhD thesis, ISBN 978-90-365 2957-0, University of Twente, Enschede, The Netherlands.

[13] Ringsberg, J.W., Loo-Morrey, M. and Josefson, B.L., 2000, Prediction of fatigue crack initiation for Rolling Contact Fatigue, International Journal of Fatigue, Vol. 22, no. 3, pp. 205-215.

[14] Smith, R.A., 2003, The wheel-rail interface - some recent accidents, Fatigue and Fracture of Engineering Materials and Structures, 26 (10), pp. 901-907.

[15] Smulders, J. and Hiensch, M., 2003, RCF management and research program in the Netherlands: approach and solutions to control the wheel-rail interface to reduce RCF damage, Proceedings of World Congress on Railway Research, Edinburgh, Scotland.

[16] UIC Leaflet 712R, 2002, Rail defects, 4th edition, version January 2002, ISBN 2-7461-0341-9.

[17] Zoeteman, A., Dollevoet, R.P.B.J., Fischer, R. and Lammers, J.W., 2009, Chapter 28, Handbook of Wheel Rail Interface Management, edited by Lewis, R. and Oloffson, U. ISBN 1-84569-412-0, Woodhead Publishing Ltd., pp. 792-818. 


\section{Chapter 2 Literature review}

\subsection{Introduction to the wheel-rail system}

Head Checks are a consequence of wheel-rail interaction. In this section the wheel-rail interaction system is introduced.

Usually two wheels are rigidly mounted on an axle to form a wheelset. An unconstrained wheelset as a rigid body has six degrees of freedom. A railway wheelset is, however, constrained by the track along which it runs. Apart from the rolling, a wheelset only has two independent degrees of freedom (DOF) to consider, namely the lateral displacement of the centre of the wheelset with respect to the centre of the track $\Delta y$, and yaw angle $\psi$, see Figure 2.1.

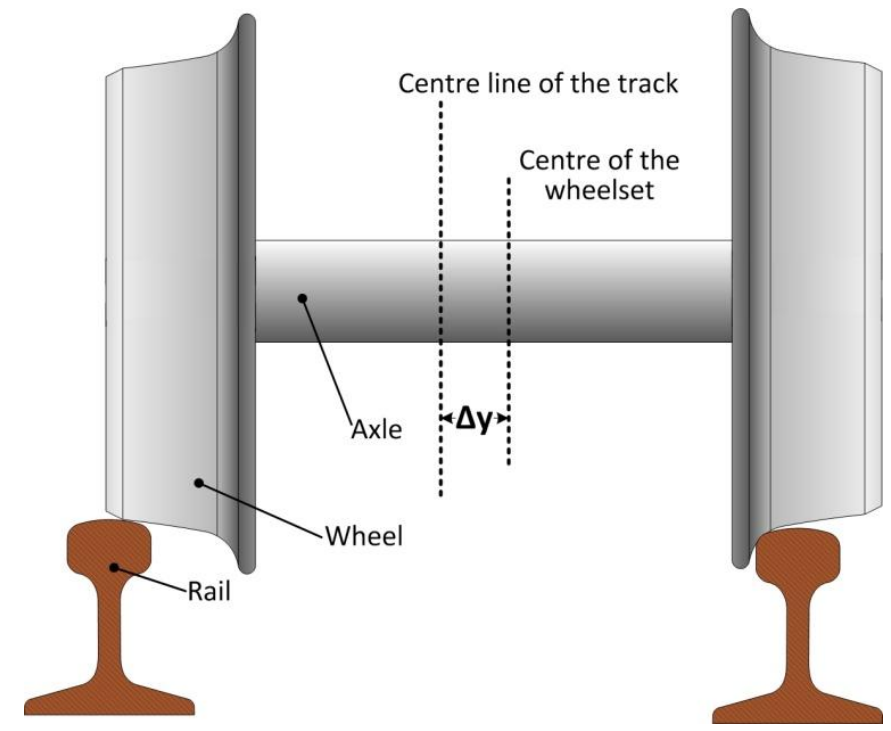

Figure 2.1 (a) Lateral displacement $\Delta y$ of a wheelset. 
The translational motion in the rolling direction is constrained by the wheel-rail contact force, and is not allowed under normal circumstances; this DOF is not considered. The roll motion of the wheelset $\theta$, see Figure 2.2, is dependent on $\Delta y$ and $\psi$. Notice that the $\theta$ DOF should not be confused with the rolling motion of a wheel along a rail. The downward translation is hindered by the rails and the upward motion to separate a wheelset from the rails should not happen for safe operation.
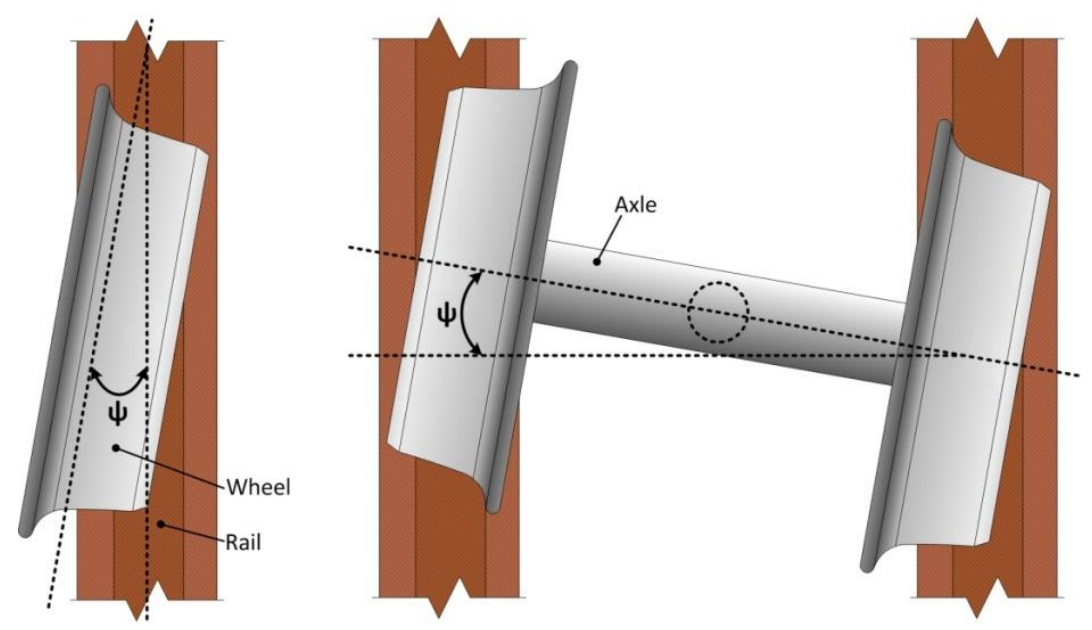

Figure 2.1 (b) Yaw angle $\psi$.

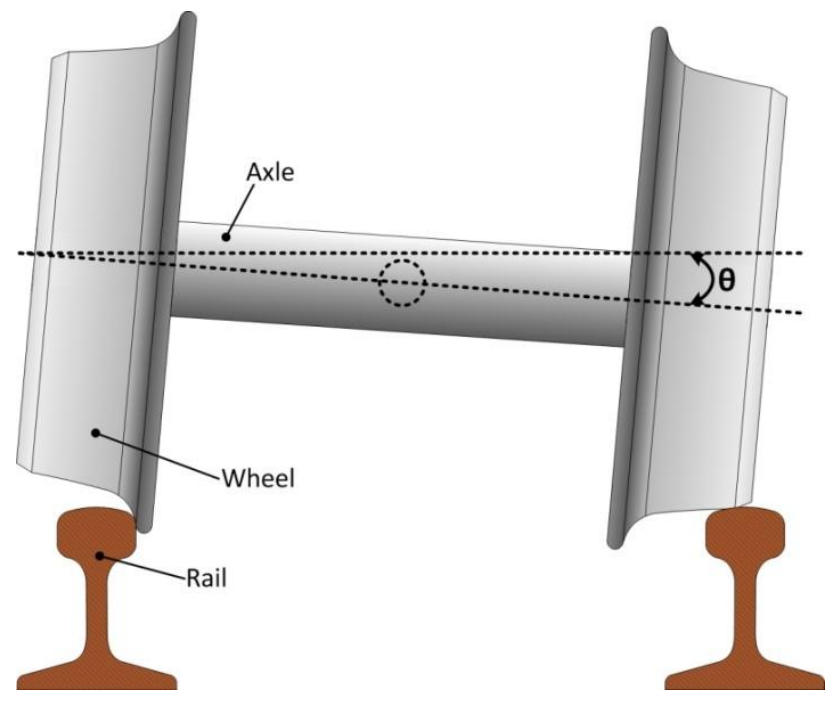

Figure 2.2 Roll motion of a wheelset, indicated with angle $\theta$. 
Although the rail cross section is usually symmetric, rails are normally not installed in an upright position in the track, but inclined with an angle $\alpha$ towards the track centre, as shown in Figure 2.3. This inclination can significantly change the contact location of a wheel on a rail.

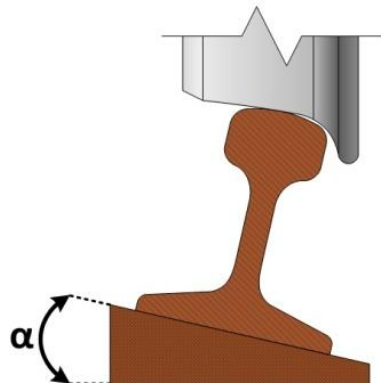

Figure 2.3 Rail inclination indicated with angle $\alpha$.

The assumption is that rolling takes place in the horizontal plane. The rolling direction is conventionally called the longitudinal direction $x$. The other horizontal direction, perpendicular to the longitudinal direction, is called the lateral direction $y$.

When a wheel rolls along a rail under the action of a traction or braking force that is not too large so that gross sliding takes place, the actual rolling velocity of the wheel will be different from that of pure (free) rolling, the latter being equal to the circumferential speed of the wheel as a rigid body. This difference in the two velocities is due to micro-slip in the contact area, Carter (1926) and Kalker (1990). The dimensionless difference is called the longitudinal creepage $\gamma_{x}$. Referring to Figure 2.4,

$$
\gamma_{x}=2\left(c_{x}-v_{x}\right) /\left(c_{x}+v_{x}\right)
$$

Where $\boldsymbol{c}$ is the circumferential velocity of a wheel as a rigid body. Its projection to the rolling direction is $c_{x}$, while the actual forward speed is $v_{x}$. 


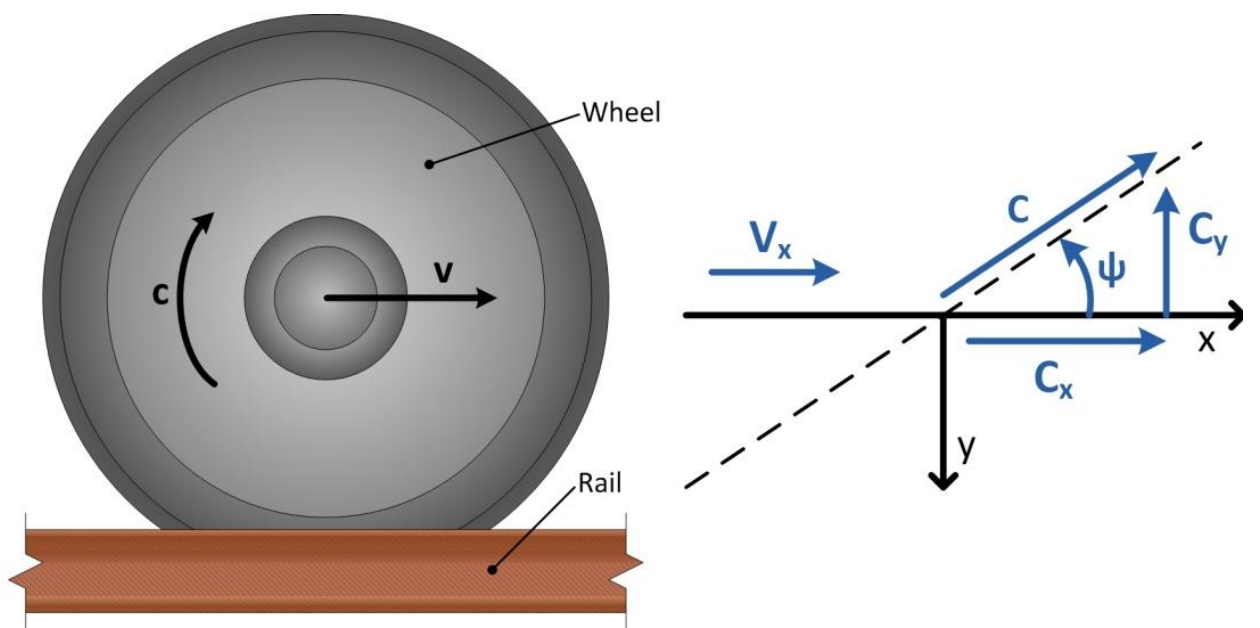

Figure 2.4 Creepage and velocity directions.

And similarly for Figure 2.4 , the lateral creepage is

$$
\gamma_{y}=2 c_{y} /\left(c_{x}+v_{x}\right)
$$

It can be shown that for small values of yaw angle $\psi$

$$
\gamma_{y} \approx \psi
$$

If the wheel rolling surface is not cylindrical, but conical, as is usually the case, geometrical spin will arise. Spin is a function of the angular velocity about an axis normal to the rolling surface. In Figure 2.5, the wheel rolls with an angular velocity $\Omega$ about the y axis. Because the conical wheel tread forms a contact angle $\delta$ with the rail, the normal direction $\mathbf{n}$ of the contact surface at the contact point is inclined at an angle $\delta$ relative to the vertical direction. $\Omega$ therefore has a component along $\mathbf{n}$, which causes spin. This spin is given in equation (2.4).

$$
\phi=2 \Omega \sin \delta /\left(c_{x}+v_{x}\right)
$$

Notice that at gauge corner $\delta$ changes in the contact area, so that $\phi$ is not constant. 


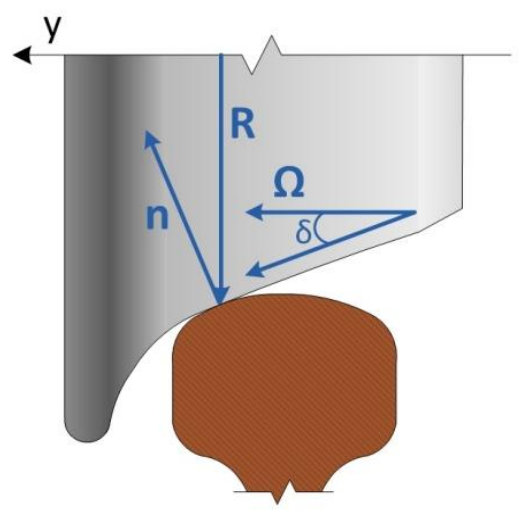

Figure 2.5 Overview of spin definition.

Figure 2.6 shows that due to creepage, a contact area is divided into a stick area at the leading part of the contact, and an area of micro-slip at the trailing part. Here different types of "slip" are distinguished: (1) micro-slip in the contact area when there is no gross sliding of the wheel relative to the rail. (2) macro-slip when gross sliding occurs, the stick area vanishes, and the contact area is completely occupied by the area of micro-slip. (3) "slip" used Section 2.2.

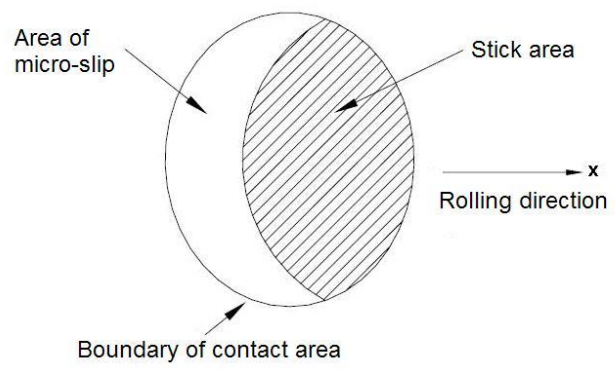

Figure 2.6 Areas of stick and micro-slip in wheel-rail contact.

A wheel, depending on its motion and the profiles of the wheel and rail, can take various positions relative to the contacting rail, see Figure 2.7. They are (a) wheel tread - rail head contact, (b) wheel flange - gauge face contact, (c) flange root - gauge corner/shoulder contact. The aforementioned three types of contact can also combine to form multiple-point contact. Figure 2.7(d) shows a two-point contact. In the cases of Figure 2.7(b to d), large spin will occur. And in the cases of Figure 2.7(c to d) the geometrical spin varies across the contact area. 


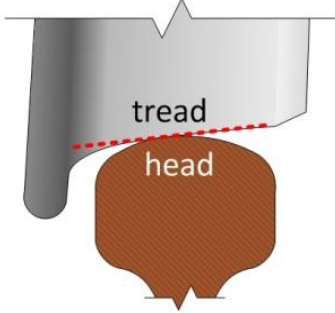

(a)

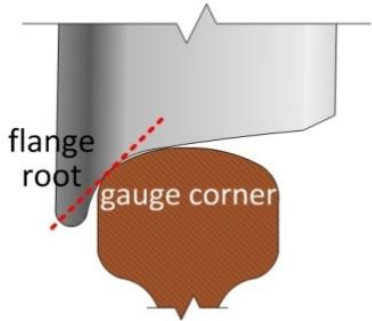

(c)

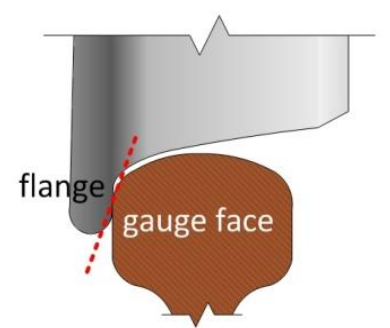

(b)

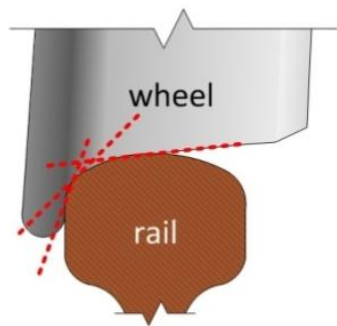

(d)

Figure 2.7 Various wheel-rail contact types.

Figure 2.8 shows the names of the various parts of a rail profile. They are used for later discussions.

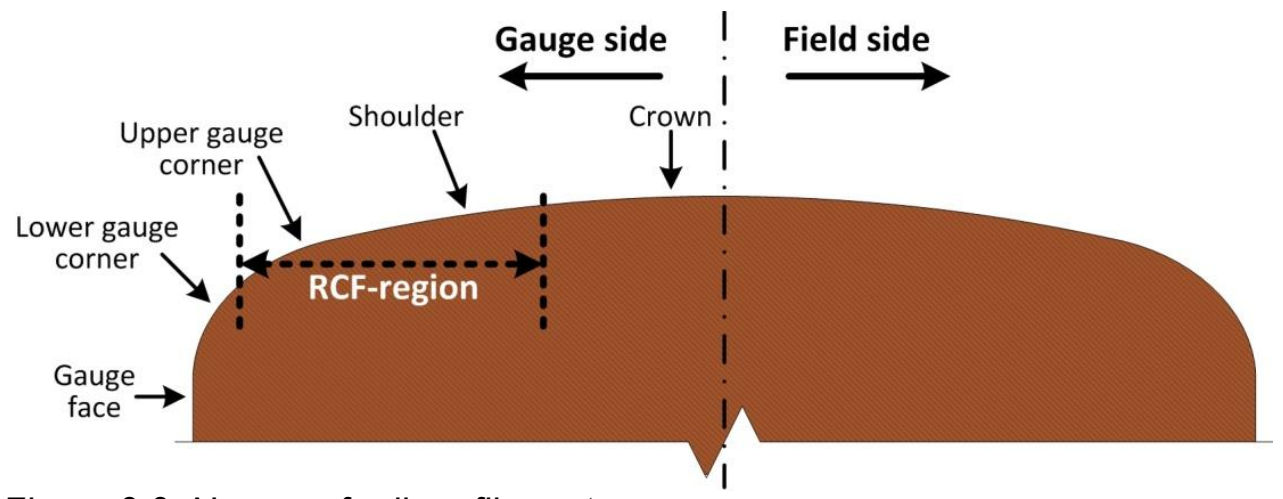

Figure 2.8 Names of rail profile parts.

Head Checks take place most frequently in curved tracks. This is due to the special wheel-rail contact there. When a vehicle travels along a curve, centrifugal force arises. To balance this force, the outer rail is usually elevated relative to the inner rail. This is called superelevation or cant. A fixed cant corresponds to a fixed balance speed of trains, at which the centrifugal force is precisely cancelled by the inclination of the train towards the centre of the 
track due to the cant. But even at balance speed, the centre of the wheelset will not coincide with the track centre, i.e. the wheelset will laterally be displaced, see Figure 2.9. This is because on a curve the outer rail is longer than the inner one. The wheelset has to displace towards the outside by $\Delta y$ so that the rolling radius of the outer wheel is larger than that of the inner wheel. If it is not constrained, the wheelset should be aligned along the ideal radial direction of the curve. With an ideally radially aligned wheelset, and if the difference in the rolling radii of the inner and outer wheels compensates precisely the length difference of the inner and outer rails, the wheelset will roll free of creepage as long as no traction or braking force is applied.

But a wheelset is usually constrained in a bogie, as shown in Figure 2.9, both in the longitudinal and lateral directions, so that it cannot be ideally aligned in the radial direction. The leading wheel (the one on the right-hand side in Figure 2.9) has the tendency to run towards the outer rail, forming an angle of attack (AOA), which is equivalent to a yaw angle in the case of straight track. This leads to an increase in the rolling radius of the outer rail and often also a decrease in the rolling radius of the inner rail, causing the outer wheel to travel more than the inner wheel, reducing the $A O A$. If the train is not travelling at the balance speed, the unbalanced centrifugal force will cause additional lateral displacement, affecting the AOA. Usually the travelling speed is higher than the balance speed, that is, cant deficiency occurs. The actual AOA is determined by the cant deficiency, the primary yaw stiffness (PYS) of the bogie etc. Modern railway vehicles have higher PYS, resulting in increased $A O A$.

The AOA causes lateral contact force and causes the wheel-rail contact to take place at the flange root - gauge shoulder and gauge corner, where large geometrical spin occurs. These are the conditions which promote $\mathrm{HC}$. 


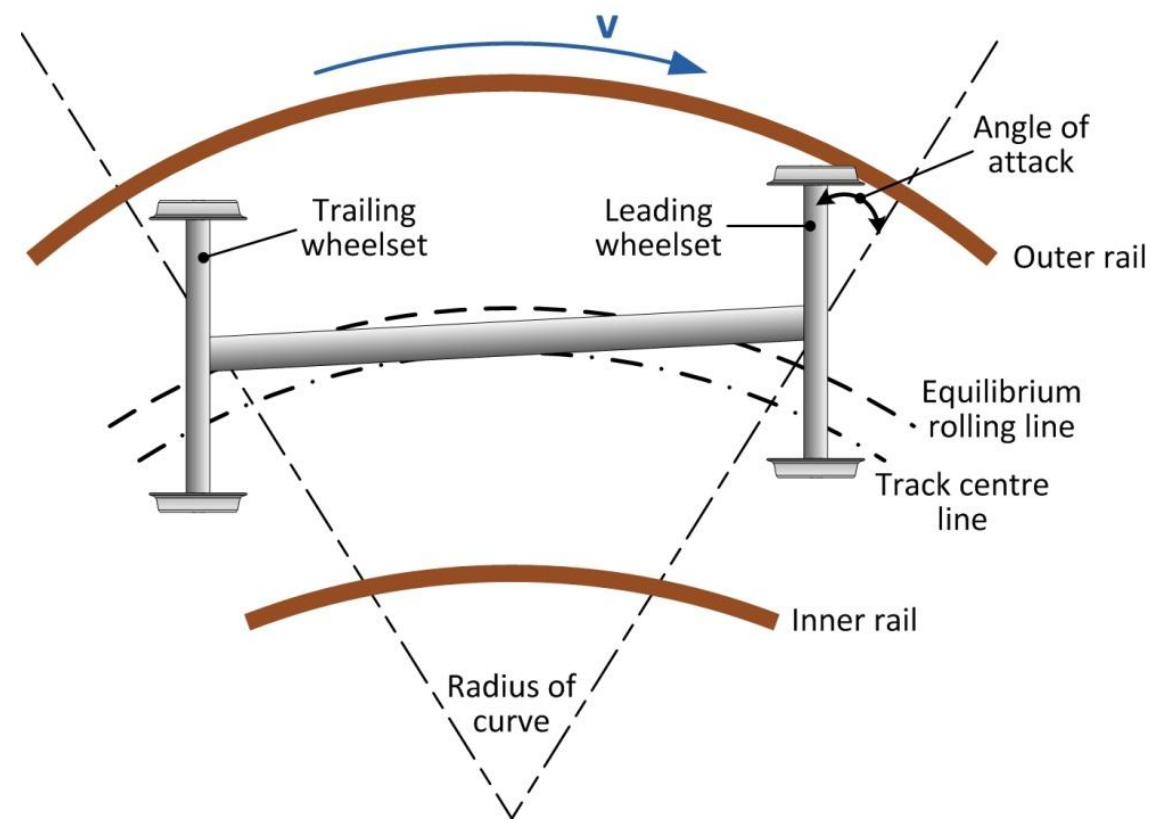

Figure 2.9 Wheel positions in curves.

\subsection{Comparison of rail and wheel RCF with other types of fatigue}

Wheel-rail rolling is steel-on-steel contact. In this section the general mechanism of steel fatigue is reviewed, RCF of rail and wheel is compared to classic structural fatigue and to RCF of machine elements such as rolling bearings and gears, in an effort to determine the similarities and differences between them, and to see what can be learnt from study and treatment of the other fatigue types. The characteristics of rail and wheel rolling contact are identified.

\subsubsection{General mechanism of fatigue}

Fatigue has been estimated to account for up to $80-90 \%$ of mechanical failure in engineering structures and components, Illson et al (1979). Failure by fatigue and the ultimate fracture is associated not only with economic loss, but also safety consequences. 
Fatigue occurs in steels when the stress is above a certain level and when the number of cyclic loading is high enough. The fatigue process involves crack nucleation/initiation, crack growth and ultimate fracture. The load needed to cause fatigue damage is lower than that for static failure. The cracks can initiate either at the surface or at subsurface. The subsurface-initiated category occurred more frequently in the past than it does now when inclusions exist in the material so that they can easily become a centre of stress and strain concentration. Nowadays the steels are made much cleaner, and it is the surface-initiated category which is of great practical importance.

In this section three types of fatigue are considered: the classical structural fatigue, Rolling Contact Fatigue (RCF) of bearings and gears, and RCF of rails and wheels. In structural fatigue, the stress may be uni-axial, proportional $^{1}$ and is usually tensile, Olver (2005). In RCF the stresses are always multi-axial, non-proportional and compressive.

Fatigue theories have been developed and applied to analyses and design of aerospace structures, pressure vessels, welded structures, as well as rolling components. The mechanism of typical crack initiation of classic structural fatigue at micro-structure level is described by Meyers et al. (1999), and Suresh (1998), and Soboyejo (2003), etc.

Any heterogeneity in a material that produces a stress concentration can nucleate cracks. For example, depressions, holes, scratches and so on act as stress raisers on surfaces. In the interior of the material, there may be voids, air bubbles, inclusions, second-phase particles, etc. Crack nucleation will occur at the weakest of these defects. Modern engineering steels are usually made clean, usually free from internal defects. Pre-existing surface defects can also be prevented in manufacturing and machining processes.

Yet under applied load shear stress causes plastic deformation by causing propagation of dislocations. Dislocations can be generated by rupture of the atomic bonds of a material under load, or they can also be emitted by steps and ledges at grain boundaries etc. Material grains have different orientations. Because the mechanical properties of crystals are anisotropic, and slip of dislocations occurs only in certain planes along certain directions, slip will first

\footnotetext{
1 Stresses being proportional means that stress components increase and decrease in proportion to one another.
} 
take place under applied stresses in grains in the softest orientation and with not much constraint from their neighbours, even if the stresses are well below the static elastic limit. Under cyclic loading dislocations multiply and pile up at grain barriers; steps, veins and ladders form; and persistent slip bands (PSB) occur, leading to strain localization. The material deforms and hardens locally.

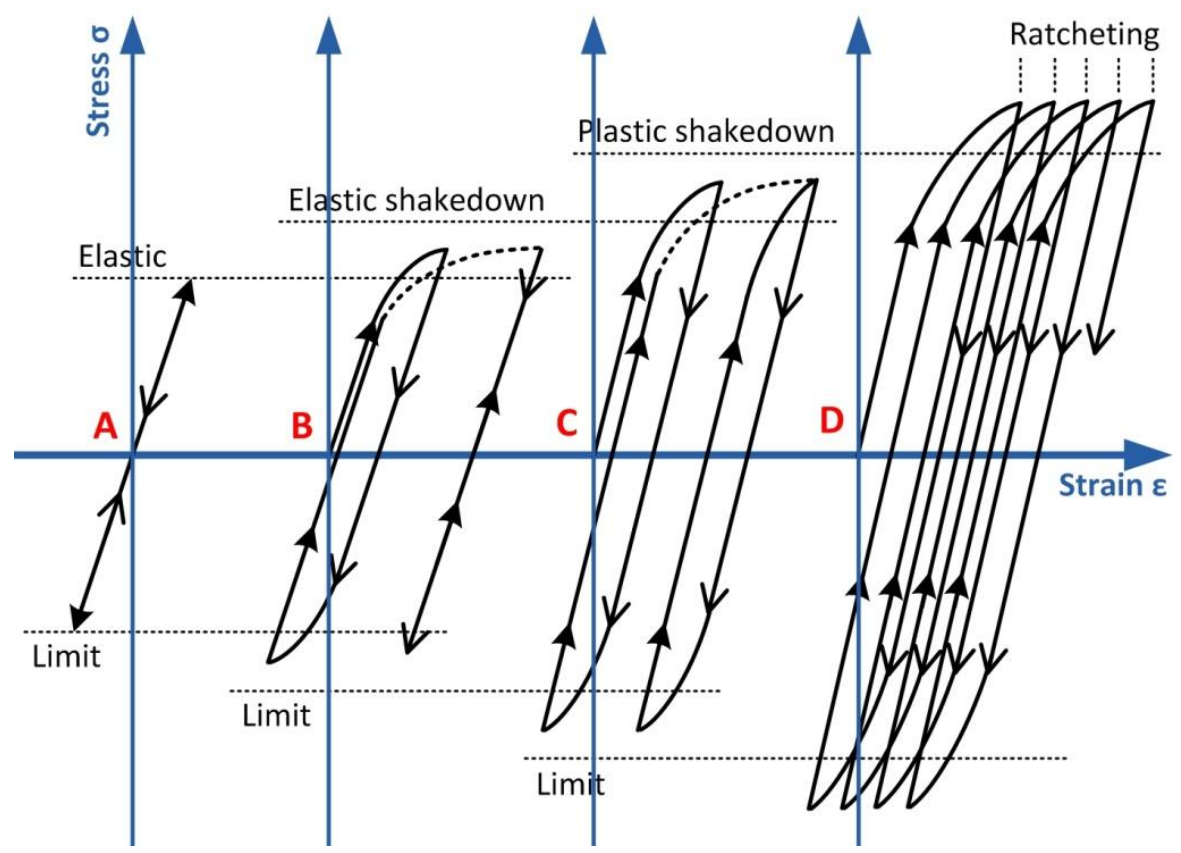

Figure 2.10 Different types of loading cycles related to fatigue: perfectly elastic (A), elastic shakedown (B), cyclic plasticity (plastic shakedown) (C) and incremental (ratcheting) (D). After Bower and Johnson (1989).

The interface between the PSB and the material matrix represents a discontinuity in the density and distribution of dislocations, causing stress concentration. When the local stress is high enough, micro-fracture occurs, and a microcrack is generated so that the stress can be relaxed, Meyers et al. (1999). After this the fatigue process enters the crack propagation stage. The microcracks often propagate initially along the crystallographic planes of maximum shear stress by Mode II shear mechanism, until the formation of macrocracks of usually larger than several grains in size as a result of microcrack coalescence or crack growth to a particular crack size where the crack begins to propagate by Mode I (tensile) mechanism with the direction of 
crack propagation being perpendicular to the direction of the principal axis of stresses, Meyers et al. (1999) and Soboyejo (2003).

A structure or element may respond to cyclic loading on a macro-scale in four different ways depending on the stress level, Johnson (1995), see Figure 2.10. (1) When the load is sufficiently low, the response will completely be elastic and reversible. (2) If, in the first loading cycles, the yield stress is exceeded, plastic deformation takes place.The consequent strain hardening, geometry change and residual stress cause the structure or element in the subsequent cycles to act perfectly elastically: it is then elastic shakedown. (3) If closed-cycle plastic deformation happens in every loading cycle, it is said to be plastic shakedown. (4) If repeated increments of unidirectional plastic deformation are accumulated, ratcheting occurs.

\subsubsection{Structural fatigue versus RCF}

The general mechanism of classic fatigue applies to RCF. But RCF also differs in a number of aspects: the load of rolling contact is non-proportional, multiaxial, local and compressive, see Figure 2.11. The PSB and the resulting intrusion and extrusion found in classic fatigue have not been observed for RCF, Olver (2005). It is rare that local compressive stresses give rise to failure in structural fatigue.

Rolling contact changes its contact geometry by plastic deformation, wear and crack formation. This is particularly of great importance in unlubricated situations where wear of material is significant. Because of the high stiffness of the steel-steel contact, small alternation in the topology can result in a large change in the magnitude and distribution of the stress and strain, influencing the initiation and growth of cracks. Figure 2.12 shows how a rail profile was changed by wear, and that $\mathrm{HC}$ occurred at a location where initially there was no contact. Figure 2.12(a) shows a rail shortly after grinding. The grinding marks which were not yet worn away were dark, while locations where wheels rolled over were run in, hence smooth and shining. Figure 2.12(b) shows an intermediate status. The area with grinding marks had shrunk due to wear; contact started to take place at the gauge corner which corresponds to the lowest shining strip (arrowed). It is noticed that the major running band, which is the broadest shining part in Figures 2.12(a), (b) and (c), and which bears the wheel load, had shifted downwards towards the gauge side. Figure 2.12(c) shows that HC had already occurred at a location which in Figure 
2.12(a) was an area of dark grinding mark. It is also observed that the running band had further shifted towards the gauge side, compared to Figure 2.12(b).

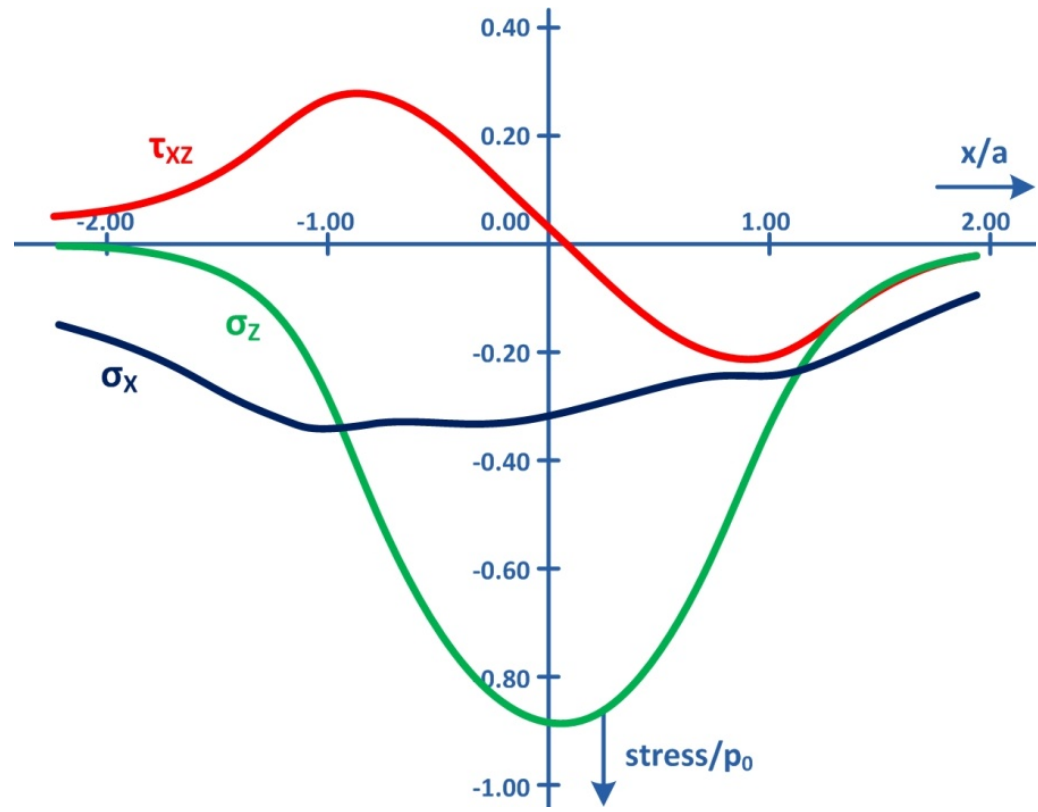

Figure 2.11 Non-proportional stresses evolution at a point of $z=a / 2$ under the surface when a line contact rolls over it. The shear stress $\tau_{x z}$ is reversed while the direct stress rises from zero to its maximum. $a$ is half the width of the contact area, $x$ is the distance along the rolling direction between the observation point and the contact, $p_{0}$ is the maximum pressure. After Bower and Johnson (1989).

Figure 2.12(d) and (e) show the profiles corresponding to Figure (b) and (c). The difference in the profiles seems small, the difference in contact is large: For the profile of Figure 2.12(b), the contact would be at two locations, in the form of the so-called two-point contact: the major contact would be on the upper broad running band which bears the vertical load, and a second contact would take place at the lower shining band, where the lateral force would be counteracted. It will later in sections 3.2 and 4.2 be shown that a small change in the rail profile can result in significant change in the location of contact, and the associated stress, strain and micro-slip. 


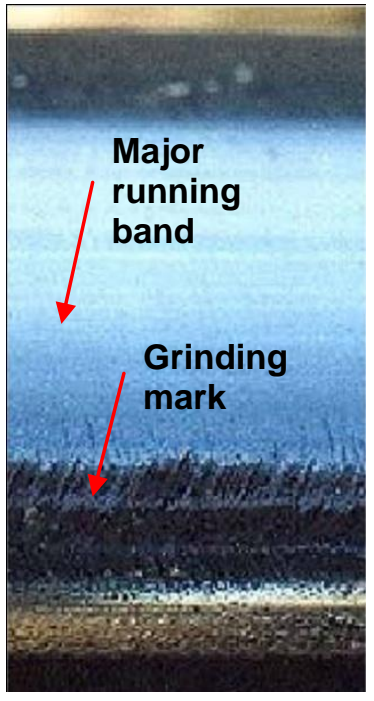

(a)

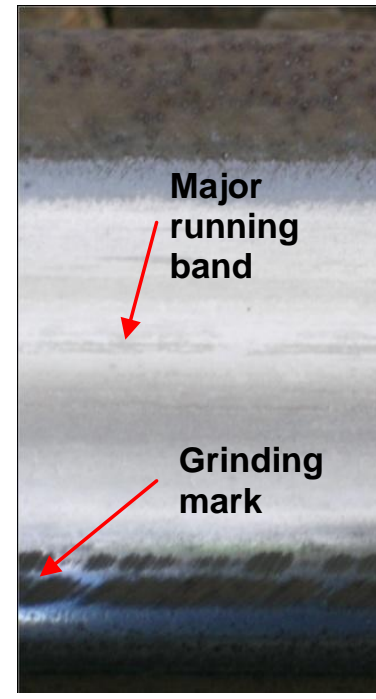

(b)

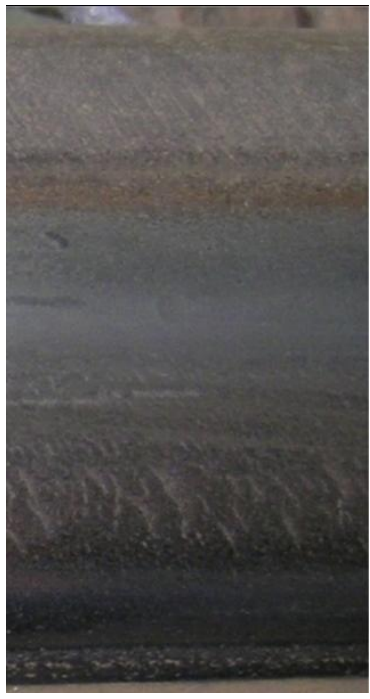

(c)

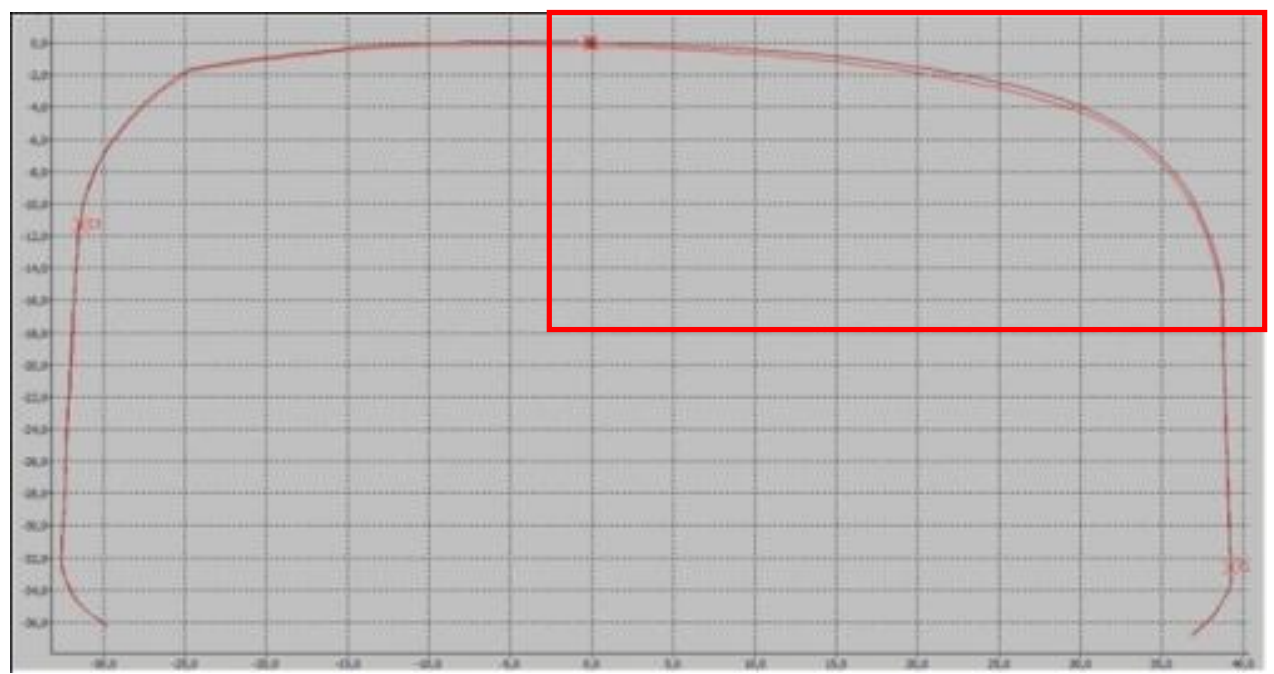

(d) 


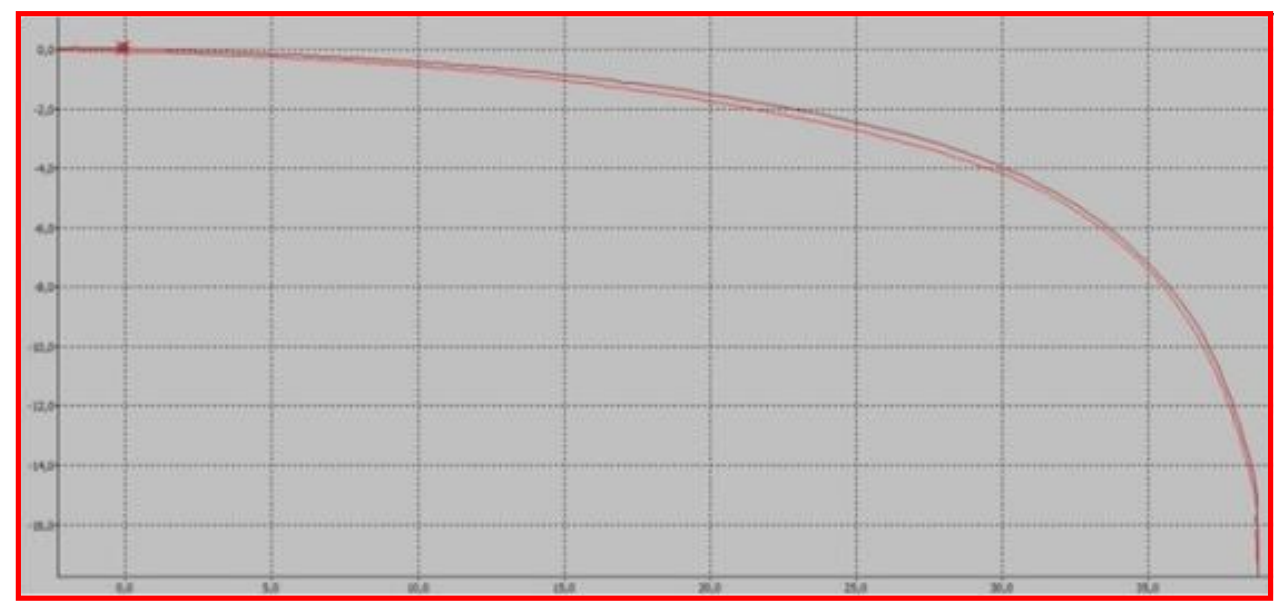

(e) Zoom-in of the upper-right part of (d).

Figure 2.12 Change of contact topography of a rail due to wear. HC occurred at location where initially there was no contact. In (d) and (e) the brown and red lines correspond to the profiles of (b) and (c) respectively. The unit of the abscissa and ordinate in (d) and $(e)$ is in millimetres.

The combined effect of pressure and tangential stresses on the contact surface leads to another important difference of RCF from classic structural fatigue. The cracks are closed when they are rolled over, and rubbing may occur between the faces of a crack. Striation, which is often observed in structural fatigue as a result of cyclic loading, is usually not observed in RCF because of the fretting, although some coarser features typical of fatigue such as 'beach marks' (crack arrests) can still be observed, Meyers et al. (1999) and Olver (2005). Spherical particle debris can be produced in the cracks by friction, Scott et al. (1973a and b) and Loy et al. (1973). But the most important effect is that the closure of the cracks may lead to liquid entrapment and subsequent pressurization of the crack tips. This will increase the Mode I (tensile stress normal to the plane of the crack) stress intensity factor. The friction and pressurization can greatly influence the growth of the cracks. Figure 2.13 shows a typical consequence of $\mathrm{HC}$ promoted by liquid pressurization. 


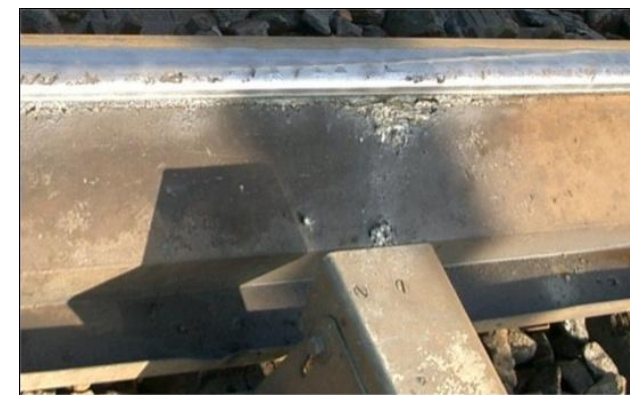

(a)

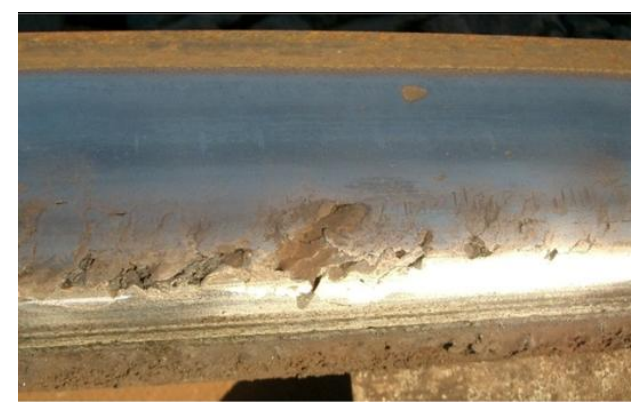

(b)

Figure 2.13 HC growth promoted by liquid pressurization.

In Figure 2.13(a) a track lubrication installation is seen. It should provide lubrication to the gauge corner of the rail upon wheel passages to reduce the coefficient of friction, so that the surface shear stress of the contact can be reduced to prevent $\mathrm{HC}$ from initiation. This should work if everything functions well. But actually severe $\mathrm{HC}$ can be seen in the two pictures. This situation happened, probably because the installation stopped providing the rail with lubricants, at a certain moment for one reason or another, so that $\mathrm{HC}$ initiated. When lubricant was again supplied to the rail later, the grease, and more probably a mixture of grease and water, came into the cracks (Figure 2.14(a)) and became entrapped and pressurized when a wheel rolled over, causing high pressure on the crack faces, resulting in tensile stress at the crack tip, which tore the crack open. Further, the lubricant accelerated the HC propagation in the sense that it prevented rain water from drying, so that the pressurization of the crack faces happened for a much longer time than without lubrication.

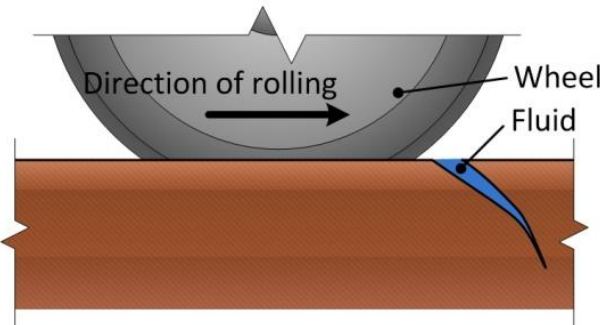

(a)

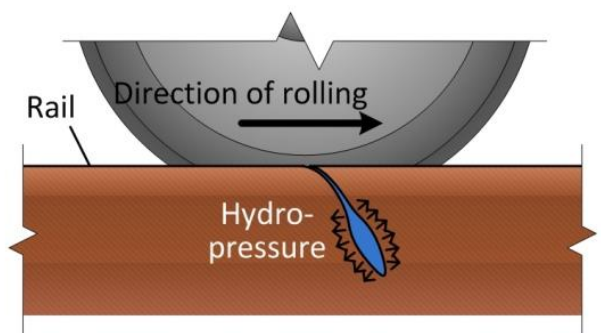

(b)

Figure 2.14 Crack propagation due to liquid entrapment and pressurization. 


\subsubsection{RCF of rails and of machine elements}

Rolling contact finds its applications in machine elements such as rolling bearings and gears, and in wheel-rail and tire-road contacts. Classical studies of RCF mainly focus on bearings and gears where the rolling materials, e.g., hardened steels, do not sustain bulk plastic deformation, Meyers et al. (1999). In softer materials of rail steel, large plastic deformation may occur in the form of laminates, Franklin et al. (2005), Arias Cuevas et al. (2010). The macro process is ratcheting, as described in Figure 2.10. The micro process, the formation of lamellar texture, is as follows, see Figure 2.15.

In polycrystalline materials, the individual grains usually have a random orientation with respect to one another. A single crystal rotates when it deforms plastically in a particular slip system. When a polycrystal is deformed under repeated rolling contact, the randomly oriented grains will slip on their appropriate glide systems and rotate from their initial conditions, but this time under a constraint from the neighbouring grains. Consequently texture in the preferred orientation of the grains develops after large strains; that is, certain slip planes and slip directions tend to align parallel to the rolling surface. The grains are elongated through plastic deformation, and a lamellar microstructure forms. Figure 2.15(a) illustrates the relation between the direction of the tangential contact stress and the orientation of the laminates. Figure 2.15(b) shows schematically how the laminates transit from the bulk material to the severely deformed surface layer. Figure 2.15(c) presents an actual example of such texture. It is the deformation of the grade $\mathrm{R} 260 \mathrm{Mn}$ rail material under 1.2 GPa pressure, dry friction with a maximum coefficient of friction (COF) of 0.6 , and maximum creepage $=0.03$ on a twin disc machine, Aries Cuevas et al. (2010).

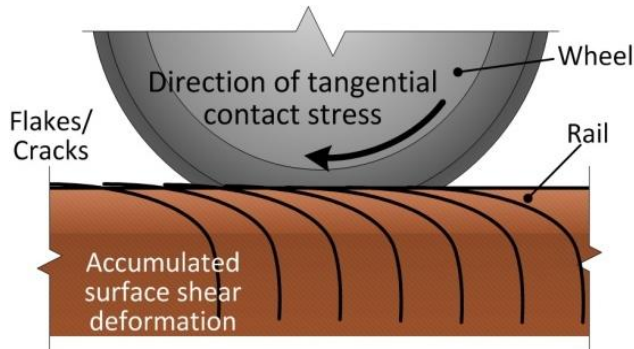

(a)

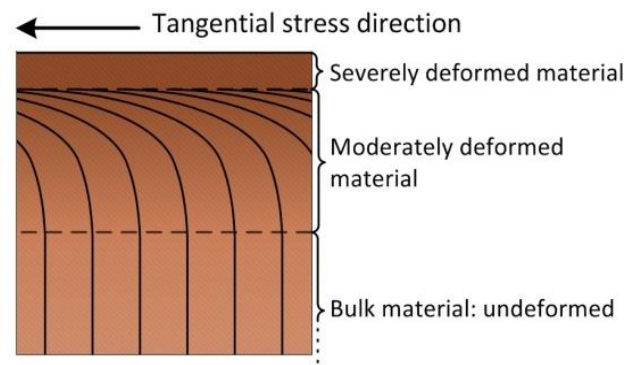

(b) 


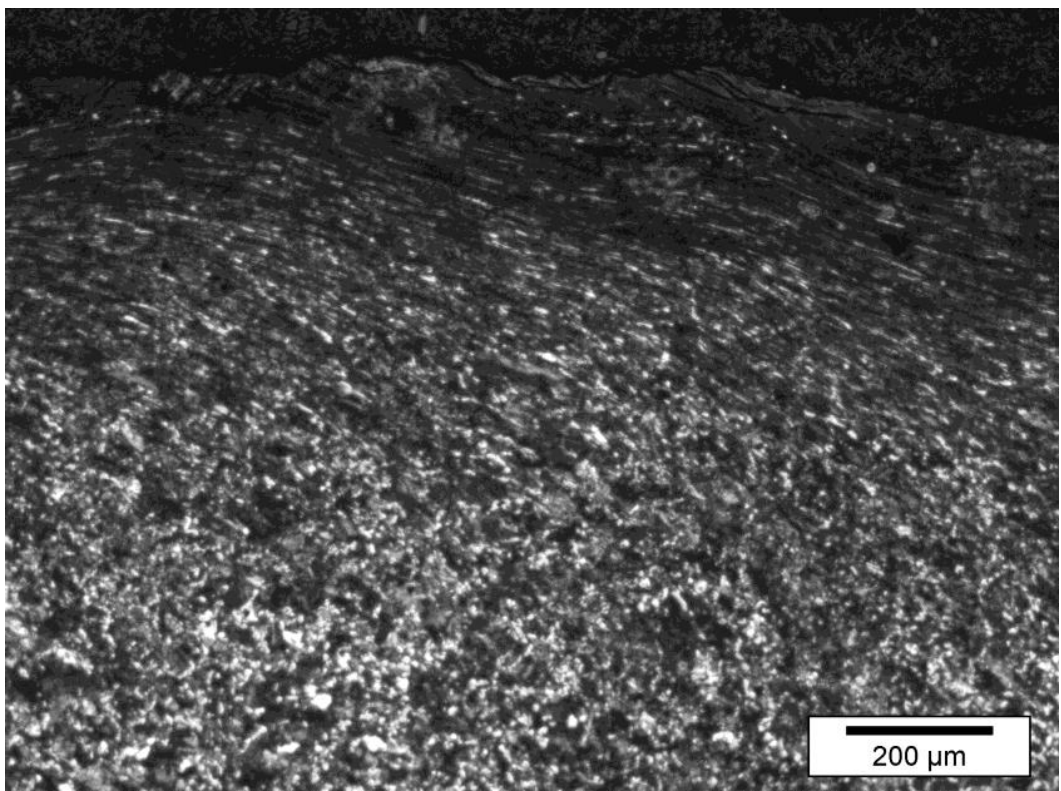

(c) Actual texture forming of rail material

Figure 2.15 Texture forming of rail material due to ratcheting under tractive rolling contact.

Strongly textured material can exhibit highly anisotropic properties and the yield stress can be significantly affected. Cracks are likely to propagate along the direction of the texture, Franklin et al. (2005). In the highly deformed top layer of Figure 2.15(c) cracks can be observed which is likely to lead to small wear debris. In Chapter 3 it will be shown that $\mathrm{HC}$ cracks indeed develop along the texture orientation, and the initiation takes place between 20,000 50,000 load cycles. The maximum shear stress is above ratcheting limit. This is reminiscent of low cycle structural fatigue Ellyin (1997), Franklin et al. (2007).

For hard steel, RCF is less commonly accompanied by widespread plasticity and crack initiation occurs at stress and strain concentrations such as asperities. This recalls similar behaviour of the high cycle fatigue of structural fatigue Ellyin (1997), which occurs in the elastic regime. This does not necessarily mean that there is no plastic deformation associated with RCF of hard steels. Rather, some plastic deformation seems to take place in RCF even in the hardest steels at sufficiently high loads, Voskamp (1985), 
although the texture forming may not be very significant, suggesting that the plastic strains were predominantly cyclic and that the stress was above the elastic shakedown limit but below the ratcheting limit so that plastic strain did not accumulate, Johnson (1995).

Micro-pitting occurs most frequently in hard steels that have been ground and in situations where the lubricant film is thin compared to the height of the roughness of the surfaces. It is usually thought to be a form of RCF associated with the asperity stress field, Berthe et al. (1980), Olver (2004). On the other hand asperities on the softer rail steel seem not to cause any fatigue, even if the most common rail roughness which is caused by grinding, is in the order of $0.1 \mathrm{~mm}$ (Figure 2.12), 2 orders higher than the magnitude of asperities of bearings and gears. This may be attributed to the lower yield stress, high ductility and higher wear rate, such that the roughness can be easily smoothed by plastic deformation and/or wear, without causing significant stress and strain concentration. Figure 2.12(a-c) gives a clear example, where the grinding marks were worn away.

It appears that wear of soft steel cannot only smooth away the surface roughness, it may also be able to suppress initiation or propagation of a surface crack by removing the embryonic cracks. In Figure 2.15(c) some wear debris were forming because of cracks which were parallel to the contact surface due to the severely strained surface layer of the soft and ductile steel. In Figure 2.16 the consequences of different wear and RCF resistance of rail materials are shown. The two rails were in a curve of radius $500 \mathrm{~m}$. The outer rail of the inner track was manufactured and installed in track in 1998. Although it was head hardened and had a tensile strength of $1200 \mathrm{MPa}$ (380 HV (10) hardness), it was severely head-checked at the time when the photos were taken, as shown in Figure 2.16(a), and had to be replaced. The outer rail of the outer track was put in service in 1984 and was naturally hardened with a tensile strength of $900 \mathrm{MPa}$ (280 HV (10) hardness). It was worn at the gauge side (Figure 2.16(b)), but was still good enough to remain in service. The uni-directional traffic on the two rails was the same but in opposite directions. The initial profiles of the rails were all 54E1. The operational conditions were therefore the same. If looked at purely from a material strength angle, the rail shown in Figure 2.16(a) should actually be less susceptible to crack initiation. 
Nevertheless the results were totally different. Severe HC had developed in the stronger rail in shorter time (Figure 2.16(a)), while there was no $\mathrm{HC}$ at all in the soft one (Figure 2.16(b)). Notice in Figure 2.16(b) that there should have been significant natural wear, evidenced by the very much worn gauge face. The rail had also been ground; see the grinding marks (arrowed). On the contrary there was no wear at the gauge face in Figure 2.16(a), the wear at the gauge corner was insignificant, and there was also no evidence of grinding. In theory cracks should have initiated earlier in the soft rail. The natural wear and the artificial wear by the grinding appear, however, to have suppressed the crack growth.

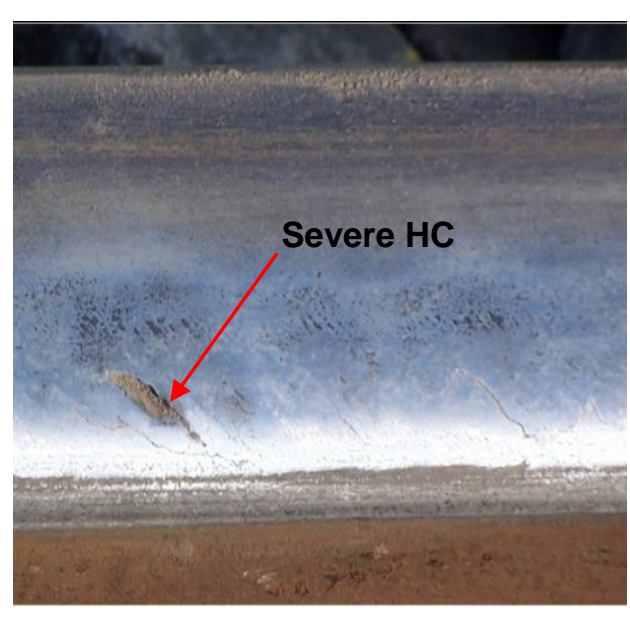

(a) R350HT rail in service since 1998 .

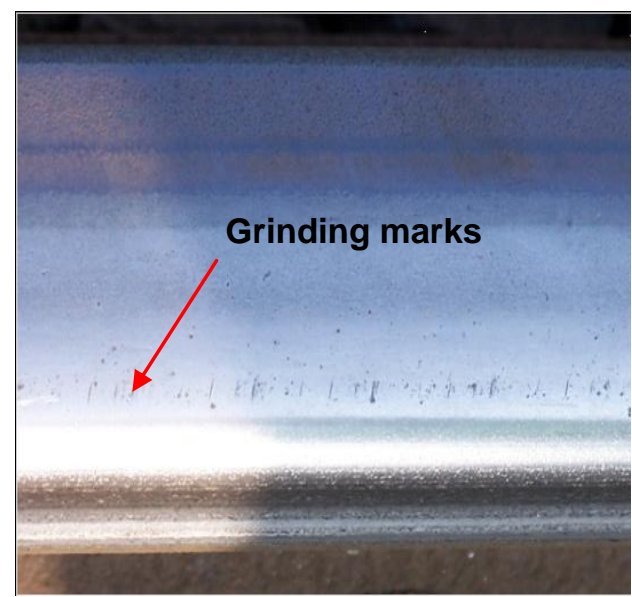

(b) R260 rail in service since 1984.

Figure 2.16 HC versus wear. Photos taken on 24th of April, 2005.

It appears that wheel-rail rolling contact differs in a number of aspects from rolling contact of machine elements: the former is often not well lubricated or not lubricated at all and, the materials are softer. The unlubricated steel-onsteel contact gives rise to a high coefficient of friction, which can be up to 0.6 , $\mathrm{Li}$ et al. (2009a). Consequently the surface shear stress is high, and often the maximal shear stress is in the surface, when the COF is larger than 0.3, Johnson (1985). See Figure 2.17 for change of shear stress with COF. This, together with the lower strength, causes both ratcheting, surface initiation of cracks and their propagation and, significant wear. It is the interaction between the rate of wear and that of crack initiation and growth that determines whether the wheels and rails fail by wear or by fatigue. On the 
other hand the lubricated machine elements have the maximal shear stress beneath the surface, and the wear is minimized. Ratcheting is usually not the cause of their failure. Further surface asperities play an important role in Rolling Contact Fatigue of machine elements, while for wheel-rail contact, surface geometrical deviation matters only when the dimension is larger than $6 \mathrm{~mm}$, Li et al. (2009b).
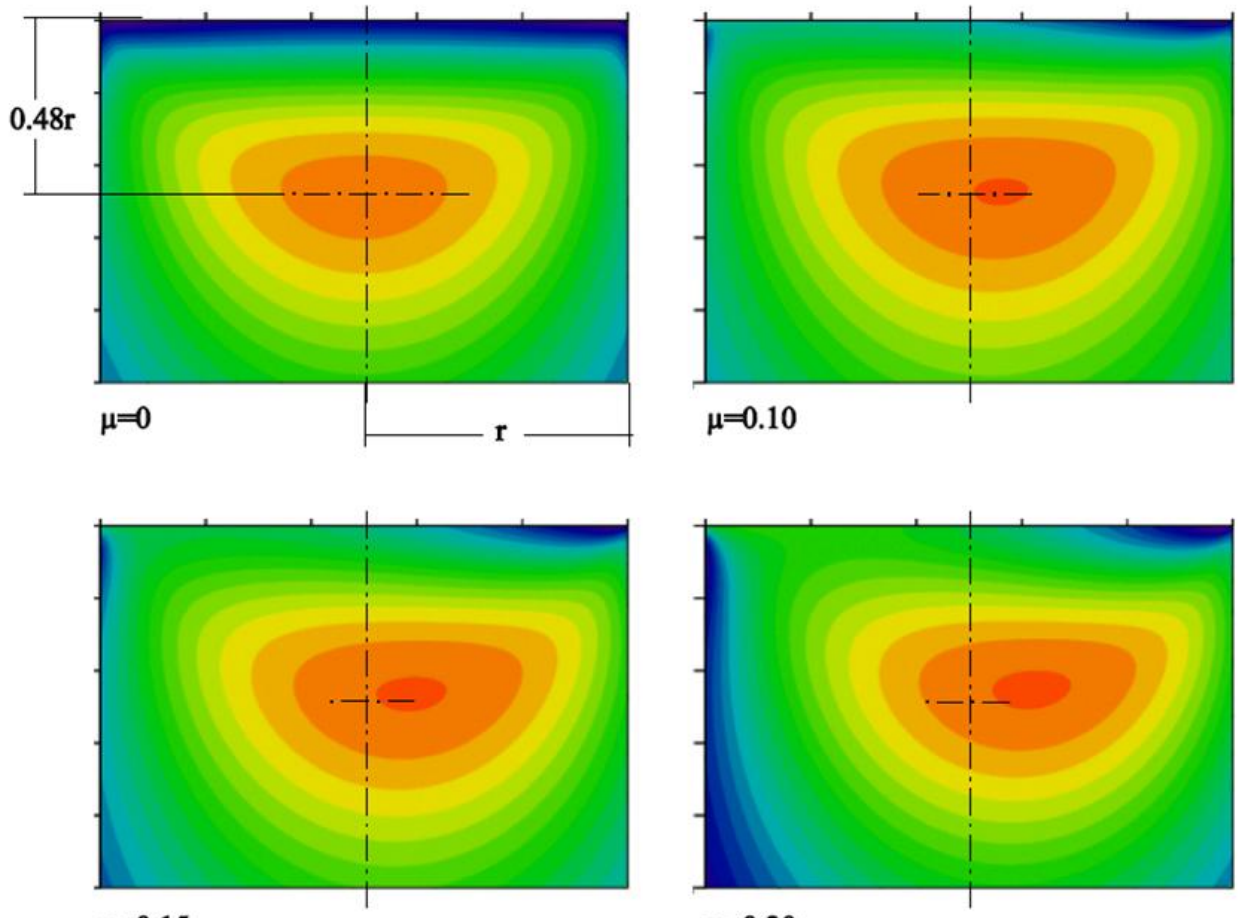

$\mu=0.15$

$\mu=0.20$
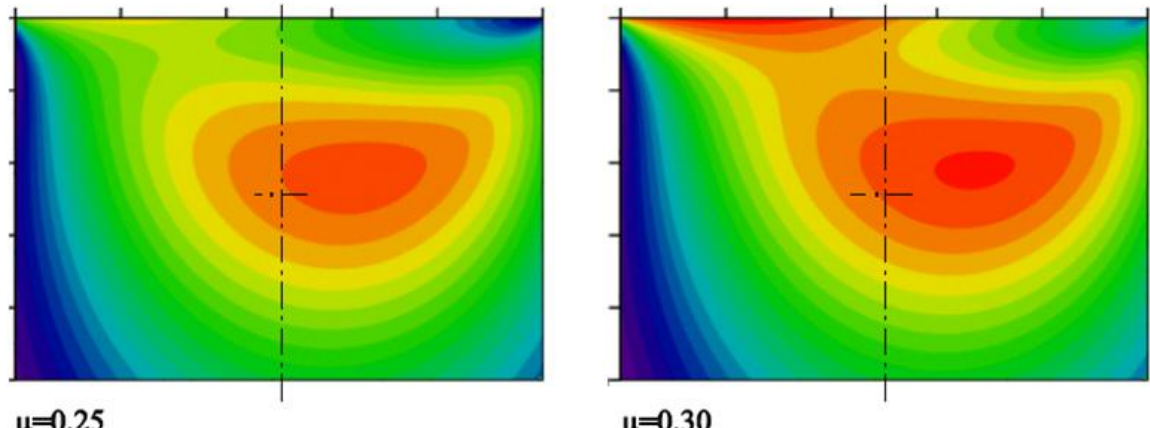

$\mu=0.25$

$\mu=0.30$

Figure 2.17 Contours of shear stress beneath a nominal point contact with $\mu=0.3$. 
Figure 2.18 gives a comparison of the three categories of fatigue mechanisms. HC belongs to the surface-initiated category. Its differences from the surface-initiated fatigue of the roller shown in Figure 2.18(d) are that $\mathrm{HC}$ is featured by the strong ratcheting texture, see Figure 2.15 , and is almost insensitive to surface asperities, see Figure 2.16(a).

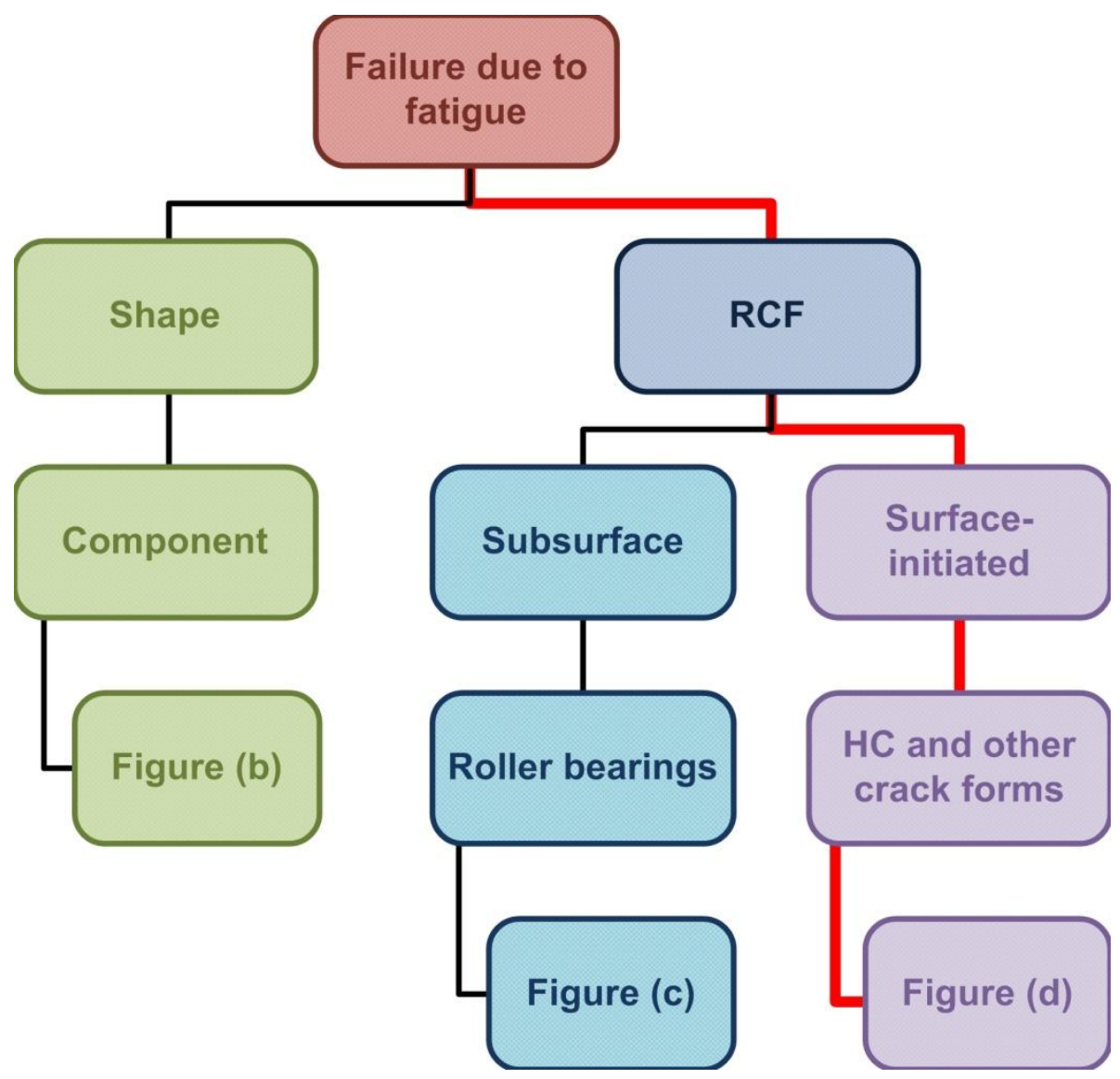

(a) Comparison of fatigue mechanisms. 

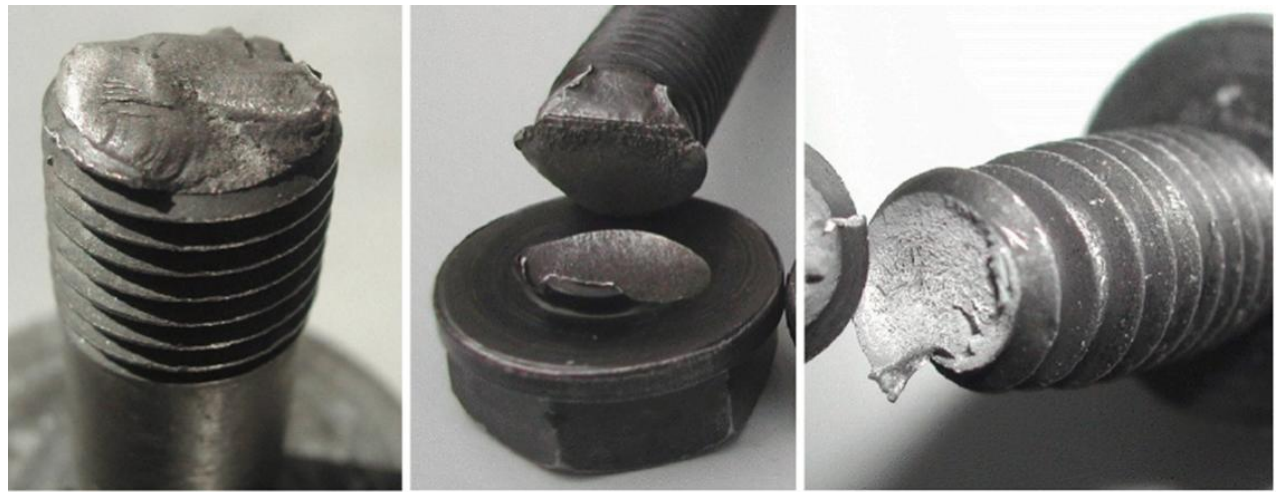

(b) Fatigue due to shape, Beek (2009).
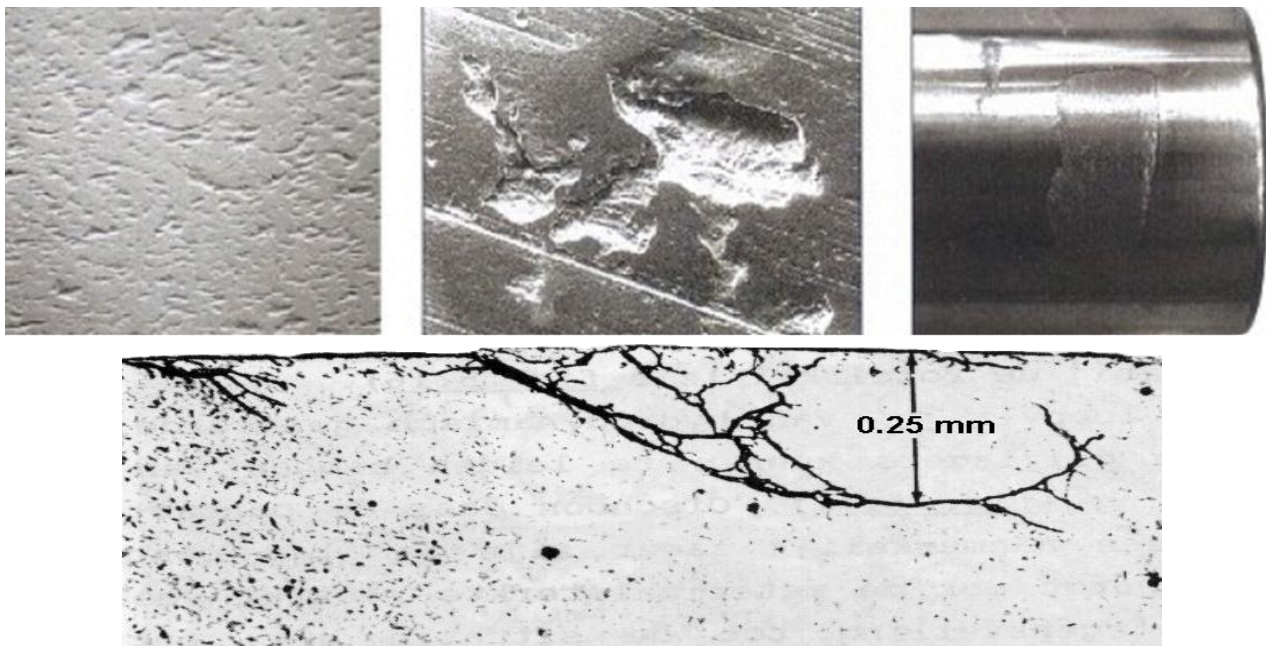

(c) Subsurface-initiated fatigue, Loannides and Harris (1985).
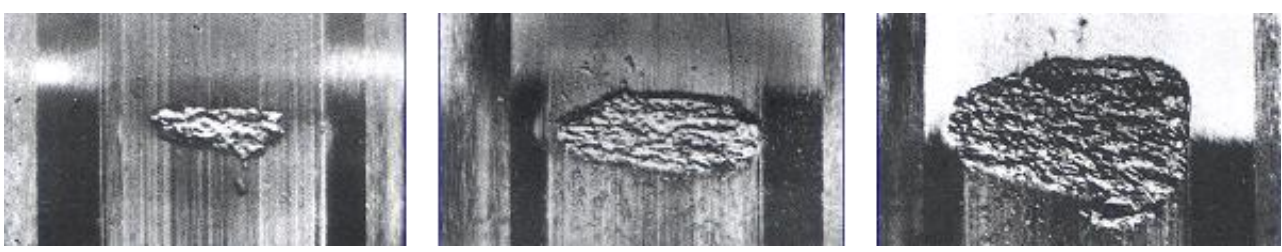

(d) Surface-initiated fatigue, Neale (1973).

Figure 2.18 Comparison of fatigue mechanisms. 


\subsubsection{Discussions}

The underlying mechanisms of structure fatigue, RCF of machine elements and of rails have a great deal in common. In many practically important aspects the rail RCF differs from the other types.

The occurrence of $\mathrm{HC}$ is determined by three factors: loads, contact geometry and material. The first two determine the stress, and the third determines the response to the stress. Any solutions for $\mathrm{HC}$ prevention, retardation and reduction have to be sought from these three aspects.

One direct solution might be increasing the material strength. This possibility will be discussed in Section 2.3. Loading conditions will also be further discussed there.

As $\mathrm{HC}$ is a low cycle fatigue due to ratcheting of high tangential stress, an effective solution would be lubrication of the $\mathrm{HC}$ vulnerable part of the wheelrail interface similar to what is applied to rolling bearings and gears. Without lubrication the coefficient of friction ranges between as low as 0.02 for severely contaminated rails to 0.6 for the dry and clean situation, AriasCuevas (2010), Eadie et al. (2008). The contaminants can be water, dusts, industrial precipitations, wear debris, fallen leaves etc. Since HC mainly occurs on the outer rail of curved tracks, lubrication of the gauge corner has been employed. This has, however, two negative consequences. One is the possible liquid entrapment and pressurization, discussed in Section 2.2.2. The other is that the lubricant may be brought to the top of the rail, where the COF has to be maintained at a certain level for traction and braking. Because the wheel-rail system is open and spreads over thousands of kilometers or more, it is virtually impossible to keep the negative effects always under control. One consequence is that trains may not be able to stop within the expected distance, and collision may occur, like what happened on $20^{\text {th }}$ of February, 2010 to the Amsterdam Metro [teletekst.nos.nl, of Monday, 22 February 2010].

Without lubrication, the rail profile, compared to that of the rolling bearings and gears, will be quickly modified by wear. The wear may bring the HCvulnerable part of the profile into contact so that $\mathrm{HC}$ takes place, like what happened in Figure 2.12. The wear may also suppress HC initiation and propagation, as is shown in Figure 2.16. Further, the rail profile may be 
altered and controlled by the artificial wear of grinding. These imply that by an appropriate design of rail profile, which may be brought about by grinding, $\mathrm{HC}$ may be prevented, retarded or reduced.

\subsection{Head Checks: State-of-the-art of understanding and solutions}

\subsubsection{Introduction}

Rolling Contact Fatigue (RCF) was, as pointed out in the 1980s, an increasing problem in high speed, mixed and heavy haul railways. A RCF research programme was therefore launched in 1987 by the European Rail Research Institute (ERRI), with the participation of 11 railway authorities, 7 rail makers and 5 universities Cannon et al. (1996). The programme lasted for more than 10 years. It was concluded that RCF associated with non-metallic oxide inclusions and hydrogen shatter cracking has substantially been reduced by the development of steel-making technology, Hodgson (1993), Cannon et al. (1996). However, RCF initiating on or very close to the rail's running surface, which are not associated with any specific material faults or imperfections, is increasing. Head Checking and Squats were among such defects. It was recognized that there is a lack of understanding of the mechanisms involved, and of solutions to the problem, Cannon, et al. (1996).

In the ERRI project the contact pressure distribution was calculated for a combination of new wheel-rail profiles, showing that Hertzian solution is not sufficient. The obtained non-Hertzian pressure distribution varies with the radii of the profiles, suggesting that the peak pressure may be reduced by profile design. Based on examination of contact pressure and conicity of the profile, some guidelines and tolerance for rail profile design were proposed (ERRI D173 RP9 (1990)). Further stress analysis was performed, but this was done for large cracks related to Squats, Bogdanski et al. (1996). It was also recognized that there was confusion in the terminology used to describe various forms of RCF. As a matter of fact RCF (including Head Checks ( $\mathrm{HC})$ and gauge-corner cracks) was all classified as Squats in the late 1990s in the UK, Cannon et al. (2003). This state of affairs seems to be related to the lack of understanding of the underlying mechanisms of RCF.

$\mathrm{HC}$ was in the early days considered to initiate in the rail crown, Cannon et al. (1996). This might be the reason why it was called Head Checking. Cracking 
at the gauge corner was separately named as gauge-corner cracking (GCC), Sawley et al. (2000), Cannon et al. (2003), see Figure 2.19. Both Head Checking and Head Checks were used by Cannon et al. (2003) for the same phenomenon, perhaps with some nuance in emphasizing the process and the results of the cracking respectively.

Although a distinction was made between HC and GCC (Figure 2.19), Cannon et al. (2003) used the name of Head Checks also for gauge corner cracks. Actually, the examples given in that paper all appear to be more GCC than $\mathrm{HC}$. As will become apparent in the subsequent development of this thesis, GCC and HC are both caused by the same fundamental mechanism ductility exhaustion of the material due to ratcheting by shear stress of (quasi) static rolling contact, GCC and HC will from now on be considered as the same phenomenon, and will be called $\mathrm{HC}$. This is in line with the current trend related to the study of HC by Eden (2005), Eadie et al. (2008).

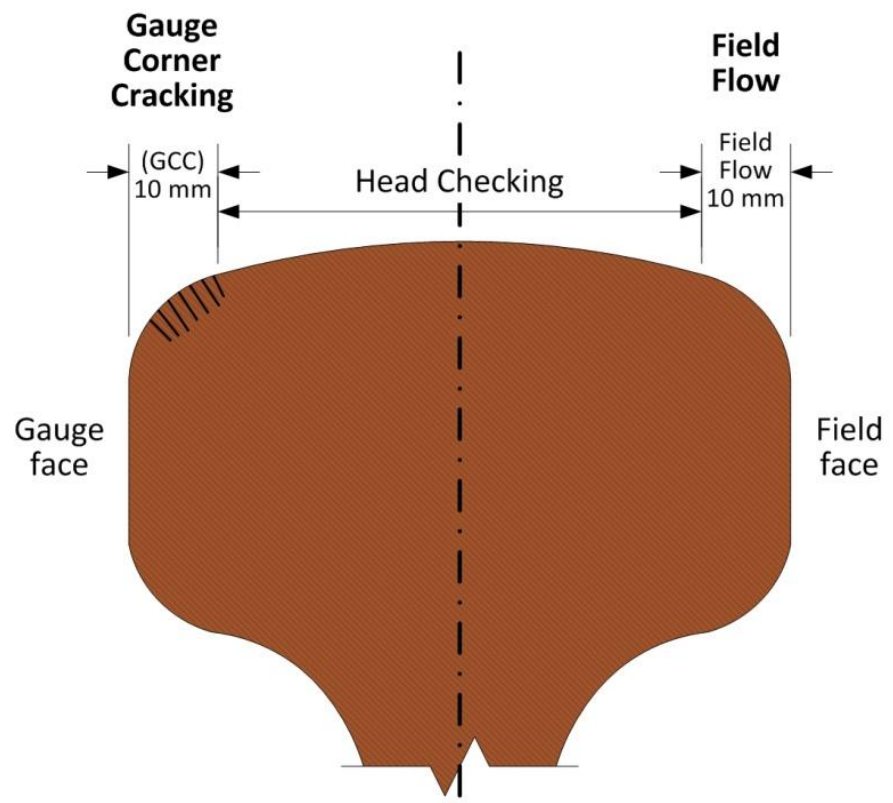

Figure 2.19 Head Checking and gauge corner cracking classified according to position on the railhead (see Sawley et al. (2000)).

The exclusion of tangential stress in the ERRI analysis and the consideration of the $\mathrm{HC}$ initiation as being on the crown suggest that the effect of the shear stress, especially that associated with the geometrical spin at the gauge shoulder and gauge corner, on $\mathrm{HC}$ initiation, and generally the effect of 
tangential stress on $\mathrm{HC}$, were not sufficiently recognized. It could also be due to the fact that the solution method for rolling contact at the gauge corner was inadequate. This seems still to be the case, as $\mathrm{HC}$ occurrences are frequently related to the tangential force, rather than to the shear stress, Grassie and Elkins (2005), Zacher (2009).

Despite recognition of the $\mathrm{HC}$ problem, no adequate attention was paid to it, until the catastrophic accident at Hatfield, Grassie (2005).

\subsubsection{An overview of possible general causes of HC}

Figure 2.20 gives an overview of some possible general causes of the increasing occurrence of $\mathrm{HC}$, in comparison to three decades ago when $\mathrm{HC}$ was relatively unknown. They fall under one or more of the three factors mentioned in section 2.2.4, which determine the occurrence of $\mathrm{HC}$ in one way or another.

Factors that influence the contact loads and consequently the contact stresses are:

- Stiffer primary suspension of the rolling stock. Results in an increase in contact forces, leading to an increase in wear and $\mathrm{HC}$ occurrence.

- Increase in axle load. This causes higher contact pressures and consequently higher shear stresses.

- Increased traffic; which means shorter time to fatigue.

- Track geometry; which affects the contact force.

Factors that influence the contact geometry include:

- Track geometry; which may change the effective rail inclination.

- Harder and more wear-resistant materials; which may cause a certain $\mathrm{HC}$-liable part of the railhead to be subject for longer time to $\mathrm{HC}$ initiating loading conditions

- Wheel maintenance, which affects the wheel profile.

- Increased traffic; which means that the rail profile may be worn in a shorter time. 


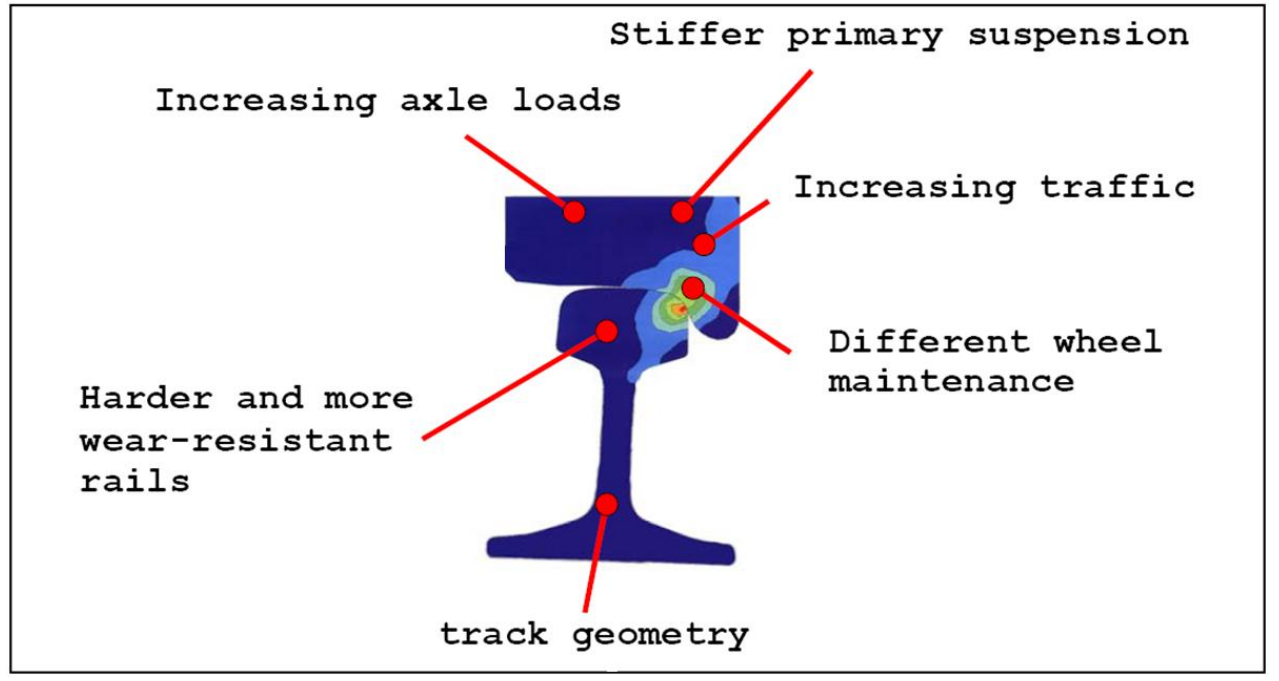

Figure 2.20 An overview of some possible causes of HC.

Among the factors listed above, the trend of increasing axle load and increased traffic cannot be avoided. Detailed discussion is presented in the next sections concerning the other aspects.

\subsubsection{Loading conditions and HC}

Wheel-rail contact forces are determined by the dynamic vehicle-track interaction system. There are a number of parameters in the system, which can affect the contact force.

One of the most influential parameters is the primary yaw stiffness (PYS) of the vehicles. Because the wheel profile is always coned to align the wheelset along the track centre and to facilitate curve negotiation, a wheelset is intrinsically instable and tends to hunt, a zig-zag motion in the rolling direction. Maintaining running stability is important, especially when the vehicle speed is high. This is usually achieved by constraining the wheelset with a high PYS, and by maintaining the conicity of the wheel profile within a certain range. In the past decades the PYS of the passenger vehicles has significantly been raised worldwide. Figure 2.21 shows the average increase of PYS over time in the UK. The consequence of this is that the ability of the wheelset to align itself radially in curves is reduced, resulting in a larger angle of attack, large 
lateral contact stresses and flange contact, leading to increased occurrence of $\mathrm{HC}$.

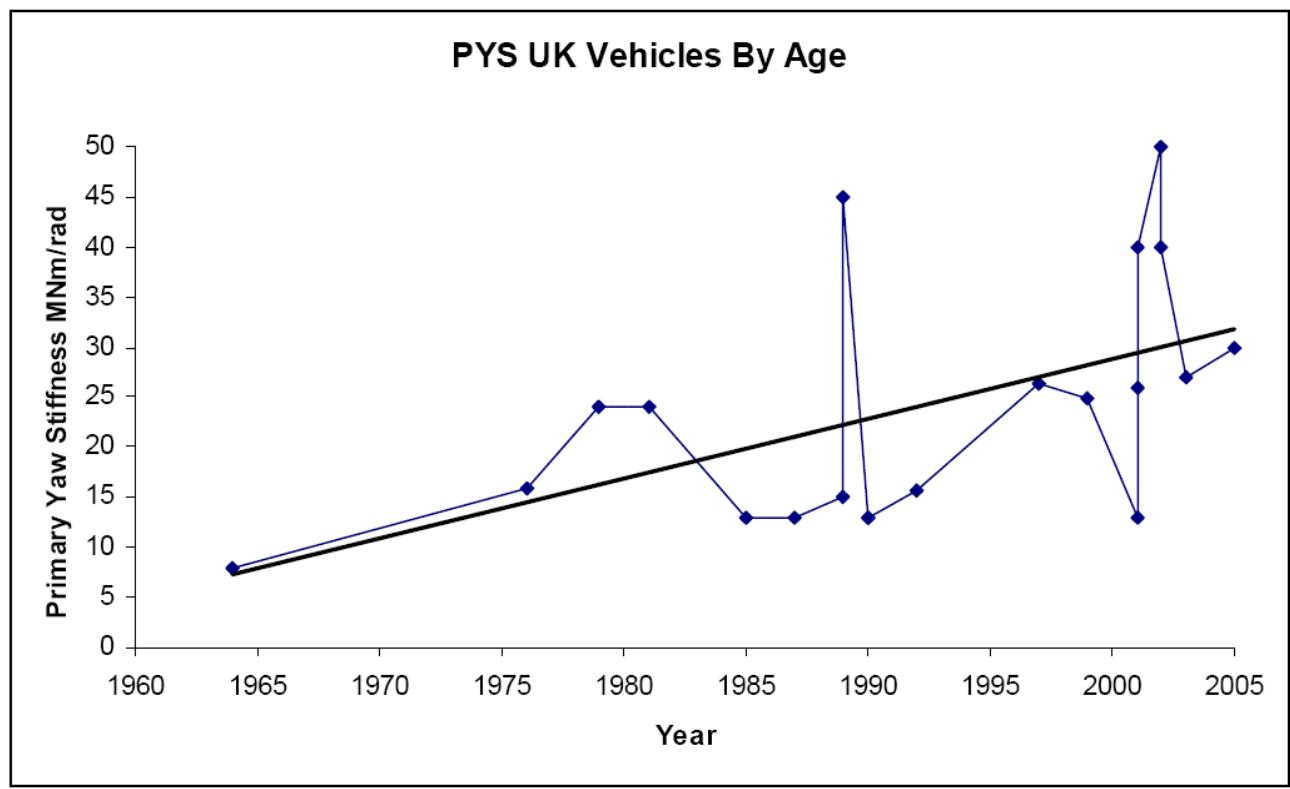

Figure 2.21 Increase of primary yaw stiffness over time (Amoore (2007)).

The relation between PYS and HC has been discussed by, e.g. Evans et al. (2002), and Kalousek (2005). Reducing the PYS has, however, proven to be difficult because safety and a comfortable journey have to be taken into consideration.

Another important parameter is the cant deficiency of the track in curves, as introduced in Section 2.1. For a curve of a certain radius the superelevation and the corresponding maximum cant deficiency is fixed. When modern rolling stock with increased maximal speed travels on a curve of a conventional track, the cant deficiency is often utilized to its maximum. Discussion on the influence of cant deficiency on $\mathrm{HC}$ can be found in Evans et al. (2002), and Kalousek (2005). It is impractical to reduce the speed, or to change the superelevation.

Care et al. (2006) explained how HC can occur at locations where the track's lateral alignment is disturbed in straight tracks or curved tracks with a very large radius. The misaligned track requires the wheelsets to shift laterally to 
follow it. If the misalignment develops itself gradually over a long section of track, a wheelset can follow the misalignment by the difference in the rolling radii of the two conical wheels, as is one of the major purposes of conical wheels, so that the shift is completely accommodated by the kinematic motion of the wheelset. The lateral contact force will then not be very large. If misalignment is, however, shorter than the kinematic wavelength of the wheelset, rolling radii difference will not have enough distance to achieve the required shift. This means that a lateral contact force is needed to push the wheelset sideways. This lateral force may generate excessive shear stress, causing $\mathrm{HC}$. The track alignment may be detected by measuring trains and subsequently corrected by maintenance. Notice that $\mathrm{HC}$ occurs predominantly in curves and at switches and crossings.

To facilitate maintenance planning to prevent $\mathrm{HC}$ or remove early $\mathrm{HC}$, the Rail Safety and Standards Board (RSSB) of the UK developed a HC damage model to predict the rail damage, Zacher (2009). It is called the Whole Life Rail Model, or the $T \cdot \gamma$ Model, where $T$ signifies the tangential contact force, and $\gamma$ is the creepage. $T \cdot \gamma$ is also called the wear number. It has the meaning of frictional work $W$ with the unit of force $(N)$ because creepage is dimensionless:

$$
W=\text { Frictional } \text { work }=\text { tangential contact force } \cdot \text { creepage }=T \cdot \gamma
$$

In a complete form

$$
W=T_{x} \cdot \gamma_{x}+T_{y} \cdot \gamma_{y}+M_{z} \phi
$$

where $\left(T_{x}, T_{y}\right)$ and $\left(\gamma_{x}, \gamma_{y}\right)$ are the tangential contact forces and the corresponding creepages in the longitudinal and lateral directions respectively, and $M_{z}$ and $\phi$ are the spin moment and the corresponding spin respectively.

The model was initially intended for wear prediction, in combination with a wear model like Archard (1980). Realizing the importance of the tangential force in (2.5) and (2.6) and that the occurrence of $\mathrm{HC}$ is the consequence of the rate of crack imitation and crack growth in competition with that of wear, the formula is extended to evaluate the $\mathrm{HC}$ damage in terms of imbalance between $\mathrm{HC}$ and wear, Zacher (2009). 
Figure 2.22 presents the $\mathrm{HC}$ damage index as a function of the wear number $T \cdot \gamma$. The reciprocal of the damage index defines the number of load cycles necessary to initiate cracks. As there is still no established numerical or laboratory test which can determine the damage index, the damage function has to be determined based on field observations.

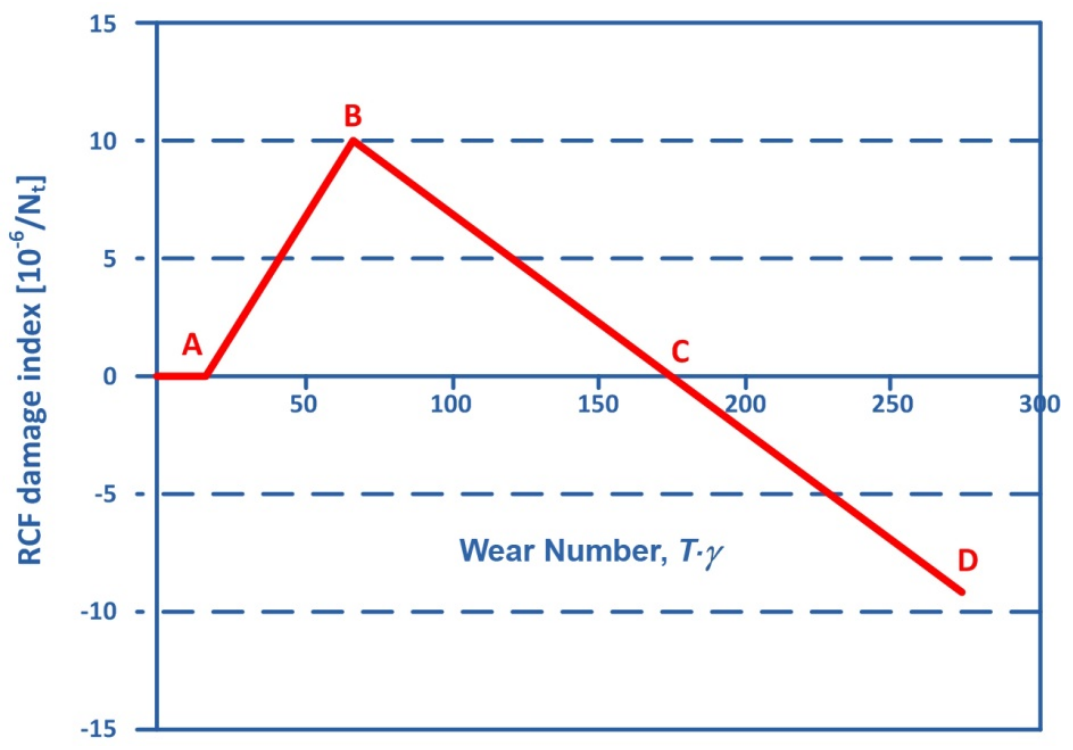

Figure 2.22 The Whole Life Rail Damage (WLRM) according to Zacher (2009), i.e. RCF damage index as a function of the wear number $T \cdot \gamma$.

Figure 2.22 shows, with a specific set of loading conditions, under what circumstances $\mathrm{HC}$ or wear will dominate. When the wear number is about 20 in this case, $\mathrm{HC}$ cracks initiate. The damage fatigue index increases until a wear number of about 65 is reached, that matches with 100.000 load cycles. After this peak $\mathrm{HC}$ in combination with wear will occur until the line crosses the $x$-axis. When the function crosses the $x$-axis at a wear number of 175 , no cracks will initiate because the wear is higher than the RCF development. This means that if the natural wear number is not high enough relative to the $\mathrm{HC}$ damage index, some artificial wear should be applied to suppress $\mathrm{HC}$ by, for example, grinding.

This approach therefore depends strongly on calibration, and a calibrated situation may only be applied to similar cases. 
While on a straight track all the variables in (2.6) can be calculated with sufficient accuracy by vehicle dynamics simulation, the flange-gauge corner contact on curved tracks, where the geometrical spin $\phi$ in the rolling contact varies, cannot be taken into account properly by the solution methods available in the existing vehicle dynamics software packages. Wear is dependent on the micro-slip, Li (2002), which is determined by $\phi$. The consequences are that both the spin and the wear cannot be properly determined. This problem can be overcome by considering the total frictional work $W$ as an integration of local frictional work over the contact area

$$
W=\int_{A}\left(\tau_{x} v_{x}+\tau_{y} v_{y}\right) d A
$$

in which $\tau_{x}$ and $\tau_{y}$ are the surface shear stress, $v_{x}$ and $v_{y}$ are the local microslips in the $x$ and $y$ directions, $A$ is the contact area, $\mathrm{Li}$ (2002). Note that the effect of spin $\phi$ is included in the local micro-slips, so that $\phi$ has disappeared in (2.7), and $\left(v_{x}, v_{y}\right)$ is different from $\left(\gamma_{x}, \gamma_{y}\right)$. Numerically $(2.7)$ is discretized and the integration becomes the sum of the frictional work in all the surface elements in the contact area, e.g. Li (2002):

$$
W=\sum_{i=1}^{N}\left(\tau_{x i} \nu_{x i}+\tau_{y i} \nu_{y i}\right) \Delta A
$$

where the summation is over $i=1, \ldots, N, N=$ the total number of elements in the contact area, and $\Delta A$ is the area of a surface element.

Another change applied in the past decades by the railways is that the rail inclination was changed from $1 / 20$ to $1 / 40$. This shifted the contact location from the rail crown towards the gauge corner, increasing the contact angle, and therefore the geometrical spin.

Tangential stresses can be reduced by reducing the coefficient of friction. The disadvantages of reducing COF by lubrication are discussed in Section 2.2. Another possibility is to maintain the COF in a certain range which is high enough for traction and braking, while significantly reducing the maximum COF. This COF range could, for instance, be between $0.2-0.3$. Such objective may be achieved by the application of a certain friction modifier, Eadie et al. (2008). 


\subsubsection{Rail grades and HC}

A simple solution to reduce $\mathrm{HC}$ might be by using rail material of sufficiently high fatigue strength. Currently pearlitic steel rail materials are predominantly used.

Muster et al. (1996) tested naturally hardened grades R260 (260 HB hardness) with head hardened $340 \mathrm{HB}$ and $370 \mathrm{HB}$ rails. The conclusion was that increasing rail hardness improved performance in wear and $\mathrm{HC}$ resistance was obtained. This is in agreement with field test results in the Netherlands, see Figure 2.23. But it is also observed that although initially the $\mathrm{HC}$ growth rate of the harder rails was low, it is much faster at a later stage. This means that with harder rails care has to be taken to remove early $\mathrm{HC}$, otherwise the residual life may be short and more difficult to predict, due to the more brittle behaviour related to the higher hardness. This may explain why in Figure 2.16 the harder rail had a shorter service life. The $\mathrm{HC}$ of the $\mathrm{R} 350 \mathrm{HT}$ (see Appendix C) could not be suppressed by the natural wear, while any initiating cracks could have been removed by the higher wear rate of the softer R260.

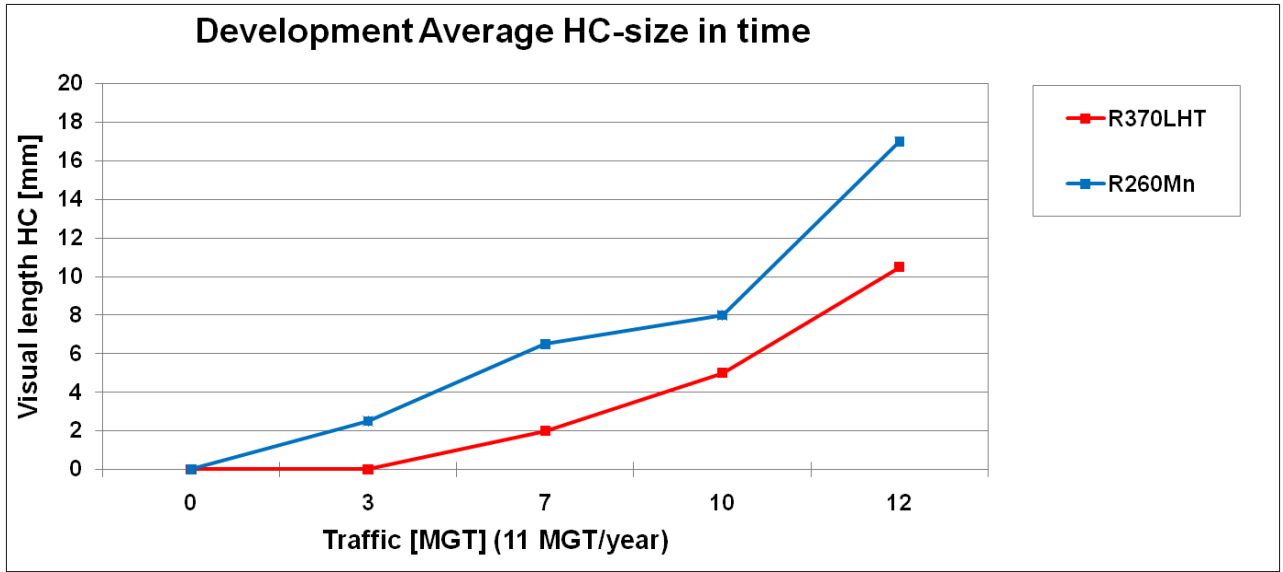

Figure 2.23 HC development in grades R260Mn and R370LHT rails.

It seems that with the never-ending ambition of railways to run fast and carry more, the potential of pearlitic rail to sustain higher load is exhausted. Now some efforts have been made to make bainitic or even martensitic steel, Shur et al. (2005). 
An attempt was also reported in developing and testing a two-material rail, Hiensch et al. (2003), by applying a layer of material on the top of the railhead. Small scale twin-disc lab tests and fatigue life evaluation by means of shakedown map were conducted. The predicted performance was promising, in agreement with the behaviour of the rail in the first two years of the field test. But later severe spalling occurred at the interface of the two materials. Grinding was impossible because of the additional layer of 0.6 $0.7 \mathrm{~mm}$.

Even if a fully anti-HC rail material can be developed, it will take many years and will require huge investment before the entire existing rail on the network can be replaced. A better and cheaper solution is needed.

\subsubsection{HC and contact geometry, stress and strain}

The discussion so far shows that combating $\mathrm{HC}$ by controlling the loads or by improving rail material is constrained by implementability, costs, long time etc.

On the other hand it is the maximal surface shear stress that is directly responsible for $\mathrm{HC}$, and this stress can directly be influenced by the contact geometry. It is shown that $\mathrm{HC}$ occurrence is also related to the local wear, which is proportional to the frictional work $\mathrm{Li},(2002)$. Since frictional work is the product of the surface shear stress and the corresponding micro-slip, HC occurrence is related to micro-slip as well. This means that by proper design of rail and wheel profiles, the shear stress and micro-slip may be kept at a certain level so that the initiation and growth rate of the fatigue cracks can be under a certain level and their growth can be cancelled by wear. The profile can readily be brought to the rail and wheel and kept in the desired condition at low costs by grinding and re-profiling.

Various profile optimization procedures have been developed for rail and wheel profile design, for instance by Smallwood et al. (1990) for minimizing contact pressure, by Magel et al. (2004) for an optimal wheel profile to reduce rail RCF. In ERRI D173 Report 9 guidelines for rail profile design are proposed to reduce HC. Grassie (2002) used an empirical principle for rail profile grinding to alleviate $\mathrm{HC}$ : the high rail should be ground to a profile which is similar to the one whereby wheels wear the rail, and that this should be ground to a tolerance which ensures that there is relatively little wheel/rail 
contact in the area where RCF defects initiate, i.e. around the gauge corner and shoulder of the rail.

\subsection{Outline of the work of this thesis}

This thesis aims at the design of an anti-HC profile, based on a fundamental understanding of the mechanical mechanism of $\mathrm{HC}$ initiation. To such end a quantitative relation is needed between $\mathrm{HC}$ occurrence and contact stress and micro-slip, particularly at the gauge corner. Such a relationship is still lacking in the literature.

In the subsequent chapters such a relationship will be investigated by way of lab tests, field observations and numerical analysis of the tests and observations. Subsequently the relationship is employed to derive a design principle for an anti-HC profile. Finally the deigned profile will be implemented and its effectiveness in preventing or reducing $\mathrm{HC}$ will be demonstrated by theoretical analysis, field monitoring and large-scale application.

\section{References:}

[1] Amoore, J., 2007, Presentation at the General Assembly of the EC FP6 project Innotrack, UIC - Paris, int-ga-01-071128-f06_Amoore_sp1_v3.pdf downloaded from http://extranet.uic.asso.fr.

[2] Archard, J.F., 1980, Wear theory and mechanism, in ASME Wear control handbook, ed. By M.B. Peterson and W.O. Winer, American Society of Mechanical Engineering, New York, pp. 35-80.

[3] Arias-Cuevas, O., Li, Z., Lewis, R. and Gallardo-Hernández, E.A., 2010 Rolling-sliding laboratory tests of friction modifiers in dry and wet wheel-rail contacts, Wear 268, pp. 543-51, doi:10.1016/j.wear. 2009.09.015.

[4] Arias-Cuevas O. and Li Z., 2010, Field Investigations on Rolling Stock Components Designed to Overcome Low Adhesion Related Problems, Proceedings of the 2010 Joint Rail Conference, UrbanaChampaign, Illinois USA.

[5] Beek, A. van, 2009, Advanced engineering design, lifetime performance and reliability, ISBN-10: 90-810406-1-8, Delft University of Technology, The Netherlands.

[6] Berthe, D., Flamand, L., Foucher, D. and Godet, M., 1980, Micropitting in Herzian contacts, Trans Am. Soc. Mech. Engrs, J. Lubrication Tech., 102, 478. 
[7] Bhushan, B., 2001, Modern tribology handbook, volume two, Material, Coatings, and industrial applications, CRC Press.

[8] Bogdanski, B., Olzak, M. and Stupnicki, J., 1996, Numerical stress analysis of rail rolling contact fatigue cracks, Wear 191, pp. 14-24.

[9] Bower, A.F. and Johnson, K.L., 1989, The influence of strain hardening on cumulative plastic deformation in rolling and sliding line contact, J. Mech. Phys. Solids 37, No.4, pp. 471-493.

[10] Cannon, D.F. and Pradier, H., 1996, Rail rolling contact fatigue Research by the European Rail Research Institute, Wear 191, pp. 113.

[11] Cannon, D.F., Edel K.O., Grassie, S.L. and Sawley, K., 2003, Rail defects: an overview, Fatigue Fract Engng Mater Struct 26, pp. 865887.

[12] Care, R., Clark, S., Dembosky, M. and Doherty, A., 2006, Why rails crack - Gauge corner cracking on the British network: Analysis, The Arup Journal 1, pp.16-19.

[13] Carter F.W., 1926, On the Action of a Locomotive Driving Wheel, Proceedings of the Royal Society of London, A112, pp. 151-157.

[14] Clayton, P., 1996, Tribological aspects of wheel-rail contact: a review of recent experimental research, Wear 191, pp. 170-183

[15] Clayton, P. and Hill, D.N., 1986, Rolling contact fatigue of a rail steel, Gladwell, G.M.L., Ghonem, H. and Kalousek, J., (Ed). Proceedings of the conference on Contact Mechanics and Wear of Rail/wheel Systems II, University of Rhode Island, Kingston, R.I., pp. 361-378, University of Waterloo Press.

[16] Clayton, P., Allery, M.B.P. and Bolton, P.J., 1982, Surface damage phenomena in rails, Kalousek, J., Dukkipati, R.V., and Gladwell, G.M.L., (Ed). Proceedings of the conference on Contact Mechanics and Wear of Rail/wheel Systems, Vancouver, British Columbia, pp. 419-443, University of Waterloo Press.

[17] Eadie, D.T., Elvidge, D., Oldknow, K., Stock, R., Pointner, P., Kalousekc, J. and Klauser, P, 2008, The effects of top of rail friction modifier on wear and rolling contact fatigue: Full-scale rail-wheel test rig evaluation, analysis and modeling, Wear 265, pp. 1222-1230, doi:10.1016/j.wear.2008.02.029.

[18] Eden, H.C., Garnham, J.E. and Davis, C.L., 2005, Influential microstructural changes on rolling contact fatigue crack initiation in pearlitic rail steels, Materials Science and Technology, 21, NO 6, pp. 623-629, DOI 10.1179/174328405X43207. 
[19] Ellyin, F., 1997, Fatigue damage, crack growth and life prediction, Chapman and Hall, London.

[20] ERRI D173 RP9, 1990, Definition of Rail Head Profiles and Tolerances , ERR1 Committee D173 Rep.9, Utrecht.

[21] Evans, J. and Iwnicki, S., 2002, Vehicle Dynamics and the Wheel/Rail Interface, Wheels on Rails - An update, Understanding and managing the Wheel/Rail Interface, IMechE Seminar, London, (๑ 2002 The Institution of Mechanical Engineers).

[22] Franklin, F.J. and Kapoor, A., 2007, Modelling wear and crack initiation in rails, Proc. IMechE Part F: J. Rail and Rapid Transit 221, pp. 23-33.

[23] Franklin, F.J., Weeda G.J., Kapoor, A. and Hiensch, E.J.M., 2005, Rolling contact fatigue and wear behaviour of the infrastar twomaterial rail, Wear 258, pp. 1048-1054.

[24] Grassie, S., 2005, Rolling contact fatigue on the British railway system: treatment, Wear 258, pp. 1310-1318, doi:10.1016/j.wear.2004.03.065.

[25] Grassie, S.L. and Elkins, J.A., 2005, Tractive effort, curving and surface damage of rails Part 1. Forces exerted on the rails, Wear 258, pp. 1235-1244, doi:10.1016/j.wear.2004.03.064.

[26] Grassie, S., Nilsson, P., Bjurstrom, K., Frick, A. and Hansson, G., 2002, Alleviation of rolling contact fatigue on Sweden's heavy haul railway, Wear 253, pp. 42-53.

[27] Hiensch, E.J.M., Franklin, F.J., Nielsen, J.C.O., Ringsberg, J.W., Weeda, G.J., Kapoor, A. and Jossefson, B.L., 2003, Prevention of RCF damage in curved track through development of the INFRASTAR two-material rail, Fatigue FEMS 26, pp. 1007-1017.

[28] Hodgson, W.H., 1993, Rail metallurgy and processing, in Kalker, Cannon and Orringer (eds.), Rail Quality and Maintenance for Modern Railway Operation, Kluwer, Dordrecht.

[29] Illston, J.M., Dinwoodie, J.M. and Smith, A.A., 1979, Concrete, Timber and Metals, Van Nostrand Reinhold, Crystal City, VA.

[30] Johnson, K.L., 1995, Contact mechanics and wear of metals, Wear 190, pp. 162-170.

[31] Johnson K.L., 1958, The effect of Spin upon the Rolling Motion of an Elastic Sphere upon a Plane, Journal of Applied Mechanics 25, pp. 332-338.

[32] Kalker J.J., 1990, Three Dimensional Elastic Bodies in Rolling Contact, Kluwer Academic Publishers, Dordrecht/Boston/London. 
[33] Kalousek, J., 2005, Wheel/rail damage and its relationship to track curvature, Wear 258, pp. 1330-1335, doi:10.1016/j.wear.2004.03.042

[34] Li, Z., Arias-Cuevas, O., Lewis, R. and Gallardo-Hernandez, E.A., 2009a, Rolling-Sliding Laboratory Tests of Friction Modifiers in Leaf Contaminated Wheel-Rail Contacts, Tribology Letters: Vol. 33, Issue2, pp. 97, doi 10.1007/s11249-008-9393-3.

[35] Li, Z., Zhao, X. and Dollevoet, R.P.B.J., 2009b, The Determination of a Critical Size for Rail Top Surface Defects to Grow into Squats, Proceedings of the 8th International Conference on Contact Mechanics and Wear of Rail/Wheel Systems, ISBN: 978-88-904370-07, Florence, Italy, 15 - 18 September, pp. 379-388.

[36] Li, Z., Zhao, X., Esveld, C., Dollevoet, R.P.B.J. and Molodova, M., 2008, An Investigation into the Causes of Squats - Correlation Analysis and Numerical Modeling, Wear 265, pp. 1349-1355, doi:10.1016/j.wear.2008.02.037.

[37] Li, Z., 2002, Wheel-Rail rolling contact and its application to wear simulations, PhD thesis, ISBN 90-407-2281-1, Delft University of Technology, The Netherlands.

[38] Loannides, E. and Harris, T.A., 1985, A new fatigue life model for rolling bearing, Journal of Tribology, 107, pp. 367-378.

[39] Loy, B. and McCallum, R., 1973, Mode of Formation of Spherical Particles in Rolling Contact Fatigue, Wt'ar, Vol. 24, pp. 219-228.

[40] Magel, E.E. and Kalousek, J., 2004, The Influence of Creep Forces on Rolling Contact Fatigue of Wheels, 14th International Wheelset Congress, pp. 17-21, Orlando, USA.

[41] Meyers, M.A. and Chawla, K.K., 1999, Mechanical behavior of materials, Prentice Hall, Upper Saddle River, New Jersey.

[42] Muster, H., Schmedders, H., Wick, K. and Pradier, H., 1996, Rail rolling contact fatigue - The performance of naturally hard and headhardened rails in track, Wear 191, pp. 54-64.

[43] Nakajima, A., 1981, Effect of asperity interacting frequency on surface durability, International Symposium on Gearing and Power Transmissions, Tokyo, paper b26.

[44] Neale, M.J., 1973, Tribology handbook, Butterworths, ISBN 0-40800082-1.

[45] Nélias, D. and Ville, F., 2000, Detrimental effects of debris dents on rolling contact fatigue, Trans Am. Soc. Mech. Engrs, J. Tribol., 122, pp. 55-64. 
[46] Olver, A.V., 2005, The mechanism of rolling contact fatigue: an update, Proc. IMechE Part J: J. Engineering Tribology, 219, pp. 313330, doi: $10.1243 / 135065005 \times 9808$.

[47] Sawley, K.J. and Reiff, R., 2000, Rail failure assessment for the Office of the Rail Regulator, ref. P-00-070, United Kingdom. Available from http://www.rail-reg.gov.uk.

[48] Olver, A.V., Tiew, L.K., Medina, S. and Choo, J.W., 2004, Direct observations of a micropit in an elastohydrodynamic contact, Wear, 256, pp. 168-175.

[49] Scott, U. and Mills, C.H., 1973a, Spherical Particles in Rolling Contact Fatigue, Nature, Vol. 241, pp. 115-116.

[50] Scott, D. and Mills, C.H., 1973b, Spherical Debris - Its Occurrence, Formation and Significance in Rolling Contact Fatigue, Wear, Vol. 24, pp. 235-242.

[51] Shur, E.A., Bychkova, N.Y. and Trushevsky, S.M., 2005, Physical metallurgy aspects of rolling contact fatigue of rail steels, Wear 258, pp. 1165-1172.

[52] Smallwood, R., Sinclair, J.C. and Sawley, K.J., 1991, An optimization technique to minimize rail contact stresses, Wear 144, pp. 373-384.

[53] Smulders, J. and Hiensch, M., 2003, RCF management and research program in the Netherlands: approach and solutions to control the wheel-rail interface to reduce RCF damage, Proceedings of World Congress on Railway Research, Edinburgh, Scotland.

[54] Soboyejo, W., 2003, Mechanical properties of engineered materials, Marcel Dekker, Inc, New York - Basel.

[55] Suresh, S., 1998, Fatigue of materials, Cambridge University Press, Cambridge, UK.

[56] Voskamp, A., 1985, Material response to rolling contact loading, Trans Am. Soc. Mech. Engrs, J. Tribology, 107, pp. 356-366.

[57] Williams, J., 2005, Engineering Tribology, Cambridge University Press.

[58] Zacher, M., 2009, Prediction of gauge corner cracking in rails for rail maintenance, Proceedings of the 8th International Conference on Contact Mechanics and Wear of Rail/Wheel Systems, Florence, Italy, pp. 689-697, ISBN: 978-88-904370-0-7. 


\section{Chapter 3 Loading conditions of Head Checking initiation}

\subsection{Introduction}

To evaluate the response of elastic-plastic rolling contact to cyclic loading, Bower et al. (1989) introduced the shakedown map. Three forms of fatigue are distinguished by Johnson (1995).

- If the load is below the elastic shakedown limit, the probable failure mechanism is high cycle fatigue.

- In case the load is above the elastic shakedown limit but is lower than the plastic shakedown limit, the cycle of plasticity is closed with no accumulation of plastic strain, low cycle fatigue (LCF) would be expected.

- When the load is higher than the plastic shakedown limit, ratcheting will occur, causing LCF. Franklin et al. (2007) suggested that in the case of ratcheting, the failure could be due to exhaustion of ductility of the material, or by closed cyclic plasticity, depending on whichever mechanism results in a shorter life. It is also possible that the two mechanisms are additive.

Eadie et al. (2008) showed that HC takes place due to ratcheting. The accumulated shear strain is a result of the superposition of the strain caused by surface shear stress as well as by the non-proportional cyclic tension and compression, Bower and Johnson (1989). If the rate of ratcheting is to be determined, both strains should be taken into account. Such attempts have been made in theoretical studies for the Hertzian contact in the case of a twodimensional contact with full slip, see, e.g. Bower and Johnson (1989) and Franklin et al. (2007). Ratcheting rate can be calculated to predict cycles to 
crack initiation. Such method is, however, not yet readily available for a threedimensional rolling contact with partial slip. In the present work, instead, an effective solution is sought for a practical problem of non-Hertzian rolling in three dimensions with dominant geometrical spin caused by conformal contact. Accurate calculation of ratcheting rate will demand great effort. Further accurate calculation of ratcheting rate is also not necessary for an approach followed in this thesis as pointed out in section 2.3.5. For an effective anti-HC measure, ratcheting should be avoided completely. Calculation of ratcheting rate is therefore excluded.

This is why this thesis focuses on the relation between $\mathrm{HC}$ initiation and stresses. Because $\mathrm{HC}$ arises due to the increase in surface shear stress, bringing the maximal shear stress from the subsurface to the surface, it is this surface shear stress that is decisive for the ratcheting and not the cyclic tension and compression. The higher the surface shear stress is, the more likely it is that HC will occur. Bower et al. (1989) and Johnson (1995) proposed evaluating the possibility of ratcheting by comparing the maximal surface shear stress with the yield stress in shear, taking different hardening laws into account.

However, it should hold that wherever the surface shear stress is the highest, the more likely it is that $\mathrm{HC}$ will occur, irrespective of what hardening law may apply and no matter whether failure might be caused by exhaustion of ductility of the material, or by closed cyclic plasticity or by a combination of the two mechanisms. This work will therefore not take a specific hardening law and failure mechanism into consideration, but will put forward a hypothesis that where the surface shear stress is the highest, $\mathrm{HC}$ occurs sooner under cyclic loading, irrespective of the cyclic tension and compression involved. Please take note that the gauge face is excluded, where the spin is so high that $\mathrm{HC}$ is suppressed by the high rate of wear and tear, as has been shown in field observations.

The hypothesis implies that there is at least one point on the rail profile where the surface shear stress exceeds the ratcheting limit. The limit depends on the material properties. It may be determined by comparing the surface shear stress with certain measures of the shear strength of the material, as proposed by Bower et al. (1989), based on lab tests and field observations. 
$\mathrm{HC}$ initiation in full-scale laboratory tests was first realized by Eadie et al. (2008). The stress analysis was performed with an approximate Hertzian method. Analyses of the relation of $\mathrm{HC}$ to operational conditions were attempted by, e.g. Grassie and Elkins (2005) and Zacher (2009), not in terms of initiation and contact stresses, but in terms of contact forces and the orientation of severe cracking.

This chapter examines the $\mathrm{HC}$ initiation location and its relation with the surface shear stress by analyzing the $\mathrm{HC}$ initiation conditions of a full-scale lab test and of a monitored track site.

\subsection{HC initiation under controlled laboratory conditions and stress analysis}

\subsubsection{Description of the test}

$\mathrm{HC}$ initiation tests were conducted on the Voestalpine (VAS) full-scale test rig. The rig has a real wheel rolling on a real rail. A vertical load $N$ is applied on the wheel through a hydraulic system. A lateral load $Q$ is applied on the rail. The rail inclination and angle of attack can be adjusted. The wheel has only one degree of freedom about its axis; all the other degrees of freedom are constrained. During the test the rail moves to and fro along the $T$ direction. During the to-movement, the wheel is in contact with, and rolls over the rail; the $N$ and $Q$ forces are applied. This part of the test is called "rolling". When the rail moves in the opposite direction, the wheel is lifted, without contact with the rail. The test "rolling" simulates the $\mathrm{HC}$ initiation condition by applying the lateral force $Q$, pushing the rail gauge corner against the wheel flange. The longitudinal force $T$ needed to overcome the frictional resistance due to the geometrical spin at the flange-gauge corner contact is less than $5 \%$ of the vertical force $N$ multiplied by the coefficient of friction $f$. $T$ is therefore negligible compared to the vertical and lateral force, and the test is approximately considered as free rolling in the sense of the small $T$. The angle of attack used in the test is zero. Water spray was applied at every 10 wheel passes to reduce the coefficient of friction. 


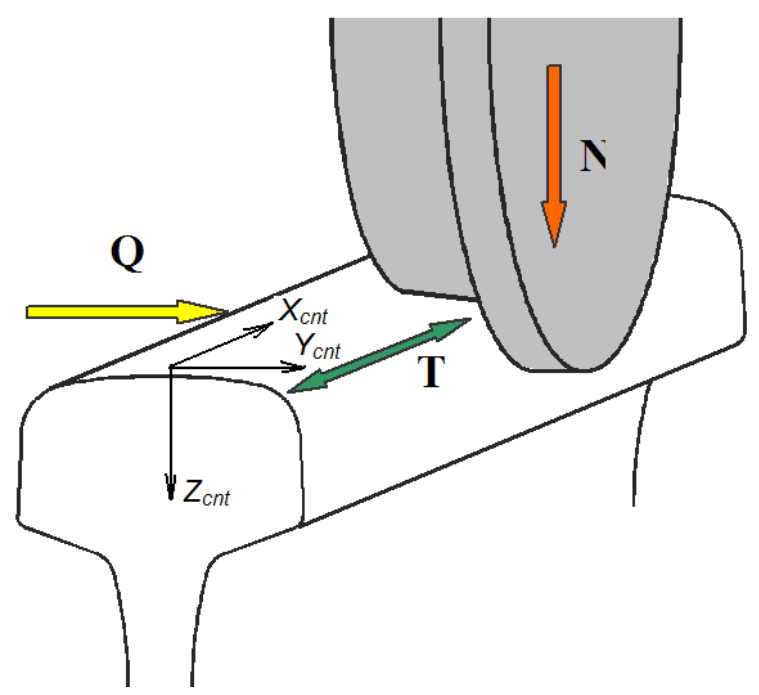

(a) Wheel-rail contact on the Voestalpine Schienen GmbH (VAS) rig. Courtesy of Richard Stock, VAS. A contact coordinate system $X_{c n t} Y_{c n t} Z_{c n t}$ is defined with its origin at the centre of the rail profile. $Z_{\text {cnt }}$ point into the rail so that contact pressure is positive.

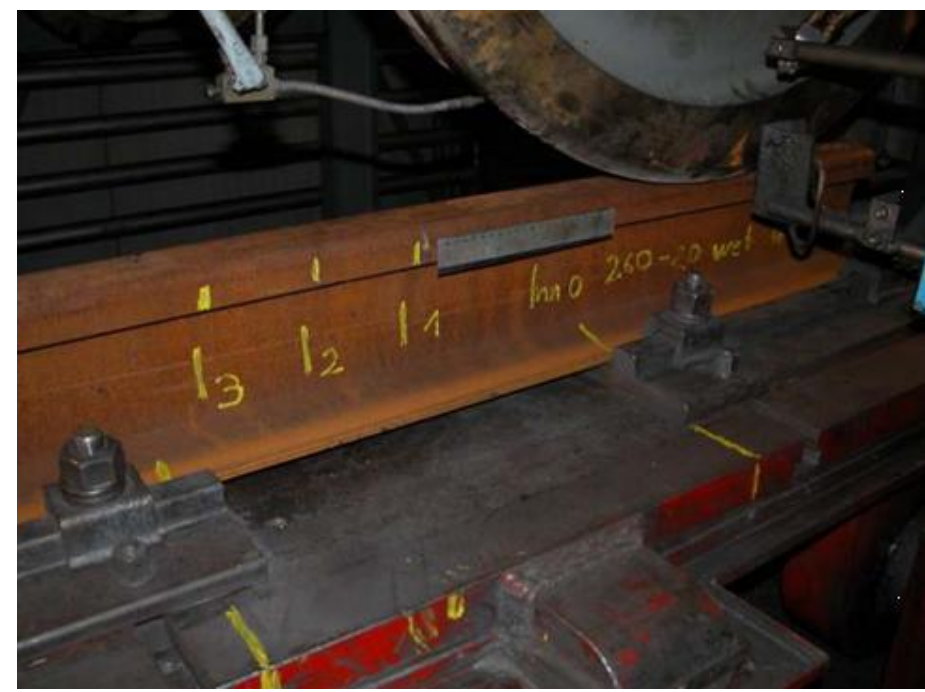

(b) The rail and wheel test rig.

Figure 3.1 The VAS test rig. (a) Schematic representation and (b) photograph of the test rig. 
Table 3.1 gives an overview of the VAS test.

Table 3.1 overview of the VAS test.

\begin{tabular}{|l|l|}
\hline Parameters \\
\hline Rail profile & Measured 60E2 \\
\hline Rail inclination & $1: 40$ nominal \\
\hline Wheel profile & Measured S1002 \\
\hline Wheel diameter & $920 \mathrm{~mm}$ \\
\hline Rail steel & R260 \\
\hline Wheel steel & R7 \\
\hline Angle of attack & 0 \\
\hline Vertical load & $20 \mathrm{t}$ \\
\hline Lateral load & $4 \mathrm{t}$ \\
\hline Longitudinal force & Negligible \\
\hline Lubrication & Water spray \\
\hline Water interval & Every 10 passes \\
\hline HC initiation & HC initiation between $20,000 \& 50,000$ passes \\
\hline Young's modulus E & $210 \mathrm{GPa}$ \\
\hline Poisson's ratio & 0.28 \\
\hline (Shear modulus G) & $82 \mathrm{GPa}$ \\
\hline
\end{tabular}

\subsubsection{Observations of the test}

Visual observation showed that $\mathrm{HC}$ initiated on the rail between the $20,000^{\text {th }}$ and the $50,000^{\text {th }}$ wheel passes. Figure 3.2 shows the rail surface at $20,000^{\text {th }}$ and $50,000^{\text {th }}$ wheel passes. The initiated $\mathrm{HC}$ can be seen at the gauge corner. The test was stopped after 100,000 passes. Figure 3.3 shows the HC cracks after 100,000 passes. It can be seen that the top layer was severely plastically deformed, in the way of ratcheting as discussed in Chapter 2, and the initial part of the cracks followed the direction of the plastic flow. 


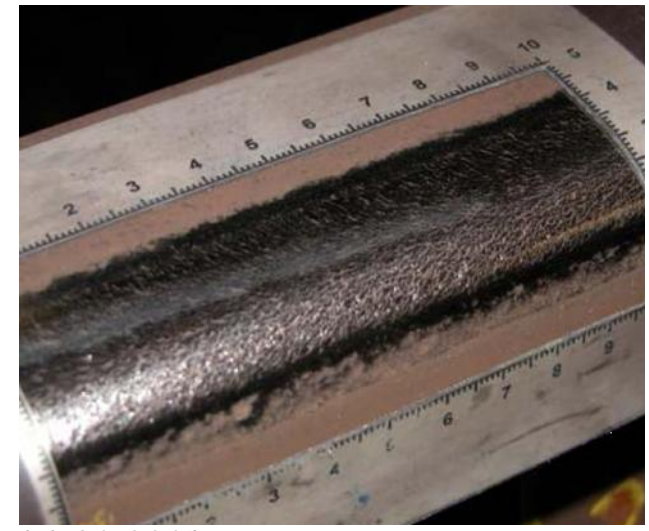

(a) 20,000th pass.

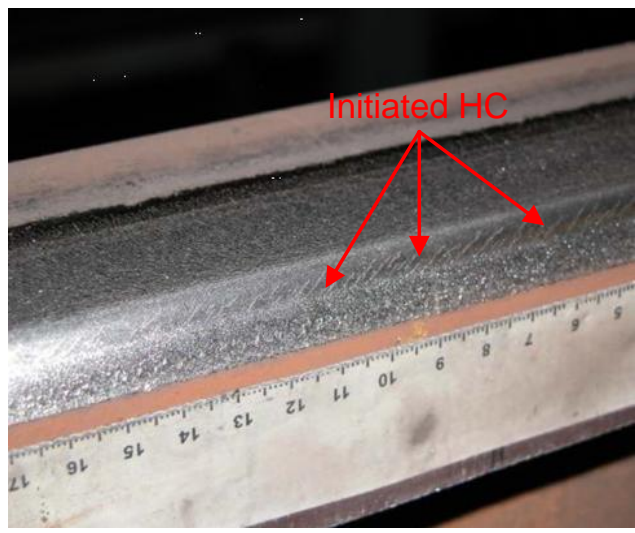

(b) $50,000^{\text {th }}$ pass.

Figure 3.2 Rail surface at 20,000th and 50,000th pass. No crack can be found at $20,000^{\text {th }}$ pass. Initiating cracks are visible at 50,000th pass.

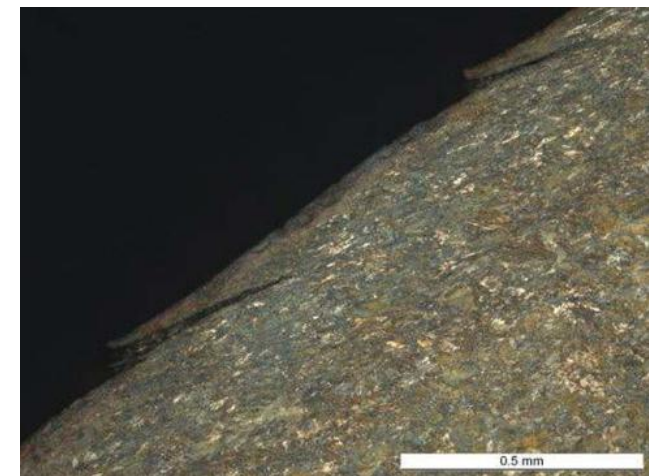

(a)

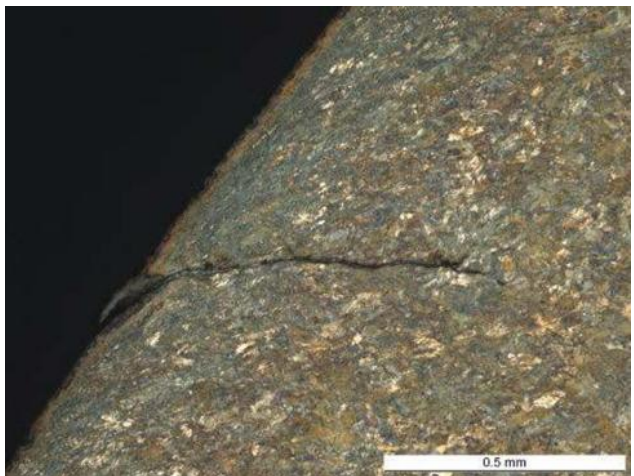

(b)

Figure 3.3 Rail sections with Head Check cracks after 100,000 wheel passes. 


\subsubsection{Analysis of the test for $\mathrm{HC}$ initiation}

\subsubsection{The solution method}

The $\mathrm{HC}$ was found to occur at the gauge corner and gauge shoulder, where the contact geometry is warped, and the contact can be conformal. This means that the traditional half-space assumption employed in the Hertz theory, Hertz (1882), and in the Kalker's program CONTACT, Kalker (1990), may not be valid. This work employs a non-Hertzian solution method, which is based on CONTACT and has been developed by Li (2002) for solving the wheel-rail conformal contact at the gauge corner. This method uses the quasiquarter spaces (see Appendix E) instead of the flat half spaces to simulate the warped geometry of the rail at the gauge corner and of the wheel at the flange root. The geometrical spin at the gauge corner contact is significant, and the spin creepage is not constant in the contact area due to the warped geometry. This is taken into account by adding the additional geometry dependent spin creepage to the total creepage terms for each surface element in the mesh shown in Figure 3.4, Li (2002).

The contact problem is formulated on the surfaces of the two contact bodies, namely the wheel and the rail, and solved in the so-called potential contact area, Li (2002). The potential area is an estimation of the real contact area. It should be large enough to include the entire real contact area, but as small as possible to reduce the computational time. The computational time is approximately proportional to the square of the number of elements. By appropriate estimation of the potential contact area, a multi-point contact problem, including two-point contact, can be solved automatically by the algorithm as a non-Hertzian contact.

The stresses in the contact area are more convenient to visualize on a flat surface than on a curved surface. For this purpose the warped contact geometry is stretched onto a horizontal plane, see Figure 3.4. By this stretching, the distance at the gauge corner on the warped surface may become longer than the distance stretched from the same length on the crown, e.g. if $\Delta Y_{\text {cnt2 }}=\Delta Y_{\text {cnt1 }}$ one has $\Delta Y_{\text {cur2 }}>\Delta Y_{\text {cur1. It is important to bear }}$ this in mind in understanding the discussion below. 


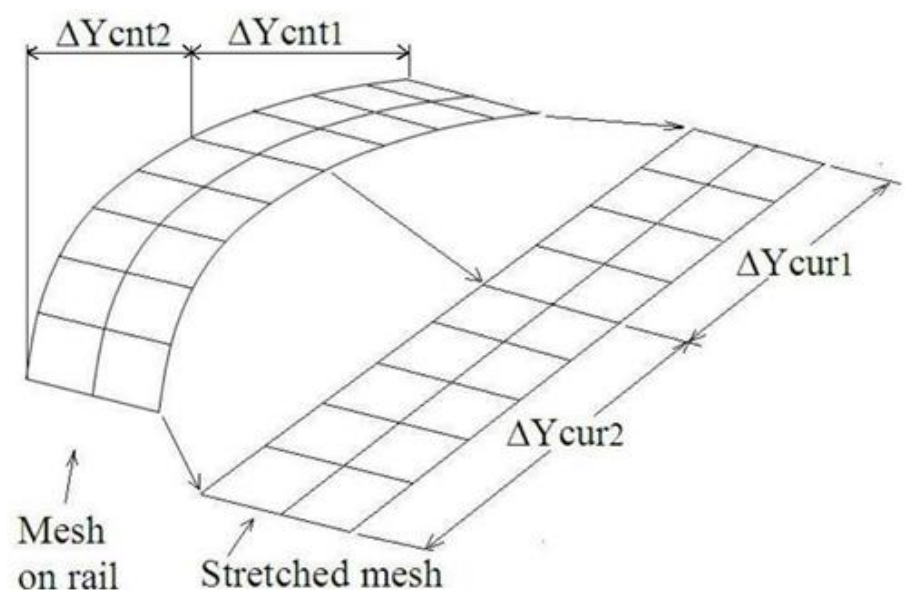

Figure 3.4 Discretization of the warped potential contact area (on the right upper side), and its mapping onto a plane for convenience of visualization in Figures 3.7 through 3.11.

\subsubsection{Analysis of the Lab Test}

Figures 3.5 and 3.6 show the measured profiles. It is observed that the evolution of the profiles of the wheel and rail is consistent, and the wear between the $20,000^{\text {th }}$ and $50,000^{\text {th }}$ passes is almost uniform on the shoulder and gauge corner, see Fig. 3.5 (b). It can also be seen that there was plastic flow at the junction of the lower gauge corner and the gauge face. This is evidenced by the material accumulation there. The material should have been pushed downwards, and flowed horizontally at the same time, see the profile change from $0^{\text {th }}$ pass to $50,000^{\text {th }}$ pass, as arrowed in Fig. 3.5 (c). Relative to $50,000^{\text {th }}$ pass, the material accumulation at $100,000^{\text {th }}$ was slightly less, indicated by the retreat of the profile to the left. This should have been due to wear and break-off of the material, because with the load cycles, the wheelrail contact went further down the gauge face, so that the accumulated material was also in contact with the wheel. This can be seen in Figure 3.2; some of the rusty part at the gauge face in Figure 3.2(a) is shining in Figure $3.2(b)$, indicating that that part has changed from no contact into being in contact. 
The wheel profile measurements are shown in Figure 3.6; the wear was concentrated mainly on a relatively small part of the flange throat, i.e. the part of wheel between tread and flange.

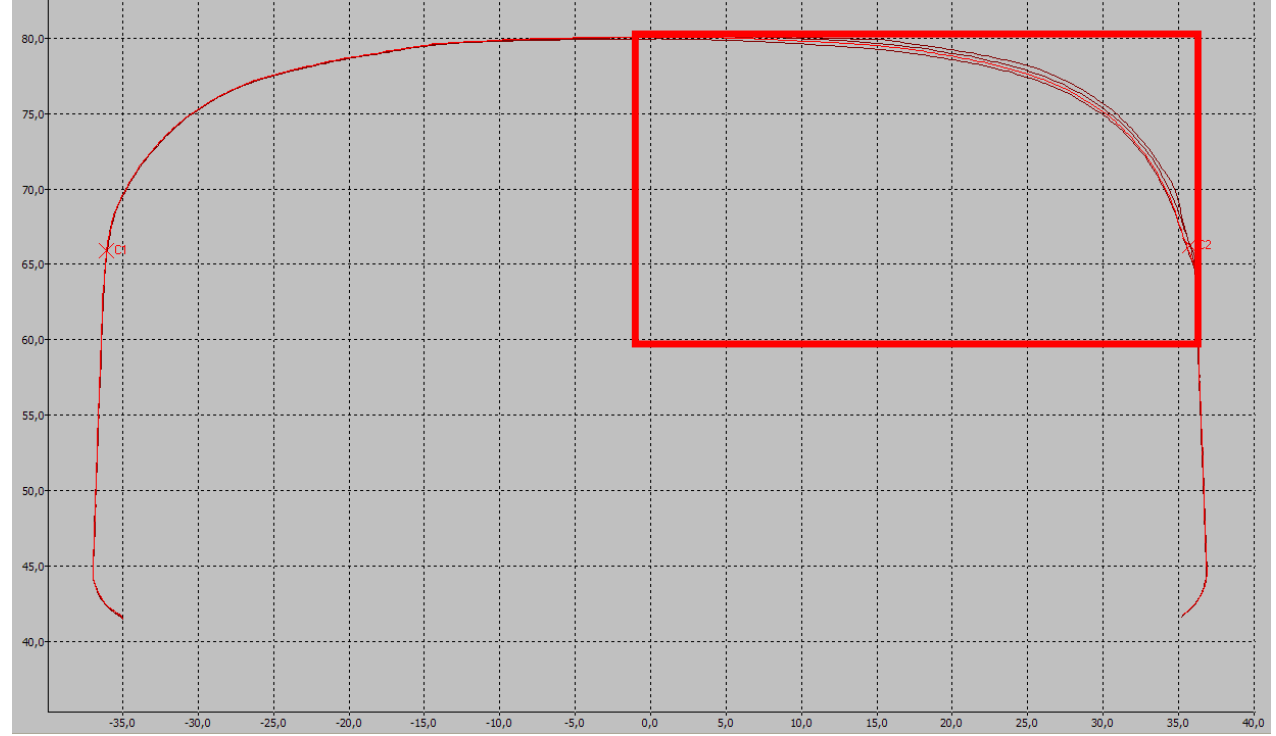

(a) Overall view of the measured profiles. Red line was measured at 50,000th passes.

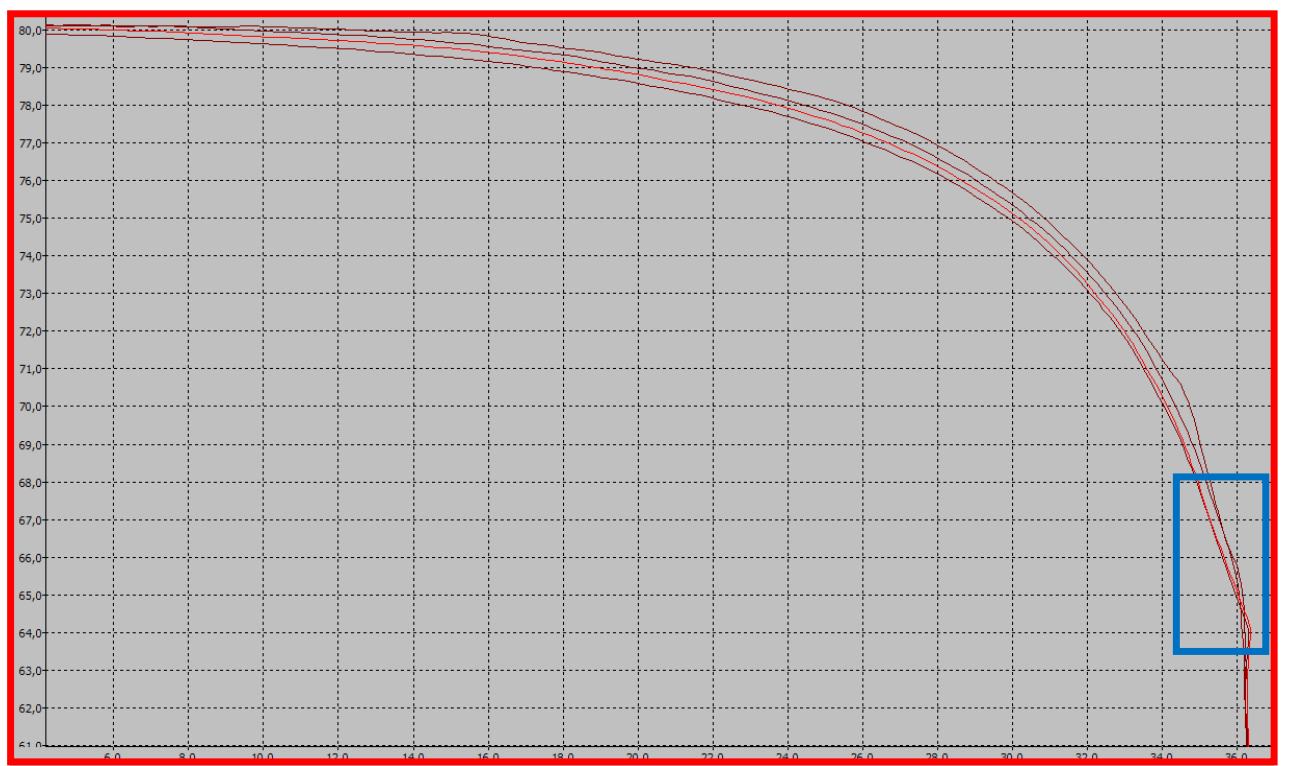

(b) Profile measurement of the rail in the gauge corner. From top down are profiles at $0^{\text {th }}, 20,000^{\text {th }}, 50,000^{\text {th }}$ and $100,000^{\text {th }}$ wheel passes. Red line was measured at 50,000 th passes. 


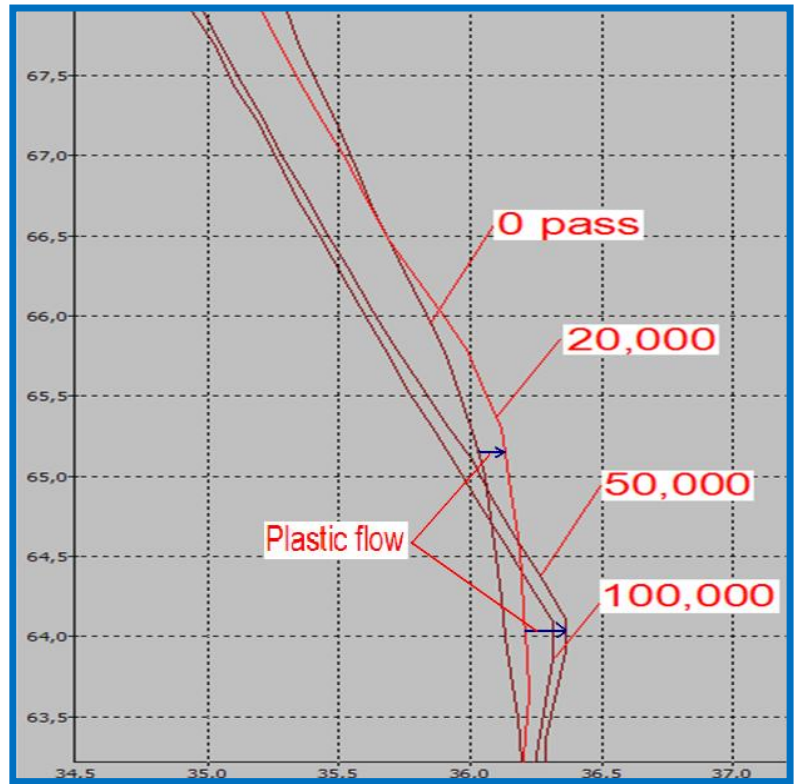

(c) Zoom-in of plastic flow at the junction of the lower gauge corner and the gauge face between $0^{\text {th }}$ and $50,000^{\text {th }}$ passes. Red line was measured at $20,000^{\text {th }}$ pass. The blue arrows indicate the direction of the plastic flow in the horizontal direction.

Figure 3.5 Measured rail profile.

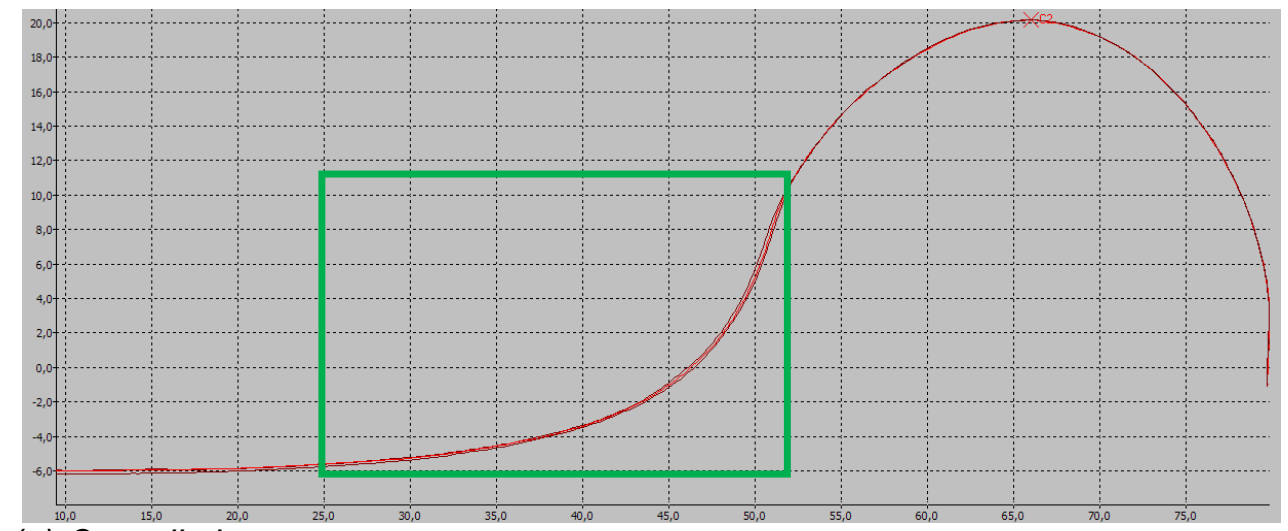

(a) Overall view. 


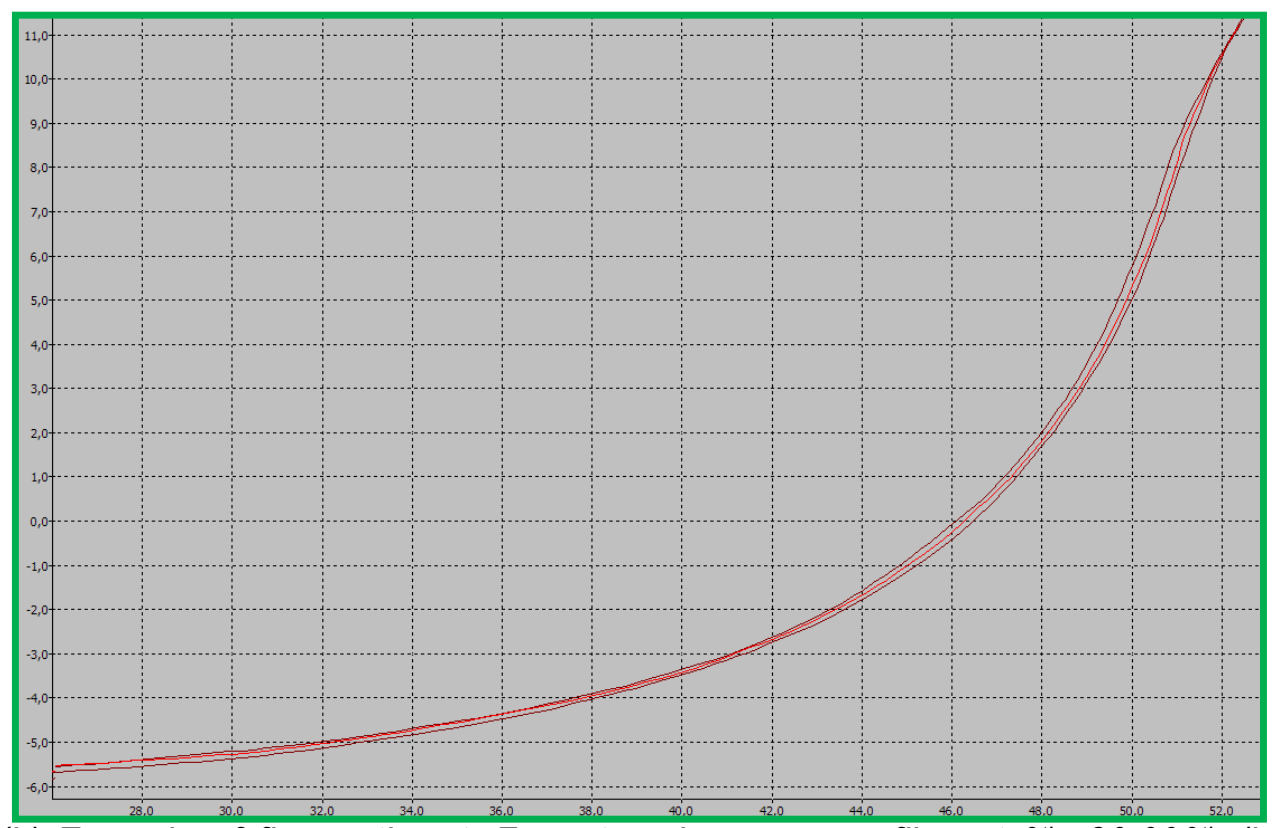

(b) Zoom-in of flange throat. From top down are profiles at $0^{\text {th }}, 20,000^{\text {th }}$ (in red) and 50,000 th wheel passes.

Figure 3.6 Profile measurements of the wheel at 20,000th (brown) and $50,000^{\text {th }}$ (red) passes. The flange throat area is shown.

The contact stresses are evaluated at the $20,000^{\text {th }}$ and the $50,000^{\text {th }}$ wheel passes. The consistency in the rail and wheel profile evolution indicates that it was a controlled test. There are two uncertainties with the test, namely the coefficient of friction and the effective rail inclination. The coefficient of friction (COF) was not measured. The effective rail inclination may be different from the nominal one due to deformation of the test rig in the load chain.

In the sequel, the profile measurement at $20,000^{\text {th }}$ pass is used for the identification of the effective rail inclination to eliminate its uncertainty, and then the identified effective rail inclination is checked against the measurement at $50,000^{\text {th }}$ pass. The influence of the uncertain level of friction is discussed later in this section. 


\subsubsection{Analysis of the measurement at $20,000^{\text {th }}$ wheel pass}

The analyses are first performed on the profiles measured at $20,000^{\text {th }}$ passes. Analysis with the nominal rail inclination of $1 / 40$ indicated that wheel-rail contact with such an inclination should not have happened with the measured profiles. Inclination values of $1 / 20$ and 0 were tried, and it was found that 0 inclination yielded solutions of wheel-rail contact that were the most reasonable. In the subsequent analyses the effective rail inclination is taken as 0 . This may have happened due to the flexibility of the components of the rig in the load path owing to the large force applied. Validity of this value will be presented later in this section.

The wheel-rail contact is solved for a series of wheel lateral positions relative to the rail $\Delta Y$ to identify the most probable location of contact. The contact should have taken place around the same location because the applied loads were constant; the only change was the profiles of the rail and wheel.

The results are given in table 3.2 and Figures 3.7 and 3.8. Contact range means the range that a contact area covers in terms of $Y_{\text {cnt,. }}$. At $\Delta Y=9.8 \mathrm{~mm}$ the contact is mainly on the gauge shoulder. There is also a minor contact point at $y=15 \mathrm{~mm}$ in Figure 3.7(a), corresponding to $Y_{\text {cnt }}=10 \mathrm{~mm}$, see the corresponding contact range. It means that this minor contact point is on the crown, $10 \mathrm{~mm}$ away from the centre line of the rail. The contact area at $\Delta \mathrm{Y}=$ $9.8 \mathrm{~mm}$ therefore contains two sub-contact areas, with the major contact around $y=0 \mathrm{~mm}$ and the other around $\mathrm{y}=15 \mathrm{~mm}$. This situation is called two-point contact. Between $\Delta \mathrm{Y}=9.9$ and $9.907 \mathrm{~mm}$ it is the transition from gauge shoulder contact to gauge face contact. This can be judged from the contact angle $\delta_{0}$, contact range and from the evolution of the shape of the contact areas in Figure 3.7. At $\Delta Y=10.0 \mathrm{~mm}$ the contact angle $\delta_{0}$ is already $66.8^{\circ}$, with $Y_{\mathrm{cnt}}=34.9 \mathrm{~mm}$, the contact is between the wheel flange and the lower gauge corner, as well as the gauge face (see Figure 2.8). Note that the nominal flange angle is $68^{\circ}$, and the nominal distance between the gauge face and rail centre line is $36 \mathrm{~mm}$, measured at a point on the profile $14.3 \mathrm{~mm}$ below the rail top, see prEN 13674-1, June, 2009.

It is observed that during the transition the contact area shifts continuously from the rail head through the gauge shoulder, gauge corner, and down to the gauge face. The contact range covers an area ranging between $Y_{\mathrm{cnt}}=10$ and $35 \mathrm{~mm}$. This situation is in agreement with the profile evolution shown in 
Figure 3.5; without continuous contact, the profile evolution between the $20,000^{\text {th }}$ pass and the $50,000^{\text {th }}$ pass would not be uniform.

The contact is very much conformal, so that a small change in $\Delta \mathrm{Y}$ can lead to a large shift of the location of the highest stress. This shift takes place when $\Delta \mathrm{Y}$ changes from $9.9 \mathrm{~mm}$ to $9.907 \mathrm{~mm}$. At $\Delta \mathrm{Y}=9.9 \mathrm{~mm}$, the contact is on the shoulder and the upper gauge corner, with a contact range between $Y_{\mathrm{cnt}}=19$ $-33 \mathrm{~mm}$. At $\Delta \mathrm{Y}=9.907 \mathrm{~mm}$, the contact range is shifted to $\mathrm{Y}_{\mathrm{cnt}}=22-35$ $\mathrm{mm}$. At $Y_{\mathrm{cnt}}=35 \mathrm{~mm}$ the contact is between the flange tip and the lower gauge corner. The conformity between the wheel and rail suddenly disappears, and the contact becomes very concentrated due to the small radii of the gauge corner and the flange tip. This leads to a sharp stress increase there, see table 3.2 and compare the normal stress distributions of Figure 3.8(b) and (c), and the change in the shape of the contact areas of Figure $3.7(\mathrm{~b})$ and (c). The situation is schematically illustrated in Figure 3.8(e), where the plot on the left side corresponds to $\Delta \mathrm{Y}=9.9 \mathrm{~mm}$, with the gap between the wheel flange tip and gauge corner almost zero, and where the plot on the right side corresponds to $\Delta \mathrm{Y}=9.907 \mathrm{~mm}$, with the flange tip "penetrating" into the rail, causing high pressure. Due to the large geometrical spin, the resulting tangential stress is also high, resulting in the plastic flow shown in Figure 3.5(c). Notice that the solution is obtained with the assumption of elasticity, the calculated stresses can therefore be unrealistically high, indicating plastic deformation.

Table 3.2 Contact conditions with effective rail inclination $=0$, see also Figures 3.7 and 3.8.

\begin{tabular}{|l|c|c|c|c|}
\hline$\Delta \mathrm{Y}(\mathrm{mm})$ & 9.8 & 9.9 & 9.907 & 10.0 \\
\hline $\mathrm{Y}_{\text {cnt }}(\mathrm{mm})$ & 24.5 & 28.8 & 31.1 & 34.9 \\
\hline Contact range $(\mathrm{mm})$ & $10-32$ & $19-33$ & $22-35$ & $29-35$ \\
\hline$\delta_{0}($ degree $)$ & 17.3 & 31.5 & 42.2 & 66.8 \\
\hline 1 - or 2-point contact & 2 & 1 & 1 & 1 \\
\hline $\mathrm{P}_{0}(\mathrm{GPa})$ & 1.3 & 1.3 & 2.2 & 4.8 \\
\hline $\begin{array}{l}\tau_{\max }(\mathrm{GPa}) \\
(\text { with } \mu=0.4)\end{array}$ & 0.51 & 0.52 & 0.88 & 1.9 \\
\hline $\begin{array}{l}\tau_{\max }(\mathrm{GPa}) \\
\text { (with } \mu=0.45)\end{array}$ & 0.57 & 0.59 & 0.99 & 2.1 \\
\hline
\end{tabular}

Based on profiles measured at $20,000^{\text {th }}$ pass. The $\Delta Y$ values are chosen to give clear representation of the changes in contact conditions. 


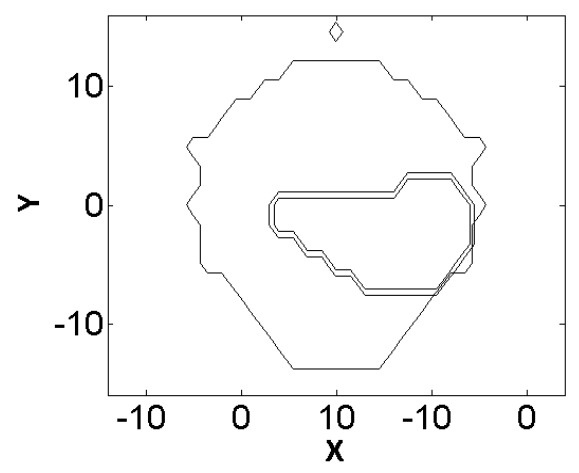

(a): $\Delta Y=9.8 \mathrm{~mm}$

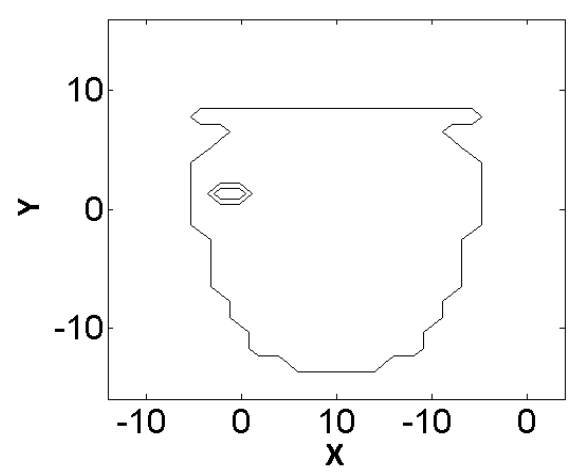

(c): $\Delta Y=9.907 \mathrm{~mm}$

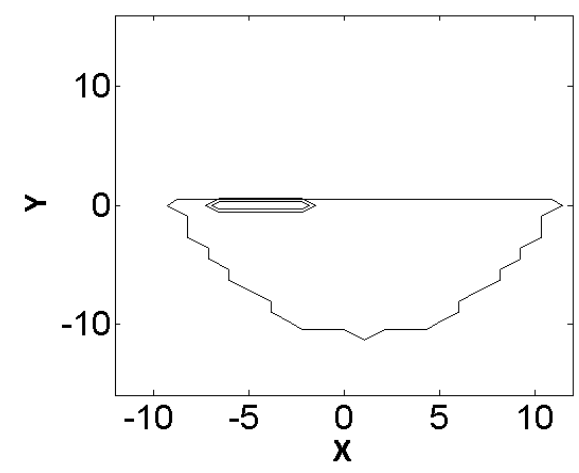

(b): $\Delta Y=9.9 \mathrm{~mm}$

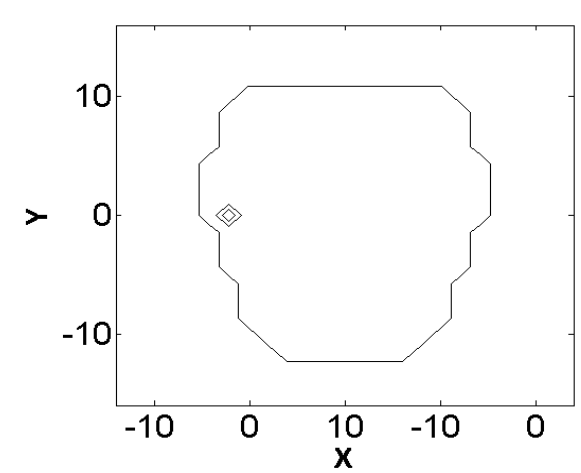

(d): $\Delta Y=10.0 \mathrm{~mm}$

Figure 3.7 Contact area change with lateral displacement of the wheel $\Delta Y$ for profile measured at 20,000th pass. Rail inclination $=0$. Single line represents the contact area and the double lines depicts the adhesion area. Outside the adhesion area but inside the contact area is the area where micro-slip occurs. Positive $X$-axis is in rolling direction, and $Y$-axis is in lateral direction. Positive $Y$-axis points laterally from field side to gauge side. Dimension in $\mathrm{mm}$. See table 3.1 for other parameters. 


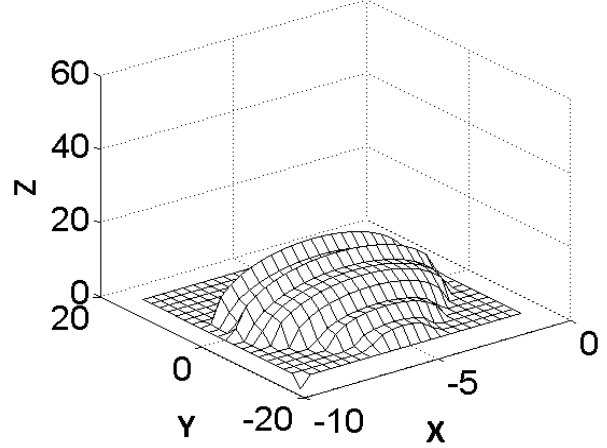

(a): $\Delta Y=9.8 \mathrm{~mm}$

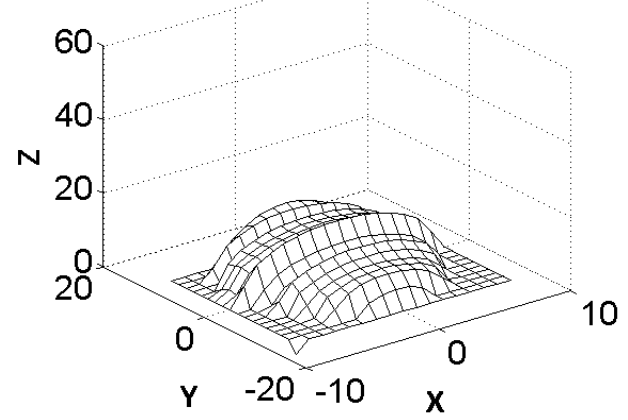

(b): $\Delta Y=9.9 \mathrm{~mm}$

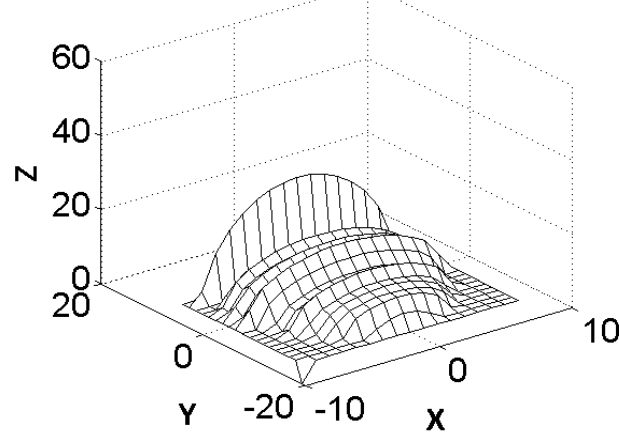

(c): $\Delta Y=9.907 \mathrm{~mm}$

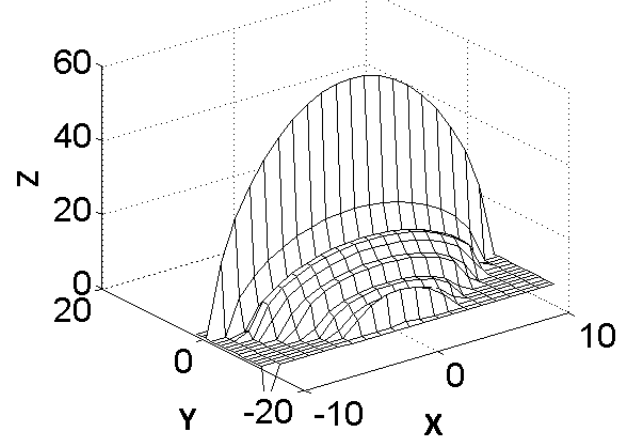

(d): $\Delta Y=10.0 \mathrm{~mm}$
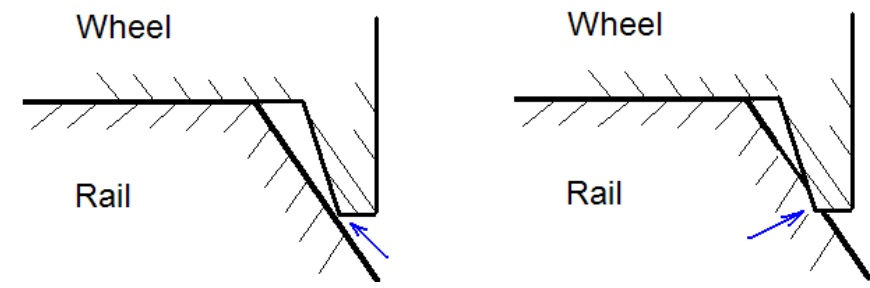

(e) Schematic explanation of contact transition between $\Delta Y=9.9$ and 9.907 $\mathrm{mm}$ and the resulting stress change. The gap on the left plot (arrowed) is almost zero. The penetration in the right plot (arrowed) is a consequence of the change of $\Delta Y$ from $9.9 \mathrm{~mm}$ to $9.907 \mathrm{~mm}$.

Figure 3.8 Contact pressure distribution for different lateral displacement of the wheel $\Delta Y$ for profile measured at 20,000th pass. Rail inclination $=0$. Horizontal axes are the $X$ - and $Y$-axes of the contact area. Dimension of contact area is $\mathrm{mm}$. Vertical axis is the normal pressure normalized with $\mathrm{G}=82 \mathrm{GPa}$. 
The contact at $\Delta \mathrm{Y}=10.0 \mathrm{~mm}$ is unlikely to occur in the test because it represents a situation of flange climbing when the contact is only between the flange tip and the gauge corner, which may happen only when derailment takes place. In such case abnormally high contact stresses will develop in the contact area of high contact angle in order to balance the vertical load $N$, see the values of $P_{0}$ and $\tau_{\max }$ in table 3.2 and Figure 3.8.

The calculated contact around $\Delta \mathrm{Y}=9.907 \mathrm{~mm}$ is realistic, as discussed above. At $\Delta Y=9.8 \mathrm{~mm}$ it is two-point contact, with the minor contact point on the crown, $10 \mathrm{~mm}$ away from the rail centre line. Calculations have shown that with $\Delta \mathrm{Y}<9.8 \mathrm{~mm}$ the contact area is irregular with multiple-point contact, indicating that the profiles were still rough and were not yet run-in, meaning that contact there was rare. This can be expected because when $\Delta Y<9.8$ $\mathrm{mm}$ the contact will be on the crown where the contact angle is almost zero. In such case the 4 ton applied lateral $(Q)$ force will cause relative lateral wheel-rail motion by the mechanism of lateral creepage, so that the gauge corner will come in contact, i.e. crown contact is prevented (This is actually the design purpose of the test to generate $\mathrm{HC}$ ). Therefore it is considered that contact with $\Delta \mathrm{Y}<9.8 \mathrm{~mm}$ is not highly relevant. From this discussion, it appears that if $\mathrm{HC}$ initiates, it should happen around $\Delta \mathrm{Y}=9.8-9.907 \mathrm{~mm}$, i.e. around $Y_{\mathrm{cnt}}=28.8 \mathrm{~mm}$, in the range of $Y_{\mathrm{cnt}}=24.5-31.1 \mathrm{~mm}$. After rounding off, it is $Y_{\mathrm{cnt}}=25-31 \mathrm{~mm}$.

\subsubsection{Coefficient of friction (COF)}

In the VAS test water was applied to the wheel-rail contact. Experience with this test rig has shown that when water spray was applied every 5 wheel passes, no $\mathrm{HC}$ would occur. If one spray of water was applied every 10 passes, $\mathrm{HC}$ would occur. It was also observed on the same rig that under dry conditions, $\mathrm{HC}$ would take place. For the test under discussion, one spray of water was applied at every 10 passes. This means that between two water sprayings the friction level would be low for the first cycles immediately after the water spray, while for the last passes the COF would be high when wheelrail interface was somewhat cleaned by the water and the water had evaporated, because of the heat generated by friction in the contact area. No COF was measured during the tests. It is known that under clean and dry wheel-rail contact the COF can be up to 0.6. 


\subsubsection{Analysis of the measurement at $50,000^{\text {th }}$ wheel pass}

The calculated results for the rolling contact at $50,000^{\text {th }}$ passes are presented in table 3.3. It can be seen that due to wear at the gauge corner, the gauge face and wheel flange, the required $\Delta \mathrm{Y}$ that results in contact conditions similar to those of table 3.2 has increased. The contact conditions corresponding to those of $\Delta Y=9.9 \mathrm{~mm}$ of table 3.2 have now shifted approximately to $\Delta Y=10.15 \mathrm{~mm}$, with little change in $Y_{\mathrm{cnt}}, \delta_{0}$ and the other parameters as shown in tables 3.2 and 3.3. The contact conditions at $\Delta \mathrm{Y}=$ $9.907 \mathrm{~mm}$ of table 3.2 have changed consistently: the $Y_{\text {cnt }}$ and $\delta_{0}$ now correspond to those of $\Delta Y=10.18 \mathrm{~mm}$ of table 3.3, while the contact stresses correspond to those of $\Delta Y=10.25 \mathrm{~mm}$. Their contact areas, tangential stress, micro-slip and their direction are shown in Figures 3.9 through 3.13. Comparing the two tangential tractions in Figure 3.11, it appears that the highest peak in Figure 3.11(a) has almost disappeared in Figure 9(b). It means that the profiles there have been worn into being conformal. In the mean time the conformal contact extended further down the gauge corner to $\mathrm{Y}_{\mathrm{cnt}}=33.2 \mathrm{~mm}$ with $\Delta \mathrm{Y}=10.25 \mathrm{~mm}$, where the maximum tangential stress is up to $1.0 \mathrm{GPa}$ (for $\mu=0.45$ ). The contact at $\Delta \mathrm{Y}=10.28 \mathrm{~mm}$ corresponds to flange climbing, and is therefore unlikely in reality.

Table 3.3 Contact conditions with rail inclination $=0$, see also Figures 7 and 8

\begin{tabular}{|l|c|c|c|c|c|}
\hline$\Delta \mathrm{Y}(\mathrm{mm})$ & 9.8 & 10.15 & 10.18 & 10.25 & 10.28 \\
\hline $\mathrm{Y}_{\text {cnt }}(\mathrm{mm})$ & 21.5 & 28.6 & 31.2 & 33.2 & 35 \\
\hline$\delta_{0}$ (degree) & 12.2 & 30.6 & 44.1 & 56.6 & 67.6 \\
\hline $\begin{array}{l}\text { 1- or 2-point } \\
\text { contact }\end{array}$ & 1 & 1 & 1 & 1 & 1 \\
\hline $\mathrm{P}_{0}(\mathrm{GPa})$ & 1.4 & 1.3 & 1.5 & 2.2 & 4 \\
\hline $\begin{array}{l}\tau_{\max }(\mathrm{GPa}) \\
(\text { with } \mu=0.4)\end{array}$ & 0.56 & 0.52 & 0.57 & 0.9 & 1.6 \\
\hline $\begin{array}{l}\tau_{\max }(\mathrm{GPa}) \\
\text { (with } \mu=0.45)\end{array}$ & 0.63 & 0.59 & 0.64 & 1.0 & 1.8 \\
\hline
\end{tabular}

Based on profiles measured at 50,000 passes. The $\Delta Y$ values are chosen to give clear presentation of the changes in contact conditions. 


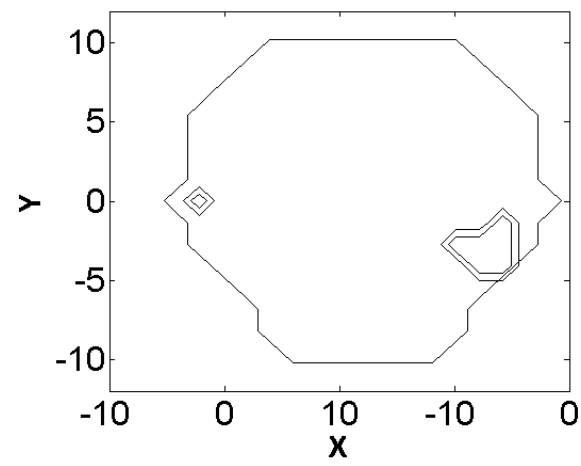

(a): $\Delta Y=10.15 \mathrm{~mm}$

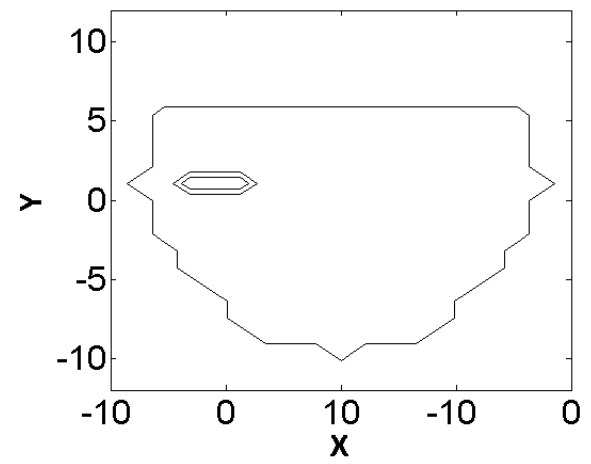

(b): $\Delta Y=10.25 \mathrm{~mm}$

Figure 3.9 Contact area change with lateral displacement of the wheel $\Delta Y$ for the profile measured at 50,000 th pass. Rail inclination $=0$. The single line represents the contact area and the double lines the adhesion area. Outside the adhesion area but inside the contact area is the area where micro-slip occurs. Positive $X$-axis is in rolling direction. Positive $Y$-axis points laterally from field side to gauge side. Dimension in $\mathrm{mm}$. See table 3.1 for other parameters.

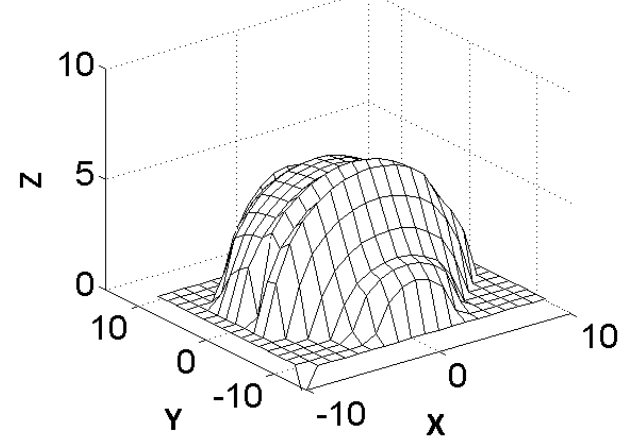

(a): $\Delta Y=10.15 \mathrm{~mm}$

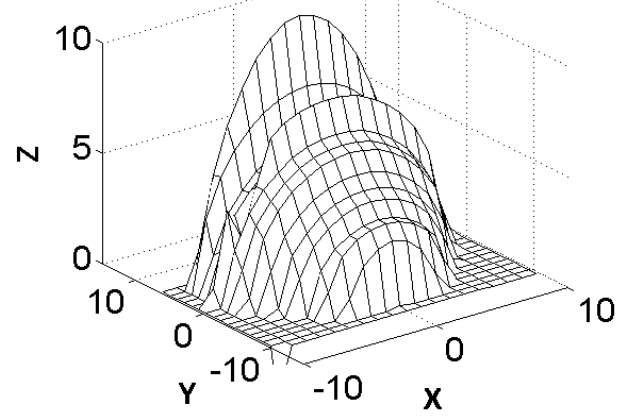

(b): $\Delta Y=10.25 \mathrm{~mm}$

Figure 3.10 Tangential traction distribution at different lateral displacement of the wheel $\Delta Y$ for profile measured at $50,000^{\text {th }}$ pass. Rail inclination $=0$ and coefficient of friction $\mu=0.4$. Horizontal axes are the $X$ - and $Y$-axes of the contact area. Dimension of contact area is in $\mathrm{mm}$. Vertical axis is the tangential traction normalized with $\mathrm{G}=82 \mathrm{GPa}$. 


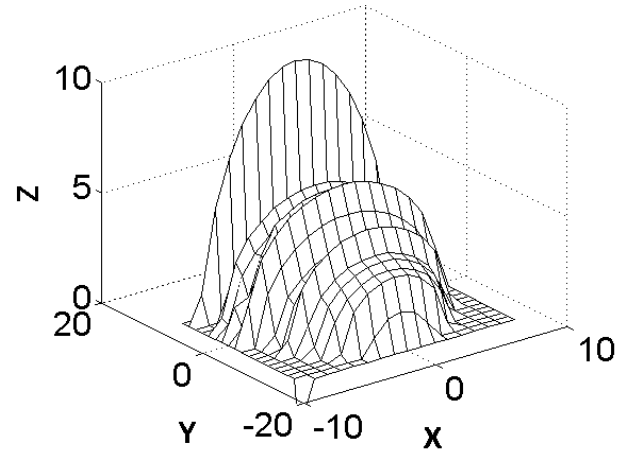

(a): $\Delta Y=9.907 \mathrm{~mm}$

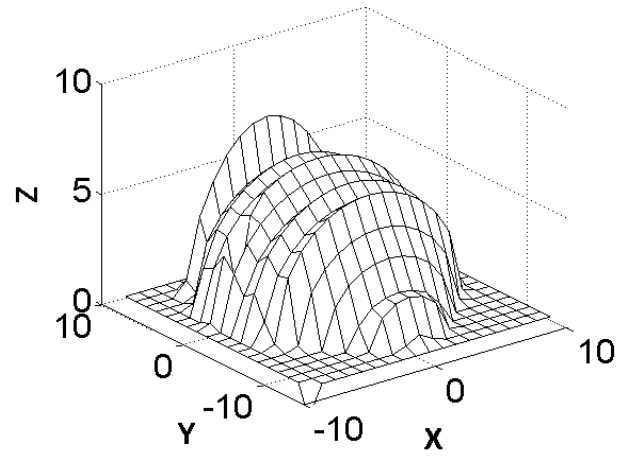

(b): $\Delta Y=10.18 \mathrm{~mm}$

Figure 3.11 Comparison of tangential traction at $20,000^{\text {th }}$ and 50,000 th wheel passes at location where HC most probably initiated. Rail inclination $=0$. Coefficient of friction $\mu=0.4$. Horizontal axes are the $X$ - and $Y$-axes of the contact area. Dimension of contact area is in $\mathrm{mm}$. Vertical axis is the tangential traction normalized with $\mathrm{G}$ $=82 \mathrm{GPa}$. (a) For the case of 20,000th pass, $\Delta Y=9.907 \mathrm{~mm}$ with $Y_{\text {cnt }}=31.1 \mathrm{~mm}, \delta_{0}=42.2^{\circ}$. (b) For the case of $50,000^{\text {th }}$ pass, $\Delta Y$ $=10.18 \mathrm{~mm}$ with $Y_{\text {cnt }}=31.2 \mathrm{~mm}, \delta_{0}=44.1^{\circ}$.

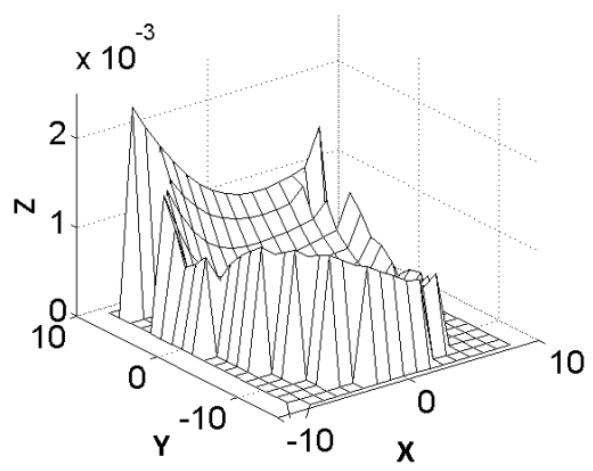

(a): $\Delta Y=9.907 \mathrm{~mm}$

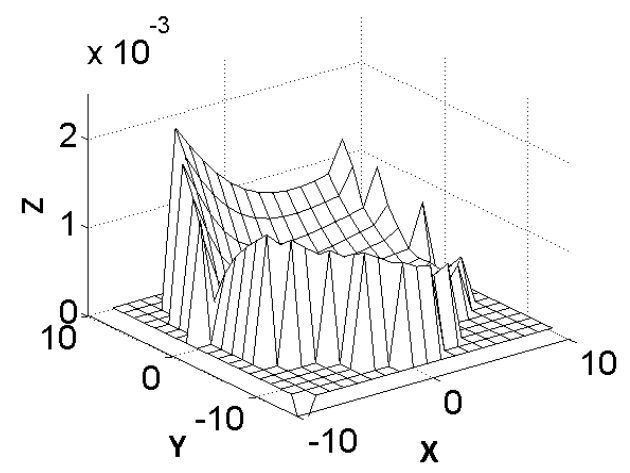

(b): $\Delta Y=10.18 \mathrm{~mm}$

Figure 3.12 Magnitude of micro-slip of the cases shown in Figure 3.11. The micro-slip is dimensionless. (a) For the case of 20,000th pass, $\Delta Y$ $=9.907 \mathrm{~mm}$ with $Y_{\mathrm{cnt}}=31.1 \mathrm{~mm}, \delta_{0}=42.2^{\circ}$. (b) for the case of $50,000^{\text {th }}$ pass, $\Delta Y=10.18 \mathrm{~mm}$ with $Y_{\text {cnt }}=31.2 \mathrm{~mm}, \delta_{0}=44.1^{\circ}$. 


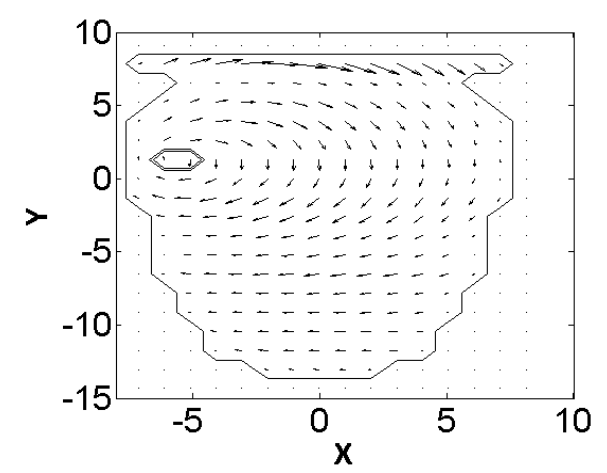

(a): $\Delta Y=9.907 \mathrm{~mm}$

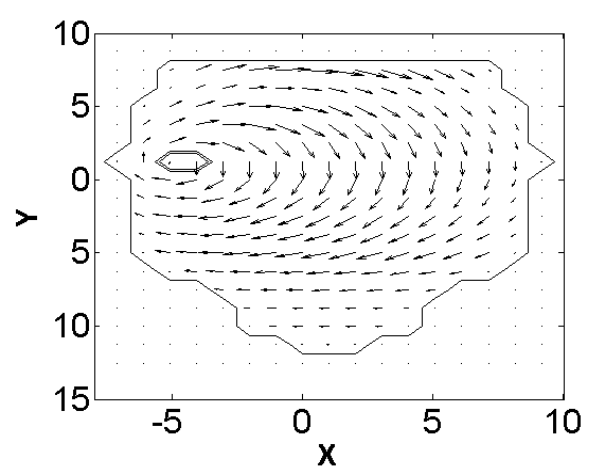

(b): $\Delta Y=10.18 \mathrm{~mm}$

Figure 3.13 Direction of tangential traction of the cases shown in Figure 9.11. Direction of the micro-slip is in the opposite direction. (a) For the case of 20,000th pass, $\Delta Y=9.907 \mathrm{~mm}$ with $Y_{\text {cnt }}=31.1$ $\mathrm{mm}, \delta_{0}=42.2^{\circ}$. (b) For the case of 50,000th pass, $\Delta Y=10.18$ $\mathrm{mm}$ with $\mathrm{Y}_{\mathrm{cnt}}=31.2 \mathrm{~mm}, \delta_{0}=44.1^{\circ}$.

\subsubsection{Discussion}

The maximum tangential stress shown in tables 3.2 and 3.3 is based on $\mu=$ 0.4 and 0.45 . The $\Delta \mathrm{Y}$ values are chosen at typical transitions of the contact conditions. During the actual test water spray was applied every 10 wheel passes. The friction coefficient could therefore vary greatly between two water applications. Due to the deformation in the load chain of the test rig and the variation in COF, the wheel-rail contact would adapt its location slightly to balance the applied loads. The related stress and micro-slip would also vary accordingly. Therefore, the maximum surface shear stress may not be precisely at the locations as given in tables 3.2 and 3.3 , but near these positions. This means that if $\mathrm{HC}$ have initiated, it would probably not be precisely at a fixed $Y_{\text {cnt, }}$ but in a range of $Y_{\text {cnt }}$.

The numerical results based on the profiles measured at $20,000^{\text {th }}$ and $50,000^{\text {th }}$ passes show good consistency with the evolution of the profile as can be seen from tables 3.2 and 3.3 and from the discussion above. The contact conditions around $Y_{\text {cnt }}=28-29 \mathrm{~mm}$ (i.e. around $Y_{\text {cnt }}=28.8 \mathrm{~mm}$ in table 3.2 and $Y_{\mathrm{cnt}}=28.6 \mathrm{~mm}$ in table 3.3) are stable, in the sense that the magnitudes of the stress and $\delta_{0}$ change very little between the $20,000^{\text {th }}$ and $50,000^{\text {th }}$ passes. It may be concluded that the contact geometry at this 
location was more or less stabilized due to run-in. It is noted that during the test the only changing parameter was the profiles. It is observed that due to the run-in the stress at $Y_{\mathrm{cnt}}=28-29 \mathrm{~mm}$ has, compared to its neighbouring areas on both sides, become the lowest at $50,000^{\text {th }}$ pass.

The change of the profiles should mainly be due to wear, and maybe to a lesser extent due to plastic deformation. Contact between run-in surfaces usually has a reduced wear rate. Since a low wear rate may give rise to $\mathrm{HC}$ initiation and growth, it is reasonable to suppose that the $\mathrm{HC}$ might have first initiated around $Y_{\mathrm{cnt}}=28-29 \mathrm{~mm}$.

The maximum tangential stress is, however, the lowest at $Y_{\mathrm{cnt}}=28-29 \mathrm{~mm}$ in table 3.3. It might have happened that the $\mathrm{HC}$ initiation and growth rate was higher elsewhere due to the higher stress so that $\mathrm{HC}$, instead of wear, dominated. Based on the profiles at $20,000^{\text {th }}$ pass it was concluded that $\mathrm{HC}$ might have occurred at $Y_{\mathrm{cnt}}=25-31 \mathrm{~mm}$. According to the results for $50,000^{\text {th }}$ pass (table 3.3), the upper limit is extended to $Y_{\mathrm{cnt}}=33.2 \mathrm{~mm}$. Therefore after rounding-off, the location for $\mathrm{HC}$ initiation would be between $Y_{\text {cnt }}=25-33 \mathrm{~mm}$ for the wheel passes between 20,000 and 50,000 .

For rail material $\mathrm{R} 260$, the maximum shear strength is about $0.64 \mathrm{GPa}$. It can be seen from table 3.2 and 3.3 that the shear stress is very close to or higher than the strength for $\mu=0.45$.

\subsubsection{Validation}

The prediction of the $\mathrm{HC}$ initiation location was based on the applied loads and the measured profiles. The actual HC location of the test was not known when the prediction was made. The actual $\mathrm{HC}$ location was measured later. It was between $Y_{\mathrm{cnt}}=28-34 \mathrm{~mm}$, or $2-8 \mathrm{~mm}$ from gauge face, with the accuracy of a tape measurement, see Figure 3.2. Note that this measurement was made on the test sample after 100,000 wheel passes, while the predicted location of $Y_{\mathrm{cnt}}=25-33 \mathrm{~mm}$, i.e. $3-11 \mathrm{~mm}$ from the gauge face, was made based on the profile measurements at $20,000^{\text {th }}$ and $50,000^{\text {th }}$ wheel passes. Taking the difference in wheel passes into account, the predicted location and the actual location are in good agreement,

A number of factors may have contributed to the difference between the predicted and the actual $\mathrm{HC}$ locations, for instance: 
- The difference in the number of wheel passes. In section 3.2.3.6, it was pointed out that $\mathrm{HC}$ might have initiated at $\mathrm{Y}_{\mathrm{cnt}}=28-29 \mathrm{~mm}$ based on information at 20,000th and 50,000th passes. Because the measurement after 100,000 passes shows that the $\mathrm{HC}$ is between $\mathrm{Y}_{\mathrm{cnt}}$ $=28-34 \mathrm{~mm}$, it is reasonable to assume that the $\mathrm{HC}$ might indeed have initiated around $Y_{\mathrm{cnt}}=28-29 \mathrm{~mm}$, or $7-8 \mathrm{~mm}$ from gauge face, and extended later to Ycnt $=28-34 \mathrm{~mm}$. This could be verified by further metallurgical and micro-structural examinations.

- Error in measurement. The large slope of the profile at the gauge corner makes it vulnerable to error during the measurement of the $\mathrm{HC}$ location.

- Error in numerical simulation. As can be seen from the preceding discussion, the contact location, and hence the location of HC initiation is sensitive to rail inclination. On the other hand it has been concluded, based on analysis with two rail inclinations, i.e. 1/40 and 0 that the actual test conditions should be around 0 . The prediction has then been made with an effective rail inclination of 0 .

The prediction on rail inclination is also verified. The design inclination was $1 / 40$, while the numerical simulation identified that it should be around 0 . Suggested by the finding of the numerical analysis, VAS derived the actual rail inclination based on measurements of displacements recorded during the test at various locations of the test rig. It was 1/172.

Compared to the design inclination $1 / 40$, the measured $1 / 172$ is very close to the predicted zero inclination. It can therefore be concluded that the prediction of the $\mathrm{HC}$ initiation location is validated.

It might still be argued that the coefficient of friction was guessed, and it could have an influence on the prediction. With parameter analysis, the COF was varied, and it turns out that it does not affect the accuracy of the prediction of the location of $\mathrm{HC}$ initiation. This is because the analysis does not employ an absolute value of the tangential stress in order to predict the $\mathrm{HC}$ initiation location. Rather, it used the relative magnitude of the tangential stress. The COF scales up or down the tangential stress linearly, so that the values of COF do not change the relative magnitude. It should be noted that the COF scales up or down the tangential stress (almost) linearly because for the cases under discussion the location of the maximal shear stress in the contact 
area is almost always in slip due to the large spin, so that it is almost always $\tau_{\max }=\mu \mathrm{P}_{0}$ in the range of relevant values of coefficient of friction, see tables 3.2 and 3.3.

\subsection{HC initiation and stress analysis under operational conditions}

This section shows that $\mathrm{HC}$ cracks initiate under operational conditions at locations of high surface shear stress, and the orientation of the initial cracks is perpendicular to the direction of the shear stress.

\subsubsection{Loading conditions and HC observations}

The $\mathrm{HC}$ initiation and the corresponding operational conditions are observed on a monitored track site in the Netherlands. The monitored location was in a curve of $1000 \mathrm{~m}$ radius, with a cant deficiency of $80 \mathrm{~mm}$. The nominal traffic speed was $120 \mathrm{~km} / \mathrm{h}$. This location was chosen owing to the uniform occurrence of severe $\mathrm{HC}$ along the $1.4 \mathrm{~km}$ long track, with the exception of the transition curve where the $\mathrm{HC}$ was irregular. The traffic was mixed. The tonnage was $11.5 \mathrm{MGT} / \mathrm{year}$.

The monitored rail grade R260Mn was installed for the high rail in June 2004. It was preventively ground into the 54E1 profile in August 2004. The first inspection was carried out in September 2004 and found no $\mathrm{HC}$ occurrence. In the subsequent inspection in November 2004 some initiating HC cracks were observed for the first time. The length of these cracks was about $5 \mathrm{~mm}$, and they were 8 to $12 \mathrm{~mm}$ away from the gauge face. Figure 3.15 shows the $\mathrm{HC}$ in September 2005, i.e. 13 months after the grinding. It can be seen that two of the cracks have an angle $\alpha$ of $18^{\circ}$ and $30^{\circ}$ at their location of initiation with respect to the transverse direction.

To analyze the stress state for the HC initiation, a typical Dutch VIRM doubledecker passenger train running on this curve was simulated for the loading conditions. The contact forces between the leading outer wheel and the high rail were found to be $97.6 \mathrm{kN}$ in the normal direction, $21.4 \mathrm{kN}$ in the rolling direction and $20.1 \mathrm{kN}$ in the lateral direction. In this section attention is paid to the analysis on the contact of the leading outer wheel with the rail because the normal force and the lateral forces were the largest there. 


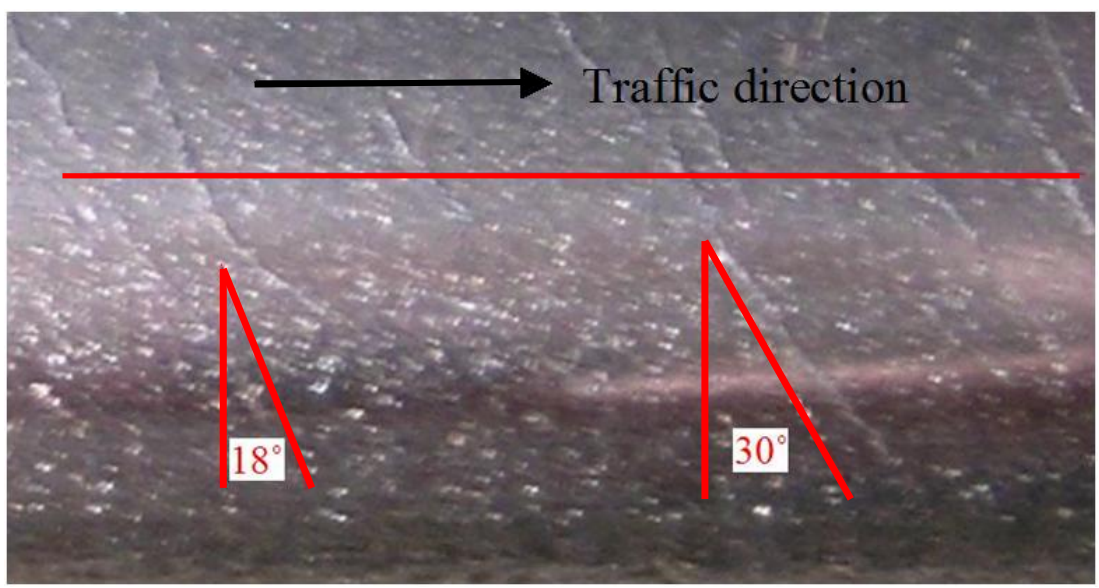

Figure 3.15 Head Checking on the monitored rail. The horizontal red line indicates the average location of the HC initiation (above the red line it is the mean wheel contact area on top of the rail). The angles are those of the cracks at the initiation location.

\subsubsection{Analysis of field observation}

\subsubsection{The profiles}

The rail profile measured at the time of the $\mathrm{HC}$ initiation is shown in Figure 3.16(a). Note that this profile already includes the rail inclination on the track.

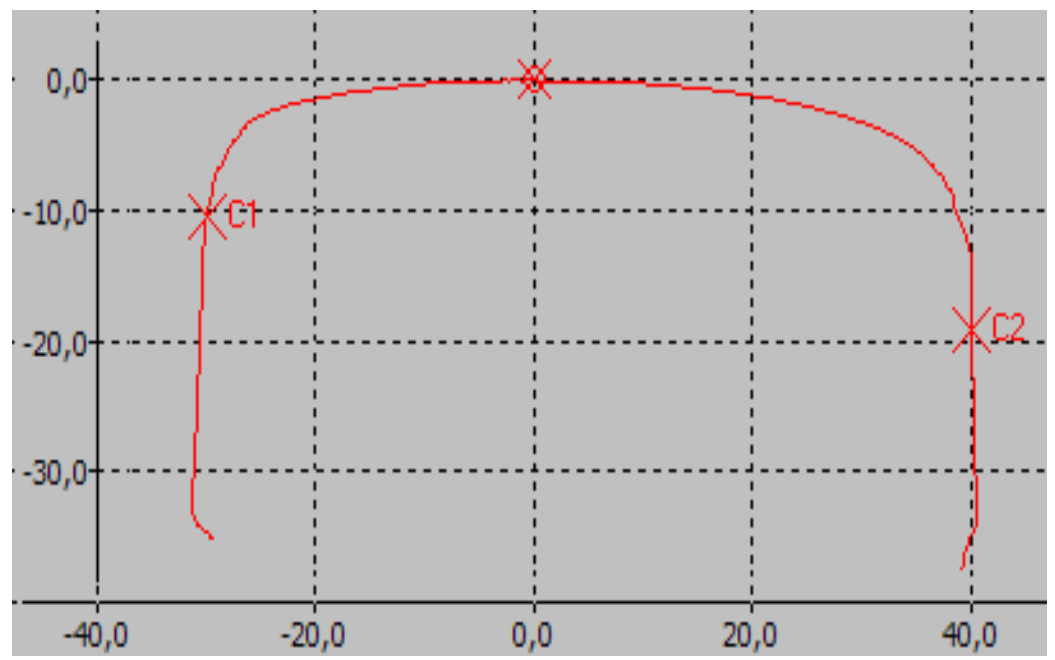

(a) The rail profile measured at the time of the $\mathrm{HC}$ initiation. The gauge side is on the right side. 


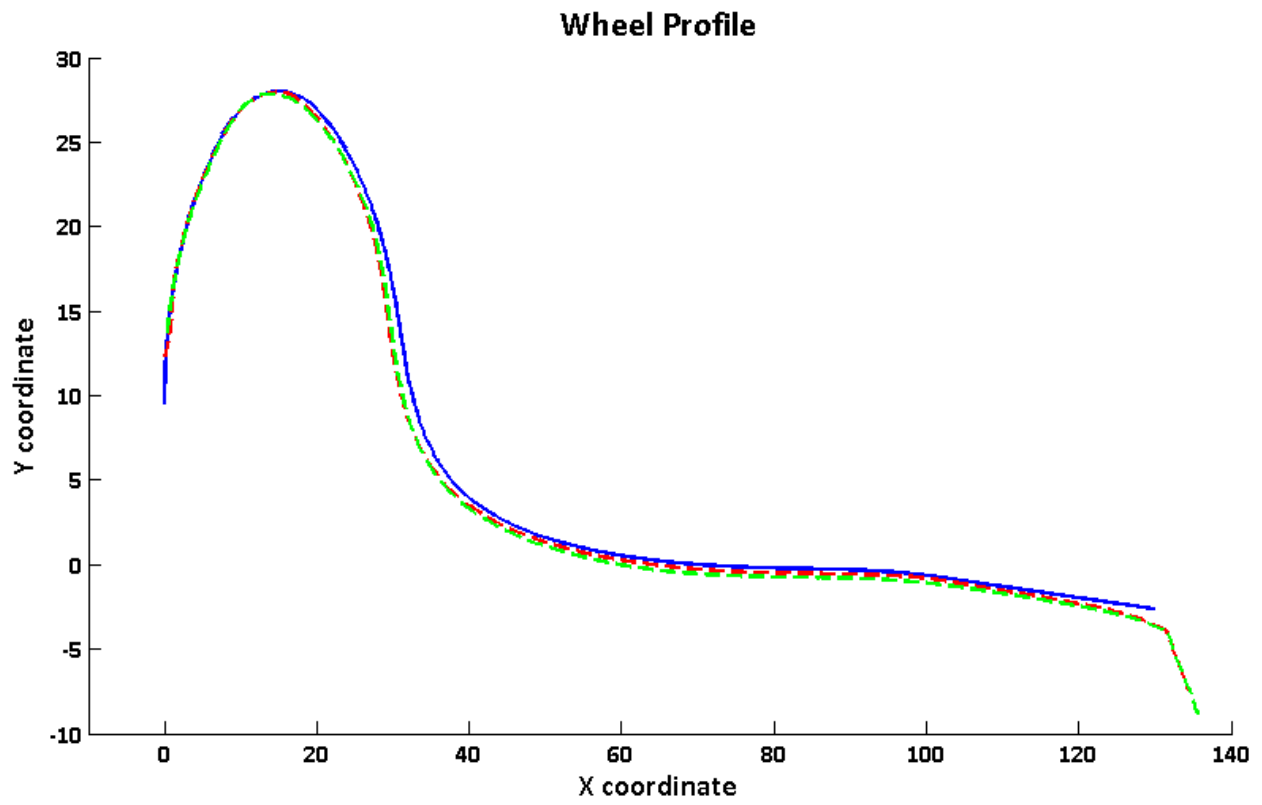

(b) Wheel profiles: The solid blue line is S1002, the broken lines are worn profiles.

Figure 3.16 The rail and wheel profiles used for the analysis. Dimension of the abscissa and ordinate is in millimetres.

The wheels that ran over the rail varied from new $\mathrm{S} 1002$ profile to worn ones of different service mileages. Figure 3.16(b) shows the new S1002 profile (solid blue line) and two worn profiles (broken lines) measured after 1.5 years in service under a VIRM train. They were those of the two wheels on the leading axle of the train, in a non-driving bogie. As a first attempt to evaluate the $\mathrm{HC}$ initiation stress, the new S1002 profile is used in this work.

\subsubsection{The results}

Applying the loading conditions mentioned above to the wheel-rail contact, it is found that the rigid body contact took place at $21.4 \mathrm{~mm}$ away from the gauge face and the contact angle is $6.5^{\circ}$. The point of rigid body contact, which corresponds to $x=0$ and $y=0 \mathrm{~mm}$ in Figure 3.17, is found by considering the wheelset and the rails as being rigid. It can be seen that this is a two-point contact, with one contact point at $y=0 \mathrm{~mm}$, and the other near $\mathrm{y}=15 \mathrm{~mm}$. 


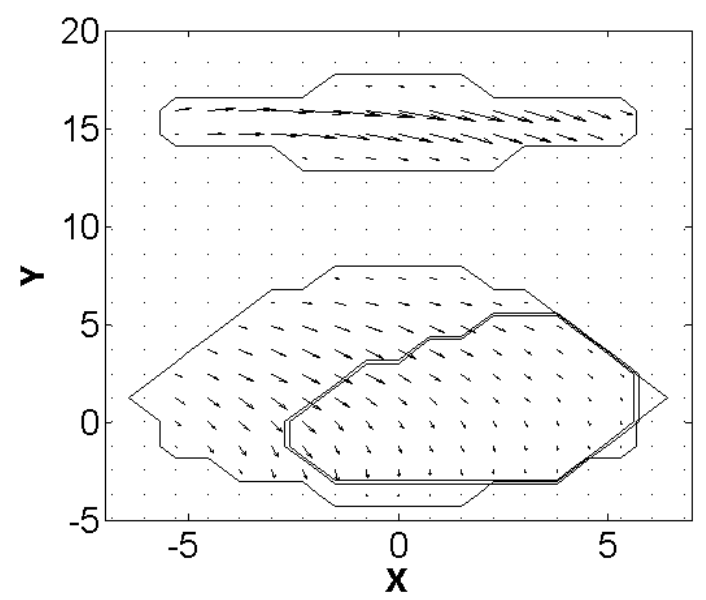

Figure 3.17 The contact area and the distribution of the tangential traction (i.e. surface shear stress). Positive y direction points from the field side to the track centre. The arrows point in the direction of the stress on the wheel. The length of the arrows is proportional to the magnitude of the local tangential traction. Enclosed by the single lines is the contact area. Enclosed by the double lines is the adhesion (stick) area. The area of slip is in the contact area, but outside the adhesion area. The dimensions of the abscissa and ordinate are $\mathrm{mm}$.

Figures 3.18 and 3.19 show the pressure and the tangential stress distribution in the contact area. The tangential stress is obtained with a coefficient of friction $\mu=0.4$. It is noticed that stress at the second contact point $(y=15$ $\mathrm{mm}$ ) is higher than that of the first point at $y=0 \mathrm{~mm}$. The second point is 7.2 $\mathrm{mm}$ away from the gauge face, with a contact angle of $23.4^{\circ}$ (Compare: the first contact point is $21.4 \mathrm{~mm}$ away from the gauge face, with a contact angle of $6.5^{\circ}$ ). Note that $7.2 \mathrm{~mm}+15 \mathrm{~mm}>21.4 \mathrm{~mm}$, because the $7.2 \mathrm{~mm}$ and the $21.4 \mathrm{~mm}$ are measured in the way of $\Delta \mathrm{Y}_{\mathrm{cnt} 2}$, while the $15 \mathrm{~mm}$ is measured in the way of $\Delta \mathrm{Y}_{\text {cur2, }}$ See Figure 3.4.

\subsubsection{Relation between surface shear stress and $\mathrm{HC}$ initiation}

Table 3.4 shows the shear stress $\tau$ and its angle with the rolling direction $\alpha$ for two values of coefficient of friction $\mu$ in the four surface elements, which have the highest shear stress. All the four elements are found in the second contact area of $\mathrm{y}=15 \mathrm{~mm}$. 


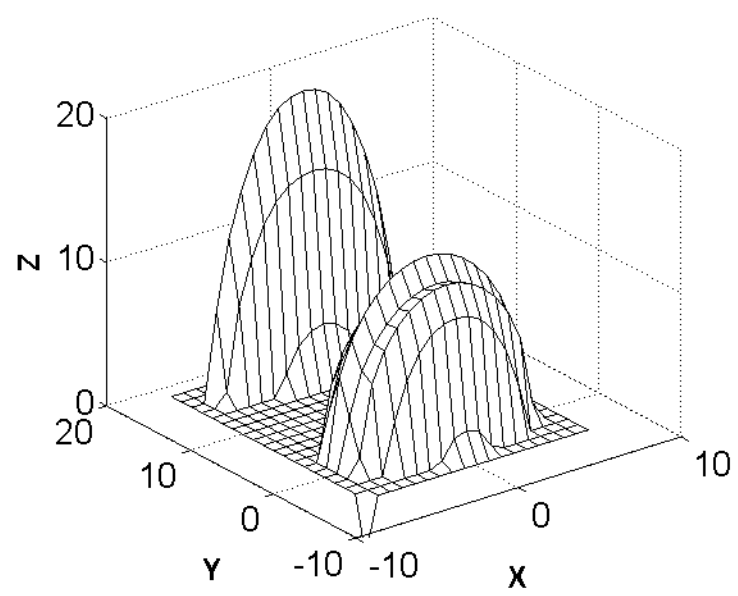

Figure 3.18 Normal pressure at the wheel-rail contact where the $\mathrm{HC}$ initiated. It is normalized by the shear stiffness $\mathrm{G}=82 \mathrm{GPa}$ and it is, therefore, dimensionless. Positive $x$ direction is in the rolling direction, and positive $y$ direction points to the track centre. Dimension of $x$ and $y$ axes is $\mathrm{mm}$.

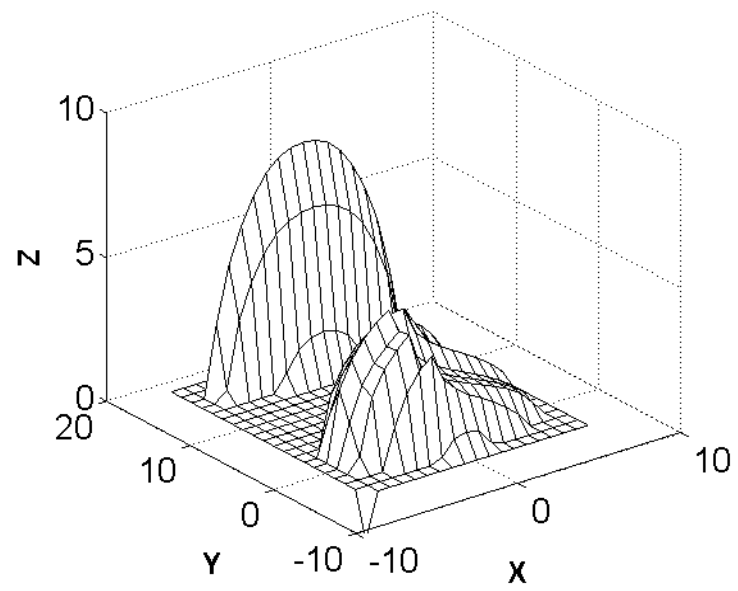

Figure 3.19 Tangential stress at the wheel-rail contact where the $H C$ initiated. It is normalized by the shear stiffness $G=0.82 \mathrm{GPa}$ and it is, therefore, dimensionless. Positive $x$ is in rolling direction, and positive $y$ points to the track centre. Dimension of $x$ and $y$ axes is $\mathrm{mm}$.

The location of the maximal $\tau_{\max }, 7.2 \mathrm{~mm}$ away from the gauge face, is close to the observed $\mathrm{HC}$ initiation location of $8-12 \mathrm{~mm}$ away from the gauge face, and the angle of between $18.9^{\circ}$ and $31.1^{\circ}$ is in agreement with the $18^{\circ}-30^{\circ}$ 


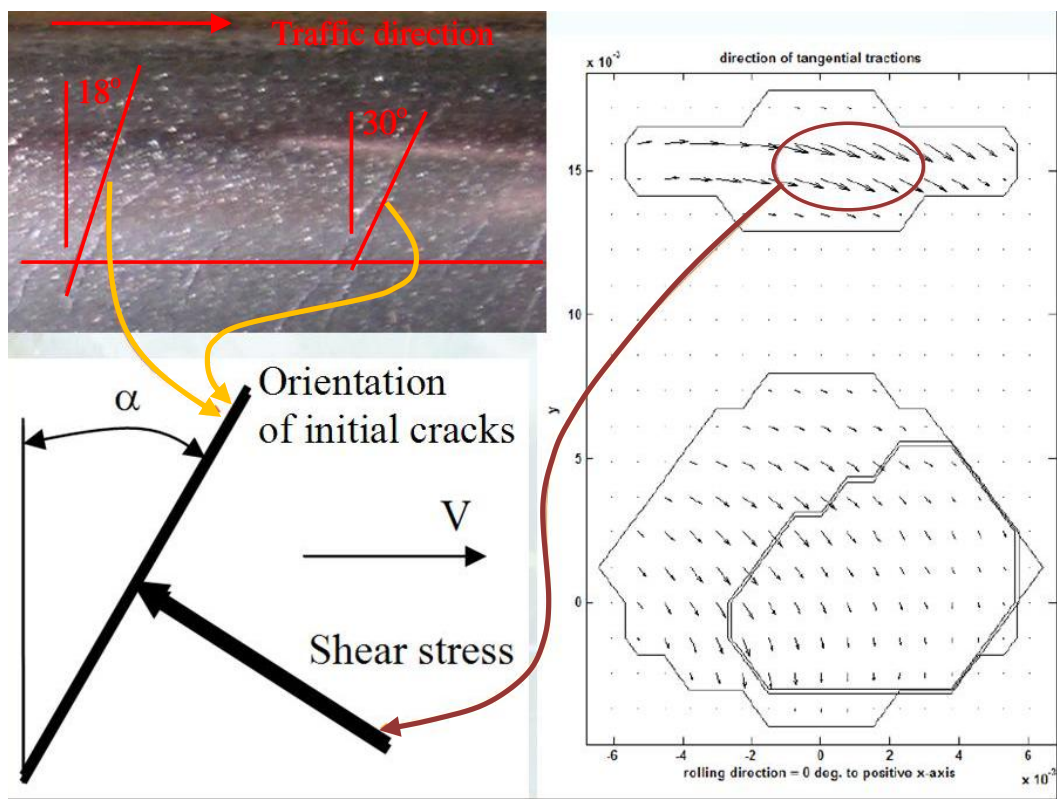

Figure 3.20 Relation between the orientation of crack and the direction of shear stress.

shown in Figure 3.15. Note that the shear stress on the rail surface is equal to but in the opposite direction of what is shown in Figure 3.17, see Figure 3.19. The direction of the cracks should be perpendicular to the direction of the shear stress, as illustrated in Figure 3.20.

Table 3.4 Maximal shear stress

\begin{tabular}{|c|c|c|c|c|}
\hline & \multicolumn{2}{|c|}{$\mu=0.4$} & \multicolumn{2}{|c|}{$\mu=0.45$} \\
\hline -ocations & $\left(\begin{array}{c}\tau \\
(\mathrm{GPa})\end{array}\right.$ & $\alpha$ & $\left(\begin{array}{c}\tau \\
(\mathrm{GPa})\end{array}\right.$ & $\alpha$ \\
\hline 1 & 0.62 & $18.9^{\circ}$ & 0.70 & $20.3^{\circ}$ \\
\hline 2 & 0.63 & $22.9^{\circ}$ & 0.71 & $24.3^{\circ}$ \\
\hline 3 & 0.62 & $26.8^{\circ}$ & 0.70 & $27.8^{\circ}$ \\
\hline 4 & 0.61 & $29.9^{\circ}$ & 0.69 & $31.1^{\circ}$ \\
\hline
\end{tabular}

The maximum shear strength of the R260Mn grade rail is $0.64 \mathrm{GPa}$. Under dry and clean conditions the coefficient of friction between wheel and rail can be up to 0.6 , Eadie et al. (2008). Usually the wheel and rail interface is more 
or less contaminated. A value of $\mu$ between 0.4 and 0.5 should be more typical of the COF in dry conditions in the field. Comparing the $\tau$ with the shear strength, it is seen that for $\mu=0.45$, the maximum shear strength of the material is already exceeded. According to Bower et al. (1989), ratcheting may take place.

Although rates of ratcheting and wear are not considered, the procedure presented, if coupled with methods such as Franklin et al. (2007), may be applied to the prediction of wear and ratcheting life of wheel-rail rolling contact.

\subsection{Conclusions}

This chapter shows by analyses of rolling contact in a controlled full scale lab test and of rolling contact under operational loading conditions that:

- $\mathrm{HC}$ may initiate at and grow from the gauge corner.

- The $\mathrm{HC}$ initiates in surface ratcheting layer.

- The HC initiation at the gauge corner is caused by the large surface shear stress, which is a result of the large geometrical spin due to the profile.

- The HC initiates at location of the largest surface shear stress, except at gauge face.

- The cracks initiate along the direction of the sheared texture.

- The orientation of the initial HC crack is perpendicular to the direction of the maximal surface shear stress.

- Wear plays an important role in $\mathrm{HC}$ initiation.

- At gauge face it is wear which dominates so that any initiating $\mathrm{HC}$ cracks are removed by wear. This is because at gauge face micro-slip is very large owing to the geometrical spin.

- The employed numerical method can correlate/predict the HC initiation with the loading conditions. 


\section{References:}

[1] Bower, A.F. and Johnson, K.L., 1989, The influence of strain hardening on cumulative plastic deformation in rolling and sliding line contact, J. Mech. Phys. Solids 37, No.4, pp. 471-493.

[2] Dollevoet, R.P.B.J., Li, Z. and Arias-Cuevas, O., 2010, A method for the prediction of Head Checking initiation location and orientation under operational loading conditions, accepted for publication in Proc. IMechE Part F: J. Rail and Rapid Transit.

[3] Eadie, D.T., Elvidge, D., Oldknow, K., Stock, R., Pointner, P., Kalousek, J. and Klauser, P., 2008, The effects of top of rail friction modifier on wear and rolling contact fatigue: Full-scale rail-wheel test rig evaluation, analysis and modeling, Wear 265, pp. 1222-1230.

[4] Franklin, F.J. and Kapoor, A., 2007, Modelling wear and crack initiation in rails, Proc. IMechE Part F: J. Rail and Rapid Transit, 221, pp. 23-33.

[5] Grassie, S.L. and Elkins, J.A., 2005, Tractive effort, curving and surface damage of rails Part 1. Forces exerted on the rails, Wear 258, pp. 1235-1244.

[6] Hertz, H., 1882, Über die Berührung fester elastischer Körper, Journal für die reine und angewandte Mathematik, 92, pp. 156-171.

[7] Johnson, K.L., 1995, Contact mechanics and the wear of metals, Wear 190, pp. 162-170.

[8] Kalker, J.J., 1990, Three dimensional elastic bodies in rolling contact, Kluwer Academic Publishers, Dordrecht/Boston/London.

[9] Li, Z., 2002, Wheel-rail rolling contact and its application to wear simulation, $\mathrm{PhD}$ thesis, TU Delft.

[10] prEN 13674-1, Railway applications - Track - Rail - Part 1: Vignole railway rails, $46 \mathrm{~kg} / \mathrm{m}$ and above, draft.

[11] Zacher, M., 2009, Prediction of gauge corner cracking in rails for rail maintenance, Proceedings of the 8th International Conference on Contact Mechanics and Wear of Rail/Wheel Systems, Florence, Italy, pp. 689-697, ISBN: 978-88-904370-0-7. 


\section{Chapter 4 Designing and testing an Anti Head Check rail profile}

\subsection{Designing an $\mathrm{AHC}$ rail profile}

\subsubsection{Introduction}

Based on discussions of the previous chapters, $\mathrm{HC}$ occurs usually in curved tracks, and at gauge corners of high rails. An effective way to prevent $\mathrm{HC}$ from occurring is to reduce the maximal surface shear stress $\tau_{\max }$. This can be achieved, for example, by reducing the contact force exerted by the wheels on the rail. To reduce such force, changes have to be made to the vehicles that run on the rail, or the track, like changing the cant deficiency of a curve. Such changes are difficult to implement, maintain or control.

The analysis of chapter 3 shows that $\tau_{\max }$ depends on contact geometry. It suggests that by changing the contact geometry the contact pressure and/or the spin may be reduced, so that $\tau_{\max }$ may be reduced. Change of the wheelrail contact geometry can be achieved by profile optimization. In principle, either or both of the wheel and rail profiles may be optimized. And from a system point of view it is better to optimize both profiles together.

Simultaneous change in the design of both the rail and wheel profiles will, however, involve too many factors in the vehicle-track system. The profiles have a significant influence on the dynamic behaviour, and the hunting stability in tangent track in particular, which may affect the ride comfort and derailment safety. It is extremely rare on a worldwide scale to read reports of simultaneous changes to both profiles in an entire rail system. Since HC occurs mainly in the high rail of curved tracks, it is convenient and easier to 
start the optimization first with the profile of the high rail in curves. Compared to other possibilities, changing rail profile is relatively easy to implement: a new rail profile can readily be brought to the rail head by grinding. Rail grinding is a proven mature technology.

Therefore, in this thesis, the profile of the high rail is optimized to prevent or retard the occurrence of $\mathrm{HC}$.

In the past few years many mathematical methods have been proposed for optimization of wheel and rail profiles. An extensive review can be found in Shevtsov (2006). It appears that a pure mathematical optimization approach cannot yet treat the many unknowns and constraints involved when Rolling Contact Fatigue is concerned, to mention only a few: unknown contact area, unknown pressure distribution and tangential stress etc. In this thesis, an analytical approach is adopted for the profile design, based on statistical analysis of field observations and measurements, supported by validation in numerical simulation and field tests.

\subsubsection{Observations and statistics}

This approach was inspired by a statistical analysis of the $\mathrm{HC}$ occurrences of two different rail profiles, the $46 \mathrm{E} 3$ and the $54 \mathrm{E} 1$ profiles. The former with an inclination of 1/20 was most frequently used before the 1990s in the Netherlands, and there are still many of them in service. The latter, installed in track with an inclination of $1 / 40$, is the currently standard rail profile. The probability of RCF between 46E3 and 54E1 on the ProRail network is shown in table 4.1, Hiensch and Watson (2004):

Table 4.1 Probability of RCF occurrence (\%).
\begin{tabular}{|l|c|c|}
\hline Rail profile & Curved track & Straight track \\
\hline $46 \mathrm{E} 3$ & 5.8 & 0.7 \\
\hline $54 \mathrm{E} 1$ & 23.5 & 1.9 \\
\hline Confidence level $^{*}$ & 97.0 & 100 \\
\hline
\end{tabular}

* The confidence levels are high enough to regard all these RCF probabilities as being absolute. 
It shows that the $\mathrm{HC}$ occurrence of the $54 \mathrm{E} 1$ profile is 4 times that of the $46 \mathrm{E} 3$ profile, with the other conditions being nearly the same.

Prompted by this finding, a comparison of the contact point distributions of the two profiles with the standard S1002 wheel profile was made, see Figure 4.1. The distributions are calculated by laterally displacing the wheelset with respect to the track, so that the contact points shift along the profiles.

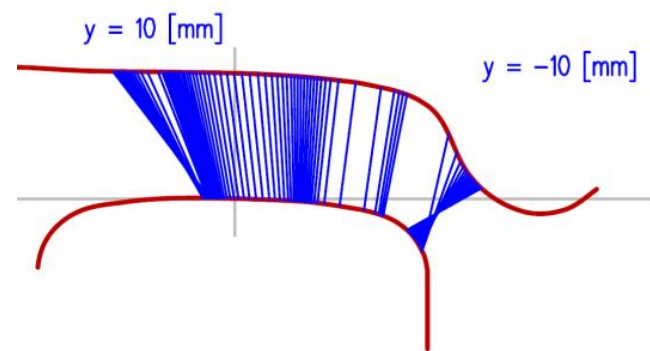

(a) 54E1 at $1 / 40$ inclination.

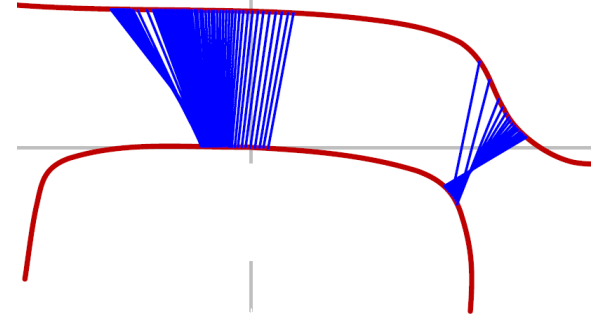

(c) Rail profile measured at Krg-Rsd.

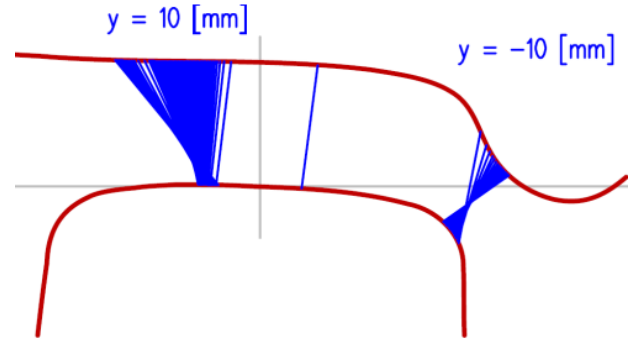

(b) $46 E 3$ at $1 / 20$ inclination.

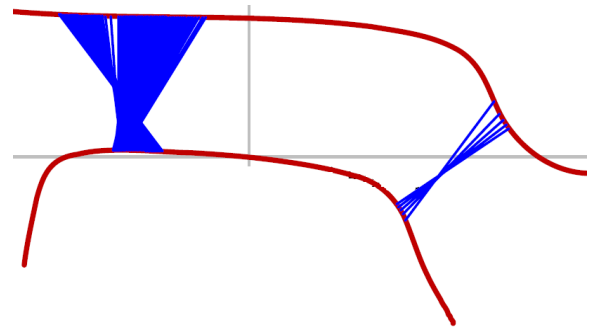

(d) Rail profile measured at Zp-Ah.

Figure 4.1 Contact distributions of new S1002 profile with different new and worn rail profiles. For the distribution the lateral displacement of the wheelset relative to the track $Y$ is varied between -10 and 10 $\mathrm{mm}$. The rail profiles of Figures (c) and (d) are two typical $\mathrm{HC}$-free worn 54E1 measured in the track of Kruiningen - Roosendaal (Krg-Rsd) and Zutphen - Arnhem (Zp-Ah). The contact between rails and wheel in (c) and (d) has shifted towards the field side, compared to the contact between new 54E1 and new S1002, see (a). Change of the profile by wear can be observed at the gauge corner, which are on the right side of the profiles. Note that in the measured rail profiles the actual inclination is already included. 
It is observed that with the $54 \mathrm{E} 1$ rail, contact was distributed along the entire gauge side of the profile, while with $46 \mathrm{E} 3$, there was almost no contact at the shoulder and the upper gauge corner, where $\mathrm{HC}$ usually occurs.

Figure 4.2 shows the comparison of the two profiles. It can be seen that with $1 / 40$ inclination, the 54E1 profile is higher than 46E3 at the shoulder and the gauge corner, so that the higher part of the 54E1 will come into contact with the wheel, whilst that part of the 46E3 rarely is, as shown in Fig. 4.2. Fig. 4.2(c) shows the difference of the two profiles. Figure 4.2 also shows the $54 \mathrm{E} 1$ inclined at $1 / 20$. With this inclination the 54E1 comes very close to the $46 \mathrm{E} 3$ profile. One can imagine that if the 54E1 were installed at $1 / 20$, its $\mathrm{HC}$ propensity would be reduced. The 54E1 can, however, not be installed at 1/20 installation due to the existing sleepers. On the other hand an equivalent 1/20 inclination may be brought to the rail head with grinding by "rotating" the standard 54E1 profile with $1 / 40$ angle.

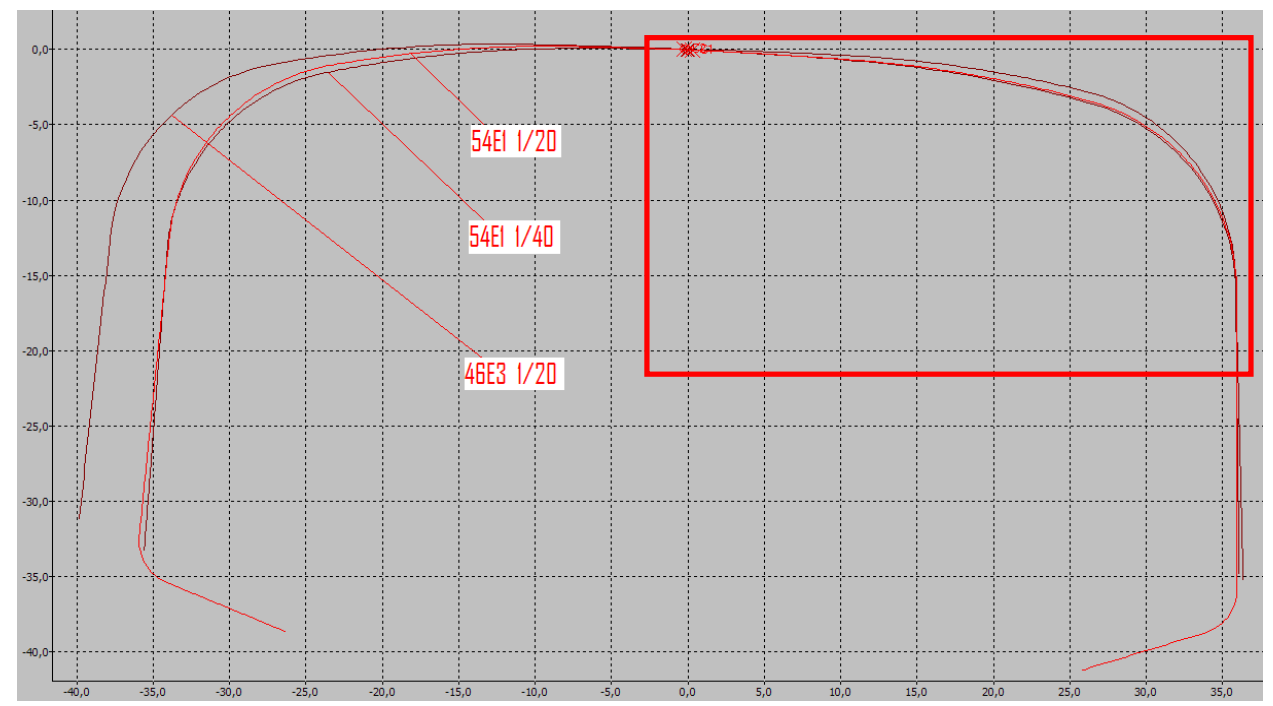

(a) Overall view. 


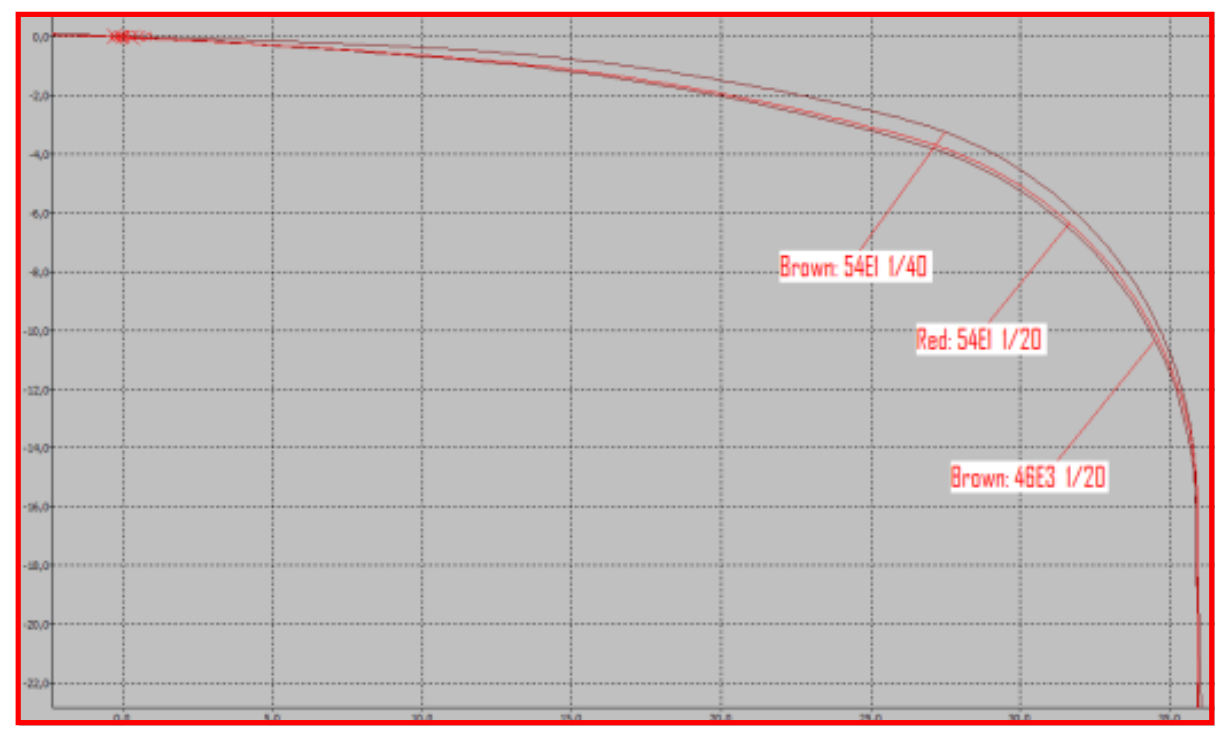

(b) Zoom-in of the gauge side.

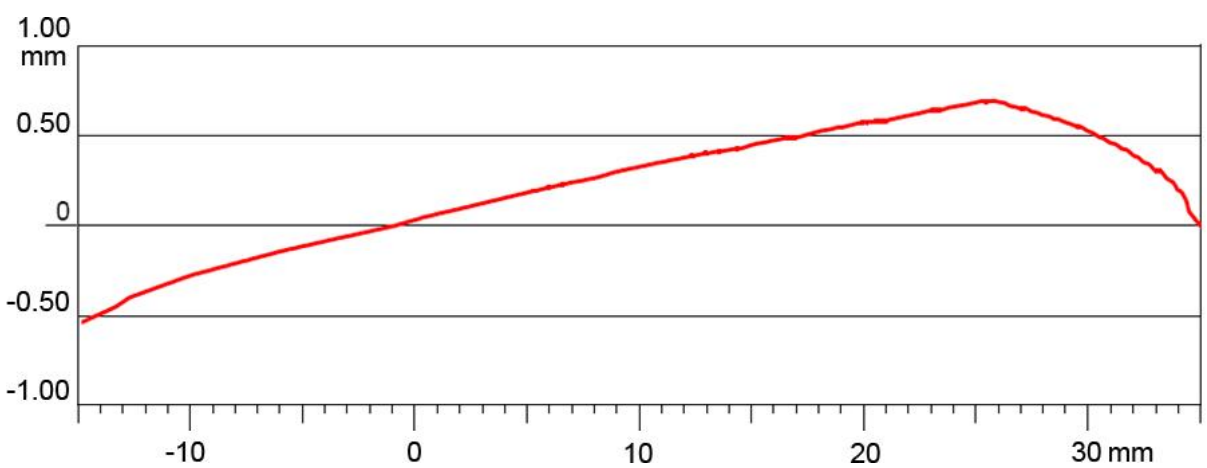

(c) Difference in the local normal direction between 54E1 at 1/40 inclination and $46 E 3$ at $1 / 20$ inclination. Coordinates are in $\mathrm{mm}$.

Figure 4.2 Comparison of 46E3 and 54E1 profiles. For the comparison the profiles are aligned at the gauge face and coincide at the profile centre, see Figure 4.2(a).

It may be concluded from the above analyses in combination with the discussion in Chapter 3 , that the lower $\mathrm{HC}$ occurrence of $46 \mathrm{E} 3$ profile relative to $54 \mathrm{E} 1$ can be attributed to the fact that its shoulder and gauge upper corner, which is the HC-prone area, is free from contact. This HC-prone area, when worn, will eventually come into contact with wheels, so that $\mathrm{HC}$ may occur, if the worn profile is not restored to its design state in time. 


\subsubsection{Design principle and constraints}

The design principle is therefore relief of the rail shoulder and gauge upper corner from contact so that the HC-prone area can be free from the $\mathrm{HC}$ initiating surface shear stress.

For the actual design the following constraints have been taken into account.

A. The AHC profile is designed to be applied to the existing 54E1 rails. The rail head width is therefore $70 \mathrm{~mm}$, measured on the profile 14.1 $\mathrm{mm}$ below the rail top, see prEN 13674-1, June, 2009.

B. Large differences between radii of wheel and rail lead to high contact stress. For an optimal situation the existing difference in radii between wheel and rail should be kept constant. The radii of curvature of the $\mathrm{R} 300, \mathrm{R} 80$ and R13 mm, which determine the 54E1 profile, should therefore be preserved.

C. On a straight track the wheel-rail contact should be around the centre of the profile. This will have the following advantages: (1) The contact is on the R300 arc, so that the contact pressure is minimized; (2) The normal contact force is (almost) in the profile symmetry line, so that it will cause minimum lateral bending of the rail; (3) the associated geometrical spin is minimal.

D. For smooth transition between the arcs, they should be tangent to each other at the transition points. These arcs can provide a gradual change in curvature and smooth transition between the arcs, which prevent abrupt movement of wheel relative to rail, i.e. avoiding slip.

E. As has been found in Chapter 3 that $\mathrm{HC}$ may initiate in the range of 7 - $12 \mathrm{~mm}$ from the gauge face. In Fig. 4.2(c) it can be seen that the $54 \mathrm{E} 1$ differs the most from $46 \mathrm{E} 3$ at about $9 \mathrm{~mm}$ from the gauge face. This means that the $54 \mathrm{E} 1$ should be cut the most at about $9 \mathrm{~mm}$ measured from the gauge face. The largest cut is called undercut hereinafter. For a long anti $\mathrm{HC}$ life the undercut should be maximized, under the conditions of the other constraints.

F. The profile is intended for the high (outer) rail in curved tracks.

G. The rail inclination is $1 / 40$.

$\mathrm{H}$. The profile should have the necessary steering ability. This means that certain radii differences of the two wheels of a wheelset should be maintained. 


\subsubsection{Design of an AHC rail profile}

In view of constraints $A$ and $B$, a coordinate system is defined with its origin at the centre 01 of the 54E1 profile, with the positive $x$-axis pointing to the right (field) side, and positive y-axis upwards in the vertical direction, see Fig. 4.3(a). In table 4.2(a) the coordinates of the joining points and centres of the

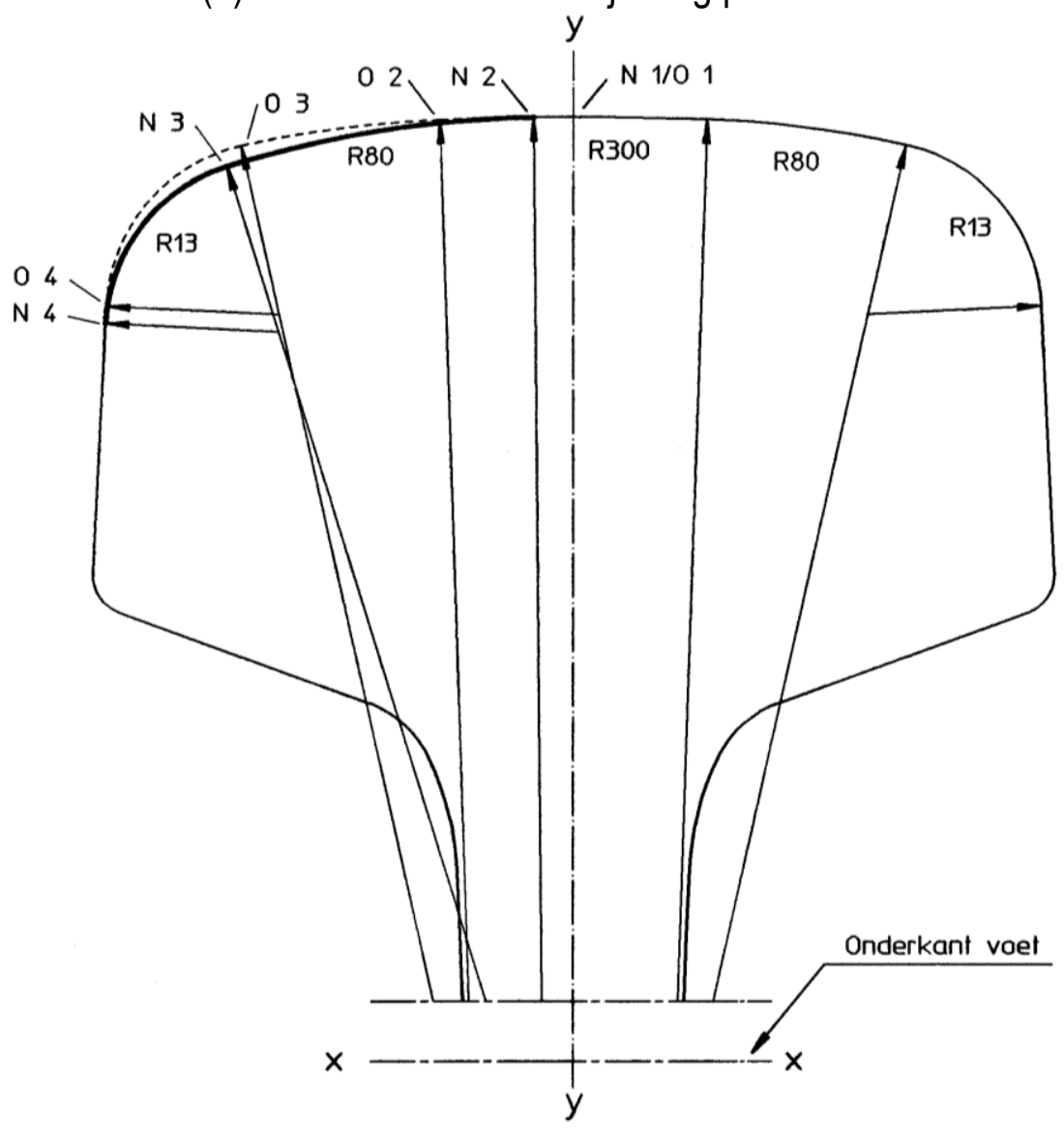

(a) The AHC profile (solid line) in comparison with its origin - 54E1 (Dashed line at the left). The two profiles coincide for the half on the right side (the field side). Oi designate points on 54E1, and Ni for points on the AHC 54E1, $i=1$, 2, 3 and 4. 


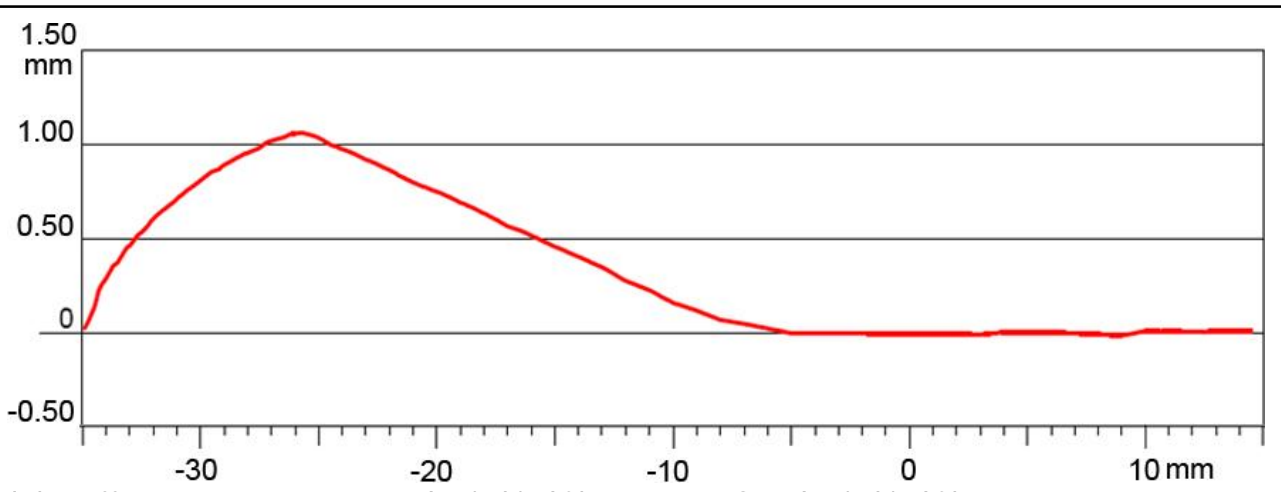

(b) Difference between 54E1 (1/40) and AHC 54E1 (1/40) in the local normal direction.

Figure 4.3 The 54E5 Anti Head Check profile (AHC 54E1) and its original 54E1 profile.

arcs are given. According to constraints $B$ and especially $C$, the radius of curvature should be R300 in the neighbourhood of the profile centre. This means that the centre of the AHC 54E1 should coincide with 01 of $54 \mathrm{E} 1$ (Fig. $4.3(a))$, i.e. $\mathrm{N} 1=01=(0.0,0.0)$, and the centre of the arc is $(0.0,-300.0)$, see Table 4.2(b).

Table 4.2(a) Coordinates of 54E1.

\begin{tabular}{|l|l|l|}
\hline Points & $\mathbf{X}$ & $\mathbf{Y}$ \\
\hline OR13 & -22.1 & -14.8 \\
\hline OR80 & -7.3 & -80.1 \\
\hline OR300 & 0.0 & -300.0 \\
\hline 01 & 0.0 & 0.0 \\
\hline O2 & -10.0 & -0.2 \\
\hline O3 & -24.9 & -3.0 \\
\hline O4 & -35.0 & -14.1 \\
\hline
\end{tabular}

Table 4.2(b) Coordinates of AHC 54E1.

\begin{tabular}{|l|l|l|}
\hline Points & $\mathbf{X}$ & $\mathbf{Y}$ \\
\hline NR13 & -22.1 & -16 \\
\hline NR80 & -2.2 & -80 \\
\hline NR300 & 0.0 & -300 \\
\hline N1 & 0.0 & 0.0 \\
\hline N2 & -3.0 & 0.0 \\
\hline N3 & -26.0 & -3.6 \\
\hline N4 & -35.1 & -15.4 \\
\hline
\end{tabular}

The next point N2, where the R300 and R80 arcs should meet and should be tangent to each other, is determined based on the following findings. After analysis of many profiles measured on high rails of curves of three typical radii ranges which are prone to $\mathrm{HC}$, namely, $750<\mathrm{R}<1500 \mathrm{~m}, 1500 \mathrm{~m}<\mathrm{R}$ $2000 \mathrm{~m}$ and $2000 \mathrm{~m}<\mathrm{R}<3000 \mathrm{~m}$, a group of $\mathrm{HC}$-free profiles were identified, 
Zijlmans et al. (2006). This group of initially 54E1 profiles suffered from mild or severe wear, and did not have HC. They did not only have contact at the shoulder and the upper gauge corner with new S1002, but also another two representative wheel profiles which were moderately and heavily worn. The two wheel profiles were selected from 48 typical worn ones. A noticeable observation with this group of profiles is that the contacts on the rail crown were shifted towards the field side, the two specific cases are shown in Fig. 4.1 (c) and (d). This shift is mainly due to change of the profile by wear and to a lesser extent by possible plastic deformation. This means that for the AHC profile under design the N2 point can be the $\mathrm{O} 2$ of the 54E1 shifted towards the field side, namely towards N1, see Figure 4.3a.

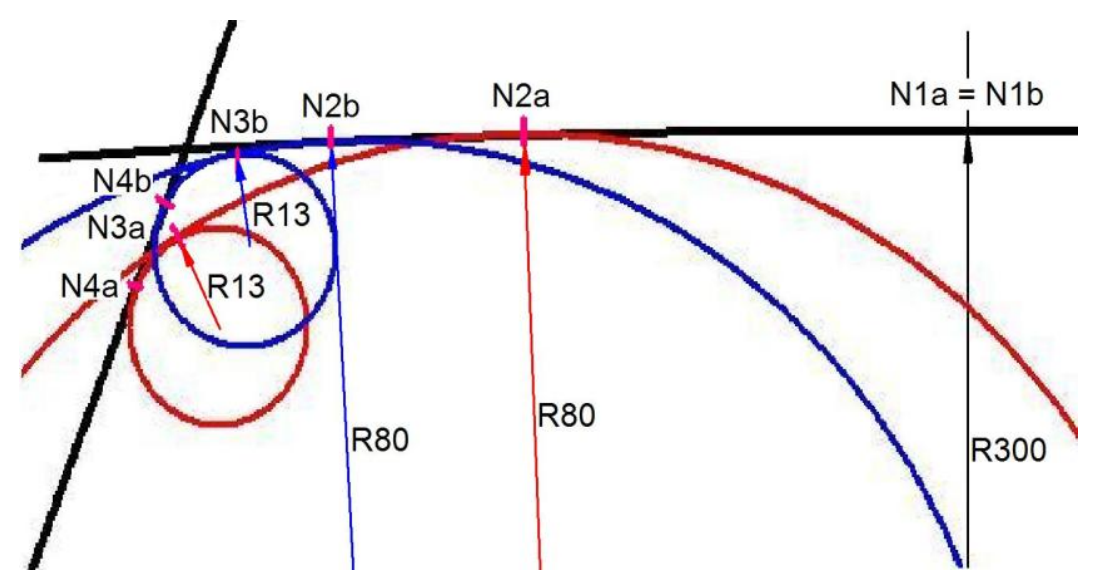

Figure 4.4 Relation between N2, N3 and N4. The slanting straight black line represents the gauge face. The curved black line is a $R 300 \mathrm{~mm}$ arc. Two design scenarios are shown. Scenario a is in red, designated with N1a, N2a, .... Scenario $b$ is in blue. In either scenario, a profile is constructed according to constraint $D$ of section 4.1.3, i.e. the arcs and the straight line meet with and are tangent to each other at N2a, N3a, N4a or N2b, N3b or N4b.

The position of $\mathrm{N} 2$ is, however, constrained by the condition that N4 must be on both the R13 arc and the gauge face, and the R13 arc and the gauge face must be tangent to each other. This constraint can only be realized through the condition that the R13 and R80 arcs must be tangent to each other, see Figure 4.4 , where two scenarios $a$ and $b$ are shown. If scenario $b$ corresponds 
to the situation of $54 \mathrm{E} 1$, scenario a corresponds then to what will be for the AHC 54E1, which is under design. It can be seen that if N2 moves towards $\mathrm{N} 1, \mathrm{~N} 4$ moves downwards on the gauge face, and the undercut increases.

By this process the position of $\mathrm{N} 2$ is determined by maximizing the undercut, i.e. constraint $E$, with constraints $B$ and $C$ being taken into account. $N 2$ has thus been fixed at $x=-3 \mathrm{~mm}$, with the centre of the R80 arc at $(-2.2,-80)$, see Table 4.2(b).

Once N2 is known, N3 and N4 can readily be determined, as shown in Figure 4.4. The resulting coordinates for $\mathrm{N} 1-\mathrm{N} 4$ and the centres of the arcs are given in Table 4.2(b). Note that the vertical coordinate of N4 is different from that of 04 , see Figure 4.4. The nominal widths of the profile are measured at $\mathrm{O} 4$ and N4 respectively, so that their values are $70 \mathrm{~mm}$ for $54 \mathrm{E} 1$ and 70.2 for AHC 54E1, with the slope of the gauge face being 1/20, see prEN 13674-1, June, 2009.

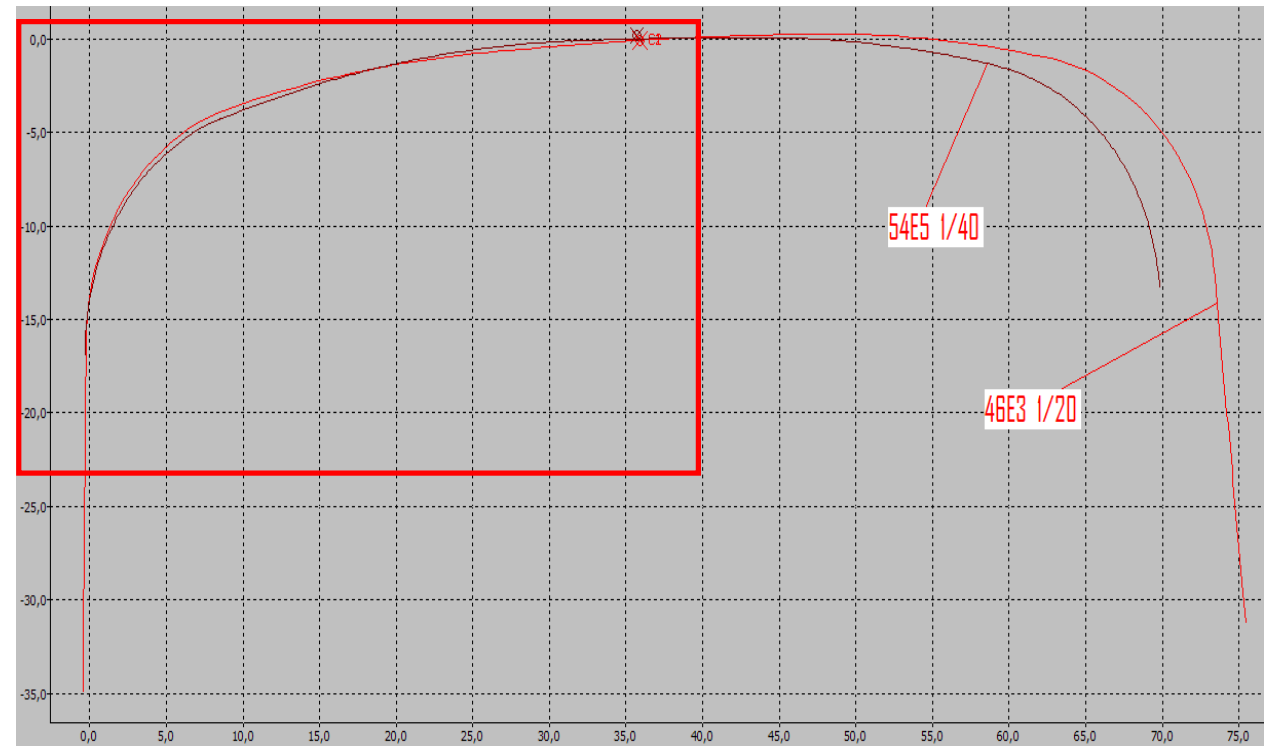

(a) Overall view. 


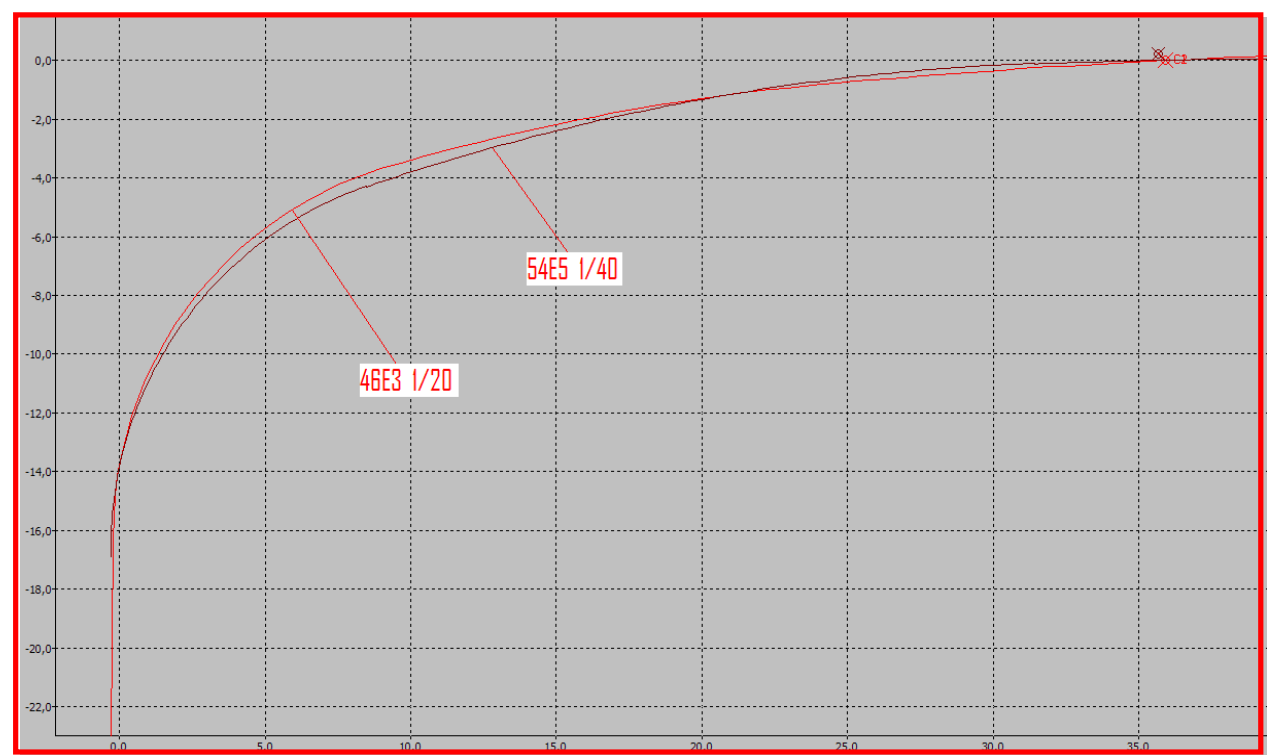

(b) Zoom-in of gauge side.

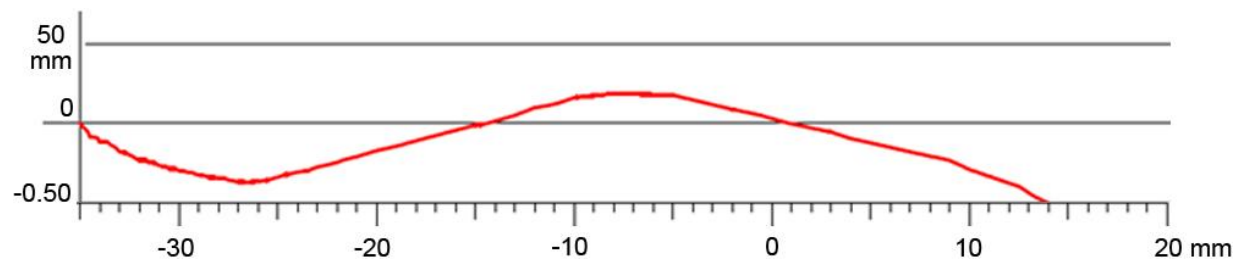

(c) Difference of AHC 54E1 and 46E3 in the local normal direction of the profiles

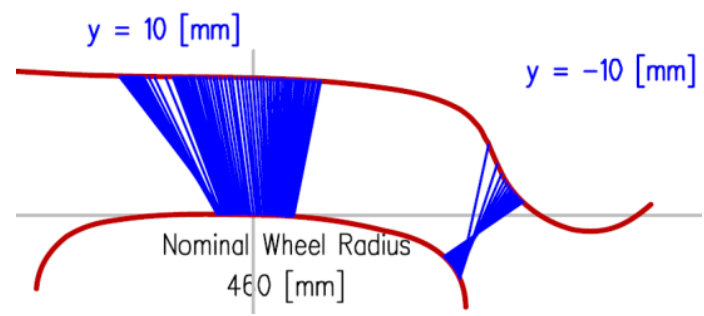

(d) Contact positions between AHC 54E1 and S1002 (coordinate y is defined from the centre of the rail)

Figure 4.5 AHC 54E1 in comparison with 46E3.

Figure 4.3(b) shows the difference between the AHC 54E1 and the original 54E1. A comparison of AHC 54E1 with $46 \mathrm{E} 3$ is shown in Fig. 4.5. The AHC 
$54 \mathrm{E} 1$ has more undercut than $46 \mathrm{E} 3$, as a result of the maximization. Fig. 4.5(d) shows the contact position distribution between the AHC 54E1 and S1002. It looks very much like those of the two $\mathrm{HC}$-free profiles measured in the field shown in Fig. 4.1(c) and (d), with the HC-prone zone being free of contact. With the AHC 54E1, the contact is around the centre of the profile, as the design constraint $C$ requires.

One may suggest that one of the above-mentioned $\mathrm{HC}$-free worn profiles could be used as an AHC profile. This might be true if a $\mathrm{HC}$-free worn profile is used for the place where it is formed. But such a worn profile is specific to its local loading, and $\mathrm{HC}$-free worn profiles vary with loading conditions, e.g. radius of the track etc, so that it may not be anti-HC elsewhere. A comparison of the HC-free worn profiles of Figure 4.1(c) and (d) show that the two profiles differ largely. Further, the gauge side of the rail in Figure 4.1(d) has been severely worn; it is not a proper profile any more. The AHC 54E 1 is compared with the measured $\mathrm{HC}$-free profiles and it can be concluded that the $\mathrm{AHC}$ 54E1 is for most of the cases better in terms of anti HC effect, for a variety of loading conditions. It is therefore the best general AHC profile out of that comparison.

A wheelset needs a certain difference in the rolling radii of the left and right wheel-rail contacts to negotiate smoothly through curves (constraints $\mathrm{F}$ to $\mathrm{H}$ ) The difference renders the rolling radius of the outer wheel larger than that of the inner rail, so that the outer wheel traverses a longer distance in each rotation. Notice that the difference is determined not only by the wheel profile itself, but also by the contacting rails. Figure 4.6 shows the difference of rolling radii of the profile of Fig. 4.1(c) and (d) and that of the AHC 54E1. The three profiles are for the left rail in the calculation, while 54E1 is used for the right rail. It can be seen that the difference of rolling radii of the AHC 54E1 is larger than that of the two measured profiles, but smaller than that of 54E1. Since the two measured profiles are typical of the $\mathrm{HC}$-free rails in reality, and $54 \mathrm{E} 1$ is the standard profile, a difference of rolling radii between them will not cause problems. Because the difference is smaller than that of $54 \mathrm{E} 1$, its hunting stability should also not be a problem. The relief of contact at the shoulder and gauge upper corner means that lateral contact force may have to be resisted by flange-gauge face contact, which will lead to a two-point 
contact: one between tread and crown, and the other at the gauge lower corner/gauge face.

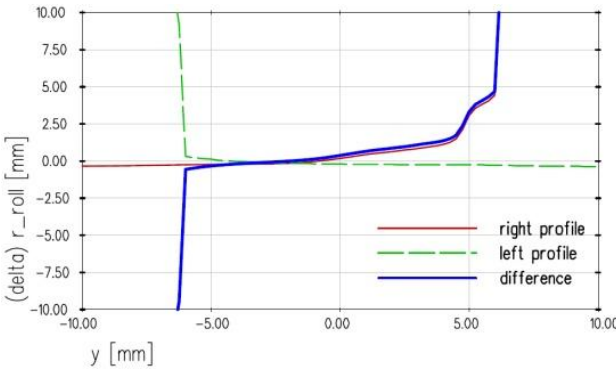

(a)

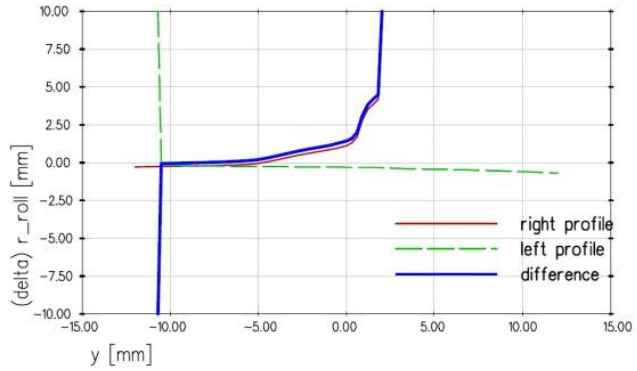

(b)

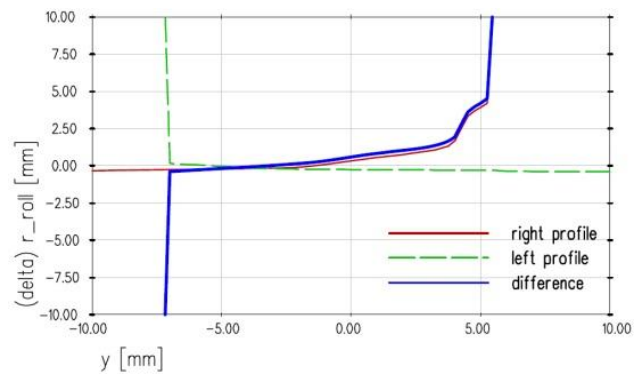

(c)

Figure 4.6 Rolling radii difference with new S1002, assuming that the left rail has different profiles, and the right rail is 54E1. (a) and (b) are for the same measured HC-free worn profiles of Fig. 4.1 (c) and (d) respectively; (c) is for $A H C$ 54E1.

\subsection{Theoretical analyses of the AHC profile}

\subsubsection{Contact stress of the AHC profile}

In this section the contact mechanics performance of the AHC 54E1 profile is analysed and compared with that of the 54E1 profile.

\subsubsection{Measurement and observations}

The rail profiles used in this analysis are new AHC 54E1 and a worn one measured at $\mathrm{HC}$ initiation on a monitored site near Bunnik, the Netherlands. 
There have been a number of points monitored. The data of point $\mathrm{M} 0$ are used. At this point $\mathrm{HC}$ initiated between the 3rd and 4th monitoring, i.e. between 50 MGT and 77 MGT of traffic after the rail was installed, or equivalently between 27 MGT and 54 MGT after the rail was ground (last time) into the AHC 54E1 profile. Figure 4.7 shows the rail before and after $\mathrm{HC}$ initiation. In Figure 4.7(a) some grinding marks were still present at the lower gauge corner and near the gauge face, indicating the stress relief effect of the undercut. The initiated $\mathrm{HC}$ was about $10-15 \mathrm{~mm}$ from the gauge face, see Figure 4.7(b), where the undercut was already worn away at the time of the 3rd monitoring, compare the corresponding location in Figure 4.7(a) and (b). Figure 4.8 shows the new and measured profiles. For a worn 54E1 profile measured at $\mathrm{HC}$ initiation the one used in Section 3.3 is employed here; its comparison with new 54E1 is shown in Figure 4.9. Wear took place mainly between $5-25 \mathrm{~mm}$ measured from gauge face.

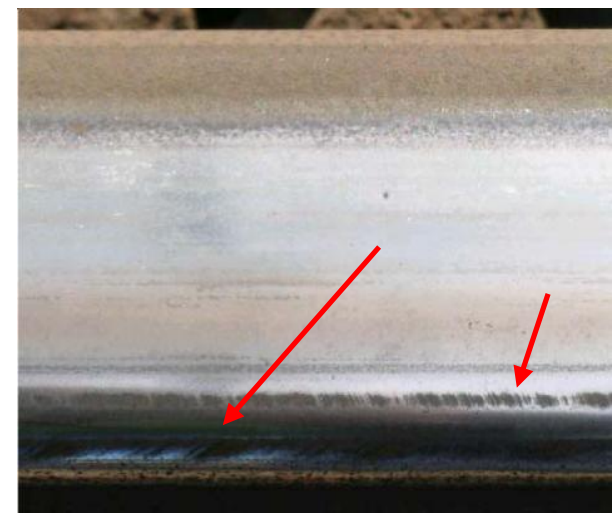

(a)

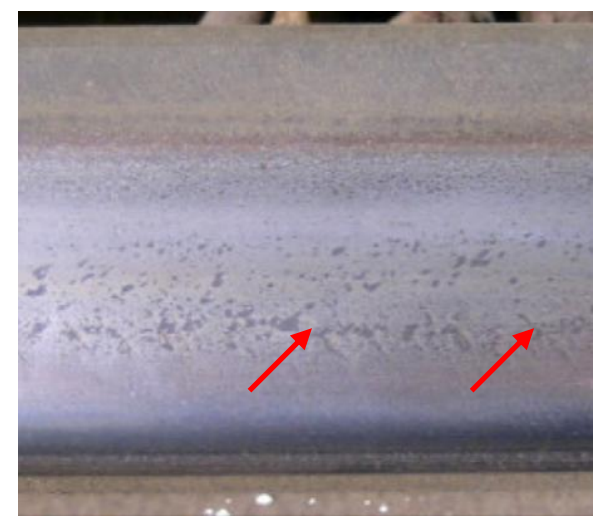

(b)

Figure 4.7 The AHC 54E1 rail at monitoring location MO of the Bunnik monitoring site. (a) The rail at the 3rd monitoring. Remaining marks from the grinding is visible (arrowed). No HC crack was present. (b) The rail at the 4th monitoring. The grinding marks were worn away and $\mathrm{HC}$ cracks were present (some arrowed). 


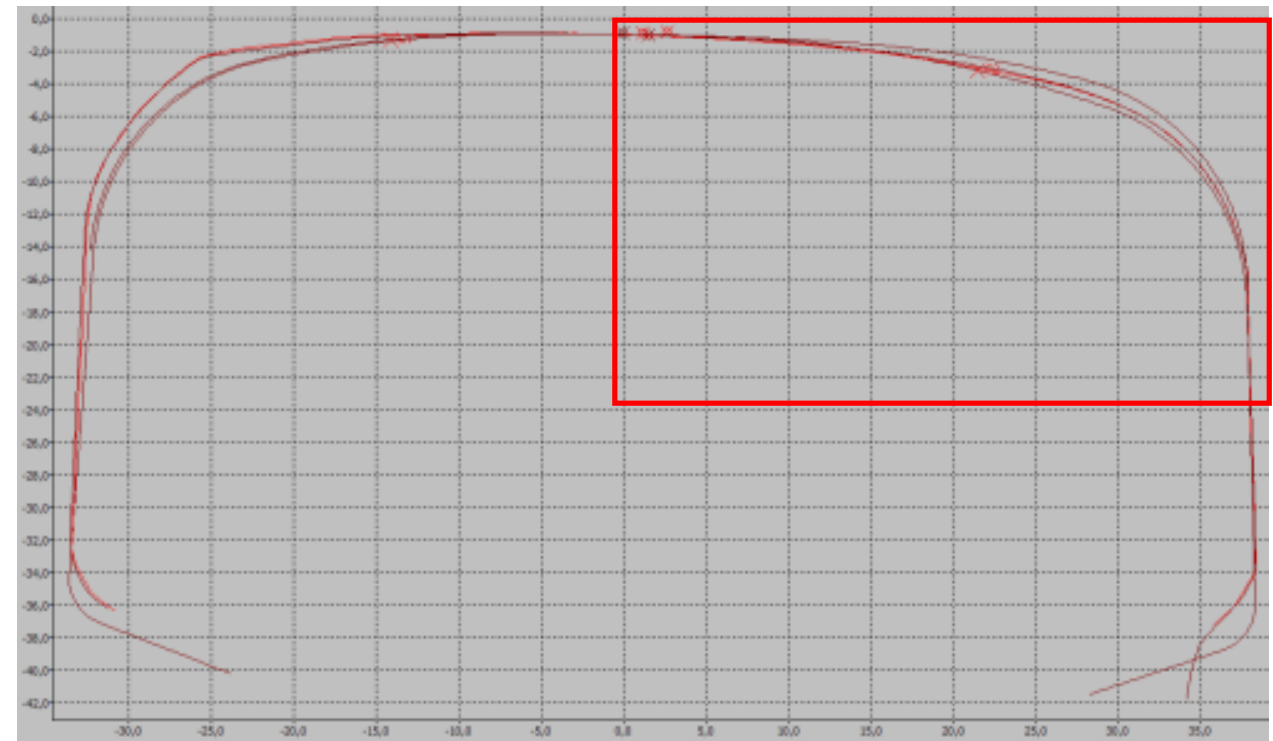

(a) Global view.

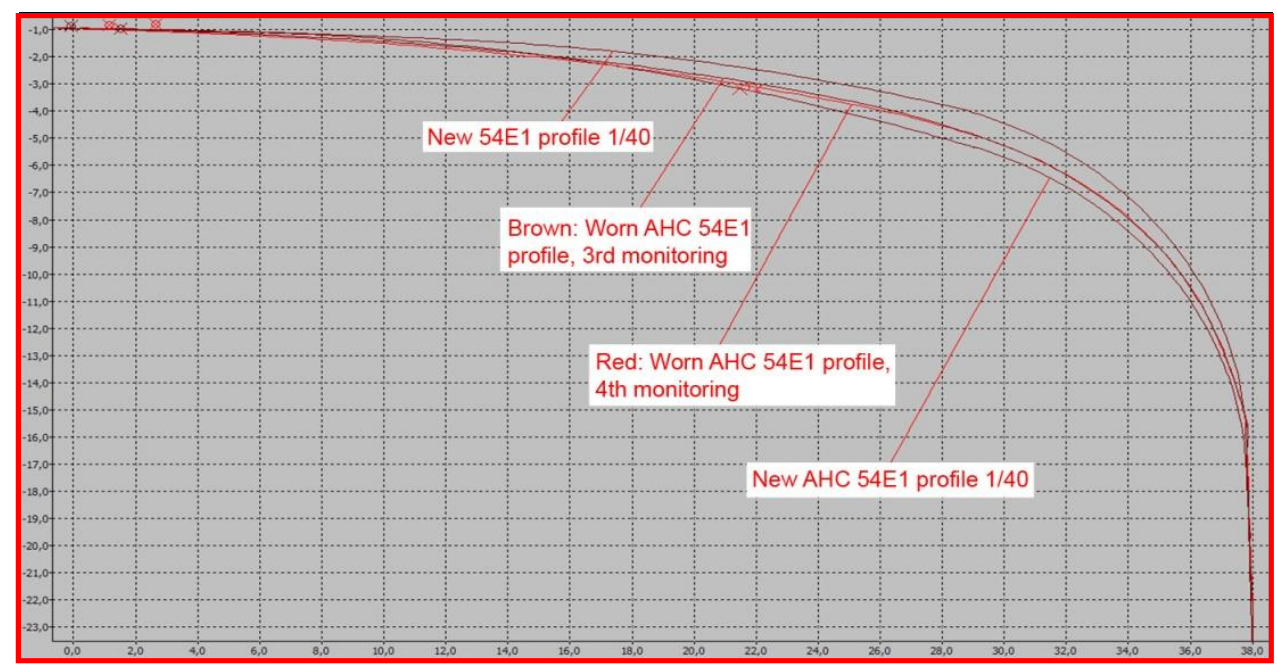

(b) Zoom-in of gauge side.

Figure 4.8 Worn AHC 54E1 profile measured at M0 in comparison with new 54E1 and new AHC 54E1 (i.e. 54E5) profiles. Units of abscissa and ordinate are $\mathrm{mm}$. For comparison the profiles are aligned in such a way that they coincide in the middle of the rail top and at the gauge face. 


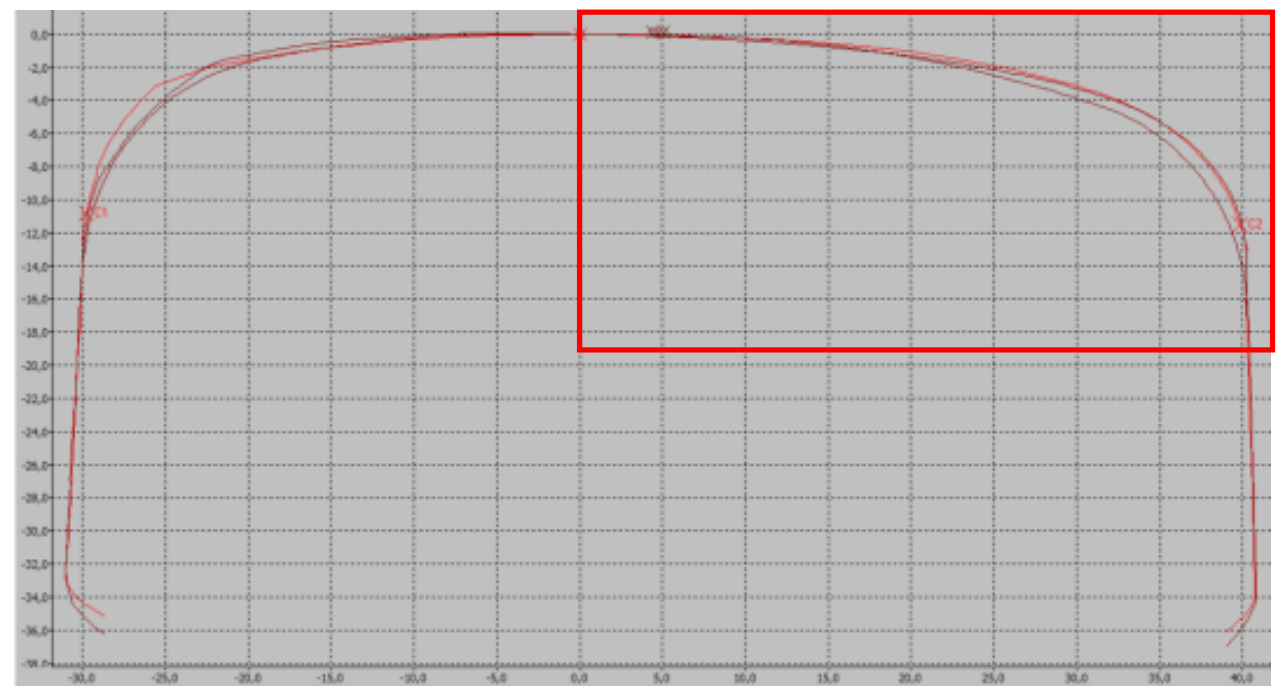

(a) Overall view.

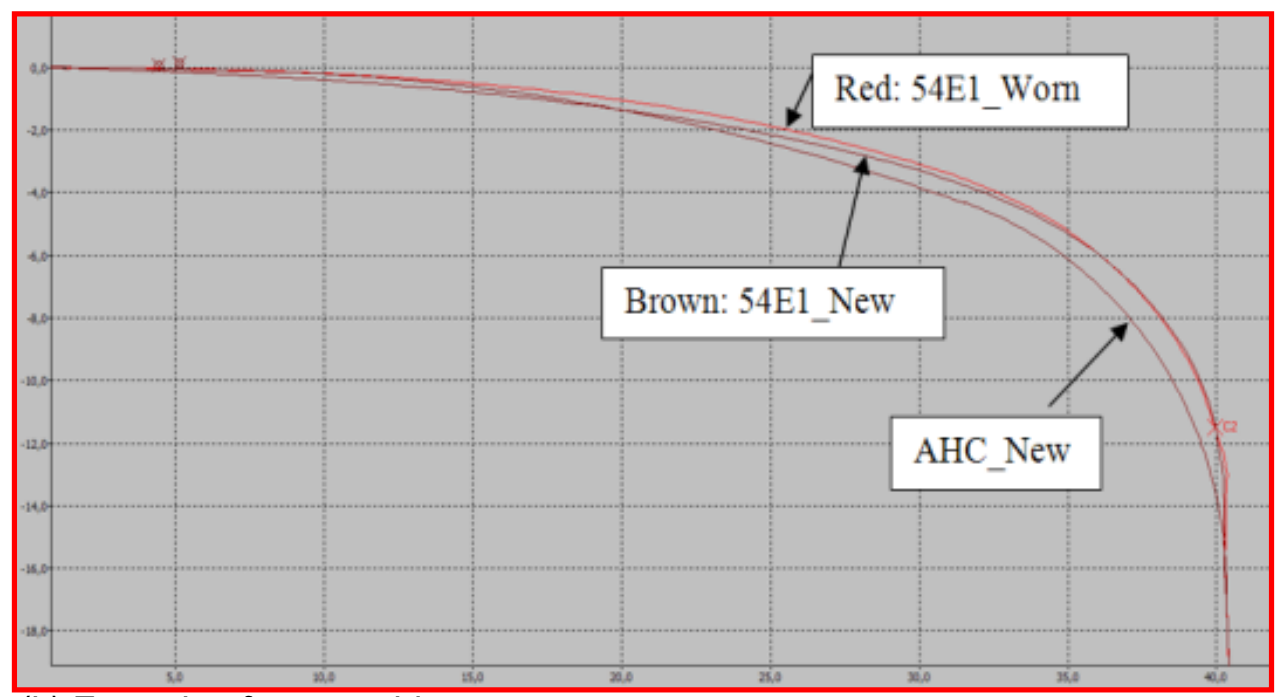

(b) Zoom-in of gauge side.

Figure 4.9 The measured worn 54E1 profile in comparison with new 54E1 and AHC 54E1 profiles.

Two wheel profiles are used: new S1002, and a worn S1002 measured after 1.5 years in service from a mainstream VIRM double-decker train of the Dutch Railways, see Fig. 4.10. The wear occurred mainly at the flange. Wheelsets 
are usually re-profiled in the Dutch Railways more frequently than every 1.5 years, thus most of the wheel profiles in service are between the new and the selected worn profiles. In other words, results calculated with these two profiles may roughly be considered as the lower and upper bounds of what may happen with all new or worn S1002 wheels.

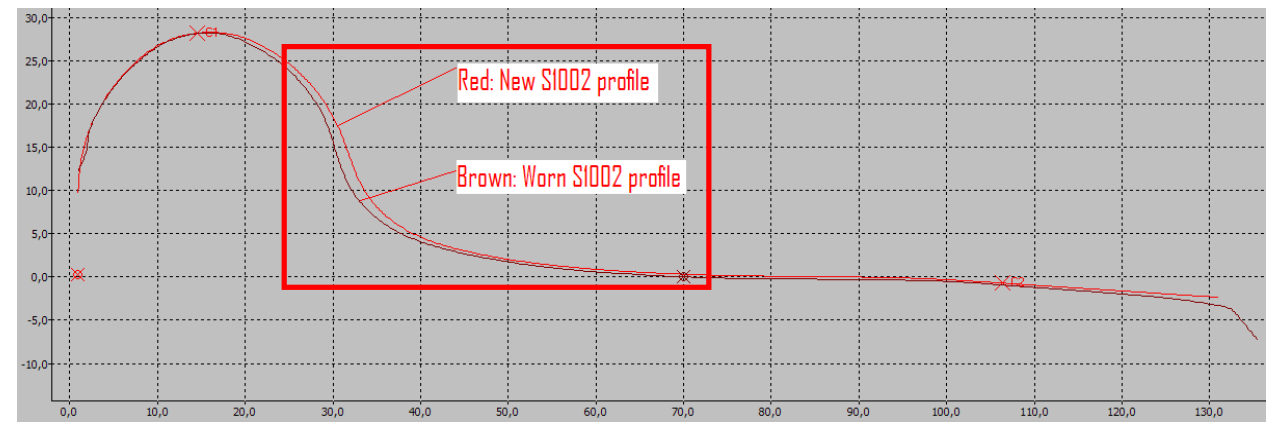

(a) Overall view.

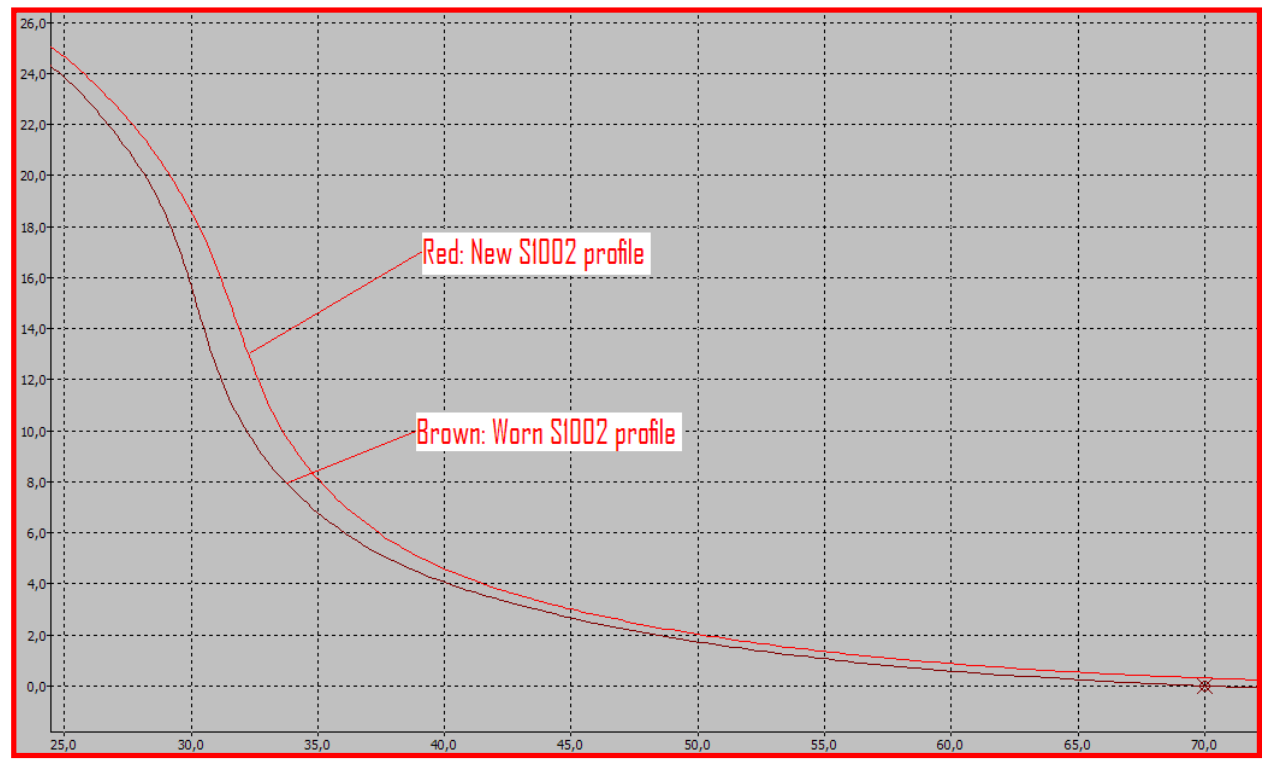

(b) Zoom-in of the flange part.

Figure 4.10 Wheel profiles 


\subsubsection{Calculated maximal shear stress}

Table 4.3 shows the maximal surface shear stress calculated for the 8 combinations of the profiles (4 rails and 2 wheel profiles). Notice for M0 the profile of the $3 \mathrm{rd}$ monitoring, i.e. before $\mathrm{HC}$ initiation, has been used. The applied normal force is $100 \mathrm{kN}$, a typical wheel load for the Dutch railways. The tangential loading is applied through an angle of attack of $0.001 \mathrm{rad}$. This value is chosen as an average for the monitored tracks. The coefficient of friction used is 0.45 , in accordance with the discussion in Section 3.3. Notice that gauge face is excluded in the comparison because the slip there is large due to the large spin so that wear dominates and any embryonic cracks will be removed by wear and no mature crack can form.

Table 4.3 Comparison of the maximal shear stress $\tau_{\max }$

\begin{tabular}{|l|c|c|c|c|c|c|}
\hline & \multicolumn{3}{|c|}{ S1002 New } & \multicolumn{3}{c|}{ S1002 Worn } \\
\hline & $\begin{array}{c}\tau_{\max } \\
(\mathrm{GPa})\end{array}$ & $\begin{array}{c}\mathrm{Y}_{\mathrm{g}}{ }^{*} \\
(\mathrm{~mm})\end{array}$ & $\begin{array}{c}\delta_{0} \\
(\mathrm{Deg})\end{array}$ & $\begin{array}{c}\tau_{\max } \\
(\mathrm{GPa})\end{array}$ & $\begin{array}{c}\mathrm{Y}_{\mathrm{g}} \\
(\mathrm{mm})\end{array}$ & $\begin{array}{c}\delta_{0} \\
(\mathrm{Deg})\end{array}$ \\
\hline 54E1_New & 0.83 & 7.4 & 23 & $\mathbf{1 . 1 6}$ & $\mathbf{9 . 3}$ & 16 \\
\hline 54E1_Worn & 0.71 & 7.2 & 23 & 0.7 & 10 & 20 \\
\hline AHC 54E1_New & 0.51 & 27 & 4.9 & $\mathbf{0 . 3 1}$ & $\mathbf{2 5}$ & $\mathbf{6 . 9}$ \\
\hline AHC 54E1_Worn & 0.68 & 7.1 & 29 & 0.67 & 11 & 16 \\
\hline
\end{tabular}

${ }^{*} Y_{g}$ is the distance from the gauge face

\subsubsection{Contact between new rails and worn $\mathrm{S} 1002$}

Fig. 4.11 shows the situation of contact between the new AHC 54E1 and worn S1002. For comparison the solution for contact between new 54E1 and the same wheel profile is given in Fig. 4.12. The frictional power density is the product of local surface shear stress and the corresponding micro-slip. Obviously it is zero in area of adhesion. For each case 3 wheel-rail contact positions are calculated: The left columns are for contact in the middle of rail, which corresponds to the situation on straight tracks or in curves of very large radius. In the central columns are the situations in which the shear stress is the highest, shown in bold letters in Table 4.3. The right columns are for contact at the gauge face. It can be seen that: 
A. Towards the gauge side, the contact areas of AHC 54E1 are larger than those of 54E1. This can be seen by comparing the middle and right plots of Figures 4.11(a) and 4.12(a)

B. Consequently the maximum pressure, shear stress and frictional power density of 54E1 are all higher towards the gauge corner than those of AHC 54E1, compare the corresponding middle and right columns of Figures 4.11 and 4.12 .

C. Compared to $54 \mathrm{E} 1$, the maximal shear stress $\tau_{\max }$ of AHC $54 \mathrm{E} 1$ is shifted from the HC-prone area to the crown, at $Y_{g}=25 \mathrm{~mm}$. For $54 E 1$, it is at $Y_{g}=9.3 \mathrm{~mm}$ from the gauge face.

$D$. Because of the change in the location of the maximal shear stress, the contact angle at the corresponding point of rigid-body contact $\delta_{0}$ is reduced from $16^{\circ}$ to $6.9^{\circ}$. This will reduce the spin significantly. Notice that for new $\$ 1002$ the reduction in $\delta_{0}\left(4.9^{\circ}\right)$ is even larger, see Table 4.3.

E. Consequently $\tau_{\max }=0.31 \mathrm{GPa}$ of AHC $54 \mathrm{E} 1$ is reduced to only about a quarter of that of $54 \mathrm{E} 1\left(\tau_{\max }=1.16 \mathrm{GPa}\right)$.

F. For AHC 54E1, the contact jumps from the rail head to the gauge face when contact is shifted towards the flange part, owing to the relief of the $\mathrm{HC}$-prone area. The two-point contact in the right plot of Figure 11(a) indicates discontinuity of the contact transition. This discontinuity is reflected by the rusty grinding marks in Figure $4.7(\mathrm{a})$, which still existed after 27 GMT of wheel passages. For 54E1 the transition of the contact location from the crown to the gauge face is gradual.

$G$. The frictional power density at the gauge face (the right column) is much higher than elsewhere. This agrees with the fact that at gauge face the wear rate is higher so that embryonic cracks are removed. 

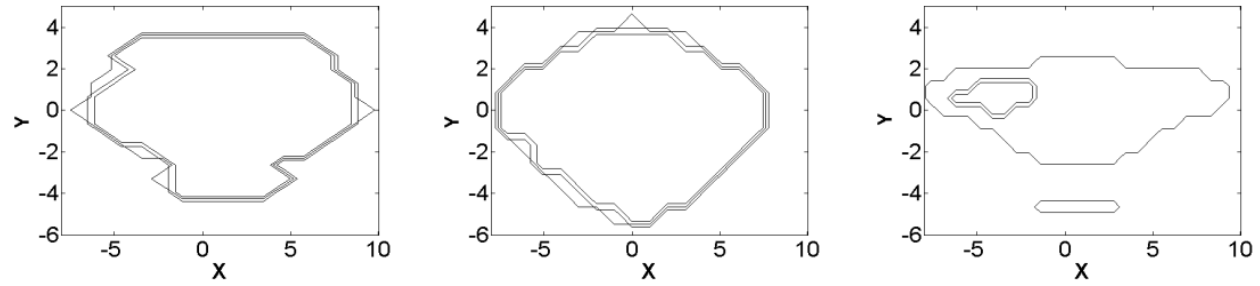

$$
y_{g}=30
$$

$y_{g}=25$

$y_{g}=0.89$

(a) The contact area
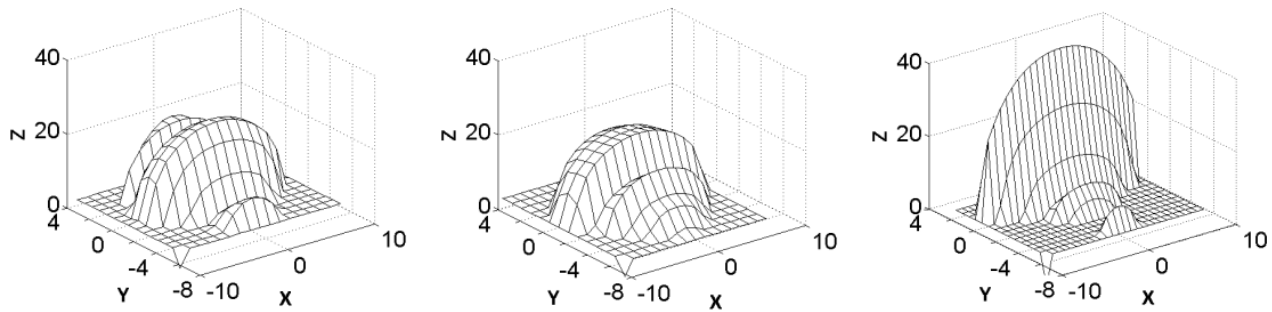

(b) Normal pressure
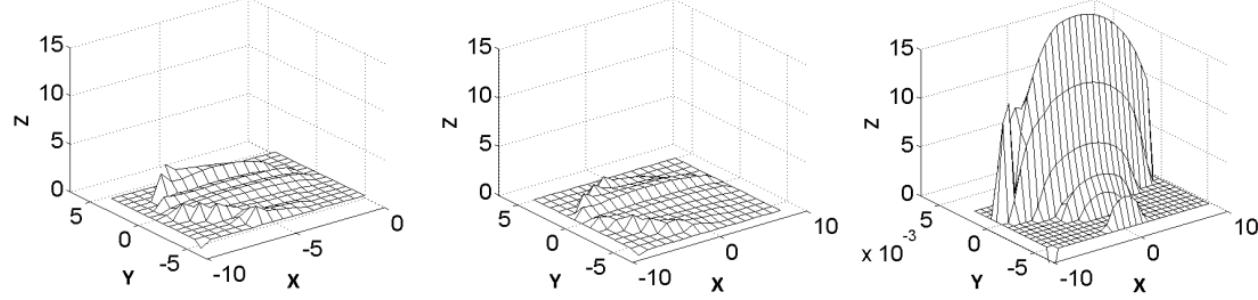

(c) Magnitude of tangential tractions
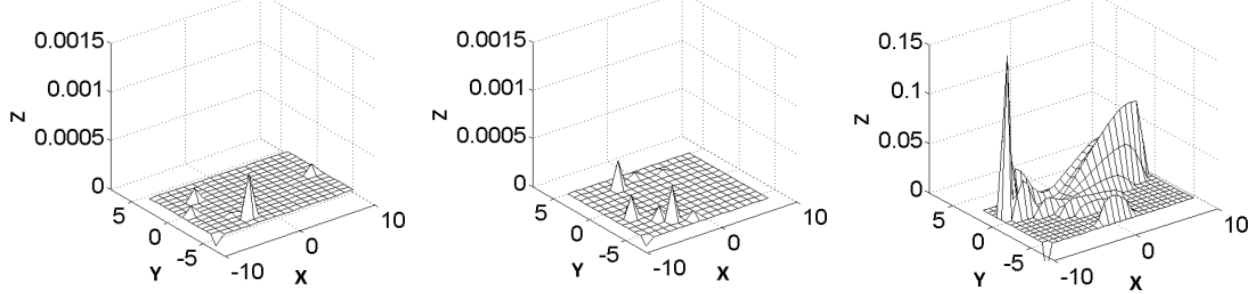

(d) Frictional power density

Figure 4.11 Contact conditions of new AHC 54E1 with worn S1002. The left, central and right columns correspond to rigid-body contact points at 30.00, 25.00 and $0.89 \mathrm{~mm}$ respectively measured from 
the gauge face. (a) Contact area and its division into area of micro-slip and area of stick. Positive $y$ direction points from the field side to the gauge face. $X$ direction points in the rolling direction. Dimensions in $x$ and $y$ directions are in $\mathrm{mm}$. Enclosed by the single lines is the contact area. Enclosed by the double lines is the area of stick. The area of micro-slip is in the contact area, but outside the area of stick. (b) Pressure. (c) Tangential (shear) stress. The stresses in (b) and (c) are normalized by shear modulus $G=82 \mathrm{GPa}$. (d) Frictional power density, which is the product of the normalized shear stress and the local micro-slip normalized by the rolling velocity. The friction power is zero at location of no micro-slip (i.e. area of stick).
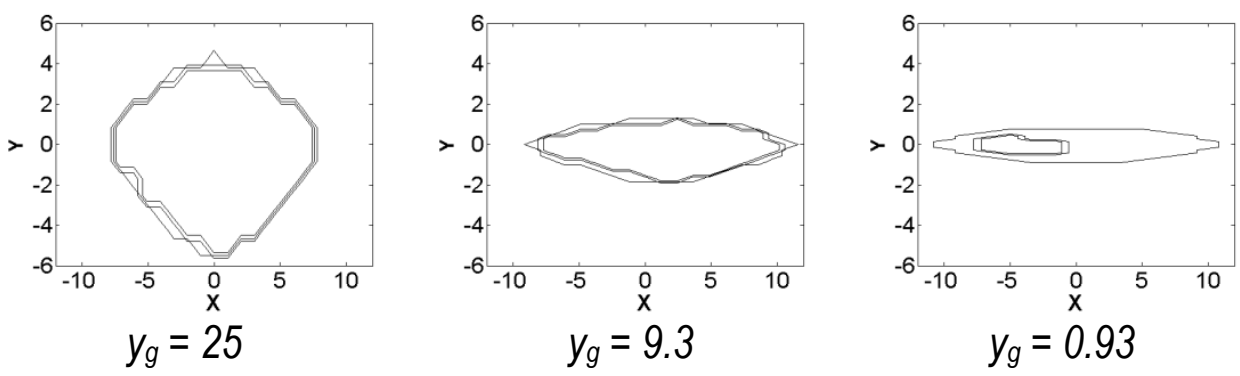

(a) The contact area
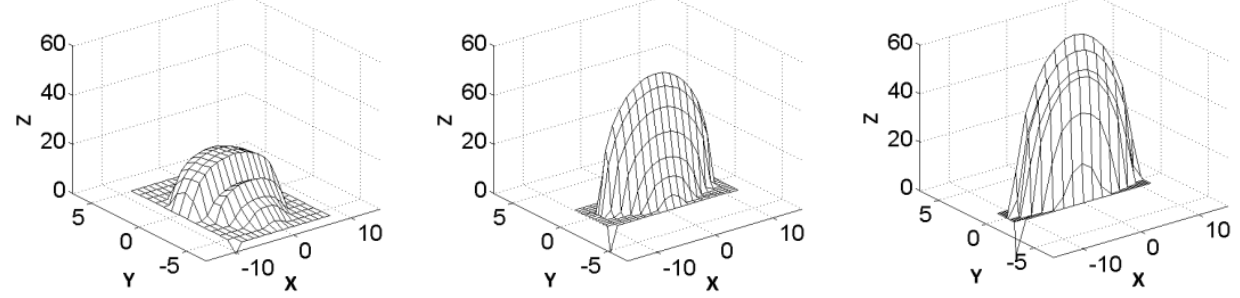

(b) Normal pressure
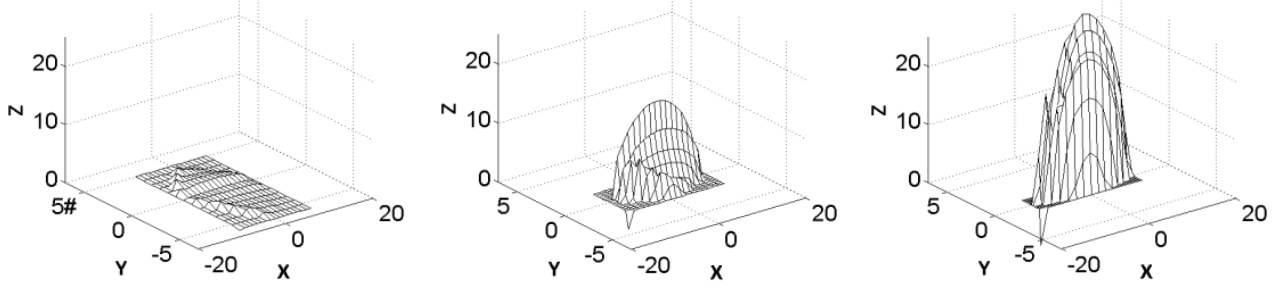

(c) Magnitude of tangential tractions 

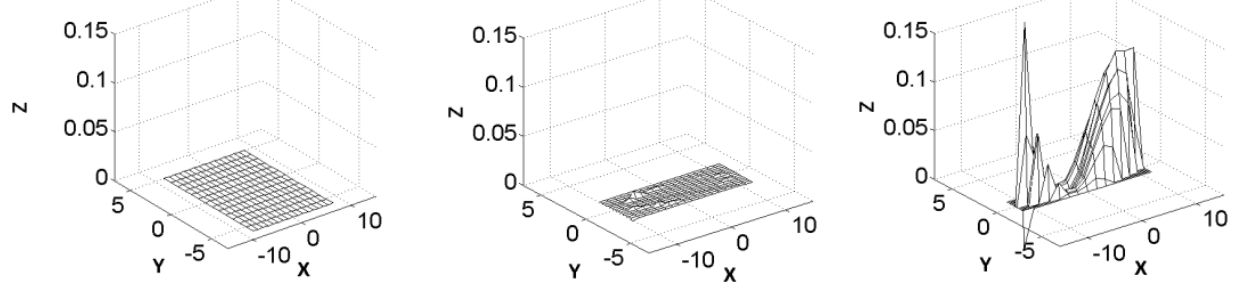

(d) Frictional power density

Figure 4.12 Contact conditions of new 54E1 with worn S1002. The left, central and right columns correspond to rigid-body contact points at 25.00, 9.3 and $0.93 \mathrm{~mm}$ respectively measured from the gauge face. Other convention is the same as Figure 4.11.

\subsubsection{Relation between HC initiation, wear rate and shear stress with worn AHC 54E1}

It can be seen from table 4.3 that the $\tau_{\max }$ at places where cracks are prone to occur, decreases when 54E1_New changes to 54E1_Worn, while on the contrary it increases when AHC 54E1_New is worn into AHC 54E1_Worn. With new AHC 54E1, the $\tau_{\max }$ is lower than the shear strength $0.64 \mathrm{GPa}$ of the R260Mn rail grade, see Sections 3.2 and 3.3. When it is worn close to the tonnage of $\mathrm{HC}$ initiation at the third monitoring, the $\tau_{\max }=0.67 \mathrm{GPa}$ has reached the shear strength. $\mathrm{HC}$ may therefore occur.

Keeping in mind that the $\mathrm{HC}$ has initiated between the $3^{\text {rd }}$ and $4^{\text {th }}$ monitoring, the relation between $\mathrm{HC}$ initiation, wear rate and surface shear stress is examined. It can be seen from Figure 4.8(b) that between the $3^{\text {rd }}$ and $4^{\text {th }}$ monitoring, the least material was worn away between abscissa $28-32 \mathrm{~mm}$, i.e. $Y_{g}=6-10 \mathrm{~mm}$ : in this range the two worn profiles coincide, while on both sides of this, the profile of the $4^{\text {th }}$ monitoring (the red curve) is different from that of the $3^{\text {rd }}$ monitoring. On the other hand it must be noted that in table 4.3 the calculated $\tau_{\max }$ of the worn AHC 54E1 is for the new and worn $\mathrm{S} 1002$ at $\mathrm{Yg}_{\mathrm{g}}$ $=7.1 \mathrm{~mm}$ and $11 \mathrm{~mm}$. Since these two $\mathrm{S} 1002$ profiles represent the two extremes of $\mathrm{S} 1002$ wheels, as discussed above, it may be considered that for all new and worn S1002 wheels passing over this worn AHC 54E1 rail, the $\tau_{\max }$ should occur in the range of $Y_{g}=7.1-11 \mathrm{~mm}$. Taking into account possible error in the measurement of the profiles etc, this location of $Y_{g}=7.1$ 
- $11 \mathrm{~mm}$ for $\tau_{\max }$ is in good agreement with the location of $Y_{g}=6-10 \mathrm{~mm}$ where the rail was the least worn between the $3^{\text {rd }}$ and $4^{\text {th }}$ monitoring. Combining these two ranges, it may be concluded that the vehicle-track system tends to wear the rail the least in the area of $Y_{g}=6-11 \mathrm{~mm}$ between the $3^{\text {rd }}$ and $4^{\text {th }}$ monitoring, while the surface shear stress tends to be the highest there.

It was noticed that the location of the initiated $\mathrm{HC}$ cracks observed at the $4^{\text {th }}$ monitoring was at about $Y_{g}=10-15 \mathrm{~mm}$, see Figure 4.7(b). This area is in overlap with the above-mentioned area of $Y_{g}=6-11 \mathrm{~mm}$. This implies that the high shear stress, together with the low wear rate has caused the $\mathrm{HC}$ initiation and growth between the $3^{\text {rd }}$ and $4^{\text {th }}$ monitoring. The $\mathrm{HC}$ could have initiated in the overlapped range of $Y_{g}=10-11 \mathrm{~mm}$ and grown further.

\subsubsection{More general observation of HC initiation, wear rate and shear stress}

It is interesting to notice in table 4.3 that except with new AHC 54E1, for all the other 6 cases the $\tau_{\max }$ is found in the range of $Y_{g}=7-11 \mathrm{~mm}$. Further, it can be seen that although the $\tau_{\max }$ varies largely with the new rail profiles, it seems to converge to a value around $0,7 \mathrm{GPa}$ when the rail is worn to a shape of $\mathrm{HC}$ initiation. Recalling that in Chapter 3 , it was found that for the field observation, the $\mathrm{HC}$ initiated in the range of $\mathrm{Y}_{\mathrm{g}}=8-12 \mathrm{~mm}$, with the corresponding $\tau_{\max }$ being around $0.7 \mathrm{GPa}$. This indicates that with $\mathrm{S} 1002$ wheel profiles, new or worn, the $\mathrm{HC}$ initiation stress and location could tend to converge to $\tau_{\max }=0.7 \mathrm{GPa}$ at $\mathrm{Y}_{\mathrm{g}}=7-12 \mathrm{~mm}$, as indicated in table 4.3. Notice for the lab test of Section 3.2, the location of the $\mathrm{HC}$ initiation was probably at $\mathrm{Y}_{\mathrm{g}}=7-8 \mathrm{~mm}$, with $\tau_{\max }$ close to $0.64 \mathrm{GPa}$. The difference from the field observations could be due to the closed controlled loading condition.

This location of the profile $\mathrm{Y}_{\mathrm{g}}=7-12 \mathrm{~mm}$ seems therefore to be the most $\mathrm{HC}$ vulnerable region of the rail. Looking back at Figure 4.3(b), it can be seen that as a measure to elongate the anti $\mathrm{HC}$ life of the AHC 54E1 profile, the AHC $54 \mathrm{E} 1$ has an undercut with respect to the 54E1 profile of, at the most, about $Y_{g}=9 \mathrm{~mm}$. $Y_{g}$ of $9 \mathrm{~mm}$ is about at the mean of $7-12 \mathrm{~mm}$. The design of the $\mathrm{AHC} 54 \mathrm{E} 1$ is therefore optimal in the sense of stress relief. 


\subsubsection{Some conclusions}

From the discussion it can be concluded that:

- The AHC 54E1 profile can significantly improve the contact mechanics performance of the wheel-rail rolling contact. In this way we can retard $\mathrm{HC}$ initiation, as the field monitoring has shown.

- By avoiding contact in the HC-prone part of the profile, the maximum surface shear stress is greatly reduced, mainly owing to the decrease in contact angle, thus spin. The increase in contact area leads to lower pressure, which also contributed to the shear stress reduction.

- Due to wear the undercut gradually disappears and as a consequence the anti $\mathrm{HC}$ capability is lost and $\mathrm{HC}$ may occur.

- Field observations and lab test indicate that $\mathrm{Yg}=7-12 \mathrm{~mm}$ is the location prone to $\mathrm{HC}$ initiation.

- Maximum surface shear stress is an effective criterion for the determination of $\mathrm{HC}$ initiation location.

- At the HC-prone location of $\mathrm{Yg}=7-12 \mathrm{~mm}$, the maximum surface shear stress $\tau_{\max }$ calculated with a coefficient of friction 0.45 seems to be a reasonable indication for $\mathrm{HC}$ initiation. The chance for $\mathrm{HC}$ to initiate and grow there would be high if $\tau_{\max }$ is close to or exceeds the shear strength of the material.

\subsubsection{Analysis of running performance}

The running stability of the AHC 54E1 profile is checked by vehicle dynamic simulations. In Fig. 4.13 the position of the contact point on the AHC 54E1 is shown when a worn wheel on the typical Dutch IRM train is perturbed laterally at the instant 0 second. Two typical cases are simulated. The first case is an IRM vehicle moving along a length of straight track followed by a curve of 200 $\mathrm{m}$ radius without superelevation; the speed is $35 \mathrm{~km} / \mathrm{h}$. This corresponds to the situation when a train moves along a turnout. In the second case the vehicle travels first on a straight track, then in a curve of $2462 \mathrm{~m}$ radius, with a superelevation of $57 \mathrm{~mm}$ and the typical Dutch main line speed of $140 \mathrm{~km} / \mathrm{h}$. In both cases it can be observed that on the straight track the perturbation causes an oscillation of the contact positions, but the oscillation decays after a few seconds. In the first case the wheelset enters the curve after 15 
seconds; the large centrifugal force shifts the contact point to the gauge corner. Although this lateral shift is also a perturbation, it does not cause any oscillation of the lateral motion of the wheelset because the lateral force is large enough to suppress such oscillation. For the second case the vehicle enters the curve after 10 seconds. The centrifugal force causes a shift of the contact position towards the gauge side. This perturbation leads to an oscillation of the wheelset motion, which decays quickly. It can therefore be concluded that the AHC 54E1 profile should not cause a running stability problem. This is in agreement with the expectation, because the difference of rolling radii of the $\mathrm{AHC} 54 \mathrm{E} 1$ is lower than that of 54E1.

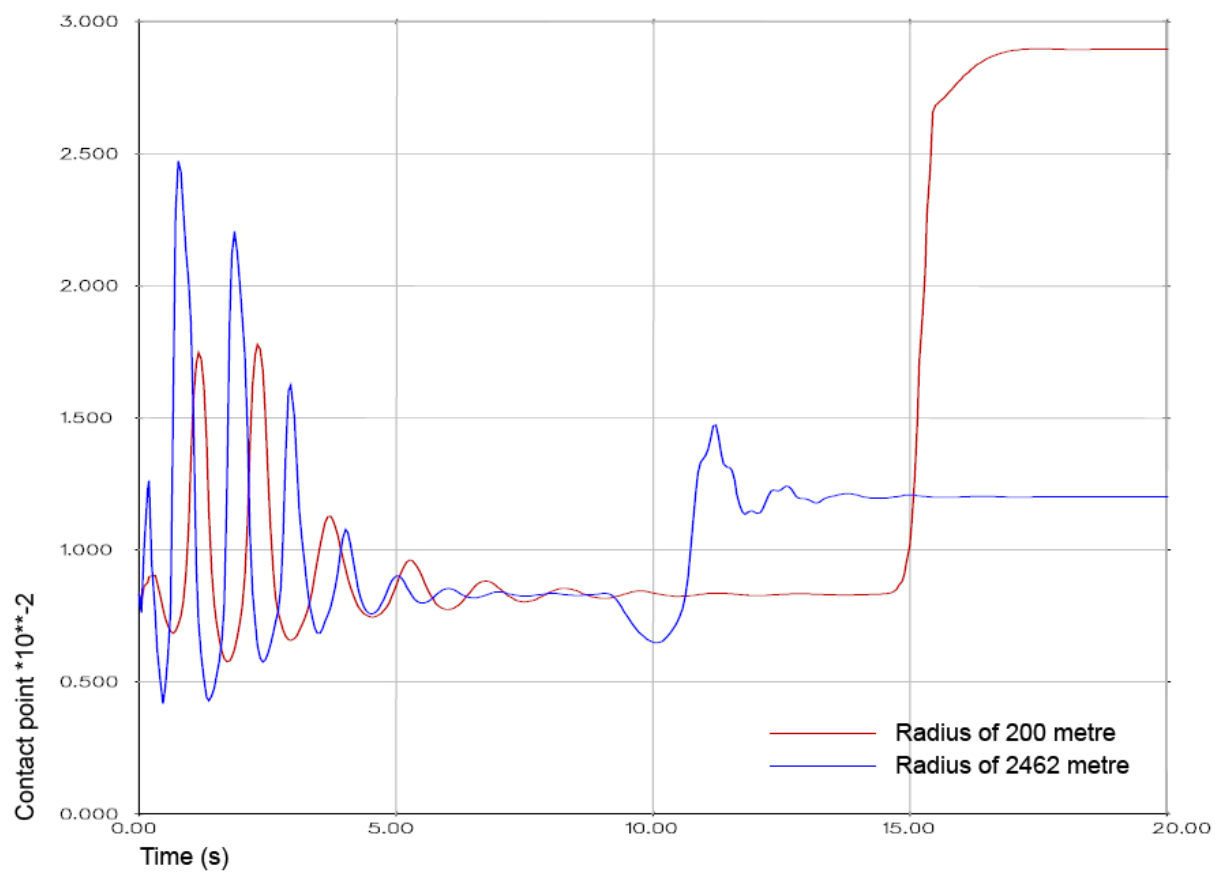

Figure 4.13 Running stability of the AHC 54E1 profile on straight and curved tracks of small and large radii. 


\subsection{In-service performance monitoring of the AHC profile}

\subsubsection{RCF and wear}

The performance of the AHC 54E1 was evaluated by monitoring in service in a curve at Bunnik. It had a radius of $2445 \mathrm{~m}$, with a cant deficiency of $60 \mathrm{~mm}$. The traffic was mixed with international high speed trains like ICE, intercity trains and local passenger trains, as well as freight traffic. The traffic speed ranged from $90 \mathrm{~km} / \mathrm{h}$ to $140 \mathrm{~km} / \mathrm{h}$. This location was chosen because severe $\mathrm{HC}$ had been experienced there, and because of the typical mixture of traffic.

There were two tracks, where on both tracks the traffic was unidirectional. Traffic types and tonnage on these two tracks were the same. The rail grade was R260Mn, which has most frequently been used in the ProRail network. The AHC 54E1 profile was brought by grinding to the high rail of one of the tracks, referred to as Track $A$ hereinafter. On the other track, called Track B in the sequel, 54E1 profile rail was used on the high rail for comparison. On track A 5 points with the AHC 54E1 profile were monitored. On track B 3 points with the $54 \mathrm{E} 1$ profile were monitored.

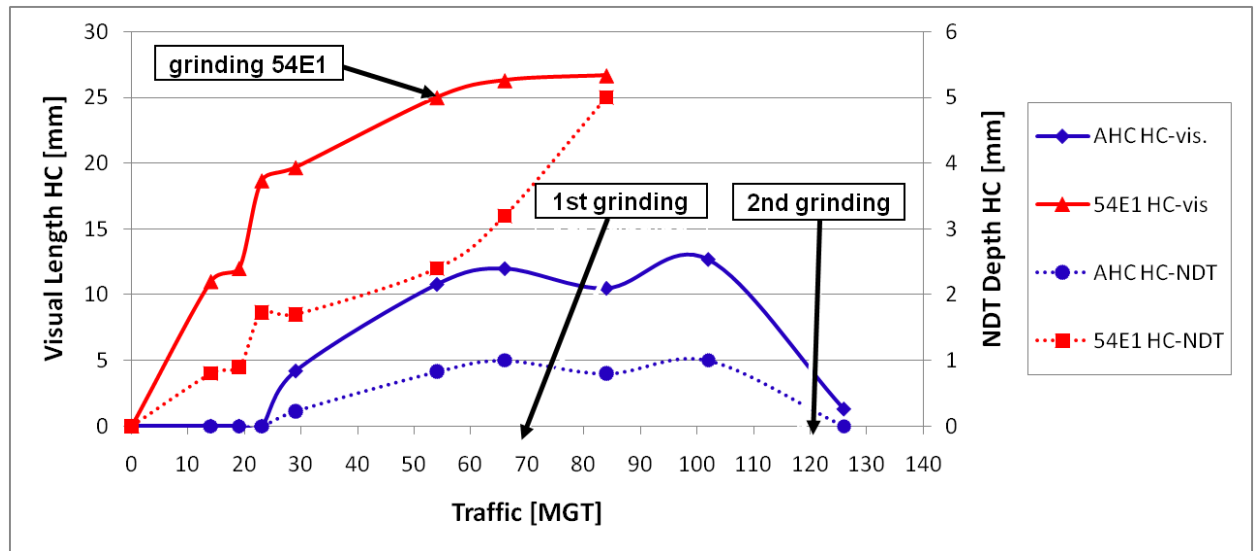

Figure 4.14 Comparison of the $\mathrm{HC}$ development in the $\mathrm{R} 260 \mathrm{Mn}$ rail with $\mathrm{AHC}$ $54 E 1$ profile at track $A$, against the $R 260 M n$ rail with $54 E 1$ profile at the opposite track $B$. Abscissa is the accumulative MGT. Ordinates are visual length of the $\mathrm{HC} \mathrm{HC}$-vis and the depth of $\mathrm{HC}$ detected by non-destructive testing HC-NDT. 
Figure 4.14 shows the $\mathrm{HC}$ development of the two profiles with traffic. Notice that no $\mathrm{HC}$ data is available for the $54 \mathrm{E} 1$ profile after about $80 \mathrm{MGT}$ because the cracks were too deep and the rail had to be removed.

Figure 4.14 shows that:

- The AHC 54E1 can delay HC initiation by about 22 MGT.

- For both visual length of the $\mathrm{HC}$ cracks and their non-destructive test (NDT) depth, the growth rate of AHC 54E1 is much lower than those of $54 \mathrm{E} 1$.

- In the AHC 54E1 profiled rail the visual $\mathrm{HC}$ length grew with approx. $0.25 \mathrm{~mm} / \mathrm{MGT}$ by the 1 st grinding at $70 \mathrm{MGT}$, whereas in the 54E1 profile rail the visual $\mathrm{HC}$ length grew with approx. $0.45 \mathrm{~mm} / \mathrm{MGT}$ by the (1st and only) grinding at 55 MGT.

- In AHC 54E1 profiled rail the depth of the HC's grow with approx. $0.021 \mathrm{~mm} / \mathrm{MGT}$ by the 1 st grinding, whereas in 54E1 profile rail the depth of the HCs grow with approx. $0.042 \mathrm{~mm} / \mathrm{MGT}$ by the $1^{\text {st }}$ grinding.

- The $1^{\text {st }}$ grinding for the AHC 54E1 could effectively suppress the growth of the $\mathrm{HC}$, and the $2^{\text {nd }}$ grinding can remove the cracks completely, whilst the grinding for the 54E1 is ineffective, even though the grinding was earlier in terms of MGT, because the cracks were too deep.

The general outcome of the monitoring is that grinding $\mathrm{R} 260 \mathrm{Mn}$ rail into an AHC 54E1 profile delays the HC formation and once the first HCs have arisen, it also decreases the "HC crack growth rate" as well in length as in depth by a percentage of about $45-50 \%$. The AHC profile disappears due to wear, so that it has to be restored with cyclic grinding to maintain its effectiveness. 


\subsection{Performance of the AHC profile in large- scale application}

\subsection{1 $\mathrm{HC}$ and the associated cost reduction}

The designed AHC profile has been implemented since July 2004 on the upper rail of $\mathrm{HC}$ sensitive curves (radius $\mathrm{R}: 0<\mathrm{R}<3000 \mathrm{~m}$ ) on the Dutch railway network. For existing rails the profile has been brought to the rail head by grinding, and for new rails the profile is made during manufacturing. Its effectiveness now becomes obvious: together with the accompanying cyclic grinding policy started in 20052. HC in 2008 has been reduced by $50 \%$ compared to the situation of 2005 , and by about $70 \%$ if compared to that of 2004 when $\mathrm{HC}$ was the most widespread, see Figure 4.15. It can be seen that since 2004, the amount of HC has been steadily decreasing. The aforementioned actions of grinding the $\mathrm{AHC}$ profile and steel grades have resulted in a systematic reduction of the total cost of RCF maintenance (renewals and rail replacements) by about 50 million euros a year.

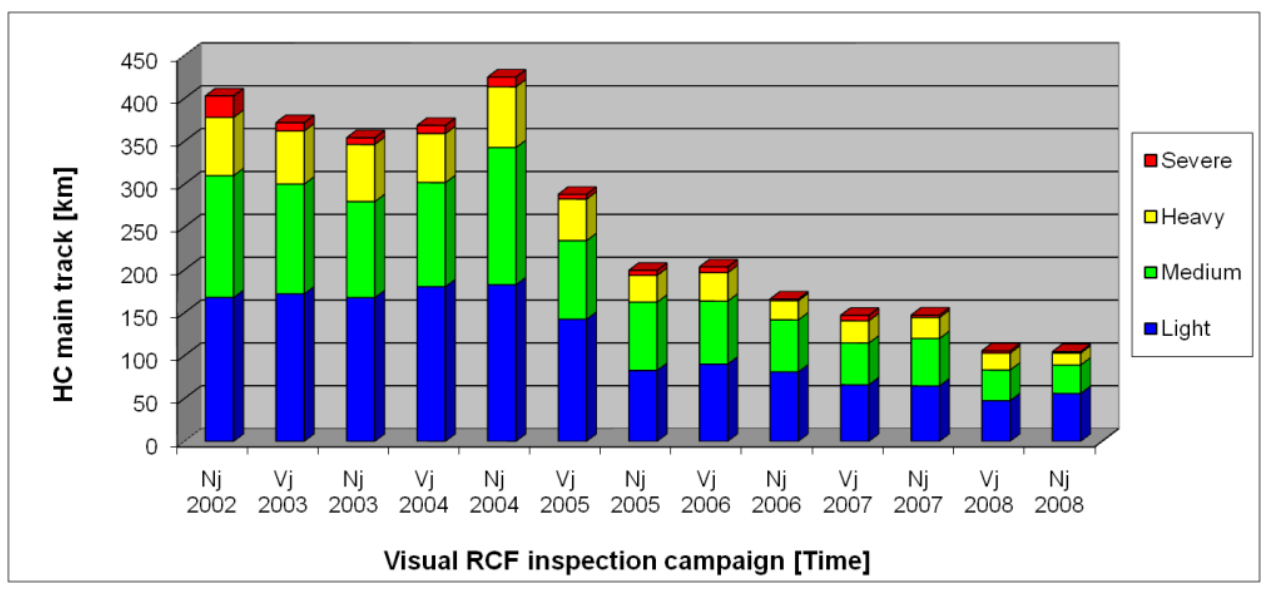

Figure 4.15 $\mathrm{HC}$ defects in plain track (i.e. excluding switches and crossings) in 2002-2008 in the Netherlands. See RCF Monthly Report, January, 2009, ProRail.

2 Use of special rail grades also contributed to the reduction, but that contribution is less than $10 \%$. 


\subsubsection{Stability and comfort}

No negative effect of the AHC 54E1 profile has been observed on the stability and ride comfort of the trains.

\subsubsection{Normalization}

The author put forward a proposal to have the AHC profile accepted as a European Standard and it was officially accepted as European Standard EN 13674-1:2009 as the only European AHC profile named 54E5 at 1:40.

\subsection{Conclusions}

The principle of stress relief at the rail shoulder and the upper gauge corner has been proposed for the design of Anti Head Check profiles based on discussions in previous chapters and the observations and statistics presented in this chapter. Subsequently, an AHC profile has been designed in keeping with this proposed principle and taking other factors into consideration. Contact mechanics analysis has shown that the designed profile should, indeed, significantly relieve the surface shear stress and microslip, particularly at the HC-prone area gauge corner whilst maintaining the required ride comfort and running stability. The profile was first tested when in service on a monitored site and it clearly demonstrated benefits with respect to $\mathrm{HC}$ prevention/retardation. The test also indicated that $\mathrm{HC}$ can be prevented when combined with cyclic grinding. This is why the profile has been applied to the entire Dutch rail network. In 2008, in combination with cyclic grinding, the $\mathrm{HC}$ was reduced to $70 \%$ of the peak that occurred in 2004 .

The AHC 54E1 design has been accepted as a European Standard EN 13674-1:2009 as the only European AHC profile named 54E5 at 1:40.

\section{References:}

[1] Hiensch, M. and Watson, A., 2004, ProRail predicts RCF hotspots, Railway Gazette, Vol. 160 no1, pp. 38-40.

[2] prEN 13674-1, 2009, Railway applications - Track - Rail - Part 1: Vignole railway rails, $46 \mathrm{~kg} / \mathrm{m}$ and above, draft. 
[3] Shevtsov, I., 2008, Wheel/rail interface optimization, PhD thesis, Delft University of Technology, The Netherlands.

[4] Zijlmans, P., Wiersma, P.K. and Dirks, B., 2006, Optimalisatie AHC profielen, DeltaRail, Utrecht, The Netherlands. 


\section{Chapter 5 Conclusions and further research}

\subsection{Conclusions}

There are two major types of Rolling Contact Fatigue (RCF) in railway rails, i.e. Head Checking $(\mathrm{HC})$ and Squats. After a brief comparison, it is concluded that they are different with respect to locations of occurrence, loading conditions and initiation mechanisms, so that distinctive treatments are required for them. This thesis focuses on $\mathrm{HC}$.

The literature review shows that although rail RCF seems to have much in common with structural fatigue and with RCF of machine elements, it differs from the common fatigue phenomena because the wheel-rail system suffers from high surface shear stresses and as a result the cracks are initiated at the surface (not subsurface). The cracks may develop into $\mathrm{HC}$ if the wear rate is not high enough to suppress crack growth.

Besides the coefficient of friction (COF), there are another two factors that can cause the high shear stress and possible accompanying (micro-)slip: i.e. loads and contact geometry. Based on discussions of the findings, a conclusion was reached that the most effective approach for rail infrastructure managers is to optimize the contact geometry in terms of implementability, cost and time span. This is why this thesis focuses on optimization of the rail profile, which on the Dutch railway network is predominantly 54E1, to prevent or retard $\mathrm{HC}$ from occurring.

Chapter 3 therefore focuses on a quantitative relationship between $\mathrm{HC}$ occurrence, contact geometry, stresses and micro-slip. $\mathrm{HC}$ initiation has been reproduced under controlled laboratory conditions on a full-scale wheel-rail 
test rig. At the same time, $\mathrm{HC}$ initiation has been monitored in the field under service conditions. Using a non-Hertzian rolling contact solution method, it is found that $\mathrm{HC}$ initiation location tends to develop at a certain distance from the gauge face, $7-12 \mathrm{~mm}$, where the surface shear stress is the highest as a result of the large geometrical spin in the wheel-rail contact.

Optimization focuses on the gauge part of the profile, with the objective of relieving the maximum shear stress. A conclusion was reached after statistical analysis of the anti $\mathrm{HC}$ performance of the 54E1 and 46E3 profiles that this objective could be achieved with an undercut of the 54E1 profile at gauge corner, with the maximum undercut at about $9 \mathrm{~mm}$ from the gauge face. An optimal Anti Head Checking profile (AHC 54E1) has been designed, taking into account a number of constraints arising from the already existing $54 \mathrm{E} 1$ profile, from vehicle running performance, track structure and contact mechanics.

This designed profile has shown its merits:

(1) By avoiding contact in the HC-prone part of the profile, the maximum surface shear stress is greatly reduced, mainly owing to the decrease of spin in the contact.

(2) A monitored field test shows that the AHC 54E1 profile can largely delay the $\mathrm{HC}$ formation and once $\mathrm{HC}$ arises, it also decreases the crack growth by a percentage of about $50 \%$. The AHC profile changes due to wear, so that it has to be restored with cyclic grinding to maintain its effectiveness (see also Appendix D).

(3) Large-scale application on the Dutch railway network shows that

- $\mathrm{HC}$ in 2008 was reduced by about $70 \%$ with respect to 2004 when $\mathrm{HC}$ was the most widespread.

- The systematic reduction of the associated maintenance costs is in the order of 50 million euros per year.

At the same time, no negative influence of the AHC 54E1 on the running performance of the trains has been reported, either from the monitored site or from the large-scale application.

As a result, the AHC 54E1 profile has been normalized as a standard European rail profile named 54E5 at 1:40, see prEN 13674-1, June, 2009. 


\subsection{Further research}

\subsubsection{Optimal grinding interval}

No matter how a profile is designed, it will eventually become worn. Findings of this thesis indicate that with the $\mathrm{S} 1002$ wheel profile and $\mathrm{R} 260 \mathrm{Mn}$ rail grade, the rail profiles seem to tend to wear into a shape in which $\mathrm{HC}$ initiates in the range of $7-12 \mathrm{~mm}$ from the gauge face. The discussion in section 4.3.1 has shown that the AHC $54 \mathrm{E} 1$ should be regularly restored by grinding to maximally make use of its advantage. The question is, what should be the grinding intervals?

Attempts have been reported in determining a grinding interval based on the wear index $T \cdot \gamma$, see Zacher (2009). But such an approach is too rough because it cannot properly consider the large varying geometric spin at the gauge corner.

Grinding interval depends on the wear rate of rail profile and the wear rate is a function of the frictional work and material properties. Assuming that rail grade is fixed, a grinding interval will then be dependent upon the frictional power, which can be computed from the loading conditions as analysed in section 4.2.1. Because for different curved tracks the loading conditions can vary largely in terms of curve radius, superelevation, tonnage, types of traffic etc, the wear rate may change significantly from curve to curve. There is an optimal grinding interval for each curved track, and it can be estimated based on a calculation of frictional work.

$\mathrm{HC}$ occurrence is, however, a result of imbalance between wear rate and $\mathrm{HC}$ initiation rate. For a better prediction of grinding interval, the $\mathrm{HC}$ crack initiation rate should thus be taken into account. The crack initiation rate can be expressed in terms of the number of load cycles to crack initiation, and it may readily be determined by computing the ratcheting rate for a 2dimensional contact, see section 3.1. For the 3-dimensional case, the numerical method of Li (2002), employed in Chapters 2 and 3, can be used in combination with the work of Bower and Johnson (1989).

Therefore, an accurate prediction of the grinding interval may be made for individual loading conditions of a curved track, in the way illustrated in Figure 2.22, in combination with equation (2.8). This can be an important topic of 
further research for tailored AHC maintenance. In this approach, the effect of a changing rail profile due to wear can be taken into account by wear simulation. Different new and worn wheel profiles can also be considered.

\subsubsection{High strength rail}

Increasing the material strength of a rail can delay crack initiation. According to Pointner (2008), changing from R260 to standard high strength rail R350HT results in an improvement for both wear and $\mathrm{HC}$ resistance by a factor of 2 . A test of high strength rail material on the Dutch network confirms such advantages, see Figure 2.23. On the other hand, hard steel is usually less ductile. This means that once cracks initiate, grinding should be carried out earlier than on softer rails, otherwise the total life of high strength rail can be even shorter than on softer rails, as shown in section 2.2.3.

Because the change in wear rate and $\mathrm{HC}$ initiation rate could affect not only the balance between wear and $\mathrm{HC}$ initiation, but also the quantitative relationship between contact geometry and HC occurrence, the AHC 54E1, which is optimal for R260Mn, might not be optimal for other rail steels, for instance, the optimal largest undercut might not be at $9 \mathrm{~mm}$ from the gauge face. This should be investigated, especially when more high strength rails are used in the network.

For such an investigation the approach employed in this thesis can be used, i.e. a quantitative correlation between rail material, loading conditions and $\mathrm{HC}$ initiation can be derived via the fundamental relationship between maximum surface shear stress and HC, by means of controlled lab tests, field monitoring and numerical analysis.

\subsubsection{Friction management}

As it is the maximum surface shear stress $\tau_{\max }$ leading to $\mathrm{HC}$ initiation, and the typical coefficient of friction $\mu$ which results in $\tau_{\max }$ corresponding to the $\mathrm{HC}$ initiations shown in Chapter 4 is about 0.45 , a direct method to prevent $\mathrm{HC}$ is to reduce the COF.

In train operations the maximum demand for $\mathrm{COF}$ is during acceleration and braking. For the Dutch railways the required COF is 0.24 for acceleration and 0.14 for braking, Li et al. (2009), which is only about half of 0.45 . Therefore, if the COF could be controlled by friction management, the maximum surface 
shear stress corresponding to $\mathrm{HC}$ initiation discussed in Chapters 3 and 4 could almost be halved. That would prevent $\mathrm{HC}$ from occurring, or at least change the fatigue to a high cycle regime.

Friction management by lubrication to reduce wear and energy consumption has widely been applied; the COF can be lower than 0.1 . Since HC occurs mainly at gauge corner, lubrication could also be effective for $\mathrm{HC}$ prevention if the disadvantages can be avoided, i.e. pressurization of initiated cracks and lubrication of rail head where higher COF is needed for acceleration and braking, as mentioned in sections 2.2.3 and 2.2.4.

Friction management can also mean maintaining COF in an intermediate range, for instance with $\mu=0.24-0.3$, or any other desired values, so that it is just above what is required for train operations, while sufficiently lower for $\mathrm{HC}$ initiation.

Hence friction management, besides profiling, may be a very effective method to reduce $\mathrm{HC}$, wear and energy consumption. The key issue is how to keep the COF always under control in the desired range. Research and development in friction modifiers, in applicators of the modifiers, maintenance of the applicators, dozing of the modifiers and suchlike are necessary to achieve this goal.

\subsubsection{Managing the wheel-rail system}

$\mathrm{HC}$, like other rolling contact related problems, is a consequence of interaction between the rail and wheel. Treatment on one side of the couple only is suboptimal. For reasons of implementability, effectiveness and cost saving, optimization of rail profile has been chosen as an initial approach. More benefits can be obtained by optimization of the whole system.

Until 2005 the S1002 profile was used for all passenger trains in the Netherlands. This profile was developed in the 1970s and since then the railway has changed significantly, leading to the occurrence of $\mathrm{HC}$. It has been recognised that similar RCF problems are found in both rails and wheels. Consequently, changes to the wheel shape, material or maintenance have a significant influence on the rail, and vice versa. A logical approach would be to optimize the combination of wheel and rail profiles. Bearing this in mind optimization of wheel profile was started in 2007, Vermeij et al. (2008). 
This resulted in a dedicated wheel profile for intercity trains, the so-called HITprofile which has led to an increase in wheelset life of up to $30 \%$, mainly by reducing RCF cracking, but also by reducing flange wear in general. The impact of this alternative wheel profile on the reduction of RCF in the rail head is not exactly known yet, and should be further investigated (see also Appendix A).

The influence of primary yaw stiffness, track geometry etc. on $\mathrm{HC}$ initiation should be addressed. It has become clear that horizontal track alignment affects $\mathrm{HC}$ occurrence. For this reason it is advised to reassess current maintenance specifications regarding alignment.

\section{References:}

[1] Bower, A.F. and Johnson, K.L., 1989, The influence of strain hardening on cumulative plastic deformation in rolling and sliding line contact, J. Mech. Phys. Solids 37, No.4, pp. 471-493.

[2] Li, Z., Arias-Cuevas, O, Lewis, R. and Gallardo-Hernandez, E.A., 2009, Rolling-Sliding Laboratory Tests of Friction Modifiers in Leaf Contaminated Wheel-Rail Contacts, Tribology Letters 33 (2), pp. 97-109.

[3] Li, Z., 2002, Wheel-rail rolling contact and its application to wear simulation, PhD thesis, TU Delft, The Netherlands.

[4] Pointner, P., 2008, High strength rail steels - The importance of material properties in contact mechanics problems, Wear 265, pp. 1373-1379.

[5] prEN 13674-1, 2009, Railway applications - Track - Rail - Part 1: Vignole railway rails, $46 \mathrm{~kg} / \mathrm{m}$ and above, draft.

[6] Vermeij I., Liefting, G. and Bontekoe, T., 2003, Optimisation of wheelset lifetime with a focus on increasing wheel tyre life, Proceedings of World Congress on Railway Research, Edinburgh.

[7] Zacher, M., 2009, Prediction of gauge corner cracking in rails for rail maintenance, Proceedings of the 8th International Conference on Contact Mechanics and Wear of Rail/Wheel Systems, Florence, Italy, pp. 689-697, ISBN: 978-88-904370-0-7. 


\section{Appendices}




\section{Appendix A: Contact variation wheel/rail interface}

To reduce or prevent RCF one can either reduce the number of load cycles or reduce the amplitude of each individual load cycle.

The width of the running surface has become much narrower over the last few years. This means that the dispersion of the contact position has been reduced and as a result an increase of load cycles at a certain spot position on the rail.

For determining the contact distribution on the Dutch railway network, a series of multi-body simulations, see Roeleveld (2008), have been performed with the majority of the rolling stock and a variety of wheel profiles.

The contact positions are calculated for track curves of 1120 and $2100 \mathrm{~m}$ as shown schematically in Figure A.1 and A.2. The results of the multi-body simulations for new and worn profiles are summarized in Figure A.3.

With respect to the new S1002 profile, contact either occurs at $-25 \mathrm{~mm}$ or at $15 \mathrm{~mm}$. Around this contact area on the rail head a small lateral movement of the wheel set will be combined with a jump of contact position from -15 to -25 or vice versa. This discrete character of the contact point distribution can be attributed to the shape of the $\mathrm{AHC}$ rail profile.

With respect to the $2500 \mathrm{~m}$ curve, the contact is positioned more on top of the rail than for a $1500 \mathrm{~m}$ curve. This is according to the expectation.

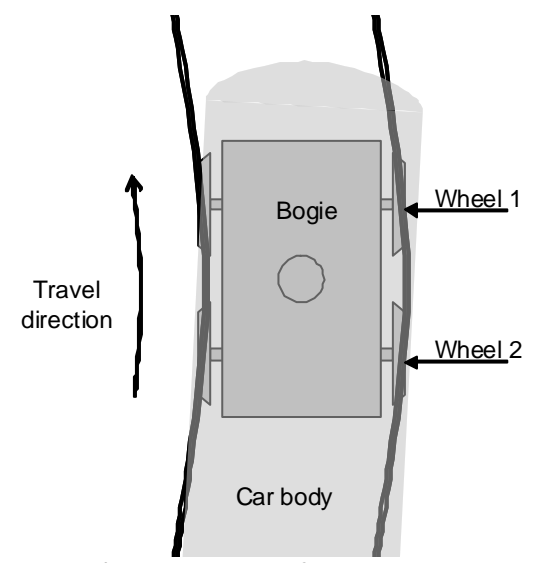

Figure A.1 Position of the bogie during curve negotiation.

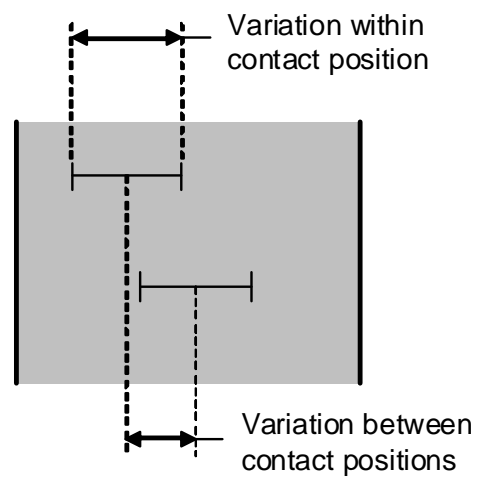

Figure A.2 Variations of contact position. 
The simulations with worn profiles of wheels have been carried out and presented on the right-hand side of Figure A.3. In observing the change in contact distribution it becomes clear the discrete nature is much less pronounced.
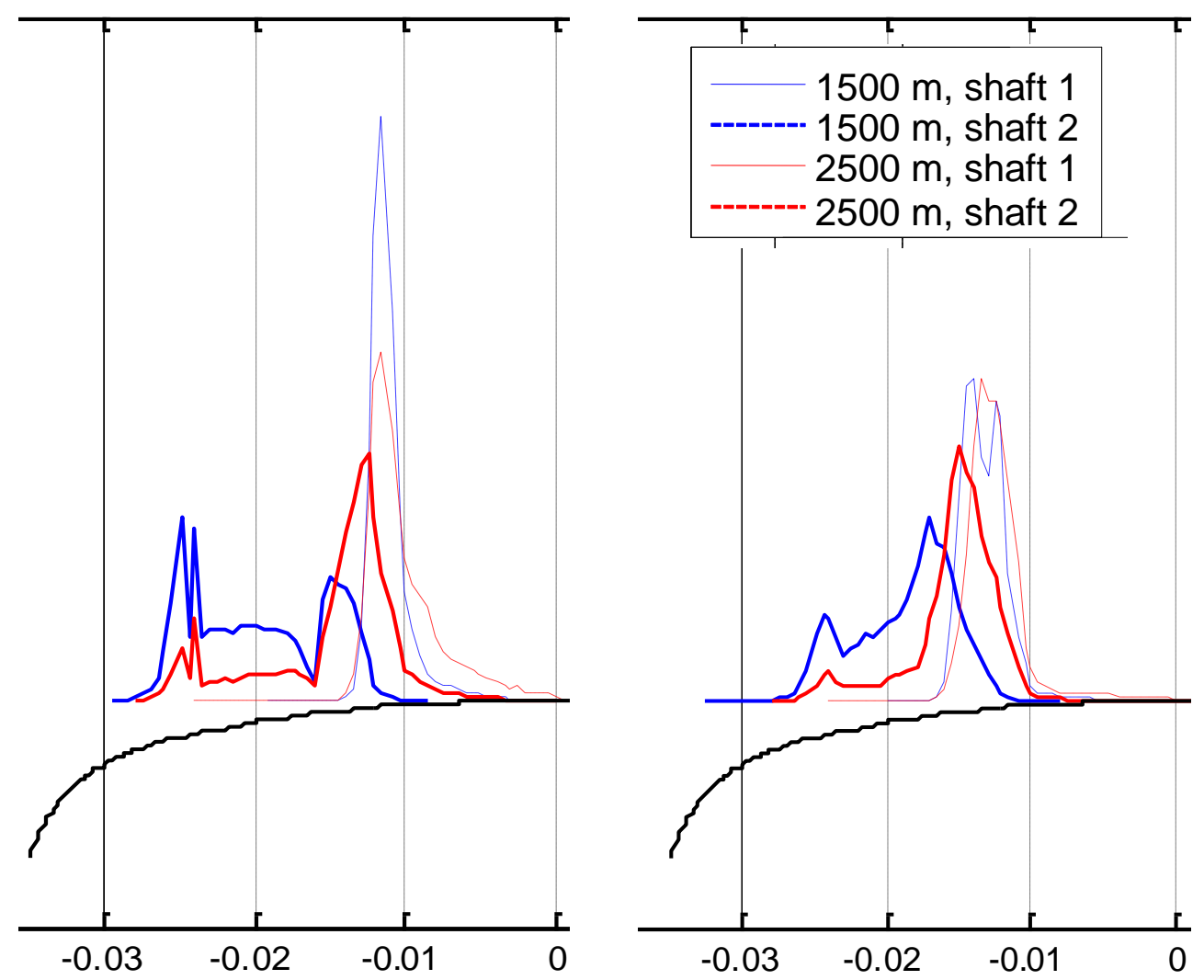

Figure A.3 Weighed distribution of contact position for S1002 (left) and worn profiles (right).

\section{Reference:}

[1] Roeleveld, T., 2008, Measurement of wheel-rail contact forces, Symposium of Advances in Contact Mechanics: a tribute to prof. J.J. Kalker, TU Delft, The Netherlands. 


\section{Appendix B: Dutch Rail profiles}

\section{Profile 60E1}

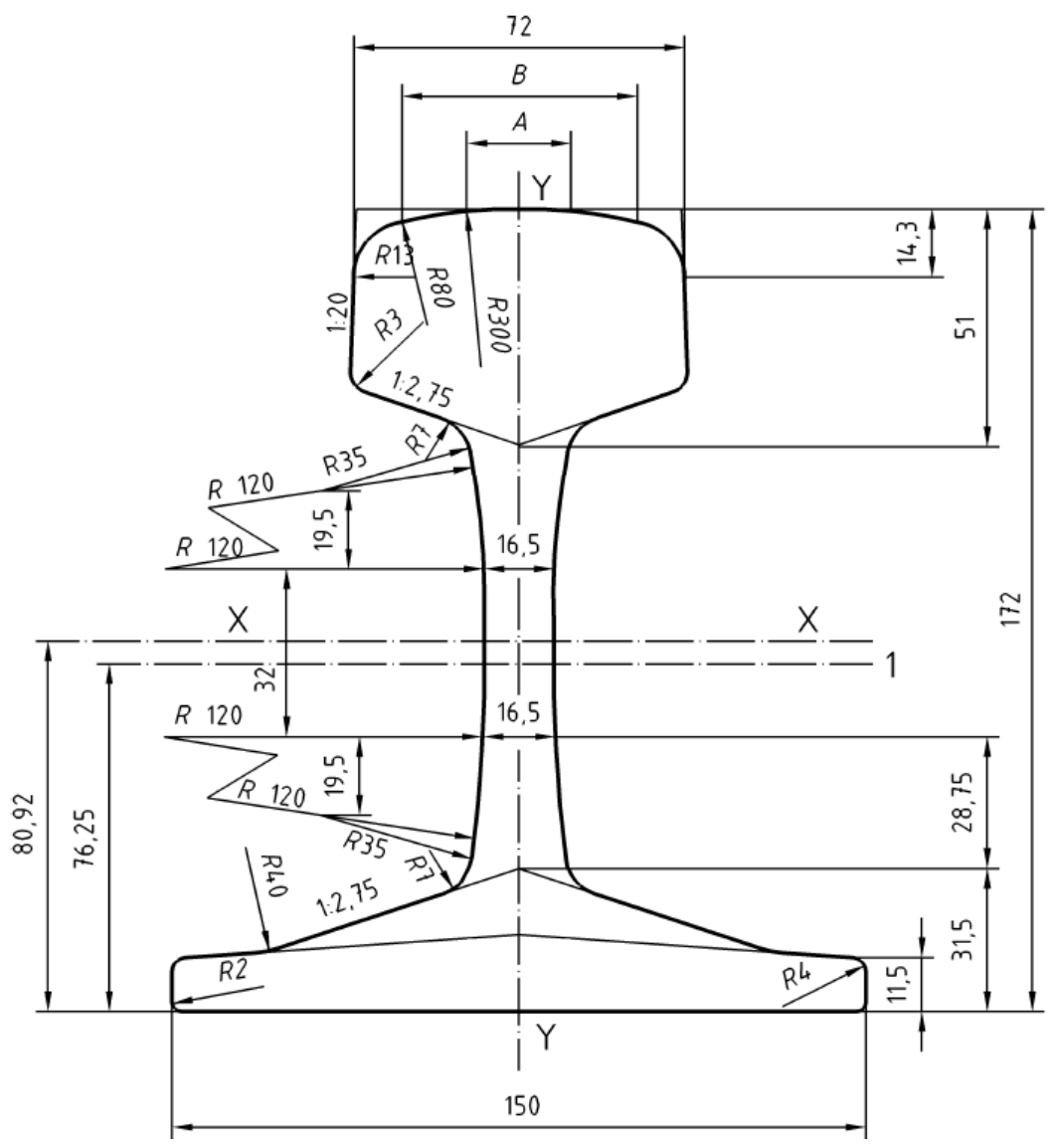

1 Centre line of branding

Cross-sectional area

Mass per metre

Moment of inertia $x-x$ axis

Section modulus - Head

Section modulus - Base

Moment of inertia $y-y$ axis

Section modulus y-y axis

: 76,70 $\mathrm{cm}^{2}$

: $60,21 \quad \mathrm{~kg} / \mathrm{m}$

: $3038,3 \mathrm{~cm}^{4}$

: $333,6 \mathrm{~cm}^{3}$

: $375,5 \mathrm{~cm}^{3}$

Indicative dimensions : $A=20,456 \mathrm{~mm}$

$B=52,053 \mathrm{~mm}$ 


\section{Profile 46E3}

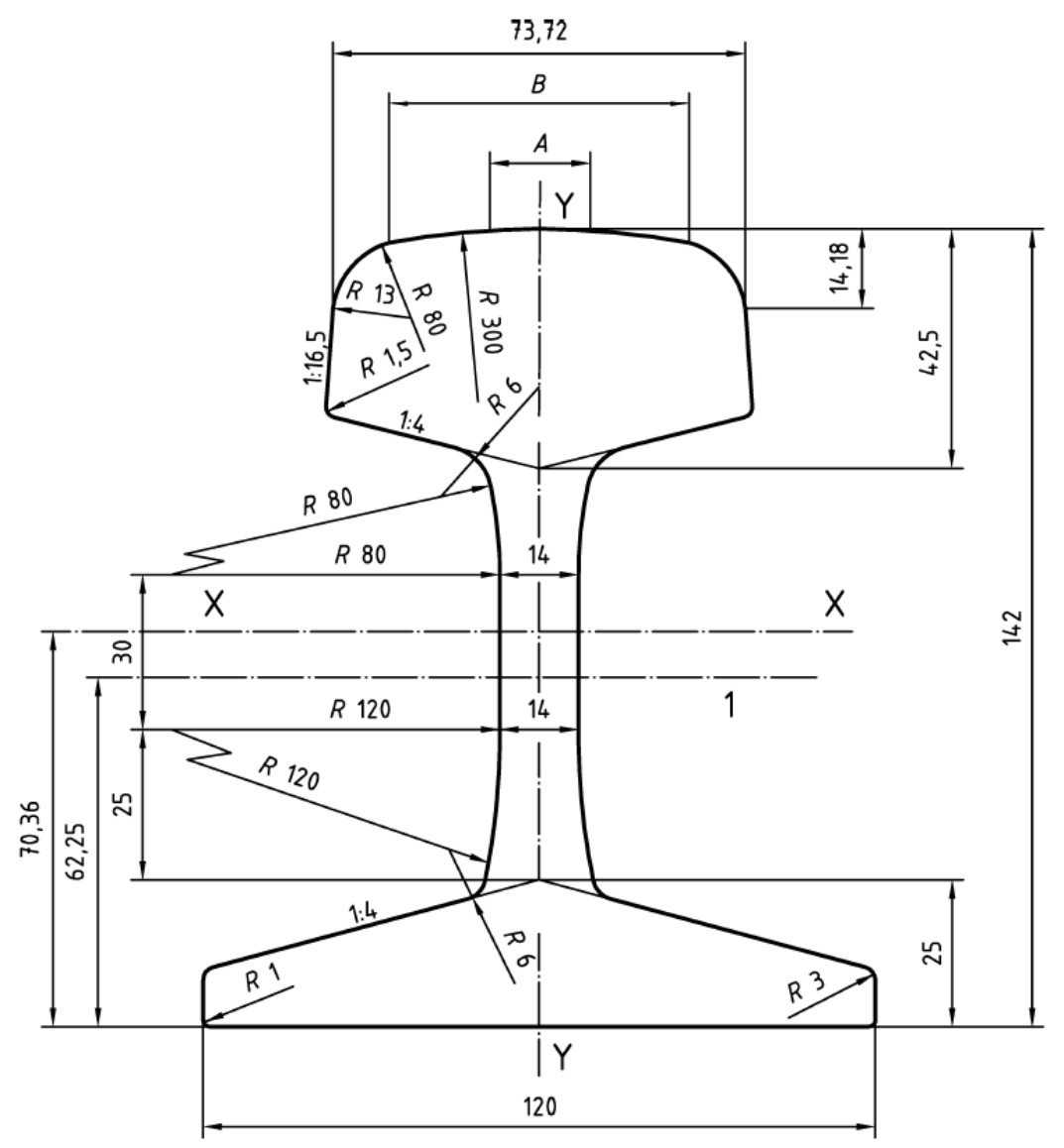

1 Centre line of branding

Cross-sectional area $\quad: 59,44 \quad \mathrm{~cm}^{2}$

Mass per metre $\quad: \quad 46,66 \quad \mathrm{~kg} / \mathrm{m}$

Moment of inertia x-x axis : $1605,9 \quad \mathrm{~cm}^{4}$

Section modulus - Head $\quad: \quad 224,2 \quad \mathrm{~cm}^{3}$

Section modulus - Base $\quad: \quad 228,2 \quad \mathrm{~cm}^{3}$

Moment of inertia y-y axis : $307,5 \quad \mathrm{~cm}^{4}$

Section modulus $y$-y axis $\quad: \quad 51,3 \quad \mathrm{~cm}^{3}$

Indicative dimensions : $A=23,015 \mathrm{~mm}$

$B=53,761 \mathrm{~mm}$ 


\section{Profile 54E1}

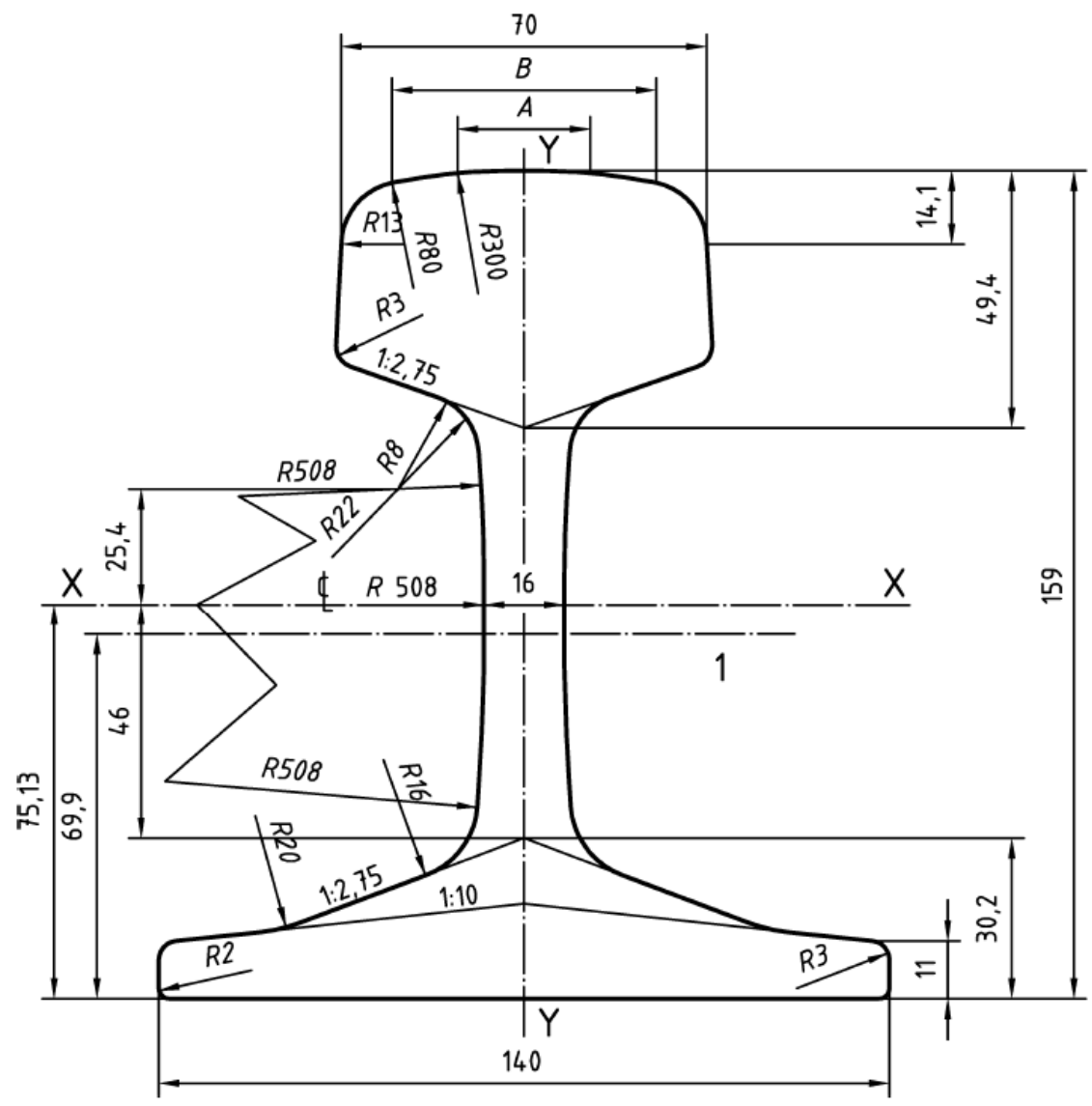

1 Centre line of branding

Cross-sectional area

: $69,77 \quad \mathrm{~cm}^{2}$

Mass per metre

Moment of inertia $\mathrm{x}-\mathrm{x}$ axis

: $54,77 \mathrm{~kg} / \mathrm{m}$

Section modulus - Head

: $2337,9 \mathrm{~cm}^{4}$

Section modulus - Base

: $278,7 \quad \mathrm{~cm}^{3}$

Moment of inertia $y-y$ axis

: $311,2 \mathrm{~cm}^{3}$

Section modulus $y$-y axis

: 419,2 $\mathrm{cm}^{4}$

Indicative dimensions : $A=20,024 \mathrm{~mm}$

: $59,9 \mathrm{~cm}^{3}$

$B=49,727 \mathrm{~mm}$ 


\section{Profile 54E5}

The AHC profile designed, based on the procedure as described in this thesis, is shown in the figure below. For comparison the 54E1 profile (dotted line) is shown as well. The 54E5 AHC profile has been adopted as EN standard (EN13674-1).

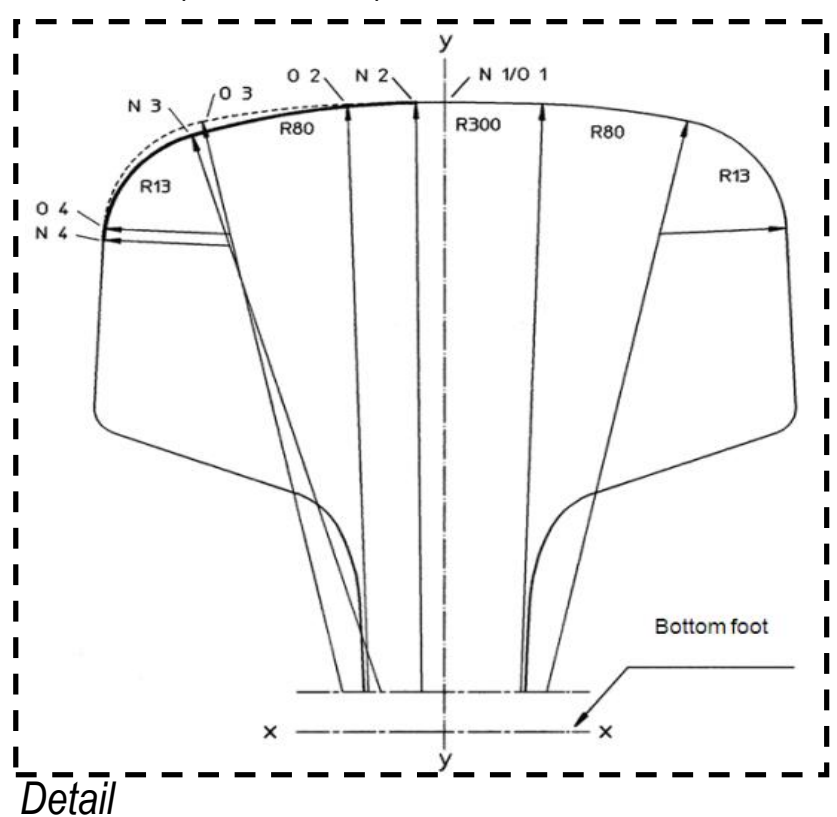

Coordinate path rail head and radius

\begin{tabular}{|c|c|c|}
\hline $\mathrm{nr}$ & $\mathrm{x}$ & $\mathrm{y}$ \\
\hline $\mathrm{N} 1$ & 0 & 159.0 \\
\hline $\mathrm{N} 2$ & -3 & 159.0 \\
\hline $\mathrm{N} \mathrm{3}$ & -26.0 & 155.4 \\
\hline $\mathrm{N} 4$ & -35.1 & 143.6 \\
\hline 01 & 0 & 159.0 \\
\hline 022 & -10.0 & 158.8 \\
\hline 03 & -24.9 & 157.0 \\
\hline 04 & -35.0 & 144.9 \\
\hline
\end{tabular}

\begin{tabular}{|c|c|c|}
\hline N R13 & -22.1 & 143.0 \\
\hline N R80 & -2.2 & 79.0 \\
\hline N R300 & 0 & -141.0 \\
\hline O R13 & -22.1 & 144.2 \\
\hline O R80 & -7.3 & 78.9 \\
\hline O R300 & 0 & -141.0 \\
\hline
\end{tabular}

$\mathrm{N}$ is Anti Head Check profile $\mathrm{O}$ is standard 54E1 profile

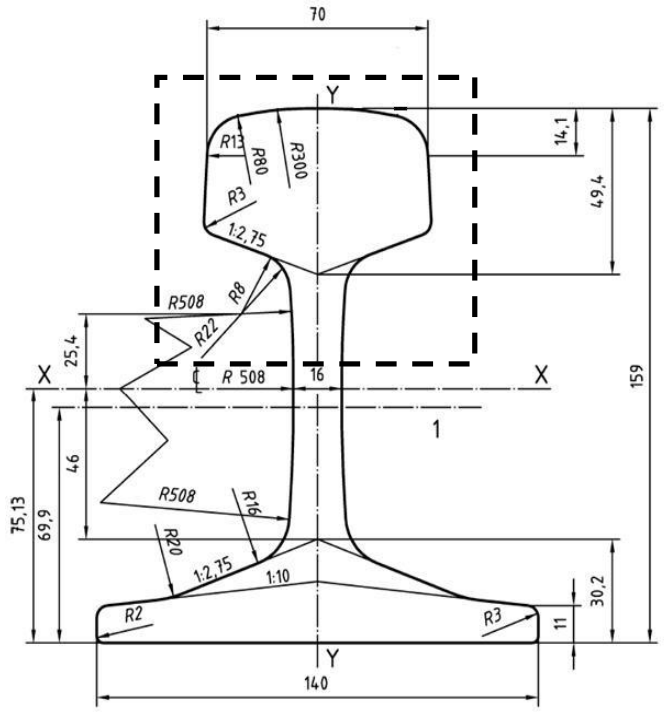

Cross section 


\section{Appendix C: Rail steel composition}

In the next table the composition and corresponding tolerances of the EN standard (EN13674-1) is given comparing the norms of the producer and the demands of the Rail-Infra manager ProRail.

Table C.1 Steel composition of the EN-standard (EN 13674-1), Corus, Voestalpine and ProRail.

\begin{tabular}{|c|c|c|c|c|c|c|}
\hline $\begin{array}{l}\text { Steel grade / } \text { Chem. } \\
\text { Analysis } \\
\quad \text { (liquid) }\end{array}$ & C & $\mathrm{Mn}$ & $\mathbf{P}$ & S & Si & $\mathrm{Cr}$ \\
\hline \multicolumn{7}{|l|}{ МНн } \\
\hline$E N$ & $\begin{array}{l}0.70- \\
0.82\end{array}$ & $0.70-1.10$ & $\begin{array}{c}0.020 \\
\max \end{array}$ & $0.020 \max$ & $\begin{array}{c}0.40- \\
1.00\end{array}$ & $\begin{array}{c}0.40- \\
0.60\end{array}$ \\
\hline ProRail & $\begin{array}{l}0.72- \\
0.82\end{array}$ & $0.80-1.10$ & $\begin{array}{c}0.020 \\
\max \end{array}$ & $0.020 \max$ & $0.80 \max$ & $0.60 \max$ \\
\hline Corus & $\begin{array}{l}0.75- \\
0.80\end{array}$ & $0.86-1.00$ & 0.018 & $\begin{array}{c}0.005- \\
0.018\end{array}$ & $\begin{array}{l}0.58- \\
0.72\end{array}$ & $\begin{array}{l}0.44- \\
0.58\end{array}$ \\
\hline \multicolumn{7}{|l|}{ R350HT } \\
\hline EN & $\begin{array}{l}0.72- \\
0.80\end{array}$ & $0.70-1.20$ & $\begin{array}{c}0.020 \\
\max \end{array}$ & $0.025 \max$ & $\begin{array}{l}0.15- \\
0.58\end{array}$ & $0.15 \max$ \\
\hline Corus & $\begin{array}{l}0.76- \\
0.80\end{array}$ & $1.06-1.20$ & $\begin{array}{l}0.020 \\
\max \end{array}$ & $\begin{array}{c}0.013- \\
0.023\end{array}$ & $\begin{array}{l}0.38- \\
0.52\end{array}$ & $0.07 \max$ \\
\hline \multicolumn{7}{|l|}{$R 260 M n$} \\
\hline ProRail (EN) & $\begin{array}{l}0.55- \\
0.75\end{array}$ & $1.30-1.70$ & $\begin{array}{c}0.025 \\
\max \end{array}$ & $\begin{array}{c}0.008- \\
0.025\end{array}$ & $\begin{array}{l}0.15- \\
0.60\end{array}$ & $0.15 \max$ \\
\hline Corus & $\begin{array}{l}0.57- \\
0.62\end{array}$ & $\begin{array}{l}1.525- \\
1.665\end{array}$ & $\begin{array}{c}0.020 \\
\max \end{array}$ & $0.13-0.023$ & $\begin{array}{l}0.39- \\
0.48\end{array}$ & - \\
\hline \multicolumn{7}{|l|}{$R 260$} \\
\hline ProRail (EN) & $\begin{array}{l}0.62- \\
0.80\end{array}$ & $0.70-1.20$ & $\begin{array}{c}0.025 \\
\max \end{array}$ & $\begin{array}{l}0.008- \\
0.025\end{array}$ & $\begin{array}{l}0.15- \\
0.58\end{array}$ & $0.15 \max$ \\
\hline Corus & - & - & - & - & - & - \\
\hline \multicolumn{7}{|l|}{ R370LHT } \\
\hline ProRail (EN) & - & - & - & - & - & - \\
\hline Voestalpine & $\begin{array}{l}0.70- \\
0.82\end{array}$ & $1.70-1.10$ & $\begin{array}{c}0.020 \\
\max \end{array}$ & $0.020 \max$ & $\begin{array}{l}0.40- \\
1.00\end{array}$ & $\begin{array}{l}0.40- \\
0.70\end{array}$ \\
\hline
\end{tabular}

For the standard R260 and the R260Mn rail steel grades, the mechanical properties can be achieved by normal cooling of the rails on the cooling bank. The tight tolerances defined for the chemical composition guarantee the hardness or other characteristics required by the EN-standard, by the RailInfra manager or in the producer specification, as defined in Table C.2. 
Mechanical tests are performed on samples from rails, as defined by the EN standard (EN13674-1; paragraph 9.1.8).

Table C.2 Mechanical properties and tensile strength for different positions (samples) according to EN standard EN13674-1, Corus, Voestalpine and ProRail.

\begin{tabular}{|c|c|c|c|c|c|c|c|c|}
\hline Steel gradel & $\begin{array}{c}\text { Ys } \\
(\mathrm{MPa})\end{array}$ & $\begin{array}{c}\mathrm{Rm} \\
(\mathrm{MPa})\end{array}$ & $\mathrm{El} \%$ & $\begin{array}{c}\text { RS } \\
\text { (HBW) }\end{array}$ & $\begin{array}{c}\text { position } \\
1\end{array}$ & $\begin{array}{c}\text { position } \\
2\end{array}$ & $\begin{array}{c}\text { position } \\
3\end{array}$ & $\begin{array}{c}\text { position } \\
4\end{array}$ \\
\hline \multicolumn{9}{|l|}{$\begin{array}{l}\text { Tensile } \\
\text { MHH }\end{array}$} \\
\hline $\begin{array}{l}\text { EN } \\
(R 370 \mathrm{CrHT})\end{array}$ & - & $\begin{array}{l}1280 \\
\min \end{array}$ & $9 \min$ & $370-410$ & $>360$ & $>350$ & $>340$ & $>360$ \\
\hline ProRail & $830 \mathrm{~min}$ & $\begin{array}{l}1280 \\
\min \end{array}$ & $\begin{array}{c}11 \\
\min \end{array}$ & $375-408$ & $>363$ & $>357$ & $>352$ & $>363$ \\
\hline Corus & $>850$ & $>1300$ & $>12$ & $380-400$ & $370-390$ & $360-380$ & $355-375$ & $370-390$ \\
\hline \multicolumn{9}{|l|}{ R350HT } \\
\hline$E N$ & - & $>1175$ & $>9$ & $350-390$ & $>340$ & $>331$ & $>321$ & $>340$ \\
\hline Corus & - & $>1180$ & $>11$ & $360-380$ & $350-370$ & $340-360$ & $330-350$ & $350-370$ \\
\hline \multicolumn{9}{|l|}{$R 260 M n$} \\
\hline ProRail (EN) & - & $880 \mathrm{~min}$ & $\begin{array}{c}10 \\
\min \end{array}$ & $260-300$ & - & - & - & - \\
\hline Corus & - & $>800$ & $>10$ & $260-300$ & - & - & - & - \\
\hline \multicolumn{9}{|l|}{$R 260$} \\
\hline ProRail (EN) & - & $880 \mathrm{~min}$ & $\begin{array}{c}10 \\
\min \end{array}$ & $260-300$ & - & - & - & - \\
\hline \multicolumn{9}{|l|}{ R370LHT } \\
\hline ProRail (EN & - & - & - & - & - & - & - & - \\
\hline Voestalpine & $>830$ & $>1280$ & $>9$ & $>370$ & $>370$ & $>360$ & $>352$ & $>352$ \\
\hline
\end{tabular}




\section{Appendix D: HC tests in the Netherlands}

$\mathrm{HC}$ tests have been performed for several years on 4 locations in the Netherlands. The results from these locations have been used in this thesis. The four locations considered are:

1) Curve Bunnik (started up in 2002)

2) Curve Amersfoort (started up in 2004)

3) Track Zutphen - Arnhem (started up in 2007)

4) Track Kruiningen- Roosendaal (started up in 2007)

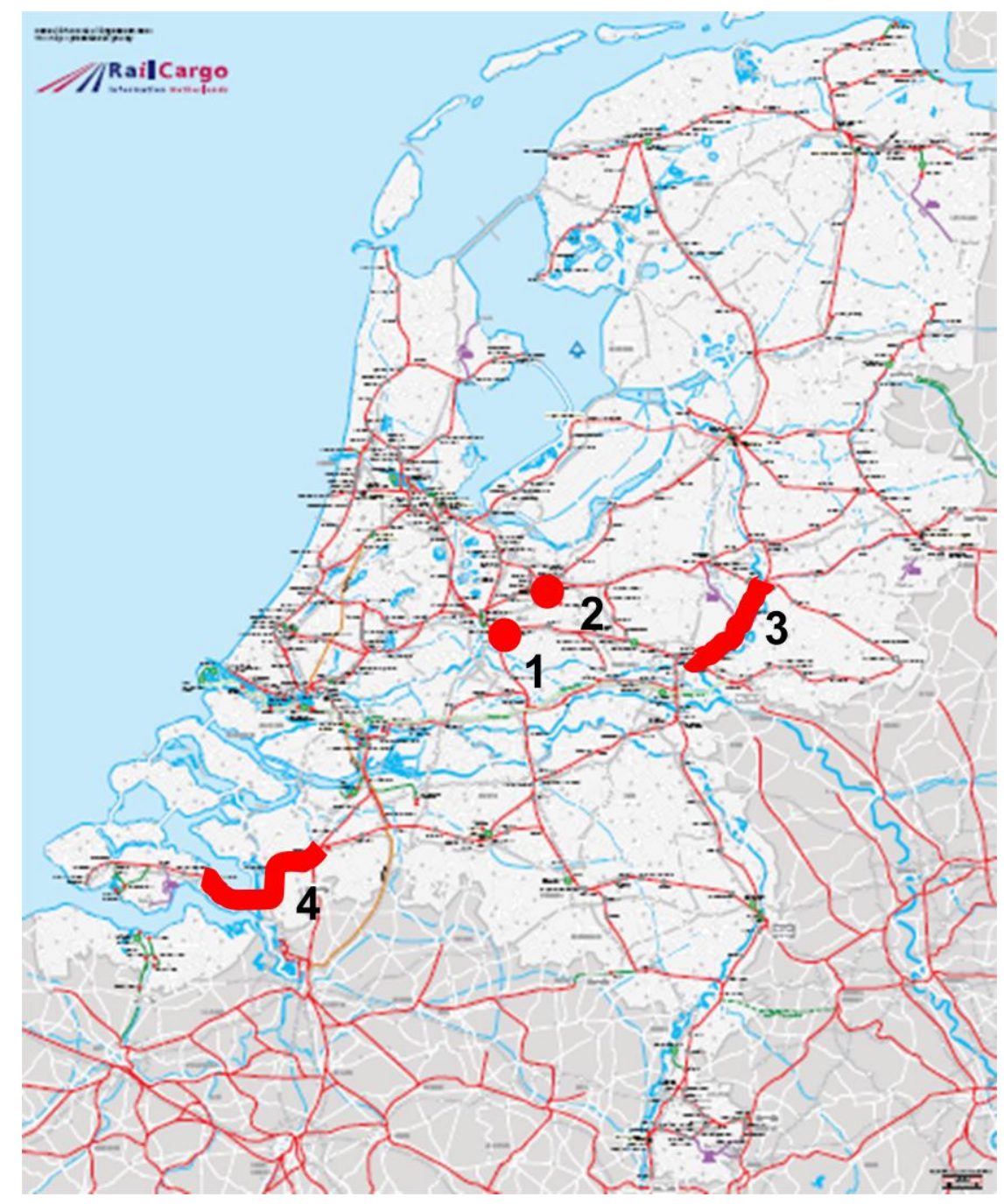




\section{Appendix E: Quasi-quarter Space}

(Excerpted from Li (2002))

An infinite space can be divided into two half spaces, four quarter spaces etc.

Half space has been employed for the solution of rolling contact by Kalker (1990). In the case of wheel and rail contact, wheel and the contacting rail are each considered as a half space. This approximation has been proven valid for contact between wheel tread and rail head, where the contacting surfaces are relatively flat, Kalker (1990).

When the contact is between the wheel flange root and the rail gauge corner, the surfaces are much curved in the contact area. Li (2002) proposed to use quasi-quarter spaces in this case to replace the half spaces. For rail, a quasiquarter space looks like what is shown in Figure E.1.

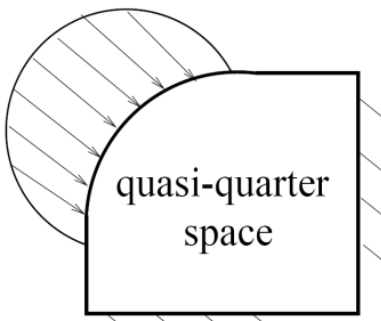

Figure E.1 Illustration of a quasi-quarter space for rail. Notice that the right vertical and lower horizontal border lines are theoretically at infinity. The quasi-quarter space is also infinite in the direction perpendicular to the paper. The contact is assumed to be on the circular part where pressure is applied symbolically.

It is called quasi, because in the part where contact is assumed, the quarter space is "cut" to be circular, so that the (usually) circular profile at the gauge corner can closely be approximated.

Obviously, a quasi-quarter space for a wheel should actually have (approximately) 3-quarters, as shown in Figure E.2. 


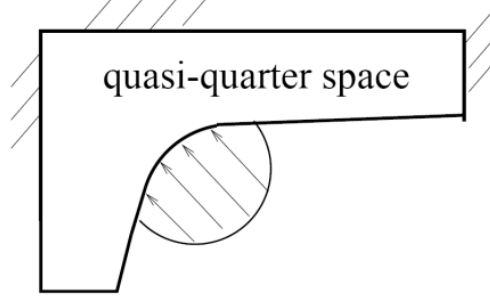

Figure E.2 Illustration of a quasi-quarter space for wheel. Notice that the left vertical and upper horizontal border lines are theoretically at infinity. The quasi-quarter space is also infinite in the direction perpendicular to the paper. The contact is assumed to be on the circular part where symbolic pressure is applied.

\section{References:}

[1] Kalker, J.J., 1990, Three dimensional elastic bodies in rolling contact, Kluwer Academic Publishers, Dordrecht/Boston/London.

[2] Li, Z., 2002, Wheel-Rail rolling contact and its application to wear simulations, PhD thesis, ISBN 90-407-2281-1, Delft University of Technology, The Netherlands. 


\section{Publications related to $\mathrm{HC}$ by Rolf Dollevoet}

2005:

[i] Ginkel, W.J. and Dollevoet, R.P.B.J., 2005, Preventive Grinding with an Anti-Head Check Profile, Wheel/Rail Interactions (Interface Journal and Advanced Rail Management Corp.), Seminar, Chicago, Illinois USA.

[ii] Steenbergen, M.J.M.M., Esveld, C. and Dollevoet, R.P.B.J., 2005, New Dutch assessment of Rail Welding Geometry (ProRail), European Railway Review issue 1.

2006:

[iii] Hiensch, M. and Dollevoet, R.P.B.J., 2006, Relationship between Track Geometry Disturbances and Development of Rolling Contact Damage, Proc. $7^{\text {th }}$ World Congress on Railway Research (WCRR), Montreal Canada.

[iv] Li, Z., Esveld, C. and Dollevoet, R.P.B.J., 2006, Causes to Squats: Correlation Analysis and Numerical Modelling, Proc. The $7^{\text {th }}$ International Conference on Contact Mechanics and Wear of Rail/Wheel system, Brisbane Australia, pp. 439-446.

2007:

[v] Steenbergen, M.J.M.M., Esveld, C. and Dollevoet, R.P.B.J., 2007, Force-based assessment of Rail Weld Geometry, Innovation Award nomination Rail-Tech Europe 2007, Utrecht The Netherlands.

[vi] Li, Z., Zhao, X., Esveld, C. and Dollevoet, R.P.B.J., 2007, The Dynamic Stress State of the Wheel-Rail Contact, Proc. $2^{\text {nd }}$ IASME/WSEAS International Conference on Continuum Mechanics (CM 2007), Portorose Slovenia, pp. 127-133. 
Special invitation (top 5 best paper) to publish at WSEAS.

[vii] Li, Z., Zhao, X., Esveld, C. and Dollevoet, R.P.B.J., 2007, Rail Stresses, Strains and Fatigue under Dynamic Wheel-Rail Interaction, International Heavy Haul Association (IHHA) Specialist Technical Session, Kiruna Sweden, pp. 389-396.

[viii] Li, Z., Zhao, X., Esveld, C. and Dollevoet, R.P.B.J., 2007, Numerical analysis of differential wear and the resulting squat at track local stiffness variation, In S.n. (Ed.), Dynamics of Vehicles on Road and Tracks, Berkely, USA: University of California, pp. 27-28.

2008:

[ix] Li, Z., Zhao, X. and Dollevoet, R.P.B.J., 2008, An investigation on squats growth using a transient finite element model, CROW infradagen, Delft University of Technology, The Netherlands.

[x] Li, Z., Molodova, M. and Dollevoet, R.P.B.J., 2008, Numerical simulation of dynamic response at squats, CROW infradagen, Delft University of Technology, The Netherlands.

[xi] Dollevoet, R.P.B.J., 2008, Research Rolling Contact Fatigue, Rail Technology Conferences, Railway Museum, Utrecht The Netherlands.

[xii] Li, Z., Molodova, M. and Dollevoet, R.P.B.J., 2008, An investigation of the possibility to use axle box acceleration for condition monitoring of welds, International conference on noise and vibration engineering ISMA 2008, Leuven University of Technology, Belgium.

[xiii] Shevtsov, I.Y., Kruse, T. and Dollevoet, R.P.B.J., 2008, ProRail research on wear and Rolling Contact Fatigue problems in the railway switches, Symposium of Advances in Contact Mechanics: a tribute to prof. J.J. Kalker, Delft University of Technology, The Netherlands.

[xiv] Li, Z., Zhao, X., Esveld, C., Dollevoet, R.P.B.J. and Molodova, M., 2008, An investigation into the causes of Squats - Correlation analysis and numerical modeling, WEAR Volume 265, issue 9-10, Contact Mechanics and Wear of Rail/Wheel systems CM2006, Elsevier, pp. 1349-1355.

\section{9:}

[xv] Li, Z., Arias Cuevas, O. and Dollevoet, R.P.B.J., 2009, Relation between Head Checks Initiation, Growth and Operational Loading Conditions, $9^{\text {th }}$ International Heavy Haul Association (IHHA) 
Specialist Technical Session, Shanghai China.

[xvi] Zoeteman, A., Dollevoet, R.P.B.J., Fischer, R. and Lammers, J., 2009, Managing the wheel-rail interface: the Dutch experience, Wheel-Rail interface handbook (856 pages) Chapter 28, part 2, edited by Lewis, R., Olofsson, U., ISBN 1845694120, pp. 792-818.

[xvii] Li, Z., Zhao, X. and Dollevoet, R.P.B.J., 2009, The determination of a critical size for rail top surface defects to grow into squats, $8^{\text {th }}$ International Conference on Contact Mechanics and Wear of Rail/Wheel Systems (CM2009), Florence Italy, ISBN 978-88-9043700-7, pp. 379-388.

[xviii] Li, Z., Dollevoet, R.P.B.J., Molodova, M. and Zhao, X., 2009, The validation of some numerical predictions on squats growth, $8^{\text {th }}$ International Conference on Contact Mechanics and Wear of Rail/Wheel Systems (CM2009), Florence Italy, ISBN: 978-88-9043700-7, pp. 369-377.

[xix] Zhao, X., Li, Z. and Dollevoet, R.P.B.J., 2009, Solution of the wheelrail rolling contact in elasticity and elasto-plasticity using a transient finite element model, $8^{\text {th }}$ International Conference on Contact Mechanics and Wear of Rail/Wheel Systems (CM2009), Florence Italy, ISBN: 978-88-904370-0-7, pp. 871-879.

[xx] Molodova, M., Li, Z. and Dollevoet, R.P.B.J., 2009, Simulation of dynamic responses of vehicle-track system for detection of track short wave defects, $8^{\text {th }}$ International Conference on Contact Mechanics and Wear of Rail/Wheel Systems (CM2009), Florence Italy, ISBN: 978-88-904370-0-7, pp. 1121-1128.

[xxi] Schoech, W., Heyder, R. and Dollevoet, R.P.B.J., 2009, Specific rail head profiles to control rolling contact fatigue, - design and maintenance, the European approach, $8^{\text {th }}$ International Conference on Contact Mechanics and Wear of Rail/Wheel Systems (CM2009), Florence Italy, ISBN: 978-88-904370-0-7, pp. 645-653.

[xxii] Zoeteman, A. and Dollevoet, R.P.B.J., 2009, Practical approach and projects in wheel-rail interface management in the Netherlands, 17th International Convention workshop OVG, Graz, Austria.

2010:

[xxiii] Zoeteman, A. and Dollevoet, R.P.B.J., 2010, Combating rolling contact fatigue: strategies adopted in the Netherlands, Rail

Engineering International, number 1, printed in the United Kingdom, ISSN 0141-4615, pp. 4-7. 
[xxiv] Li, Z., Molodova, M., Zhao, X. and Dollevoet, R.P.B.J., 2010, Squat treatment by way of minimum action based on early detection to reduce life cycle costs, Proceedings of the 2010 joint rail conference, Urbana-Champaign, Illinois USA.

[xxv] Dollevoet, R.P.B.J., Li, Z. and Arias-Cuevas, O., 2010, A method for the prediction of Head Checking initiation location and orientation under operational loading conditions, accepted for publication in Proc. ImechE PartF:J. Rail and Rapid Transit.

\section{Reports ProRail (Rolf Dollevoet) studies AHC and thesis support:} Most ProRail fieldwork and validation work has been done by DeltaRail. These ProRail reports (more than 30 in the Dutch language) are confidential at the RCF website controlled by DeltaRail http://www.gilgamesh.nl/deltarail. Basic reports that contribute to this thesis are:

ProRail, 2006, Optimalisatie AHC profielen, reference:

DeltaRail/06/4600215/007

ProRail, 2006, Analyse van vermoeiingsschade (RCF) in de boog bij Bunnik \& Spoorligging en RCF-schade in de boog te Bunnik, reference: DeltaRail 5600011

ProRail, 2007, Audit 1-7: Field test AHC (Bunnik), reference: DeltaRail/08/80002/006

ProRail, 2007, Rolling Contact Fatigue Research for ProRail: Comparison of RCF Prediction Models, reference: DeltaRail-ES-2007-116 Draft 1

ProRail, 2007, Relationship between Track Geometry Disturbances and the Development of Rolling Contact Fatigue Damage, reference: DeltaRail-ES-2007-116 Draft 2

ProRail, 2009, RP Optimalisatie AHC profielen, reference: DeltaRail/09/4600215/008 


\section{Acknowledgements}

Deze dissertatie is het resultaat van vele jaren intensief onderzoekswerk aan de Universiteit Twente. Naast studeren aan de Universiteit Twente ben ik full time werkzaam bij ProRail B.V., die mijn ambitie voor promotieonderzoek heeft gefaciliteerd. Johan de Ruiter stimuleerde mij om te gaan promoveren waarna Kees Wijbrandts, Marcel Hendriks Boers en Frits Verheij de steunende mensen geweest zijn om dit onderzoeksproject te kunnen starten. Een "hell of a job" om studietijden passend te krijgen met mijn reguliere werk bij ProRail B.V. waar ik functioneer als Systeem Expert Spoor. Met enige trots wil ik na het afronden van mijn onderzoek vele mensen bedanken, die mij hebben geholpen om deze dissertatie te kunnen afronden.

Allereerst heeft ProRail B.V. dit tot werkelijkheid kunnen maken. De afdeling Railsystemen (Onno Hazelaar) waar ik werkzaam ben, heeft vaak werk van mij overgenomen om mij "lucht" te geven voor mijn wetenschappelijk onderzoek. Dank daarvoor. Speciale dank aan mijn directe collega's (afdeling Spoor) Taco, Dick, Fred, Coen als ook Ivan, Arjen, Agnes en Hetty. Fijn dat jullie er waren wanneer deadlines naderden. Top!

Binnen ProRail B.V. ben ik Onderzoeksleider van het Rolling Contact Fatigue (RCF) project. Ingenieursbureau Lloyd's Register Rail Europe B.V., DeltaRail B.V. en TU Delft zijn deelnemers in dit research-project. Deze partijen hebben voor mij uitvoerend werk uit handen genomen zoals statistische onderzoeken, RCF voorspellingsonderzoek in Nederland, duizenden praktijkmetingen in de baan/werkplaats en verwerking daarvan tot bruikbare informatie.

Dank aan Sander, Edward, Thijs, Ilse, Dennis en speciaal Mieke welke werkzaam zijn bij Lloyd's Register Rail Europe B.V. Ook dank aan John, 
Remco, Geert-Jaap, Jaap, Wim, Theo, Jan, Jakko, Jerry en speciale dank aan Martin, Babette en Pier welke werkzaam zijn bij DeltaRail B.V.

De TU Delft heeft een cruciale rol gespeeld in mijn onderzoek. Juist de Kalker theorie is in Delft ontstaan welke ik moeilijk te begrijpen en te doorgronden vind. Om deze basis software toepasbaar te maken voor de specifieke situatie voor Head Checks in de spoorwereld heeft mij veel denkwerk en tijd gekost. Mijn oprechte dank aan co-promotor Zili Li die mij stimuleerde, inspireerde met zijn enorme inzet, specifieke kennis en wijsheid - coachte en zeer kritisch was tijdens het schrijven van mijn dissertatie. Hulde daarvoor! De andere leden van de Railbouwkunde sectie aan de TU Delft wil ik danken die hun bijdragen hebben geleverd voor de vele publicaties: Michaël, Oscar, Xin en Marija.

Met groot respect voor gevoel van evenwicht tussen pragmatisch maar zeker ook zuiver fundamenteel onderzoek, het vrijlaten en richtinggevend coachen, wil ik mijn promotor Dik Schipper (Universiteit Twente) hartelijk danken. Ik keek altijd uit naar onze zeer levendige gesprekken die voor mij erg nuttig waren, leerzaam en sturend. Fijne momenten en ik hoop dat dit wordt vervolgd na dit onderzoek.

Dank aan de staf en medestudenten van Dik Schipper voor steun en medeleven; speciaal voor Radu vanwege de gesprekken die wij samen hadden met Dik Schipper voor het ADREM project. Ik zal zeker de koffiemomenten missen met jullie.

Het gaat te ver om alle anderen te noemen en te bedanken waarmee ik dagelijks ProRail B.V. onderzoek verricht. ledereen weet dat ik het enorm waardeer wanneer er goed werk wordt geleverd, ondanks mijn kritische houding. Toch wil ik Rick en Marco (Avante-Consultancy) bedanken voor hun inzet om mijn dissertatie passend te krijgen in het juiste format voor de drukker.

De basis van mijn werkkracht, evenwicht en gezondheid wil ik mijn lieve, zorgzame en geduldige vrouw Linda en mijn twee zonen Floris en Lucas danken. Jullie zijn mijn alles, mijn inspiratie en levenskracht. Zonder jullie steun was het nooit gelukt. De komende tijd zal ik er vooral voor jullie zijn; iets wat niet vanzelfsprekend was van mij naar jullie toe tijdens mijn onderzoek. Ik 
ben jullie eeuwig dankbaar. Ook mijn ouders, Corrie en Jos, hebben vaak ingesprongen op drukke momenten in het reilen en zeilen op en rondom onze boerderij met de paarden; dat zal ik altijd blijven waarderen. Dank voor jullie liefde, altijd durende steun en toeverlaat!

Tot slot wil ik mijn kennissen en vrienden danken voor hun geduld en welke moeite hadden met mijn vele sociale afwezigheid in de afgelopen hectische jaren. Hopelijk gaat dit helemaal goed komen in de toekomst.

Special thanks to my international friends of INNOTRACK EU refund project for the fruitful discussions and open cooperation to share knowledge. Thanks to the INNOTRACK leaders Björn Paulsson (UIC), Anders Ekberg (Charmec University), Peter Pointner (Voestalpine) and Jay Jaiswal (Corus) for their advice; especially WP4.5 (chairman Wolfgang Schoech (Speno)) and his members. Very special thanks to member Richard Stock (PhD student) of Voestalpine Leoben, Austria. He did many validation measurements for me on the test rig of Voestalpine. Thank you very much that I could use the very valuable measurement results for my thesis.

Rolf P.B.J. Dollevoet

Rosmalen, augustus 2010. 


\section{Stellingen}

behorend bij het proefschrift

"Design of an Anti Head Check profile based on stress relief" door ir. Rolf P.B.J. Dollevoet.

Verdediging op donderdag 7 oktober 2010 om 13.15 uur, Universiteit Twente.

1. Het gebrek aan een differentieel in een treinas is mede de oorzaak van Head Checks in de spoorwereld.

2. Treinen die rijden in de Half $\mathrm{Nul}(\mathrm{HO})$ modelwereld kennen geen RCF wat duidt op schaaleffect.

3. Head Checks kunnen beter Gauge Shoulder Cracks (GSC's) genoemd worden.

4. ledere manager zou een cursus "paardenfluisteraar" moeten volgen.

5. Hoe vager de functie-omschrijving, hoe hoger het salaris.

6. Voor diegenen die, uit hoofde van hun maatschappelijke positie, weinig openlijke tegenspraak ontmoeten, biedt het zelfstandig berijden van een Engelse Volbloed een heilzame compensatie.

7. Treinen rijden op spoorstaven; niet op tijd.

8. Tijd en (in-)spanningen resulteren in vermoeiing; ook van spoorstaven.

9. Wie rijk wil zijn moet niet zijn vermogen vergroten, maar zijn hebzucht verkleinen.

10. Liefde is het enige dat zich kan vermenigvuldigen wanneer je het deelt. 